\title{
TOLERÂNCIA A FALHAS EM ROBÔS MANIPULADORES COOPERATIVOS
}

\author{
Renato Tinós
}

Tese apresentada à Escola de Engenharia de São Carlos da Universidade de São Paulo, como parte dos requisitos para obtenção do título de Doutor em Engenharia Elétrica

Orientador:

Prof. Dr. Marco Henrique Terra

São Carlos

2003 
À Lúcia Maria As dificuldades de um caminho dependem de quem o percorre: o caminho, nós o trilhamos juntos; as dificuldades, você as fez menores. 


\section{AGRADECIMENTOS}

Ao Prof. Dr. Marco Henrique Terra pela orientação, amizade e pela confiança depositada durante a realização deste trabalho.

Aos meus pais, Denir e Elisabet, por terem me permitido chegar até aqui e pelos exemplos de perseverança e dedicação.

Ao co-orientador Dr. Marcel Bergermam (Genius Instituto de Tecnologia) pela sugestão do tema desta tese e pelas valiosas discussões ao longo do trabalho.

Aos pesquisadores: Dr. João Y. Ishirara (EESC-USP), pelas valiosas contribuições ao problema de controle dos robôs cooperativos com juntas passivas; Prof. Dr. Christiaan J. J. Paredis (Georgia Institute of Technology), pelas valiosas críticas e sugestões feitas durante o estágio realizado em 2000 na Carnegie Mellon University; aos professores Dr. Edson R. De Pieri (UFSC), Dr. Fernardo Gomide (UNICAMP) e Valentin O. Roda (EESC-USP) pelas valiosas críticas, sugestões e comentários feitos durante o exame de qualificação e/ou defesa deste trabalho. Também ao anônimo assessor técnico do processo FAPESP nº . 98/15732-5 pelas valiosas críticas e comentários.

A todos os amigos que me acompanharam nesta jornada. Em especial, aos colegas do Laboratório de Sistemas Inteligentes pelas diversas discussões e sugestões.

Aos funcionários do Depto. de Engenharia Elétrica, que sempre estiveram dispostos a colaborar.

À Fundação de Amparo à Pesquisa do Estado de São Paulo (FAPESP) pelo suporte financeiro durante a realização deste trabalho através do Processo 98/15732-5, sem o qual o mesmo não seria possível. Espero que possa retornar aquilo que em mim foi investido. 
SUMÁRIO

LISTA DE FIGURAS _.vii

LISTA DE TABELAS _..ix

LISTA DE ABREVIATURAS PRINCIPAIS H...

NOTAÇÃO GERAL _ ...xi

LISTA DOS SÍMBOLOS PRICIPAIS -.xii

RESUMO .xiv

$\begin{array}{lll}\text { ABSTRACT } & \ldots \mathrm{xv}\end{array}$

CAPÍTULO 1. INTRODUÇÃO $\quad$ _...1

1.1. Motivação $\quad \ldots .2$

1.2. Descrição do Trabalho $\quad \ldots . .4$

1.3. Estrutura do Texto $\quad$....7

CAPÍTULO 2. FALHAS EM ROBÔS MANIPULADORES _...9

2.1. Introdução $\quad \ldots 10$

2.2. Análise de Falhas em Robôs Manipuladores $\quad \ldots 13$

2.2.1. Funcionamento Básico do Robô Manipulador $\quad$...16

2.2.2. Análise dos Modos e Efeitos das Falhas $\quad$...16

2.2.3. Análise Através de Árvores de Falhas $\quad$...23

2.3. Falhas Tratadas Neste Trabalho $\quad$...29

CAPÍTULO 3. ROBÔS COOPERATIVOS $\quad$...30

3.1. Introdução

3.2. Dinâmica do Sistema Cooperativo $\quad \ldots 33$

3.3. Cinemática do Sistema Cooperativo $\quad \ldots 38$

3.4. Cálculo das Forças no Objeto $\quad$...39

3.5. Controle do Sistema Cooperativo Sem Falhas $\quad \ldots 43$

3.5.1. Controle Híbrido de Movimento e Esmagamento Para o Sistema Sem Falhas 


\section{CAPÍTULO 4. DETECÇÃO E ISOLAÇÃO DE FALHAS}

4.1. Introdução: Detecção e Isolação de Falhas

4.1.1. Detecção e Isolação de Falhas em Sistemas Dinâmicos

4.1.2. Detecção e Isolação de Falhas em Manipuladores Livres

4.2. Detecção e Isolação de Falhas em Manipuladores Cooperativos

4.3. As Redes Neurais Artificiais

4.3.1. Perceptron Multicamadas (MLP)

4.3.2. Rede com Função de Base Radial (RBF)

4.4. Detecção e Isolação de Falhas do Tipo Juntas com Balanço Livre ou Bloqueadas

4.4.1. Geração de Resíduos

4.4.2. Análise de Resíduos

4.5. Detecção e Isolação de Falhas do Tipo Informação Incorreta de Posição ou Velocidade das Juntas

4.5.1. Detecção e Isolação de Falhas do Tipo Informação Incorreta de Posição das Juntas

4.5.2. Detecção e Isolação de Falhas do Tipo Informação Incorreta de Velocidade das Juntas

\section{CAPÍTULO 5. CONTROLE E RECONFIGURAÇAO DO SISTEMA COOPERATIVO COM FALHAS}

5.1. Introdução: Controle de Robôs Manipuladores com Falhas

5.2. Controle do Sistema Cooperativo com Juntas Passivas (ou com Falhas do Tipo Juntas com Balanço Livre)

5.2.1. Matriz Jacobiana $\mathbf{Q}(\mathbf{q})$ para o Sistema Cooperativo com Juntas Passivas

5.2.2. Controle Híbrido do Sistema Cooperativo com Juntas Passivas

5.2. Controle do Sistema Cooperativo com Juntas Bloqueadas

5.4. Controle do Sistema Cooperativo com Informação Incorreta de Posição ou Velocidade das Juntas

5.4.1. Informação Incorreta de Posição das Juntas

5.4.2. Informação Incorreta de Velocidade das Juntas 
5.5.1. Capacidade Dinâmica de Carga em Manipuladores Cooperativos com Juntas Passivas

\section{CAPÍTULO 6. RESULTADOS}

6.1. Sistemas Cooperativos Utilizados

6.1.1. Sistemas Cooperativos Simulados

6.1.2. Sistema Cooperativo Real

6.1.3. Ambiente de Simulação e Controle do Sistema Real

6.2. Sistema Cooperativo com Falhas (Sem Reconfiguração)

6.2.1. Sistema Simulado 1

6.2.2. Sistema Simulado 2

6.3. Detecção e Isolação de Falhas

6.3.1. Sistema Simulado 1

6.3.2. Sistema Simulado 2

6.3.3. Sistema Real

6.4. Controle do Sistema Cooperativo com Falhas

6.4.1. Sistema Simulado 1

6.4.2. Sistema Simulado 2

6.4.3. Sistema Simulado 3

6.4.4. Sistema Real

6.5. Sistema Completo de Tolerância a Falhas

6.5.1. Sistema Simulado 1

6.5.2. Sistema Simulado 2

6.5.3. Sistema Real

6.6. Capacidade Dinâmica de Carga

\section{CAPÍTULO 7. CONCLUSÕES}

7.1. Contribuições

7.1.1. Análise das Falhas

7.1.2. Detecção e Isolação de Falhas

7.1.3. Controle e Reconfiguração do Sistema com Falhas

7.1.4. Experimentos

7.2. O Futuro... 
APÊNDICE A. Acompanhamento de Trajetórias de Dois Manipuladores

Cooperativos com Juntas Passivas [LIU et al., 1999]

APÊNDICE B. Dados do Sistema Simulado 1

. .180

APÊNDICE C. Dados do Sistema Simulado 2

APÊNDICE D. Dados do Sistema Simulado 3

. .190

APÊNDICE E. Dados do Sistema Cooperativo Real

. .192

APÊNDICE F. Ambiente de Simulação e Controle do Sistema Real

. .197

APÊNDICE G. Publicações do Autor 


\section{LISTA DE FIGURAS}

FIGURA 1.1. Diagrama do sistema de tolerância a falhas proposto.

FIGURA 2.1. Tempo Médio entre Falhas para robôs industriais

FIGURA 2.2. Taxa de falhas teórica em um robô industrial.

FIGURA 2.3.a:e. Árvores de falhas.

FIGURA 3.1. Forças aplicadas pelos manipuladores e posições dos efetuadores e do objeto

$$
\text { manipulado. }
$$

FIGURA 3.2. Subespaços ortogonais de movimento e de esmagamento.

FIGURA 4.1. MLP com uma única camada escondida.

FIGURA 4.2. Resposta da função Gaussiana.

FIGURA 4.3. Geração dos resíduos.

FIGURA 4.4. Análise dos resíduos.

FIGURA 4.5. Fluxograma do Sistema DIF.

FIGURA 6.1. Sistema Simulado 3.

FIGURA 6.2. Sistema Real.

FIGURA 6.3:5 Ambiente de Simulação e Controle do Sistema Real.

FIGURA 6.6. Ambiente de simulação (Puma 560).

Resultados: Sistema Cooperativo com Falhas (Sem Reconfiguração)

FIGURA 6.7:12. Sistema Simulado 1.

FIGURA 6.13:17. Sistema Simulado 2.

Resultados: Detecção e Isolação de Falhas

FIGURA 6.18:19. Sistema Simulado 1.

Resultados: Controle do Sistema Cooperativo com Falhas

FIGURA 6.20:30. Sistema Simulado 1. 
FIGURA 6.31:33. Sistema Simulado 2.

FIGURA 6.34:36. Sistema Simulado 3.

FIGURA 6.37:45. Sistema Real.

Resultados: Sistema de Tolerância Completo

FIGURA 6.46:49. Sistema Simulado 1.

FIGURA 6.50:54. Sistema Simulado 2.

FIGURA 6.55:63. Sistema Real.

Resultados: Capacidade Dinâmica de Carga

FIGURA 6.64:67. Sistema Simulado 1. 


\section{LISTA DE TABELAS}

TABELA 2.1: Análise dos modos e sintomas das falhas em robôs.

TABELA 2.2: Análise dos sintomas e efeitos das falhas.

TABELA 5.1. Número de componentes independentemente controlados $\left(n_{e}\right)$ do vetor $\gamma_{\mathrm{e}}$ para $m=2$ ou 3 manipuladores planares.

TABELA 5.2. Variáveis e leis usadas no controle do sistema cooperativo.

TABELA 6.1: Resultados do teste do Sistema DIF: Sistema Simulado 1.

TABELA 6.2: Resultados por falha do teste do Sistema DIF: Sistema Simulado 1.

TABELA 6.3: Resultados do teste do Sistema DIF: Sistema Simulado 2.

TABELA 6.4: Resultados por falha do teste do Sistema DIF: Sistema Simulado 2. 


\section{LISTA DE ABREVIATURAS}

$\begin{array}{ll}\text { AAF } & \text { - Análise por Árvore de Falhas } \\ \text { AMEF } & \text { - Análise dos Modos e Efeitos das Falhas } \\ \text { ASCSR } & \text { - Ambiente de Simulação e Controle do Sistema Real } \\ \text { CDC } & \text { - Capacidade Dinâmica de Carga } \\ \text { CM } & \text { - Centro de Massa } \\ \text { DIF } & \text { - Detecção e Isolação de Falhas } \\ \text { EMQ } & \text { - Erro Médio Quadrático } \\ \text { GDL } & \text { - Grau de Liberdade } \\ \text { IA } & \text { - Inteligência Artificial } \\ \text { MAOK } & \text { - Mapa Auto-Organizável de Kohonen } \\ \text { MLP } & \text { - Perceptron Multicamadas (MultiLayer Perceptron) } \\ \text { RBF } & \text { - Função de Base Radial (Radial Base Function) } \\ \text { RMI } & \text { - Reachable Measurement Intervals } \\ \text { RNA } & \text { - Rede Neural Artificial } \\ \text { ThMB } & \text { - Model-Based Threshold Algorithm } \\ \text { TMD } & - \text { Tempo Médio de Detecção } \\ \text { TMF } & - \text { Tempo Médio entre Falhas }\end{array}$




\section{NOTAÇÃO GERAL}

$a, b \quad$ letras minúsculas em itálico representam escalares.

$\mathbf{a}, \mathbf{b}$ letras minúsculas em negrito representam vetores:

$$
\mathbf{a}=\left[\begin{array}{c}
a_{1} \\
a_{2} \\
\vdots \\
a_{n}
\end{array}\right] .
$$
A, B
letras maiúsculas em negrito representam matrizes.
$\mathbf{I}_{i}$
matriz identidade com posto $i$.
$\mathbf{O}_{i x j}$
matriz de zeros $(i \times j)$.
$\mathbf{A}^{\mathrm{T}}$
transposta de $\mathbf{A}$.
$\mathbf{A}^{-1}$
inversa de $\mathbf{A}$.
$\mathbf{A}^{-\mathrm{T}}=\left(\mathbf{A}^{\mathrm{T}}\right)^{-1}$
inversa da transposta de $\mathbf{A}$.
$\mathbf{A}^{\#}$
pseudo-inversa de A.
$\hat{a}$
valor estimado de $a$.
$\|\mathbf{a}\|$
norma (Euclidiana) de a.
$\dot{a}$
primeira derivada de $a$.
$\ddot{a}$
segunda derivada de $a$.
$\operatorname{col}_{i}(\mathbf{A})$
coluna $i$ da matriz $\mathbf{A}$.
$N(\mathbf{A})$
espaço nulo da matriz $\mathbf{A}$.
$\operatorname{Im}(\mathbf{A})$
imagem da matriz A.
$\mathbf{a x b}$
produto vetorial entre $\mathbf{a} \mathbf{e} \mathbf{b}$. 


\section{LISTA DOS SÍMBOLOS PRINCIPAIS}

$n_{i}$ : número de juntas no manipulador $i$;

$m$ : número manipuladores no sistema cooperativo;

$n=\sum_{i=1}^{m} n_{i}:$ número de juntas no sistema cooperativo;

$k:$ número de coordenadas de movimento no objeto.

$\mathbf{q}_{i}=\left[\begin{array}{llll}q_{i 1} & q_{i 2} & \cdots & q_{i n_{i}}\end{array}\right]^{\mathrm{T}}$ : posições (coordenadas generalizadas) das juntas do manipulador $i$

$\tau_{i}=\left[\begin{array}{llll}\tau_{i 1} & \tau_{i 2} & \cdots & \tau_{i n_{i}}\end{array}\right]^{\mathrm{T}}$ : forças generalizadas nas juntas do manipulador $i$;

$\mathbf{x}_{i}=\left[\begin{array}{llllll}x_{i 1} & x_{i 2} & \cdots & x_{i j} & \cdots & x_{i k}\end{array}\right]^{\mathrm{T}}=\left[\begin{array}{ll}\mathbf{p}_{i}{ }^{\mathrm{T}} & \boldsymbol{\phi}_{i}^{\mathrm{T}}\end{array}\right]^{\mathrm{T}}:$ posições do efetuador do manipulador $i$, na qual as $j$ primeiras componentes de $\mathbf{x}_{i}$ são posições $\left(\mathbf{p}_{i}\right)$, e as demais são as representações mínimas das orientações $\left(\boldsymbol{\phi}_{i}\right)$;

$\mathbf{h}_{i}=\left[\begin{array}{llllll}h_{i 1} & h_{i 2} & \cdots & h_{i j} & \cdots & h_{i k}\end{array}\right]^{\mathrm{T}}=\left[\begin{array}{ll}\mathbf{f}_{i}^{\mathrm{T}} & \boldsymbol{\eta}_{i}^{\mathrm{T}}\end{array}\right]^{\mathrm{T}}$ : forças no efetuador do manipulador $i$, na qual as $j$ primeiras componentes de $\mathbf{h}_{i}$ são forças $\left(\mathbf{f}_{i}\right)$ e as demais são momentos $\left(\boldsymbol{\eta}_{i}\right)$

$\mathbf{v}_{i}=\left[\begin{array}{llllll}v_{i 1} & v_{i 2} & \cdots & v_{i j} & \cdots & v_{i k}\end{array}\right]^{\mathrm{T}}=\left[\begin{array}{ll}\dot{\mathbf{p}}_{i}{ }^{\mathrm{T}} & \boldsymbol{\omega}_{i}{ }^{\mathrm{T}}\end{array}\right]^{\mathrm{T}}=\mathbf{T}\left(\mathbf{x}_{i}\right) \dot{\mathbf{x}}_{i}$ : velocidades do efetuador do manipulador $i$, na qual as $j$ primeiras componentes de $\mathbf{v}_{i}$ são velocidades lineares $\left(\dot{\mathbf{p}}_{i}\right)$, e as demais são as velocidades angulares $\left(\boldsymbol{\omega}_{i}\right)$. A matriz de transformação $\mathbf{T}(\cdot)$ relaciona as derivadas das representações mínimas das orientações com as velocidades angulares ;

$\mathbf{x}_{\mathbf{0}}=\left[\begin{array}{llllll}x_{o 1} & x_{o 2} & \cdots & x_{o j} & \cdots & x_{o k}\end{array}\right]^{\mathrm{T}}=\left[\begin{array}{ll}\mathbf{p}_{\mathbf{0}}{ }^{\mathrm{T}} & \boldsymbol{\phi}_{\mathbf{0}}{ }^{\mathrm{T}}\end{array}\right]^{\mathrm{T}}:$ posições da origem do sistema de coordenadas fixado ao objeto, na qual as $j$ primeiras componentes de $\mathbf{x}_{\mathbf{0}}$ são posições $\left(\mathbf{p}_{\mathbf{0}}\right)$, e as demais são as representações mínimas das orientações $\left(\boldsymbol{\phi}_{\mathbf{0}}\right)$. Neste trabalho, a origem do sistema de coordenadas é fixado ao Centro de Massa (CM) do objeto; 
$\mathbf{v}_{\mathbf{o}}=\left[\begin{array}{llllll}v_{o 1} & v_{o 2} & \cdots & v_{o j} & \cdots & v_{o k}\end{array}\right]^{\mathrm{T}}=\left[\begin{array}{ll}\dot{\mathbf{p}}_{\mathbf{0}}{ }^{\mathrm{T}} & \boldsymbol{\omega}_{\mathbf{0}}{ }^{\mathrm{T}}\end{array}\right]^{\mathrm{T}}=\mathbf{T}\left(\mathbf{x}_{\mathbf{o}}\right) \dot{\mathbf{x}}_{\mathbf{o}}$ : velocidades da origem do sistema de coordenadas fixado ao objeto, na qual as $j$ primeiras componentes de $\mathbf{v}_{\mathbf{o}}$ são velocidades lineares $\left(\dot{\mathbf{p}}_{\mathbf{0}}\right)$, e as demais são as velocidades angulares $\left(\boldsymbol{\omega}_{\mathbf{0}}\right)$.

$\boldsymbol{\theta}_{i}=\left[\begin{array}{llll}\theta_{i 1} & \theta_{i 2} & \cdots & \theta_{i n_{i}}\end{array}\right]^{\mathrm{T}}$ : posições medidas das juntas do manipulador $i$;

$\mathbf{h}_{\mathbf{0}}$ : força no CM do objeto;

$\mathbf{h}_{\mathbf{o e}}$ : força de esmagamento no CM do objeto;

$\mathbf{h}_{\mathbf{o m}}$ : força de movimento no CM do objeto;

$\mathbf{M}_{i}$ : matriz de inércia do manipulador $i$;

$\mathbf{C}_{i}$ : matriz dos termos centrífugos e de Coriolis do manipulador $i$;

$\mathbf{g}_{i}$ : vetor dos termos gravitacionais do manipulador $i$;

$\mathbf{J}_{i}$ : matriz Jacobiana geométrica do manipulador $i$ (transformação entre as velocidades efetuador $i$ e a velocidade das juntas);

$\mathbf{M}_{\mathbf{0}}$ : matriz de inércia do objeto;

$\mathbf{c}_{\mathbf{0}}$ : vetor dos termos centrífugos e de Coriolis do objeto;

$\mathbf{g}_{\mathbf{0}}$ : vetor dos termos gravitacionais do objeto;

$\mathbf{J}_{\mathrm{oi}}$ : matriz Jacobiana de transformação entre as velocidades efetuador $i$ e o objeto para o CM deste;

$\mathbf{D}_{i}=\mathbf{J}_{\mathbf{o} i}{ }^{-1} \mathbf{J}_{i}$ : matriz Jacobiana de transformação das velocidades das juntas do manipulador $i$ para as velocidades no $\mathrm{CM}$ do objeto;

$\mathbf{q}_{\mathbf{a}}$ : vetor das posições (coordenadas generalizadas) das juntas ativas do sistema cooperativo;

$\mathbf{q}_{\mathbf{p}}$ : vetor das posições (coordenadas generalizadas) das juntas passivas do sistema cooperativo;

$\mathbf{q}_{\mathbf{b}}$ : vetor das posições (coordenadas generalizadas) das juntas bloqueadas do sistema cooperativo;

$\boldsymbol{\tau}_{\mathbf{a}}$ : vetor das forças generalizadas nas juntas ativas do sistema cooperativo e;

Q : matriz Jacobiana de transformação entre as velocidades das juntas e a velocidade no CM do objeto. 


\section{RESUMO}

O problema da tolerância a falhas em robôs manipuladores cooperativos conectados rigidamente a um objeto indeformável é estudado nesta tese. A tolerância a falhas é alcançada através de reconfiguração do sistema de controle. Primeiro, a falha é detectada e isolada. Então, o sistema de controle é reconfigurado de acordo com a falha isolada. As falhas em robôs manipuladores são primeiramente estudadas de acordo com suas consequências no sistema cooperativo. Quatro tipos de falhas são identificados: juntas com balanço livre (sem atuadores ativos), bloqueadas, com informação incorreta de posição e com informação incorreta de velocidade. A deteç̧ão e a isolação dos dois primeiros tipos de falhas são alcançadas através de um sistema utilizando redes neurais artificiais. Redes do tipo MLP são empregadas para mapear a dinâmica dos robôs cooperativos sem falhas e uma rede RBF é utilizada para a classificação do vetor de resíduos. As falhas do tipo informação incorreta de posição ou velocidade das juntas são detectadas e isoladas através do uso das restrições impostas pela cadeia cinemática fechada presente no sistema cooperativo. Quando falhas do tipo juntas com balanço livre ou bloqueadas são isoladas, as leis de controle são reconfiguradas. Para estes casos, controladores híbridos de movimento e esmagamento do objeto são deduzidos. Quando falhas do tipo informação incorreta de posição ou velocidade das juntas são isoladas, as medidas afetadas são substituídas por valores estimados. Resultados obtidos em simulações e em robôs cooperativos reais mostram que a metodologia proposta é viável. 


\begin{abstract}
The problem of fault tolerance in cooperative manipulators rigidly connected to an undeformable load is addressed in this work. Fault tolerance is reached by reconfiguration of the control system. The faults are firstly detected and isolated. Then, the control system is reconfigured according to the isolated fault. Four faults are considered: free-swinging joint faults, locked joint faults, incorrectly measured joint position faults, and incorrectly measured joint velocity faults. Free-swinging and locked joint faults are detected and isolated by artificial neural networks. MLP's are utilized to reproduce the dynamics of the fault-free system and an RBF is used to classify the residual vector. Incorrectly measured joint position and velocity faults are detected and isolated based on the kinematic constraints imposed on the cooperative system. When free-swinging and locked joint faults are isolated, the control laws are reconfigured. Control laws for motion and squeeze of the object are developed in these cases. When incorrectly measured joint position faults and incorrectly measured joint velocity faults are isolated, the faulty measurements are replaced by their estimates. Results obtained in simulations and in real cooperative robots indicate that the proposed methodology is viable.
\end{abstract}




\section{Capítulo 1.}

\section{INTRODUÇÃO}

The International Space Station's troublesome robot arm has now banged into the side of the station, apparently of its own accord. The Canadarm2 sprang free from its fixing and struck the station during testing designed to locate the cause of an earlier problem. At first NASA engineers thought that the 17-metre long arm might have been snagged by stray wires during a manoeuvre, but the astronauts aboard the ISS said they were not touching the controls. It is now thought that built up tension caused the arm to spring free of its anchor. Astronauts did not report any damage to the space station and said that otherwise the arm performed correctly. They had in fact hoped that an earlier fault, which has stopped the arm's shoulder joint functioning properly, might resurface during testing (...).

The next shuttle flight, to fit the space station with a 6.5-tonne airlock and also deliver a new crew of astronauts, has been delayed from its scheduled 20 June launch to 12 July at the earliest. NASA remains concerned that the arm's earlier problem might resurface during the delicate procedure (...).

A series of software patches have been created to diagnose the glitch but the problem has not recurred. Engineers could modify the software used to control the arm to ignore the affected joint, making the structure function with six of its seven joints. The only other alternative would be to replace the arm altogether and NASA has said that this could not take place until November, when the shuttle Endeavour is due to launch."

New Scientist News, 15/06/2001 http://www.newscientist.com/news/news.jsp?id=ns9999887 


\subsection{MOTIVAÇÃO}

Robôs manipuladores cooperativos geralmente são aplicados em tarefas que não podem ser executadas de modo satisfatório por um único robô. Tomando como exemplo o ser humano, que utiliza dois braços na execução de uma infinidade de tarefas, dois ou mais manipuladores representam uma nítida vantagem sobre o robô individual em inúmeras ocasiões. No caso do ser humano, além do uso de dois braços, é também comum que várias pessoas executem cooperativamente uma mesma tarefa.

Entre as tarefas nas quais o uso de manipuladores cooperativos é vantajoso ou imprescindível, podem ser citadas [ZEFRAN et al., 1995], [VUKOBRATOVIC \& TUNESKI, 1998]:

(i) Manipulação de objetos que exceda a capacidade de carga de um único robô;

(ii) Manipulação de objetos grandes;

(iii) Manipulação de objetos flexíveis ou que possuam vários graus de liberdade;

(iv) Manipulação de cargas delicadas;

(v) Montagens;

(vi) Manipulação de objetos que possa escorregar de um único efetuador.

A estas, soma-se o fato de que os robôs cooperativos deverão ser empregados em diversas tarefas que antes eram exclusividade dos seres humanos, como na execução de trabalhos domésticos, serviços de enfermagem, etc... Este fato deverá ocorrer porque os seres humanos projetaram os seus ambientes e as suas ferramentas de trabalho para que sejam apropriadas para uma pessoa dita "normal", ou seja, com duas pernas, dois braços, visão, com altura que não seja muito maior ou menor que a média, etc... Isso explica porque uma pessoa com deficiência física ou que tenha características que difiram muito da média, como as pessoas muito altas ou muito baixas, possua certas dificuldades quando o ambiente e as ferramentas não são adaptadas ou projetadas especialmente para ela. Do mesmo modo, ou seja, para que não haja a necessidade de readequação do ambiente ou das ferramentas, os robôs que trabalharão em tarefas antes executadas por seres humanos herdarão algumas características destes, como o número de braços.

Manipuladores cooperativos apresentam, na maioria dos casos, um alto grau de redundância já que o número de juntas do sistema supera o número de graus de liberdade da carga. Desta forma, além do controle do movimento, pode-se controlar as forças aplicadas e o esmagamento produzido por estas no objeto [NAKAMURA, 1991]. Por tudo isso, robôs 
cooperativos vêm recebendo atenção crescente, tanto dos setores industriais, como da comunidade científica [CACCAVALE, 1997].

A redundância também torna interessante o uso de sistemas cooperativos em ambientes pouco estruturados, remotos e/ou perigosos, pois provê condições para a reconfiguração da atuação nas juntas em caso de falhas.

Falhas em robôs manipuladores podem originar movimentos descontrolados nos elos, podendo causar sérios danos ao robô e ao ambiente de trabalho. Uma falha em um sensor de velocidade, por exemplo, pode fazer com que o sistema de controle aplique uma ação que leve o robô a bater no chão ou em outros objetos do ambiente de trabalho [VISINSKY et al., 1994]. Além disso, falhas podem causar perdas econômicas e colocar em risco a segurança dos seres humanos presentes no ambiente em que os robôs estão inseridos. Pode-se imaginar, por exemplo, as consequências que podem advir de um acidente envolvendo robôs com falhas em uma intervenção cirúrgica ou na manipulação de cargas radioativas ou explosivas. Assim, tópicos como segurança e confiabilidade devem receber atenção especial no projeto de um robô.

Segurança e confiabilidade em sistemas robóticos devem, ainda, receber atenção crescente devido à presença cada vez mais comum de robôs dentro das casas, quer na execução de tarefas domésticas ou como objeto de entretenimento. Algumas pesquisas indicam que o número aproximado de sistemas robóticos em domicílios no ano 2010 será em torno de 5 milhões [DHILLON \& FASHANDI, 1997]. Um robô doméstico com falhas que comprometa a integridade de um ser humano certamente representará uma péssima propaganda. Tal fato certamente causará um retrocesso para a Robótica, como aquele que ocorreu com o programa espacial americano após o desastre do ônibus espacial Challenger na década de 1980.

Infelizmente, existem diversas fontes de falhas em sistemas robóticos, como mecânicas, elétricas, hidráulicas, pneumáticas, eletrônicas e de software. Como consequência, falhas em robôs têm sido comuns. De acordo com algumas publicações, o Tempo Médio entre Falhas (TMF) registrado em robôs industriais é de apenas 500 a 2500 horas [DHILLON \& FASHANDI, 1997].

As consequências das falhas podem ser minimizadas através do uso de técnicas de Detecção e Isolação de Falhas (DIF). O número de pesquisas em DIF para robôs individuais tem crescido significativamente ao longo da última década.

Particularmente em sistemas envolvendo mais de um robô manipulando uma carga comum, o problema das falhas começou a ser pesquisado somente nos últimos anos. De acordo com o conhecimento do autor, Sistemas DIF para manipuladores cooperativos foram 
propostos apenas nos artigos referentes ao trabalho exposto nesta tese [TINÓS et al., 2000], [TINÓS et al., 2001].

Em ambientes pouco estruturados, remotos e/ou perigosos, Sistemas DIF são essenciais devido ao fato de falhas ocasionadas por fatores externos serem relativamente comuns. A presença de fatores como radiações, variações bruscas de temperatura e obstáculos geralmente levam a um alto índice de falhas. No entanto, prover estes robôs somente com Sistemas DIF é insuficiente. Nestes ambientes, DIF pode evitar os efeitos das falhas, mas o sistema ainda estará inoperante e pode causar o fracasso na execução da tarefa já que o envio de seres humanos para executar os reparos necessários é muitas vezes inviável. Citam-se, como exemplos, os robôs trabalhando em plataformas de prospeção de petróleo ou em programas espaciais. Além disso, dependendo do objetivo e das consequências da falha, o robô precisa rapidamente concluir sua tarefa ou se reconfigurar para ser recolhido. Este é o caso, por exemplo, dos sistemas robóticos utilizados para o desarme de explosivos.

Pelo que foi dito anteriormente, é de vital importância o estudo de sistemas tolerantes a falhas. Sistemas dinâmicos com tolerância a falhas podem ser caracterizados como robustos ou reconfiguráveis. Um sistema é dito robusto se retém satisfatoriamente o desempenho na presença de erros de modelagem, ruídos e/ou falhas. O sistema é dito reconfigurável quando a sua estrutura ou seus controladores podem ser alterados em resposta às falhas. A reconfiguração tem como objetivo a manutenção de um desempenho aceitável do sistema dinâmico [STENGEL, 1991].

Sistemas robustos em robótica quase sempre requerem redundância física através da duplicação de sensores, atuadores e controladores. Contudo, além de encarecer e aumentar o tamanho e peso do sistema, a redundância física não protege contra falhas na estrutura mecânica dos manipuladores. Já os sistemas reconfiguráveis geralmente não necessitam de instrumentação adicional. Para que ocorra a reconfiguração, primeiro as falhas devem ser detectadas por Sistemas DIF. De acordo com o conhecimento do autor, sistemas completos de tolerância a falhas em manipuladores cooperativos foram propostos apenas nos artigos referentes ao trabalho exposto nesta tese [TINÓS et al., 2002].

\subsection{DESCRIÇÃO DO TRABALHO}

O objetivo principal deste trabalho é desenvolver um sistema de tolerância a falhas para manipuladores cooperativos. 
No sistema de tolerância proposto aqui, primeiro a falha é isolada através de um Sistema DIF. Então, o sistema cooperativo é reconfigurado para que trabalhe com a falha isolada. A Figura 1.1 apresenta o diagrama do sistema de tolerância proposto. Observe que tanto o movimento quanto o esmagamento do objeto são controlados. As medidas de posição e velocidade das juntas e força nos efetuadores alimentam o Sistema DIF juntamente com a informação das forças generalizadas aplicadas nas juntas. Quando uma falha é detectada, o Sistema DIF indica o seu tipo e a sua localização. Para o caso de uma falha que afete a dinâmica do sistema cooperativo, como as que ocorrem nos atuadores das juntas dos manipuladores, o controlador é reconfigurado de acordo com a falha isolada. Para o caso de uma falha que afete as medidas fornecidas pelo sistema, como as que ocorrem nos sensores das juntas dos manipuladores, as variáveis atingidas são substituídas por suas estimativas. Em ambos os casos, a trajetória do sistema cooperativo pode ser reconfigurada após a detecção da falha.

Para que o objetivo deste trabalho seja alcançado, os seguintes problemas devem ser solucionados:

(i) Como detectar e isolar as falhas do sistema cooperativo e;

(ii) Como controlar e reconfigurar o sistema cooperativo com falhas.

Para o primeiro problema, um Sistema DIF é proposto para quatro tipos de falhas:

(i) Informação incorreta de posição da junta;

(ii) Informação incorreta de velocidade da junta;

(iii) Junta bloqueada, e;

(iv) Junta com balanço livre (junta passiva).

As duas primeiras falhas são detectadas e isoladas através do uso das restrições impostas pelas cadeias cinemáticas fechadas presentes no sistema cooperativo. As duas últimas são detectadas através do uso de Redes Neurais Artificiais (RNA's). Neste caso, as dinâmicas dos manipuladores cooperativos são primeiramente mapeadas por Perceptrons Multicamadas (Multi-Layer Perceptron - MLP), cujas saídas geram o vetor de resíduos quando comparadas com as velocidades medidas das juntas. O vetor de resíduos é, então, classificado por uma rede RBF, que indica a ocorrência e a isolação da falha.

Para o segundo problema, controladores híbridos de movimento e esmagamento do objeto são propostos para o sistema com falhas do tipo junta bloqueada ou junta com balanço 
livre. Este não é um problema simples já que, em geral, o número de juntas com atuadores ativos não é suficiente para o controle de todas as componentes do movimento e do esmagamento do objeto. Os problemas de controle de movimento e esmagamento do objeto são independentemente tratados, o que se torna possível devido ao uso de uma lei de controle de esmagamento que não afeta o movimento. Para as falhas do tipo informação incorreta de posição ou velocidade da junta, uma metodologia para a recuperação dos dados é proposta. Nela, a medida afetada pela falha é substituída por sua estimativa analiticamente obtida.

A seguir, a estrutura do texto é apresentada.

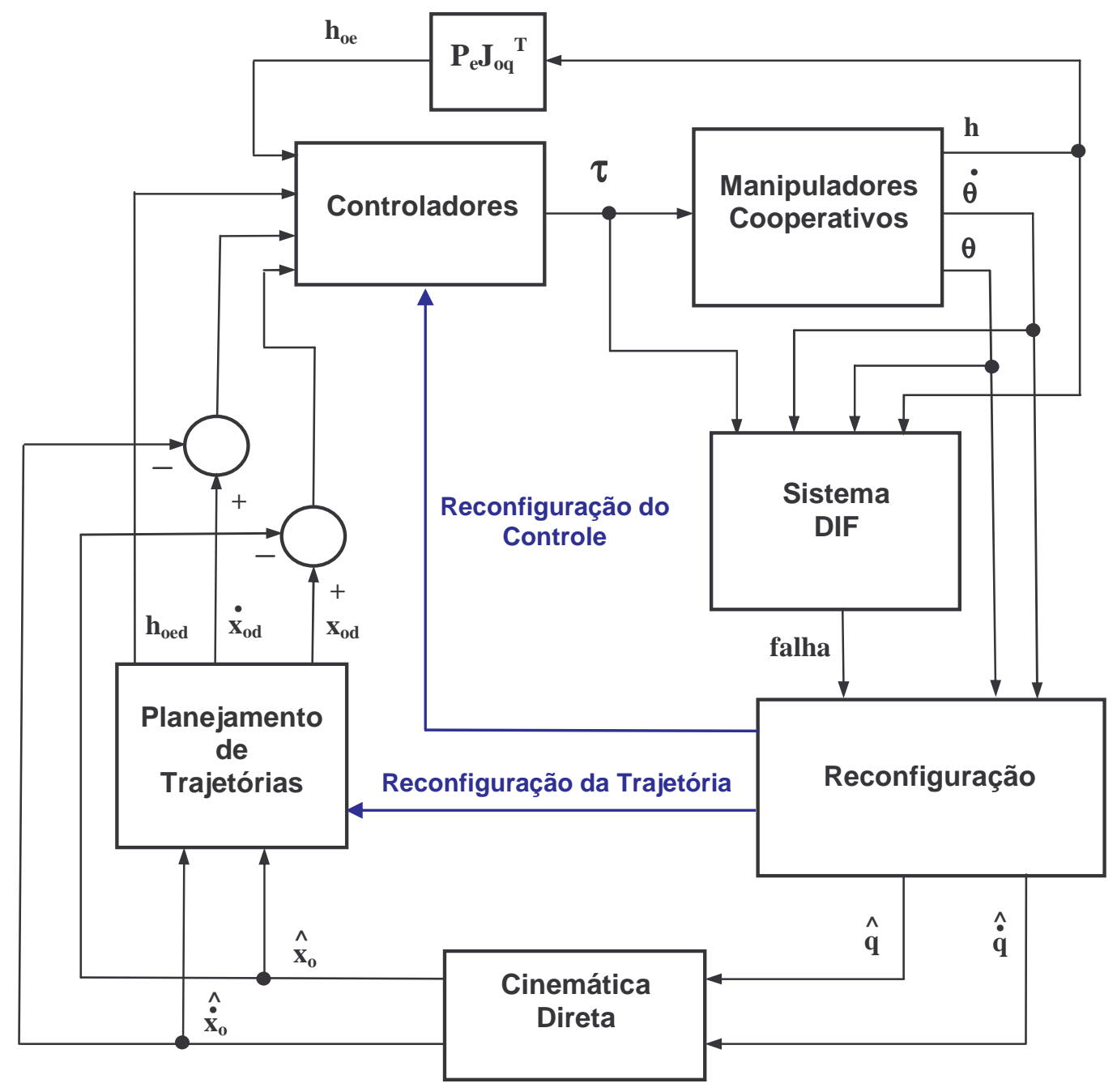

Simbologia:

$\tau$ : força generalizada aplicada nas juntas;.

$\boldsymbol{\theta}$ : posição medida das juntas;

$\mathbf{x}_{0}$ : posição do objeto;

h: força medida nos efetuadores;

q: posição da juntas;

$\mathbf{P}_{\mathrm{e}} \mathbf{J}_{\mathrm{oq}}{ }^{\top}$ : matriz de projeção.

$h_{\mathrm{oe}}$ : força de esmagamento

O subscrito $d$ indica os valores desejados $\mathrm{e}^{\wedge}$ indica que os valores são estimados.

FIGURA 1.1. Diagrama do sistema de tolerância a falhas proposto. 


\subsection{ESTRUTURA DO TEXTO}

Este texto está organizado da seguinte forma:

CAPÍTULO 2. As falhas em robôs manipuladores, suas consequências e causas são estudadas. Após uma introdução ao problema de falhas em robôs manipuladores, as falhas são analisadas através de dois métodos: Análise dos Modos e Efeitos das Falhas (Seção 2.2.2) e Análise por Árvore de Falhas (Seção 2.2.3). O capítulo termina com a apresentação das falhas nos robôs do sistema cooperativo que serão tratadas nos Capítulos 4 e 5.

CAPÍTUlO 3. A dinâmica, cinemática e controle do sistema cooperativo sem falhas são abordados. Se o objeto é indeformável e suas conexões com os efetuadores dos robôs são rígidas, as forças aplicadas no objeto podem ser decompostas em duas componentes: uma que provoca somente movimento e outra que provoca somente esmagamento (força interna). A decomposição das forças no objeto entre componentes de esmagamento e de movimento é descrita na Seção 3.4. Em geral, nos sistemas cooperativos, não somente o movimento da carga é controlado, mas também o esmagamento provocado pelos manipuladores. Os diferentes enfoques para tal problema de controle em manipuladores cooperativos sem falhas são apresentados na Seção 3.5.

CAPíTUlO 4. Um Sistema DIF para o sistema cooperativo é proposto (Seção 4.3) considerando a incidência das falhas identificadas no Capítulo 2. As falhas do tipo junta com balanço livre e junta bloqueada são detectadas através de RNA's (Seção 4.4). Já as falhas do tipo informação incorreta de posição ou velocidade nas juntas são detectadas através das restrições cinemáticas presentes no sistema cooperativo (Seção 4.5). Antes, uma revisão sobre DIF em sistema dinâmicos e em robôs manipuladores individuais é feita (Seção 4.1) e as RNA's utilizadas são brevemente descritas (Seção 4.2).

CAPÍTULO 5. Os problemas de reconfiguração e controle do sistema cooperativo com falhas são tratados. Controladores para robôs manipuladores cooperativos com falhas do tipo junta com balanço livre (ou junta passiva) e junta bloqueada são propostos respectivamente nas Seções 5.2 e 5.3. Nos casos em que ocorrem falhas do tipo informação incorreta de posição ou velocidade das juntas, as medidas incorretas são substituídas pelas estimativas produzidas pelo Sistema DIF (Seção 5.4). Na Seção 5.5, alguns comentários sobre a reconfiguração são apresentados 
juntamente com um método para cálculo da capacidade dinâmica de carga em manipuladores com juntas passivas.

CAPítulo 6. Os resultados do Sistema DIF, do controle do sistema cooperativo com falhas e do sistema de tolerância completo são apresentados. Os resultados foram obtidos em sistemas cooperativos simulados e em um sistema real composto por dois manipuladores UArmII. Os seguintes sistemas cooperativos foram simulados: sistema com dois manipuladores planares com 3 juntas rotacionais cada (Sistema Simulado 1); sistema formado por dois robôs do tipo Puma 560 (Sistema Simulado 2), e sistema com três manipuladores planares com 3 juntas rotacionais cada (Sistema Simulado 3).

CAPíTULO 7. As contribuições originais deste trabalho e as principais extensões dele visualizadas pelo autor são apresentadas.

Salienta-se que as principais contribuições originais deste trabalho encontram-se nos Capítulos 4 e 5.

O autor tomou a liberdade de acrescentar citações literais no início dos Capítulos 1, 2, 3 e 4. Embora seja procedimento mais comum aos textos da área de Humanas do que nos da área de Exatas, a inserção de citações literais visa ilustrar o tema abordado pelo capítulo. $\mathrm{O}$ autor tomou, ainda, a liberdade de não traduzir as citações em língua inglesa por temer a descaracterização de certas expressões. 


\section{Capítulo 2.}

\section{FALHAS EM ROBÔS MANIPULADORES}

“As Três Leis da Robótica:

1. um robô não pode ferir um ser humano ou, por omissão, permitir que um ser humano sofra algum mal.

2. um robô deve obedecer às ordens que lhe sejam dadas por seres humanos, exceto nos casos em que tais ordens contrariem a Primeira lei;

3. um robô deve proteger sua própria existência, desde que tal proteção não entre em conflito com a Primeira e Segunda Leis.

Manual de Robótica, 56 edição, 2058 DC" Prefácio do livro de ficção científica "Eu, Robô", publicado pela primeira vez no ano de 1950 [ASIMOV, 1978]

"Nasa prepara mais uma missão do Atlantis

Segunda-feira, 1 de abril de 2002 CABO CANAVERAL - A Nasa, agência espacial dos Estados Unidos, está finalizando a preparação para o lançamento do ônibus espacial Atlantis, que, dentro de 11 dias, cumprirá uma nova fase da construção da estação espacial Alfa. (....)

O lançamento está programado para ocorrer no Centro Espacial Kennedy, na Flórida, entre 19 e 23 horas (horário de Londres) de quartafeira. O horário exato do lançamento só será anunciado 24 horas, a fim de evitar atentados terroristas. No entanto, os técnicos ainda precisam concluir os testes de um software. Se houver problemas no programa de computador, os astronautas terão de aguardar mais alguns dias para a partida.

Este software serve para solucionar um problema que foi descoberto recentemente no braço robótico da estação - o qual desempenha uma função fundamental na instalação da carga que o Atlantis levará até o laboratório científico Destiny, da estação Alfa.

O braço de 17,5 metros de comprimento apresentou problemas quando um operador tentou soltar o freio em uma de suas sete articulações.

(...) A próxima missão será realizada pelo ônibus espacial Endeavour e deverá partir em 31 de maio. Ela inclui a instalação de uma nova articulação no braço da estação. (EFE)"

O Estado De São Paulo, 01/04/2002 http://www.estado.estadao.com.br/editorias/2002/04/01/ger009.html 
Neste Capítulo, o problema das falhas em robôs manipuladores é discutido. Os conceitos de Confiabilidade e Segurança em robôs manipuladores são introduzidos na Seção 2.1. Na Seção 2.2, as falhas no funcionamento básico de um robô manipulador (Seção 2.2.1) são analisadas através de dois métodos: primeiro, pela Análise dos Modos e Efeitos das Falhas (Seção 2.2.2) e, em seguida, através da Análise por Árvore de Falhas (Seção 2.2.3). O Capítulo termina com a apresentação das falhas nos robôs do sistema cooperativo que são tratadas nos Capítulos 4 (DIF) e 5 (reconfiguração e controle do sistema com falhas)

\subsection{INTRODUÇÃO}

$\mathrm{O}$ estudo de falhas e suas consequências em sistemas dinâmicos é recente. O início do estudo da confiabilidade dos sistemas dinâmicos deu-se durante a $2^{\mathrm{a}}$ Guerra Mundial, quando os alemães utilizaram tal conceito nos foguetes V1 e V2 [DHILLON, 1991]. Confiabilidade pode ser definida como a capacidade de um item desempenhar satisfatoriamente a função requerida, sob certas condições de operação, durante um dado intervalo de tempo [SCAPIN, 1999]. O conceito de segurança, apesar de ser mais antigo, teve seu grande florescimento na segunda metade do século XX. Já o tema DIF em sistemas dinâmicos somente começou a ser estudado com o advento do computador digital.

Os conceitos de confiabilidade e segurança passaram a ser aplicados em robôs somente na década de 1970. No entanto, a preocupação com segurança e confiabilidade em sistemas robóticos é mais antiga até mesmo que o aparecimento do primeiro robô real. Tal fato pode ser notado já no fim da década de 1940, quando o escritor Isaac Asimov formulou as "três leis da robótica" para um conjunto de contos de ficção científica [ASIMOV, 1973]. Nelas, a segurança dos seres humanos assume a prioridade máxima no funcionamento dos sistemas robóticos.

Várias publicações aparecerem em confiabilidade e segurança aplicadas a robôs industriais nas décadas de 1970 e 1980. O artigo [DHILLON, 1987] traz referências de várias delas. A ênfase maior destas pesquisas foi o estudo em segurança. Em indústrias, a segurança em robôs pode ser resumida através da seguinte sentença: "Partindo do princípio que os acidentes ocorrem somente se houver contato entre o ser humano e o robô, procura-se evitar ao máximo a proximidade entre eles". Esta meta é alcançada através de dispositivos de segurança, tais como cercas de isolamento e detectores de presença.

No entanto, mesmo com tais aparatos de segurança, existem diversos casos de acidentes relatados envolvendo robôs e seres humanos. Até 1983, existem registros de que 
cinco pessoas morreram em consequência de acidentes com robôs. A maioria dos casos ocorreu porque as vítimas inadvertidamente invadiram a área de operação do robô sem notar o funcionamento do mesmo [DHILLON, 1991]. Também existem relatos de acidentes em decorrência de falhas que provocaram movimentos descontrolados nos robôs. No que diz respeito à segurança, as duas maiores preocupações com falhas em robôs são que o manipulador solte ou lance o objeto que está carregando ou que se movimente de forma errática.

Nas últimas décadas, os robôs deixaram de ser exclusividade de indústrias e laboratórios de pesquisa. Consequentemente, a idéia de isolar os robôs está sendo revista já que robôs e seres humanos devem, cada vez mais, trabalhar cooperativamente na execução de diversas tarefas. Entre estas tarefas, podem ser citadas a execução de trabalhos domésticos e hospitalares, e a montagem de estruturas submarinas e espaciais. Quanto ao problema das falhas, a segurança em robôs pode ser aumentada através da melhora de sua confiabilidade ou através de técnicas de DIF. O problema de DIF em robôs manipuladores é tratado no Capítulo 4. A seguir, o tema confiabilidade em robôs manipuladores é tratado.

O problema da confiabilidade em robôs manipuladores é complexo. Os problemas de diminuição do número de falhas e de minimização dos efeitos destas devem ser previstos desde o início do projeto do robô. Devido à complexidade do sistema, a tarefa de projetar um robô confiável é desafiadora: o tempo de vida útil esperado deve ser de pelo menos 40000 horas de operação, o TMF de no mínimo 400 horas e o tempo médio de reparo de no máximo 8 horas [DHILLON, 1991].

Infelizmente, existem poucas informações sobre como prever o TMF dos sistemas robóticos e seus subsistemas [VISINSKY et al., 1994]. Isto acontece principalmente porque tolerância a falhas em robôs é relativamente recente e tem sido pouco estudada se comparada com outras áreas da Robótica. Fatores como acoplamento entre juntas e acelerações bruscas tornam ainda mais complexas as estimativas do TMF em robôs. Por exemplo, os acoplamentos dos elos de um robô podem causar uma alta incidência de falhas nos atuadores devido ao crescente esforço nas juntas.

A Figura 2.1 mostra um gráfico com o TMF para robôs industriais obtido empiricamente em um trabalho feito pelo Instituto de Pesquisas de Segurança na Indústria do Ministério do Trabalho Japonês na década de 1980 [DHILLON, 1991]. Observe que em $60,34 \%$ dos robôs, o TMF foi menor que 500 horas. 


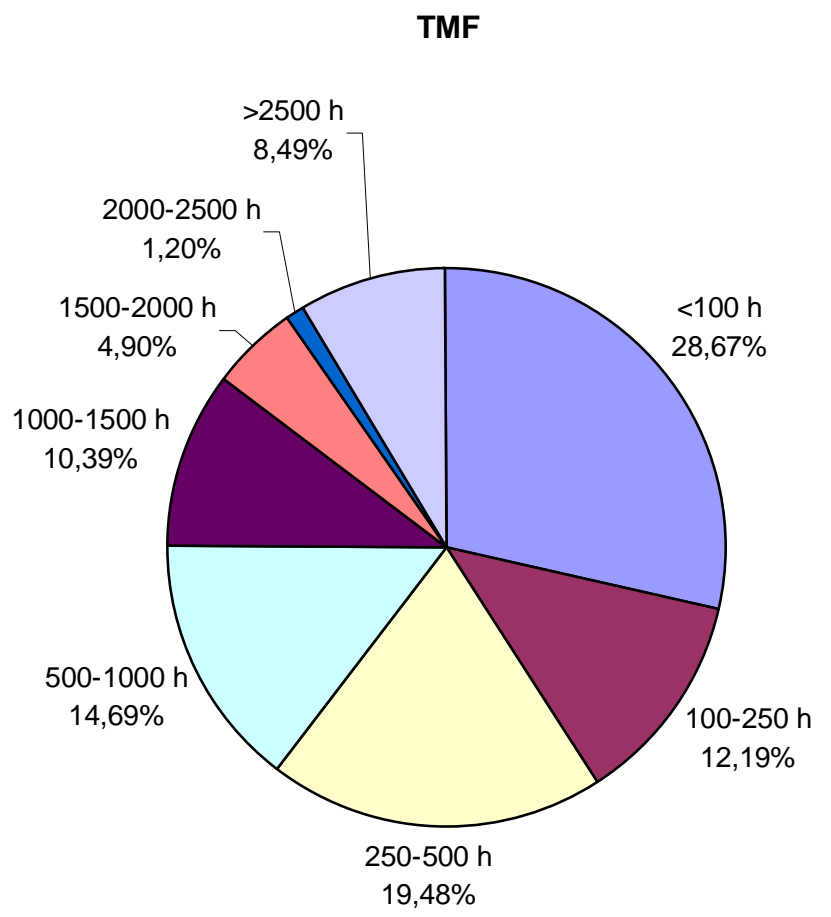

\section{FIGURA 2.1. Tempo Médio entre Falhas (em horas) para robôs industriais (pesquisa encomendada pelo Ministério do Trabalho Japonês na década de 1980).}

Os valores do TMF para robôs industriais são baixos se comparados com aqueles de outros equipamentos utilizados na indústria. Apesar de o ambiente industrial ser bem estruturado, existem diversas fontes de falhas em robôs, fato que contribui para o baixo TMF. As falhas podem ter causas mecânicas, elétricas, eletrônicas, hidráulicas, pneumáticas, de programação, etc... Além disso, existem diversas partes móveis sujeitas a desgaste e esforço que podem ser acentuados devido às altas acelerações em que são submetidos os elos e as juntas. Quando o robô está em um ambiente pouco estruturado e/ou perigoso, fatores externos ainda podem contribuir para uma maior incidência de falhas no robô. Entre tais fatores, podem ser citados:

(i) Radiação nuclear, eletromagnética, por raios cósmicos, etc.. Exemplo: robôs atuando em instalações nucleares e na exploração espacial geralmente estão sujeitos a altos índices de radiação;

(ii) Impacto. Exemplo: em um ambiente pouco estruturado, um objeto pode chocar-se com o robô. Um outro exemplo é a manipulação de explosivos; 
(iii) Calor elou frio. Exemplo: robôs trabalhando em exploração espacial podem estar sujeitos a grandes variações de temperatura. Já os robôs empregados no combate a incêndios são submetidos a temperaturas muito altas;

(iv) Produtos químicos. Exemplo: robôs atuando em instalações químicas;

(v) Água ou outros líquidos. Exemplo: robôs trabalhando submersos ou em ambientes externos sujeitos a chuva e;

(vi) Choques elétricos. Exemplo: robôs trabalhando em tubulações.

É de se esperar que nestes ambientes, apesar de tais robôs serem projetados para serem robustos, a ocorrência de falhas seja mais frequente do que em um ambiente comum.

\subsection{ANÁLISE DE FALHAS EM ROBÔS MANIPULADORES}

Um estudo empírico feito durante o ano de 1982 no Japão por uma montadora de automóveis revelou que os problemas relacionados ao funcionamento dos manipuladores foram [SHIMA, 1982]:

(i) um robô fez um movimento diferente daquele planejado;

(ii) um robô inesperadamente moveu-se em um dia quente de verão, apesar de não ter sido programado para isso;

(iii) um robô inesperadamente movimentou-se quando a pressão de óleo foi cortada do seu sistema hidráulico no fim de um dia de trabalho;

(iv) um robô destruiu um trabalho de solda ao mover-se sozinho devido a um erro de programação;

(v) um robô inesperadamente oscilou quando movia-se em um curso de treinamento;

(vi) um robô começou a mover-se quando a chave de potência foi acionada apesar das condições de intertravamento estarem ativadas e;

(vii) depois da ativação da chave de potência, um robô moveu-se sem estar programado para isso, parando somente depois de bater e ficar preso em uma máquina de solda.

De acordo com [SUGIMOTO \& KAWAGUCHI, 1983] e [SATO, 1982] os problemas em robôs seguem a seguinte ordem:

(i) problemas no sistema de controle; 
(ii) incompatibilidade de ferramentas e fixação (gabaritos);

(iii) problemas no corpo de robô;

(iv) erros associados com a programação e operação;

(v) problemas na ferramenta fixada ao efetuador (pistolas de solda, etc...);

(vi) deterioração e deficiência da precisão;

(vii) perda de controle e;

(viii) variados.

Basicamente, existem 4 tipos de falhas que afetam a confiabilidade e a segurança em robôs industriais. São elas:

(i) falhas aleatórias dos componentes: ocorrem de forma não previsível durante a vida útil do componente. A taxa de falhas teórica em sistemas de engenharia, como os robôs, tem um comportamento como o apresentado na Figura 2.2 [AMERICAN NATIONAL STANDARDS INSTITUTE, 1993]. As falhas que ocorrem em um primeiro período, conhecido como período de mortalidade infantil, são geralmente decorrentes de defeitos de projeto, fabricação e montagem. No período final, conhecido como período de exaustão, são, na maioria das vezes, decorrentes do fim da vida útil de componentes, manutenção inadequada, corrosão, desgastes devido à friç̧ão e envelhecimento. Durante o período em que a taxa de falhas é praticamente constante, conhecido como período de vida útil, as falhas ocorrem aleatoriamente devido a problemas como ocorrência de falhas naturais e defeitos não-detectáveis;

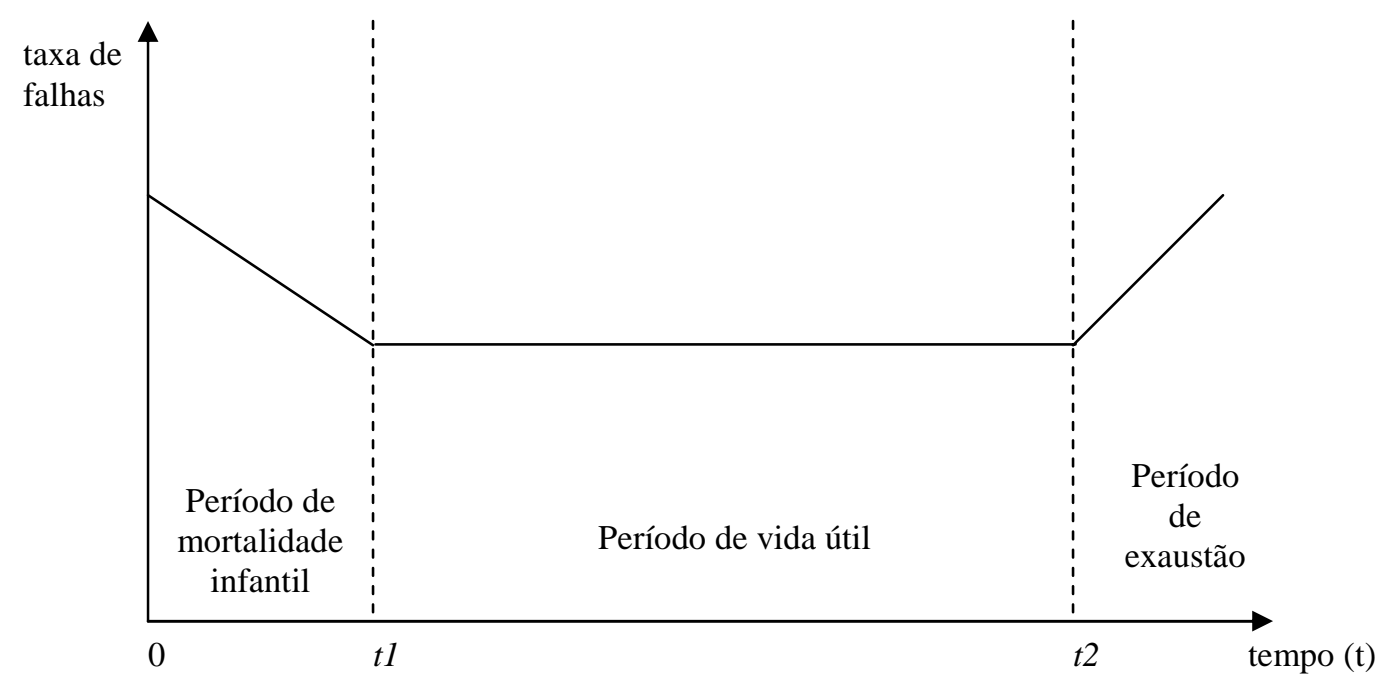

FIGURA 2.2. Taxa de falhas teórica em um robô industrial. 
(ii) falhas de programação: podem ocorrer em virtude de erros nas entradas/saídas de dados ou devido a erros de programação. Redundância de dados, testes de time out e checagem de status podem ser utilizadas para aumentar a confiabilidade na troca de informações;

(iii) falhas devido a erros humanos: podem ocorrer no projeto, manufatura, teste, manutenção e operação do robô. Estima-se que de 20 a $50 \%$ das falhas em equipamentos ocorrem devido a erros humanos [DHILLON, 1991] e;

(iv) falhas sistemáticas no equipamento: falhas que ocorrem devido a efeitos nãoprevistos ou ignorados no projeto do robô. Certas configurações cinemáticas podem impedir o movimento do robô. Podem também ocorrer em decorrência de problemas no fornecimento de energia, pressão hidráulica e pneumática para o robô. Estas podem ser evitadas através da colocação de sensores nas linhas de pressão e energia.

Apesar do alto índice de falhas em virtude de erros humanos e de erros de programação, estas falhas não serão estudadas aqui. Assim, considera-se a suposição de que o robô está trabalhando satisfatoriamente no modo automático sem intervenção humana direta.

Vários trabalhos trataram do problema da análise de falhas em robôs manipuladores. Entre eles, podem ser citados: [DHILLON, 1991], [DHILLON \& YANG, 1996], [KHODABANDEHLOO, 1996], [WALKER \& CAVALLARO, 1996], [DHILLON \& FASHANDI, 1997] e [CARRERAS \& WALKER, 2000].

Aqui, as falhas no funcionamento básico de um manipulador são analisadas através de dois métodos: primeiro, pela Análise dos Modos e Efeitos das Falhas (AMEF) [STAMATIS, 1995] e, em seguida, através da Análise por Árvore de Falhas (AAF) [SCAPIN, 1999]. AMEF é uma ferramenta preciosa na identificação dos modos das falhas e seus efeitos, permitindo a determinação das consequências das falhas e de possíveis ações preventivas. Já AAF é uma representação gráfica que estabelece a relação entre as falhas e suas causas. As duas técnicas são complementares e são utilizadas aqui para a determinação das falhas que apresentam consequências mais graves para o sistema cooperativo. Antes, no entanto, o funcionamento básico do robô manipulador é descrito. 


\subsubsection{Funcionamento Básico do Robô Manipulador}

O funcionamento básico de um manipulador pode ser resumidamente descrito pela seguinte sequência:

(i) o controle é realizado através de microprocessadores; nos robôs industriais, geralmente existe um cartão de controle microprocessado para cada junta;

(ii) o sinal de controle microprocessado é convertido por amplificadores em sinais de corrente, no caso de atuadores elétricos, ou em sinais para posicionamento da servoválvula, no caso de atuadores hidráulicos;

(iii) cada junta é atuada por um motor de corrente contínua ou hidráulico;

(iv) a rotação do motor, no caso de juntas rotacionais, ou o deslocamento do atuador linear, no caso de juntas prismáticas, é transmitido para a respectiva junta através de uma unidade de transmissão mecânica;

(v) os sensores enviam os sinais de posição das juntas ${ }^{1}$ e, quando possível, força e torque no efetuador e/ou velocidade das juntas;

(vi) os sinais são enviados para um computador de supervisão e;

(vii) este envia os sinais para os controladores. O ciclo se inicia novamente através do passo (i).

\subsubsection{Análise dos Modos e Efeitos das Falhas}

Conhecendo o funcionamento básico de um robô industrial, pode-se fazer sua AMEF. Por simplicidade, os efeitos da fricção nas juntas serão negligenciados. A Tabela 2.1 traz um estudo simplificado sobre os modos e causas das principais falhas em um único manipulador com atuadores elétricos ou hidráulicos, encoders como sensores de posição, tacogeradores como sensores de velocidade, amplificadores de corrente, controlador (computador) e freios pneumáticos. A Tabela 2.2 traz um estudo dos efeitos destas falhas na execução de uma tarefa qualquer.

\footnotetext{
${ }^{1} \mathrm{O}$ termo "posições das juntas" refere-se às coordenadas generalizadas das juntas do manipulador. As coordenadas generalizadas são ângulos nas juntas rotacionais e deslocamento nas juntas prismáticas.
} 
TABELA 2.1: Análise dos modos e sintomas das falhas em robôs (juntas $i=1, \ldots, n$ ).

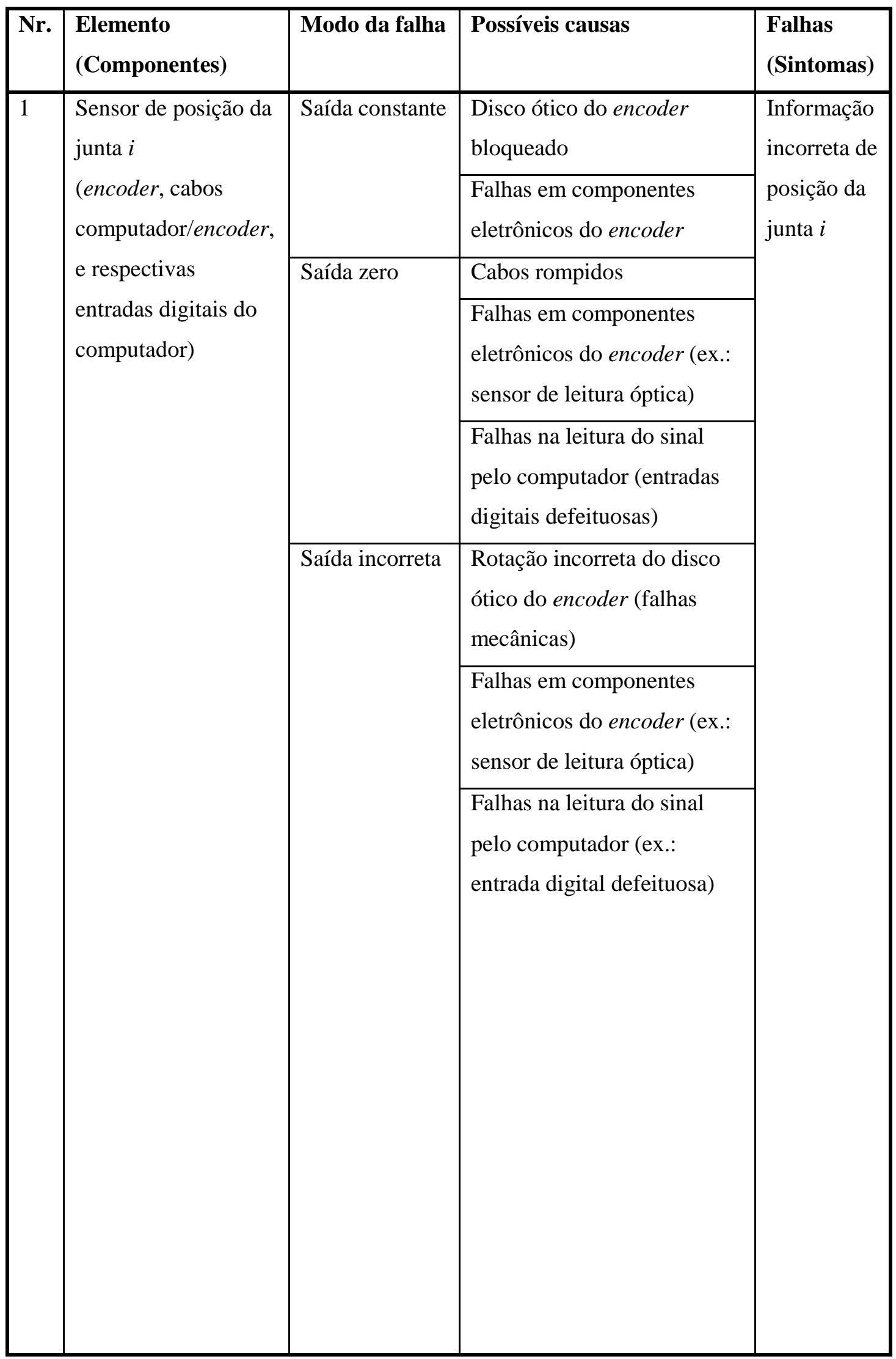




\begin{tabular}{|c|c|c|c|c|}
\hline \multirow[t]{11}{*}{2} & \multirow{11}{*}{$\begin{array}{l}\text { Sensor de velocidade } \\
\text { da junta } i \\
\text { (tacogerador, } \\
\text { conversor A/D, } \\
\text { cabos computador/ } \\
\text { tacogerador, e } \\
\text { respectivas entradas } \\
\text { digitais do } \\
\text { computador) }\end{array}$} & \multirow[t]{8}{*}{ Saída zero } & Cabos rompidos & \multirow{11}{*}{$\begin{array}{l}\text { Informação } \\
\text { incorreta de } \\
\text { velocidade } \\
\text { da junta } i\end{array}$} \\
\hline & & & Falhas em componentes & \\
\hline & & & eletro-eletrônicos do & \\
\hline & & & tacogerador ou do conversor & \\
\hline & & & $\mathrm{A} / \mathrm{D}$ & \\
\hline & & & Falhas na leitura do sinal & \\
\hline & & & pelo computador (entradas & \\
\hline & & & digitais defeituosas) & \\
\hline & & \multirow[t]{3}{*}{ Saída incorreta } & $\begin{array}{l}\text { Rotação incorreta do rotor } \\
\text { do tacogerador (falhas } \\
\text { mecânicas) }\end{array}$ & \\
\hline & & & $\begin{array}{l}\text { Falhas em componentes } \\
\text { eletro-eletrônicos do } \\
\text { tacogerador ou do conversor } \\
\text { A/D }\end{array}$ & \\
\hline & & & $\begin{array}{l}\text { Falhas na leitura do sinal } \\
\text { pelo computador (entradas } \\
\text { digitais defeituosas) }\end{array}$ & \\
\hline \multirow[t]{6}{*}{3} & \multirow{6}{*}{$\begin{array}{l}\text { Atuador da junta } i \\
\text { (no caso de atuador } \\
\text { elétrico: motor CC e } \\
\text { cabos } \\
\text { motor/amplificador; } \\
\text { no caso de atuador } \\
\text { hidráulico: motor } \\
\text { hidráulico, servo- } \\
\text { válvulas e circuito } \\
\text { hidráulico) }\end{array}$} & \multirow[t]{5}{*}{ Rotor livre } & $\begin{array}{l}\text { Circuito aberto no } \\
\text { enrolamento do rotor ( ex.: } \\
\text { circuito aberto, falha no } \\
\text { sistema de escovas) }\end{array}$ & \multirow[t]{5}{*}{$\begin{array}{l}\text { Junta } i \text { com } \\
\text { balanço } \\
\text { livre }\end{array}$} \\
\hline & & & $\begin{array}{l}\text { Circuito aberto no } \\
\text { enrolamento do estator }\end{array}$ & \\
\hline & & & Rompimento de cabos & \\
\hline & & & Vazamentos hidráulicos & \\
\hline & & & Falhas nas servo-válvulas & \\
\hline & & $\begin{array}{l}\text { Rotor } \\
\text { bloqueado }\end{array}$ & $\begin{array}{l}\text { Falhas mecânicas ou } \\
\text { eletromecânicas (ex.: } \\
\text { derretimento de cabos do } \\
\text { rotor devido a curto-circuito, } \\
\text { falha na servo-válvula) }\end{array}$ & $\begin{array}{l}\text { Junta } i \\
\text { bloqueada }\end{array}$ \\
\hline
\end{tabular}




\begin{tabular}{|c|c|c|c|c|}
\hline \multirow[t]{2}{*}{4} & \multirow[t]{2}{*}{$\begin{array}{l}\text { Transmissão da junta } \\
i\end{array}$} & Rotação livre & $\begin{array}{l}\text { Falhas mecânicas (ex.: } \\
\text { rompimento de correias) }\end{array}$ & $\begin{array}{l}\text { Junta } i \text { com } \\
\text { balanço } \\
\text { livre }\end{array}$ \\
\hline & & $\begin{array}{l}\text { Rotação } \\
\text { bloqueada }\end{array}$ & $\begin{array}{l}\text { Falhas mecânicas (ex.: } \\
\text { engrenagens travadas) }\end{array}$ & $\begin{array}{l}\text { Junta } i \\
\text { bloqueada }\end{array}$ \\
\hline \multirow[t]{3}{*}{5} & \multirow{3}{*}{$\begin{array}{l}\text { Amplificador de } \\
\text { corrente } \\
\text { (amplificador, cabos } \\
\text { computador/ } \\
\text { amplificador e } \\
\text { alimentação/ } \\
\text { amplificador) }\end{array}$} & $\begin{array}{l}\text { Correntes } \\
\text { aplicadas no } \\
\text { motor iguais a }\end{array}$ & Rompimento de cabos & \multirow[t]{2}{*}{$\begin{array}{l}\text { Junta } i \text { com } \\
\text { balanço } \\
\text { livre }\end{array}$} \\
\hline & & $\begin{array}{l}\text { motor iguais a } \\
\text { zero }\end{array}$ & $\begin{array}{l}\text { Falhas nos componentes } \\
\text { eletrônicos do amplificador } \\
\text { (ex.: transistor de potência } \\
\text { aberto) }\end{array}$ & \\
\hline & & $\begin{array}{l}\text { Valores } \\
\text { incorretos das } \\
\text { correntes } \\
\text { aplicadas no } \\
\text { motor }\end{array}$ & $\begin{array}{l}\text { Falhas nos componentes } \\
\text { eletrônicos do amplificador }\end{array}$ & $\begin{array}{l}\text { Torque } \\
\text { errado } \\
\text { aplicado na } \\
\text { junta } i\end{array}$ \\
\hline \multirow[t]{5}{*}{6} & \multirow{5}{*}{$\begin{array}{l}\text { Freio } i \text { (freio, circuito } \\
\text { pneumático, válvula } \\
\text { solenóide, cabos } \\
\text { computador/válvula } \\
\text { e respectiva saída } \\
\text { digital do } \\
\text { computador) }\end{array}$} & \multirow{5}{*}{$\begin{array}{l}\text { Acionamento } \\
\text { incorreto }\end{array}$} & Falhas mecânicas no freio & \multirow{5}{*}{$\begin{array}{l}\text { Junta } i \\
\text { bloqueada }\end{array}$} \\
\hline & & & $\begin{array}{l}\text { Falhas no circuito } \\
\text { pneumático (ex.: } \\
\text { vazamentos, falhas em } \\
\text { filtros e válvulas) }\end{array}$ & \\
\hline & & & $\begin{array}{l}\text { Falhas na válvula solenóide } \\
\text { (ex.: abertura do solenóide) }\end{array}$ & \\
\hline & & & Rompimento de cabos & \\
\hline & & & $\begin{array}{l}\text { Falhas na envio do sinal pelo } \\
\text { computador (ex.: saída } \\
\text { digital queimada) }\end{array}$ & \\
\hline \multirow[t]{2}{*}{7} & \multirow[t]{2}{*}{$\begin{array}{l}\text { Alimentação elétrica } \\
\text { e hidráulica }\end{array}$} & \multirow{2}{*}{$\begin{array}{l}\text { Tensões ou } \\
\text { pressões iguais } \\
\text { a zero }\end{array}$} & $\begin{array}{l}\text { Falhas nos componentes da } \\
\text { fonte }\end{array}$ & \multirow{2}{*}{$\begin{array}{l}\text { Falha na } \\
\text { alimenta- } \\
\text { ção }\end{array}$} \\
\hline & & & $\begin{array}{l}\text { Falha na rede de suprimento } \\
\text { (rede elétrica, baterias, } \\
\text { cabos, rede hidráulica, etc...) }\end{array}$ & \\
\hline
\end{tabular}




\begin{tabular}{|l|l|l|l|l|}
\hline 8 & Computador & Sinais de & Rompimento de cabos & Junta $i$ com \\
& (computador e cabos & controle para o & & balanço \\
& alimentação/- & amplificador & livre \\
\cline { 4 - 5 } & computador) & iguais a zero & Falha nos componentes do & \\
& & & computador & \\
\hline
\end{tabular}

TABELA 2.2: Análise dos sintomas e efeitos das falhas (juntas $i=1, \ldots, n$ ).

\begin{tabular}{|c|c|c|}
\hline $\begin{array}{l}\text { Falhas } \\
\text { (Sintomas) }\end{array}$ & Efeito na missão $^{(*)(* *)}$ & Observações \\
\hline $\begin{array}{l}\text { Informação } \\
\text { incorreta de } \\
\text { posição da } \\
\text { junta } i\end{array}$ & $\begin{array}{l}\text { Como a posição medida é incorreta, o } \\
\text { computador calcula um torque diferente } \\
\text { daquele que deve ser aplicado. Por exemplo, } \\
\text { se a posição de uma junta rotacional é } 90^{\circ} \text {, o } \\
\text { seu valor desejado final é } 45^{\circ} \text { e a leitura do } \\
\text { sensor é sempre igual a } 0^{\circ} \text {, o controlador irá } \\
\text { aplicar um torque no sentido contrário ao } \\
\text { desejado. Como o valor de posição da junta } i \\
\text { não se altera, o controlador continuará } \\
\text { aplicando um torque crescente ou constante } \\
\text { no sentido incorreto. Neste caso, o sistema } \\
\text { pode tornar-se instável ou convergir para } \\
\text { posições diferentes daquelas desejadas. }\end{array}$ & $\begin{array}{l}\text { Geralmente, quando ocorre } \\
\text { este tipo de falha, o } \\
\text { manipulador para somente } \\
\text { quando as juntas atingem } \\
\text { seus limites ou quando } \\
\text { choca-se com o chão ou } \\
\text { com objetos presentes no } \\
\text { ambiente de trabalho. } \\
\text { O mesmo ocorre para os } \\
\text { robôs cooperativos, com os } \\
\text { seguintes agravantes: } \\
\text { - os robôs podem chocar-se } \\
\text { e; } \\
\text { - o objeto pode ser } \\
\text { danificado já que o } \\
\text { esmagamento não é mais } \\
\text { corretamente controlado. }\end{array}$ \\
\hline
\end{tabular}




\begin{tabular}{|c|c|c|}
\hline $\begin{array}{l}\text { Informação } \\
\text { incorreta de } \\
\text { velocidade } \\
\text { da junta } i\end{array}$ & $\begin{array}{l}\text { Como a velocidade medida é incorreta, o } \\
\text { computador calcula um torque diferente } \\
\text { daquele que deve ser aplicado. O sistema } \\
\text { pode tornar-se instável ou convergir para } \\
\text { posições diferentes daquelas desejadas. }\end{array}$ & $\begin{array}{l}\text { As consequências desta } \\
\text { falha dependem do tipo da } \\
\text { trajetória desejada e do } \\
\text { controlador. Muitas vezes, } \\
\text { quando ocorre este tipo de } \\
\text { falha, o manipulador para } \\
\text { somente quando as juntas } \\
\text { atingem seus limites ou } \\
\text { quando choca-se com o } \\
\text { chão ou com objetos } \\
\text { presentes no ambiente de } \\
\text { trabalho. } \\
\text { O mesmo ocorre para os } \\
\text { robôs cooperativos, com os } \\
\text { seguintes agravantes: } \\
\text { - os robôs podem chocar-se } \\
\text { e; } \\
\text { - o objeto pode ser } \\
\text { danificado já que o } \\
\text { esmagamento não é mais } \\
\text { corretamente controlado. }\end{array}$ \\
\hline $\begin{array}{l}\text { Junta } i \\
\text { bloqueada }\end{array}$ & $\begin{array}{l}\text { O sistema pode tornar-se instável ou } \\
\text { convergir para posições diferentes daquelas } \\
\text { desejadas. }\end{array}$ & $\begin{array}{l}\text { Geralmente, quando ocorre } \\
\text { este tipo de falha, o robô } \\
\text { para somente quando as } \\
\text { juntas atingem seus limites } \\
\text { ou quando choca-se com o } \\
\text { chão ou com objetos } \\
\text { presentes no ambiente de } \\
\text { trabalho. } \\
\text { Para os robôs cooperativos: } \\
\text { - os robôs podem chocar-se } \\
\text { e; } \\
\text { - o objeto pode ser } \\
\text { danificado. }\end{array}$ \\
\hline
\end{tabular}




\begin{tabular}{|c|c|c|}
\hline $\begin{array}{l}\text { Junta } i \text { com } \\
\text { balanço livre }\end{array}$ & $\begin{array}{l}\text { O sistema pode tornar-se instável ou } \\
\text { convergir para posições diferentes daquelas } \\
\text { desejadas. }\end{array}$ & $\begin{array}{l}\text { Geralmente, quando ocorre } \\
\text { este tipo de falha, o robô } \\
\text { para somente quando as } \\
\text { juntas atingem seus limites } \\
\text { ou quando choca-se com o } \\
\text { chão ou com objetos } \\
\text { presentes no ambiente de } \\
\text { trabalho. } \\
\text { Para os robôs cooperativos: } \\
\text { - os robôs podem chocar-se } \\
\text { e; } \\
\text { - o objeto pode ser } \\
\text { danificado. }\end{array}$ \\
\hline $\begin{array}{l}\text { Torque } \\
\text { incorreto na } \\
\text { junta } i\end{array}$ & $\begin{array}{l}\text { O torque aplicado é incorreto. Neste caso, o } \\
\text { sistema pode ficar instável ou pode convergir } \\
\text { para posições incorretas. }\end{array}$ & $\begin{array}{l}\text { Geralmente, quando ocorre } \\
\text { este tipo de falha, o robô } \\
\text { para somente quando as } \\
\text { juntas atingem seus limites } \\
\text { ou quando choca-se com o } \\
\text { chão ou com objetos } \\
\text { presentes no ambiente de } \\
\text { trabalho. } \\
\text { Para os robôs cooperativos: } \\
\text { - os robôs podem chocar-se } \\
\text { e; } \\
\text { - o objeto pode ser } \\
\text { danificado. }\end{array}$ \\
\hline $\begin{array}{l}\text { Falha na } \\
\text { Alimentação }\end{array}$ & $\begin{array}{l}\text { Geralmente, os freios são liberados quando o } \\
\text { ar-comprimido é aplicado. Além disso, a } \\
\text { válvula solenóide libera o ar-comprimido } \\
\text { para o freio somente quando é energizada. } \\
\text { Assim, quando existem falhas no suprimento, } \\
\text { todos os freios das juntas são acionados. }\end{array}$ & $\begin{array}{l}\text { Geralmente não apresentam } \\
\text { consequências graves já } \\
\text { que os freios são acionados. }\end{array}$ \\
\hline
\end{tabular}

* as falhas devem ocorrer quando os robôs estão em movimento.

** estão sendo consideradas falhas somente nos robôs. 
Note que 6 falhas principais foram identificadas nas Tabelas 2.1 e 2.2:

(i) informação incorreta de posição da junta $i$;
(ii) informação incorreta de velocidade da junta $i$;
(iii) junta $i$ bloqueada;
(iv) junta $i$ com balanço livre;
(v) torque incorreto na junta $i$ e;
(vi) falha na alimentação.

\subsubsection{Análise Através de Árvore de Falhas}

A Figura 2.3 (a-e) mostra as árvores de causas das falhas identificadas na seção anterior para um manipulador com atuadores elétricos. As árvores de falhas para o manipulador com atuadores hidráulicos não são apresentadas por serem semelhantes àquelas do manipulador com atuadores elétricos. 


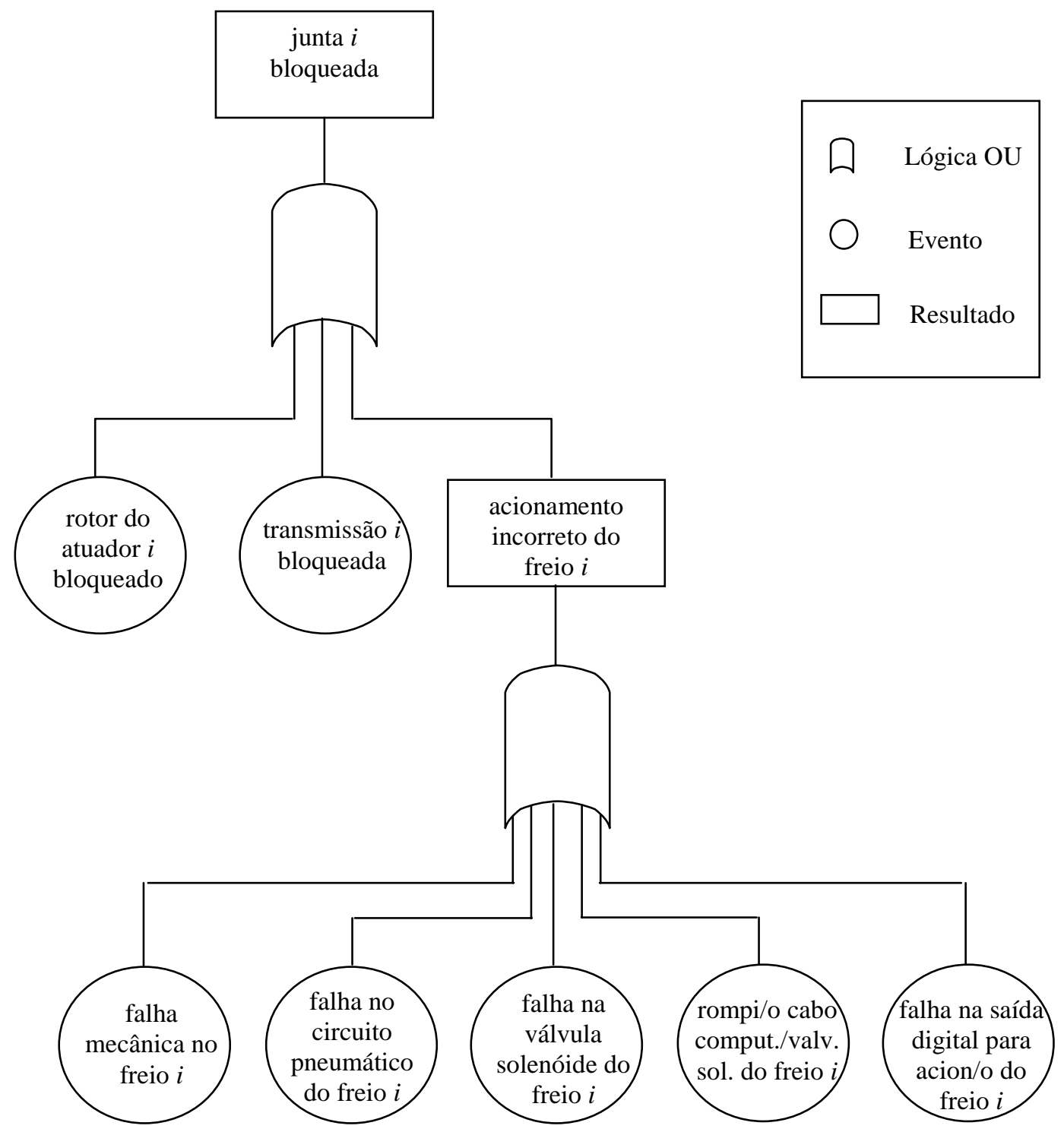

FIGURA 2.3.a. Árvore de causas da falha "Junta $i$ bloqueada". Veja Tabelas 2.1 e 2.2 para maiores detalhes sobre as falhas. 


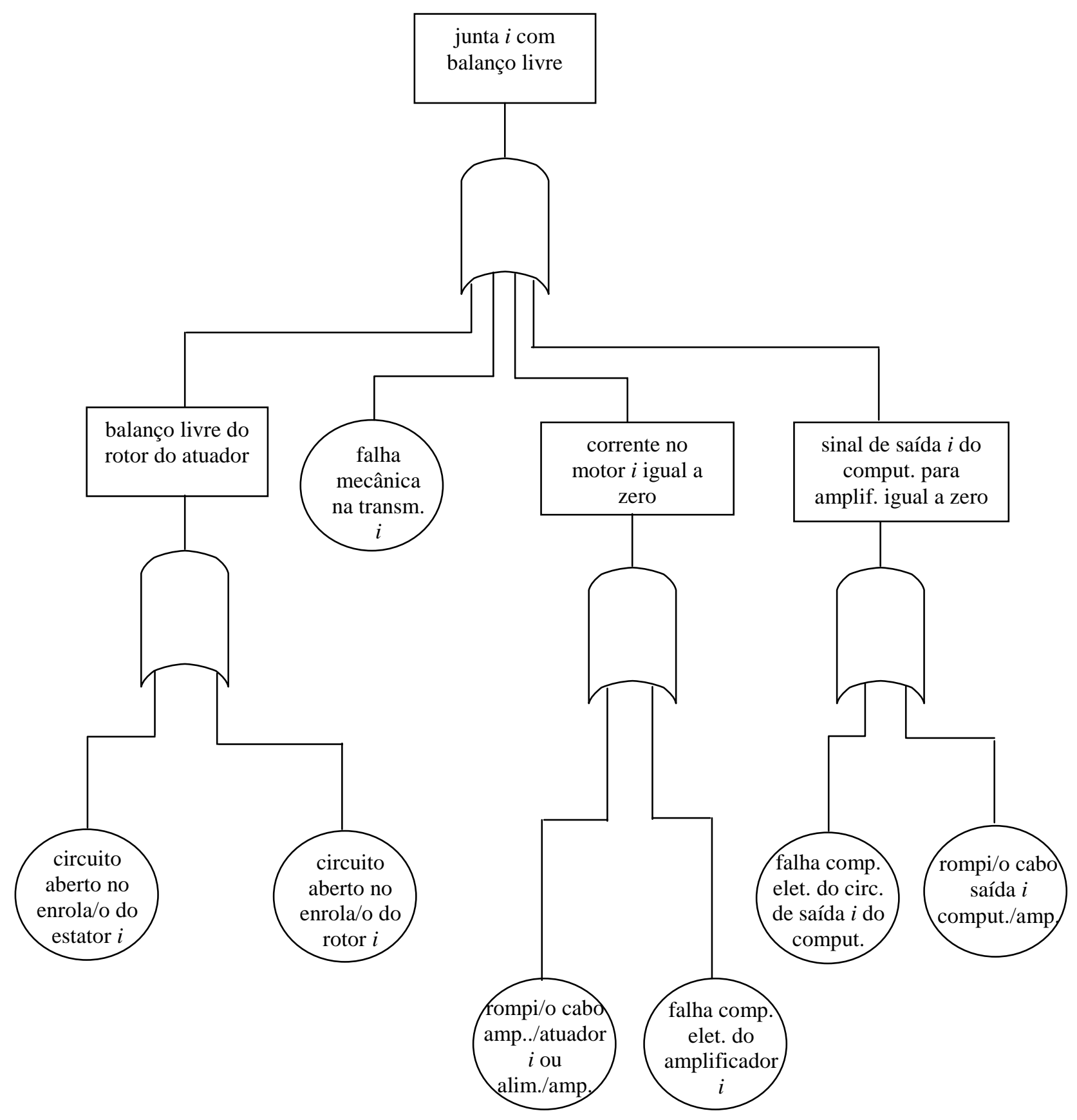

FIGURA 2.3.b. Árvore de causas da falha "Junta $i$ com balanço livre". 


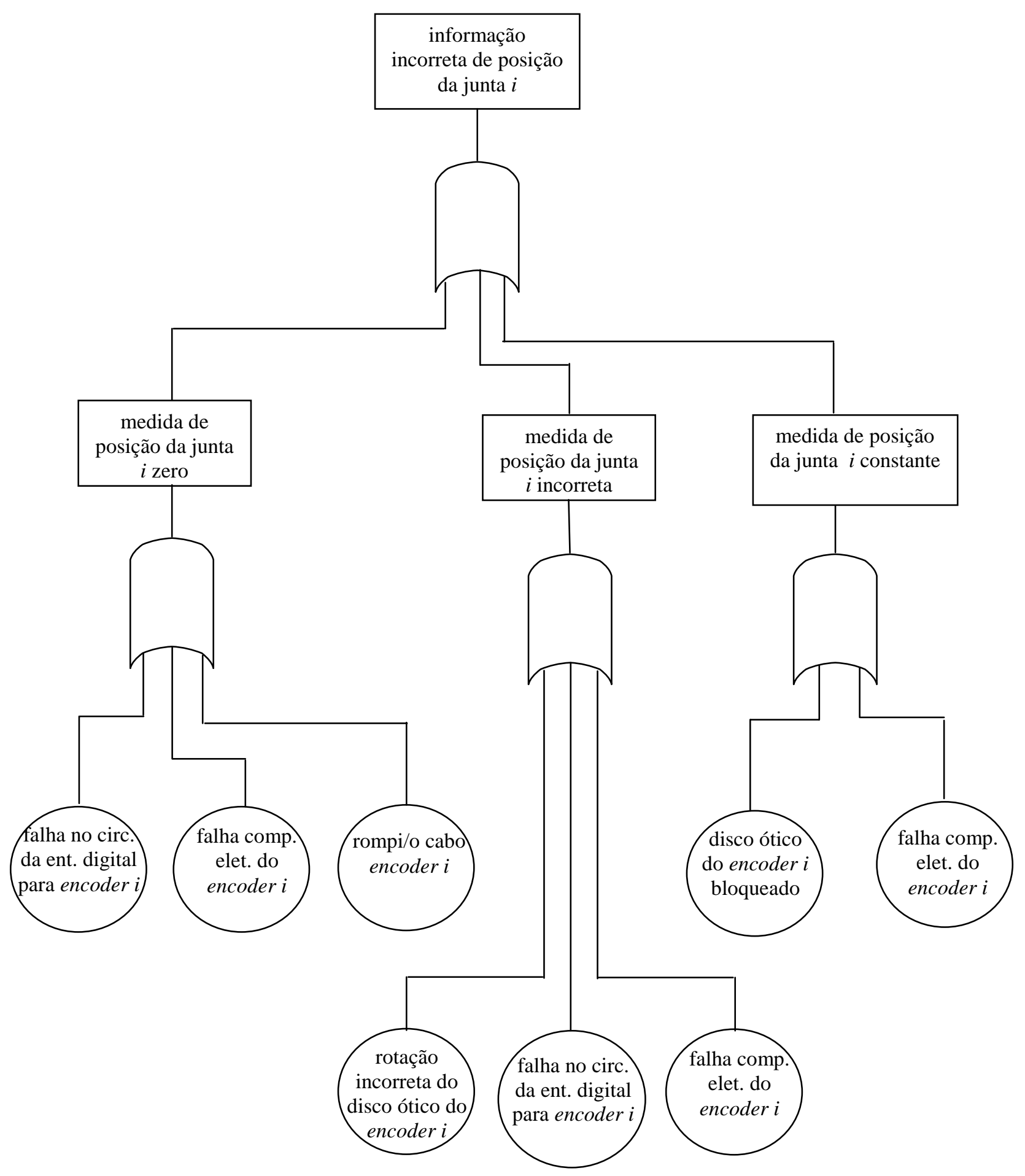

FIGURA 2.3.c. Árvore de causas da falha "Informação incorreta de posição da junta i". 


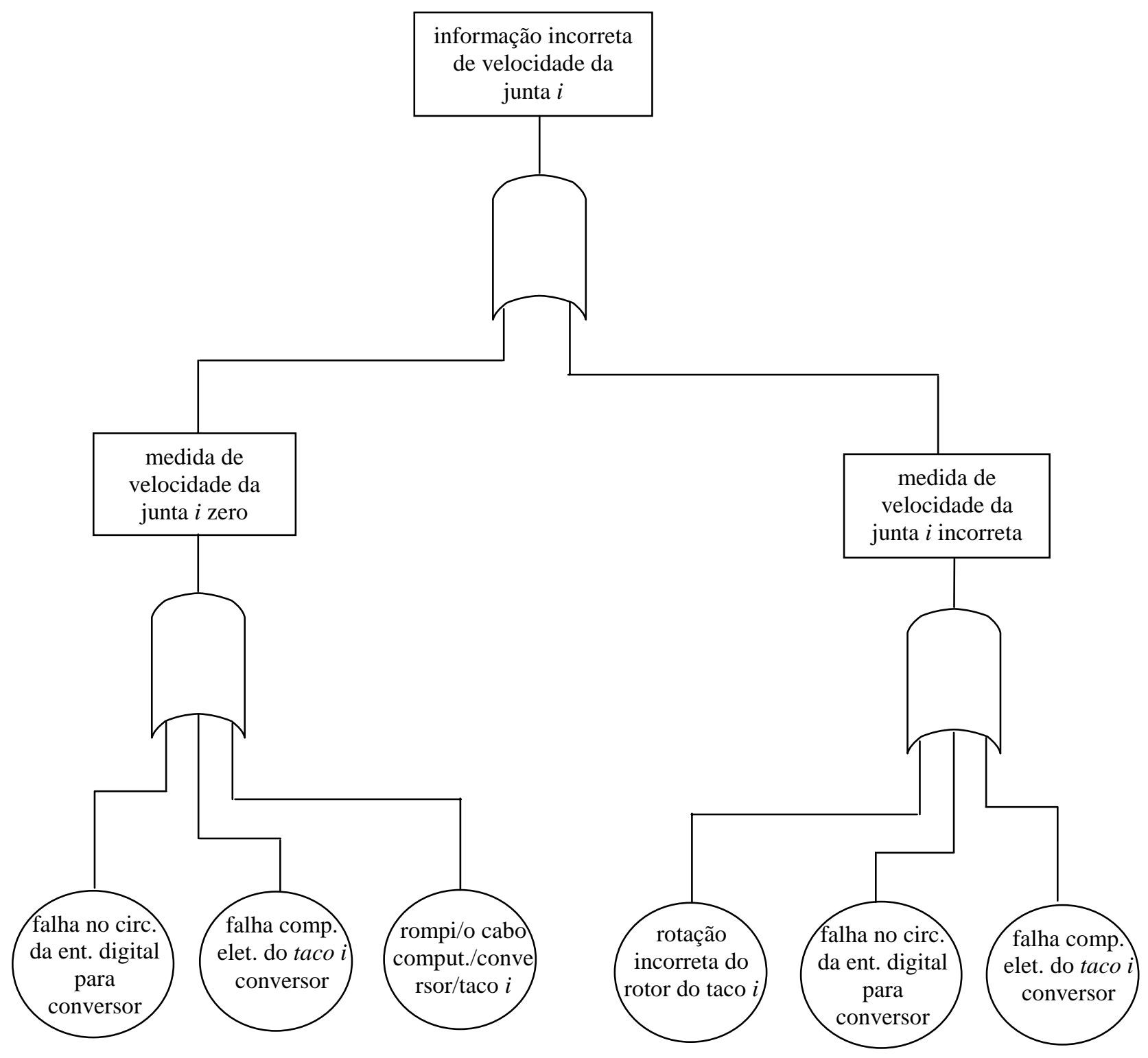

FIGURA 2.3.d. Árvore de causas da falha " Informação incorreta de velocidade da junta $i "$. 

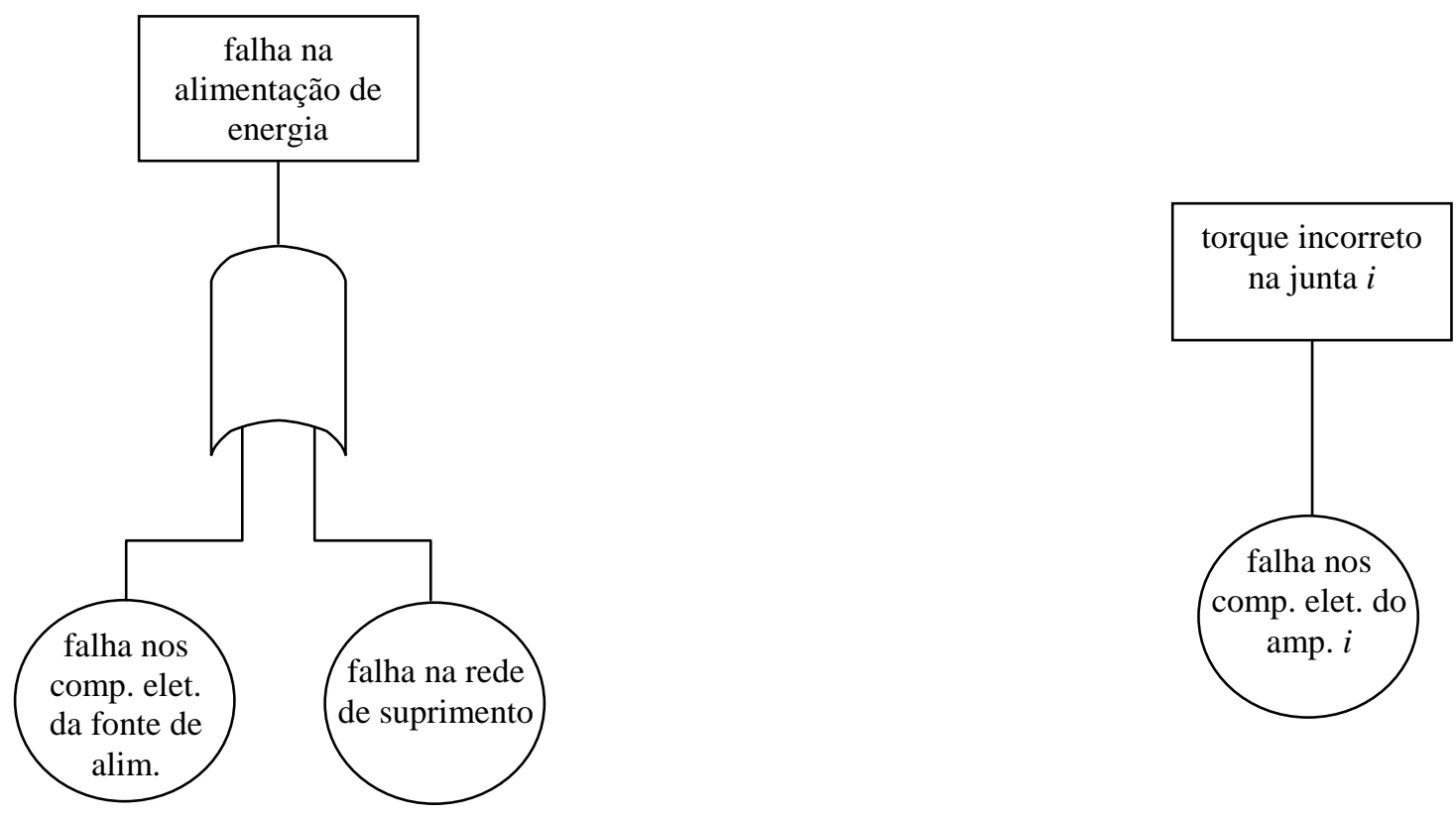

FIGURA 2.3.e. Árvore de causas das falhas "falha na alimentação da energia" e "torque incorreto na junta $i$ ". 


\subsection{FALHAS TRATADAS NESTE TRABALHO}

Como se está interessado nas falhas que ocorrem nos robôs do sistema cooperativo, as falhas identificadas na seção anterior para o manipulador individual serão tratadas nos capítulos seguintes. De fato, espera-se que poucas alterações sejam feitas em um robô para que este possa trabalhar cooperativamente com outros manipuladores e, portanto, as falhas devem ser as mesmas. Uma dessas poucas alterações seria a inclusão de sensores de força para permitir a medição do esmagamento provocado pelos manipuladores no objeto. Apesar de falhas nos sensores de força terem efeitos no controle do esmagamento, estas não serão tratadas neste trabalho.

As falhas na alimentação dos robôs não serão tratadas neste trabalho pois, como visto na seção anterior, não apresentam consequências graves já que os freios são acionados quando a energia é cortada. As falhas de torque incorreto serão tratadas como falhas do tipo junta com balanço livre. Falhas de torque incorreto são detectadas e isoladas de forma similar às falhas do tipo junta com balanço livre. Além disso, esta falha pode ser tratada como uma falha do tipo junta com balanço livre se não forem aplicados torques nas juntas com falhas.

Com base nas análises realizadas na seção anterior, as seguintes falhas serão consideradas neste trabalho:

(i) informação incorreta de posição da junta;

(ii) informação incorreta de velocidade da junta;

(iii) junta bloqueada e;

(iv) junta com balanço livre (ou junta passiva). 


\section{Capítulo 3.}

\section{ROBÔS COOPERATIVOS}

"Today, our machines are still simple creations, requiring the parental care and hovering attention of any newborn, hardly worthy of the word "intelligent". But within the next century they will mature into entities as complex as ourselves, and eventually into something transcending everything we know - in whom we can take pride when they refer to themselves as our descendants."

Hans Moravec, na página 1 do livro Mind Children de 1988

[FRANKLIN, 1995]

"Someday a human being, named perhaps Fred White, may shoot a robot named Pete Something-or-other, which has come out of a General Electrics factory, and to his surprise see it weep and bleed. And the dying robot may shoot back and, to its surprise, see a wisp of gray smoke arise from the electric pump that it supposed was Mr. White's beating heart. It would be rather a great moment of truth for both of them."

No ensaio "The android and the human", escrito em 1972 pelo escritor de ficção científica Philip K. Dick [DICK, 1988] 
Este Capítulo trata do problema da modelagem e controle do sistema formado por dois ou mais manipuladores cooperativos sem falhas. As considerações gerais sobre o sistema cooperativo são apresentadas na Seção 3.1. A dinâmica e a cinemática do sistema cooperativo são discutidas, respectivamente, nas Seções 3.2 e 3.3. Se o objeto é indeformável e suas conexões com os efetuadores dos robôs são rígidas, as forças aplicadas no objeto podem ser decompostas em duas componentes: uma que provoca somente movimento e outra que provoca somente esmagamento (força interna). A decomposição das forças no objeto entre componentes de esmagamento e de movimento é descrita na Seção 3.4. Em geral, nos sistemas cooperativos, não somente o movimento da carga é controlado, mas também o esmagamento provocado pelos manipuladores. Os diferentes enfoques para tal problema de controle em manipuladores cooperativos sem falhas são apresentados na Seção 3.5.

\subsection{INTRODUÇÃO}

Quando se fala em manipuladores cooperativos, é necessário se ter em mente a tarefa por eles executada. Isto porque a cinemática e a dinâmica do sistema cooperativo podem mudar de acordo com os tipos de carga e de conexão entre e efetuadores e o objeto manipulado.

A carga manipulada pelos robôs cooperativos pode ser um objeto flexível ou um objeto rígido. O controle de manipuladores manuseando cargas flexíveis é uma tarefa complexa e tem sido pouco estudado [SUN et al., 1998].

Quando se considera que os manipuladores cooperativos estão manuseando um objeto rígido, é importante o conhecimento do tipo de conexão entre a carga e os efetuadores. Dependendo do tipo e da geometria da conexão, um ou mais graus de liberdade (gdl's) do sistema cooperativo podem ser eliminados. O número de gdl's no sistema cooperativo em um espaço livre é dado pela soma do número de gdl's dos robôs, mais o número de gdl's do objeto manipulado, menos o número total de restrições independentes impostas pelas conexões entre efetuadores e carga [LAROUSSI et al., 1988].

O número de gdl's de um objeto rígido pode ser definido como o número de coordenadas independentes necessárias para definir sua posição e orientação, ou, ainda, o número de entradas necessárias para criar uma saída prevista [NORTON, 1999]. Um objeto rígido livre em um espaço planar tem 3 gdl's: dois de translação e um de rotação. Se a carga está rigidamente conectada aos efetuadores dos robôs, três restrições independentes 
aparecem no objeto e, portanto, três gdl's do sistema cooperativo são eliminados. Neste caso, os efetuadores e o objeto se comportam como um só corpo.

Neste trabalho, são consideradas as seguintes suposições:

Suposiçãa 3.1: o objeto manipulado é rígido, ou seja, o objeto não se deforma quando forças externas são aplicadas.

Suposição 3.2: os efetuadores dos manipuladores estão rigidamente conectados ao objeto de modo a não existir movimento relativo entre o objeto e os efetuadores.

Suposiçãa 3.3: o planejamento de trajetórias é feito a priori, evitando-se as regiões em que ocorrem singularidades nas Matrizes Jacobianas dos manipuladores.

Com as Suposições 3.1 e 3.2 , as forças entre o objeto e os efetuadores dos robôs podem ser decompostas em 2 componentes ortogonais: uma produzindo esmagamento e outra produzindo movimento no objeto (ver Seção 3.4). As Suposições 3.1 e 3.2 são bastante gerais: este é o caso, por exemplo, de manipuladores conectados rigidamente através de garras a um objeto sólido cujas deformações são desprezíveis. Já a Suposição 3.3 é adotada por motivos de simplicidade.

A seguir, algumas definições gerais serão feitas. Considere que o sistema cooperativo esteja em um espaço livre $j$-dimensional ${ }^{1}$. Seja:

$m$ : número de manipuladores no sistema cooperativo;

$n_{i}$ : número de juntas no manipulador $i$;

$n=\sum_{i=1}^{m} n_{i}:$ número de juntas no sistema cooperativo;

$k:$ número de coordenadas de movimento no objeto.

$\mathbf{q}_{i}=\left[\begin{array}{llll}q_{i 1} & q_{i 2} & \cdots & q_{i n_{i}}\end{array}\right]^{\mathrm{T}}$ : posições (coordenadas generalizadas) das juntas do manipulador $i$

$\tau_{i}=\left[\begin{array}{llll}\tau_{i 1} & \tau_{i 2} & \cdots & \tau_{i n_{i}}\end{array}\right]^{\mathrm{T}}:$ forças generalizadas ${ }^{2}$ nas juntas do manipulador $i$

$\mathbf{x}_{i}=\left[\begin{array}{llllll}x_{i 1} & x_{i 2} & \cdots & x_{i j} & \cdots & x_{i k}\end{array}\right]^{\mathrm{T}}=\left[\begin{array}{ll}\mathbf{p}_{i}{ }^{\mathrm{T}} & \boldsymbol{\phi}_{i}^{\mathrm{T}}\end{array}\right]^{\mathrm{T}}:$ posições do efetuador do manipulador $i$, sendo as $j$ primeiras componentes de $\mathbf{x}_{i}$ posições $\left(\mathbf{p}_{i}\right)$, e as demais representações

\footnotetext{
${ }^{1}$ Neste caso, $j$ é o número de coordenadas independentes de posição no espaço.

${ }^{2}$ As forças generalizadas são torques nas juntas rotacionais e forças nas juntas prismáticas.
} 
mínimas das orientações $\left(\phi_{i}\right)$. Tanto os Ângulos de Euler como os Ângulos RPY (Roll-Pitch-Yaw) podem ser escolhidos para representar as orientações do efetuador;

$\mathbf{h}_{i}=\left[\begin{array}{llllll}h_{i 1} & h_{i 2} & \cdots & h_{i j} & \cdots & h_{i k}\end{array}\right]^{\mathrm{T}}=\left[\begin{array}{ll}\mathbf{f}_{i}^{\mathrm{T}} & \boldsymbol{\eta}_{i}^{\mathrm{T}}\end{array}\right]^{\mathrm{T}}:$ forças $^{3}$ no efetuador do manipulador $i$, sendo as $j$ primeiras componentes de $\mathbf{h}_{i}$ forças $\left(\mathbf{f}_{i}\right)$ e as demais momentos $\left(\boldsymbol{\eta}_{i}\right)$;

$\mathbf{v}_{i}=\left[\begin{array}{llllll}v_{i 1} & v_{i 2} & \cdots & v_{i j} & \cdots & v_{i k}\end{array}\right]^{\mathrm{T}}=\left[\begin{array}{ll}\dot{\mathbf{p}}_{i}{ }^{\mathrm{T}} & \boldsymbol{\omega}_{i}{ }^{\mathrm{T}}\end{array}\right]^{\mathrm{T}}=\mathbf{T}\left(\mathbf{x}_{i}\right) \dot{\mathbf{x}}_{i}$ : velocidades do efetuador do manipulador $i$, sendo as $j$ primeiras componentes de $\mathbf{v}_{i}$ velocidades lineares $\left(\dot{\mathbf{p}}_{i}\right)$, e as demais velocidades angulares $\left(\boldsymbol{\omega}_{i}\right)$. A matriz de transformação $\mathbf{T}(\cdot)$ relaciona as derivadas das representações mínimas das orientações com as velocidades angulares [SCIAVICCO \& SICILIANO, 1996]. Para manipuladores planares, $\mathbf{T}(\cdot)=\mathbf{I}$

$\mathbf{x}_{\mathbf{0}}=\left[\begin{array}{llllll}x_{o 1} & x_{o 2} & \cdots & x_{o j} & \cdots & x_{o k}\end{array}\right]^{\mathrm{T}}=\left[\begin{array}{ll}\mathbf{p}_{\mathbf{0}}{ }^{\mathrm{T}} & \boldsymbol{\phi}_{\mathbf{0}}{ }^{\mathrm{T}}\end{array}\right]^{\mathrm{T}}:$ posições $^{4}$ da origem do sistema de coordenadas fixado ao objeto, sendo as $j$ primeiras componentes de $\mathbf{x}_{\mathbf{0}}$ posições $\left(\mathbf{p}_{\mathbf{0}}\right)$, e as demais representações mínimas das orientações $\left(\boldsymbol{\phi}_{\mathbf{0}}\right)$. Neste trabalho, a origem do sistema de coordenadas é fixado ao Centro de Massa (CM) do objeto ; $\mathbf{v}_{\mathbf{o}}=\left[\begin{array}{llllll}v_{o 1} & v_{o 2} & \cdots & v_{o j} & \cdots & v_{o k}\end{array}\right]^{\mathrm{T}}=\left[\begin{array}{ll}\dot{\mathbf{p}}_{\mathbf{0}}{ }^{\mathrm{T}} & \boldsymbol{\omega}_{\mathbf{0}}{ }^{\mathrm{T}}\end{array}\right]^{\mathrm{T}}=\mathbf{T}\left(\mathbf{x}_{\mathbf{0}}\right) \dot{\mathbf{x}}_{\mathbf{0}}$ : velocidades da origem do sistema de coordenadas fixado ao objeto, sendo as $j$ primeiras componentes de $\mathbf{v}_{\mathbf{0}}$ velocidades lineares $\left(\dot{\mathbf{p}}_{\mathbf{0}}\right)$, e as demais velocidades angulares $\left(\boldsymbol{\omega}_{\mathbf{0}}\right)$.

\subsection{DINÂMICA DO SISTEMA COOPERATIVO}

Considere um conjunto de $m$ robôs manipulando um objeto em um espaço livre $j$ dimensional. O que diferencia a dinâmica de cada robô do sistema cooperativo em cadeia fechada da dinâmica de um robô livre, ou em cadeia aberta, é a componente do torque em cada junta provocada pela reação às forças exercidas pelo efetuador deste robô no objeto. Considere que a força causada pelo robô $i(i=1, \ldots, m)$ no ponto de contato com o objeto seja representada por $\mathbf{h}_{i}$. Se o objeto for considerado rígido, a força aplicada pelo objeto no

\footnotetext{
${ }^{3}$ Durante o texto, para o objeto e para os efetuadores, a palavra força será utilizada para referir-se ao vetor das forças e momentos.

${ }^{4}$ Durante o texto, para o objeto e para os efetuadores, a palavra posição será utilizada para referir-se ao vetor de posições e orientações.
} 
manipulador $i$ é simplesmente igual a $-\mathbf{h}_{i}$. Assim, deseja-se determinar os componentes dos torques nas juntas do manipulador $i$ causadas pela aplicação das forças $-\mathbf{h}_{i}$ pelo objeto.

Utilizando a lei dos trabalhos virtuais [SCIAVICCO \& SICILIANO, 1996], tem-se que

$\boldsymbol{\mu}_{i}{ }^{\mathrm{T}} \mathbf{d} \mathbf{q}_{i}=-\left(\mathbf{f}_{i}^{\mathrm{T}}{ }^{\mathrm{d}} \mathbf{p}_{i}+\boldsymbol{\eta}_{i}{ }^{\mathrm{T}} \boldsymbol{\omega}_{i} d t\right)=-\mathbf{h}_{i}{ }^{\mathrm{T}}\left[\begin{array}{c}\mathbf{d} \mathbf{p}_{i} \\ \boldsymbol{\omega}_{i} d t\end{array}\right] \quad, \quad i=1, . ., m$

na qual $\boldsymbol{\mu}_{i}=\left[\begin{array}{llll}\mu_{1} & \mu_{2} & \cdots & \mu_{n_{i}}\end{array}\right]^{\mathrm{T}}$ é a componente das forças generalizadas nas juntas do manipulador $i$ causadas pela aplicação de $-\mathbf{h}_{i}, \mathbf{d q}_{i}$ é o vetor das variações nas posições das juntas provocadas por $\boldsymbol{\mu}_{i}, \mathbf{d p}_{i}$ é o vetor das variações no vetor $j$-dimensional de posições $\mathbf{p}_{i}$ do efetuador $i$ provocadas por $-\mathbf{h}_{i}, t$ é o índice de tempo e, $\boldsymbol{\omega}_{i} d t$ representa as variações nas orientações do efetuador $i$.

A velocidade do efetuador $i$ pode ser escrita como

$\mathbf{v}_{i}=\left[\begin{array}{c}\dot{\mathbf{p}}_{i} \\ \boldsymbol{\omega}_{i}\end{array}\right]=\mathbf{J}_{i}\left(\mathbf{q}_{i}\right) \dot{\mathbf{q}}_{i} \quad, \quad i=1, \ldots, m$

na qual $\mathbf{J}_{i}(\cdot)$ é a Matriz Jacobiana Geométrica do manipulador $i$ [SCIAVICCO \& SICILIANO, 1996], que transforma as velocidades das juntas em velocidades do efetuator $i$. Assim, das eqs. (3.2) e (3.1), a seguinte relação é válida

$\boldsymbol{\mu}_{i}=-\mathbf{J}_{i}\left(\mathbf{q}_{i}\right)^{\mathrm{T}} \mathbf{h}_{i} \quad, \quad i=1, . ., m$.

A eq. (3.3) relaciona a força aplicada $-\mathbf{h}_{i}$ com a componente das forças generalizadas $\boldsymbol{\mu}_{i}$ através da Matriz Jacobiana do manipulador $i$.

Desta forma, pode-se escrever a dinâmica do manipulador $i$ livre de falhas no sistema cooperativo para o instante de tempo $t$ como

$$
\mathbf{M}_{i}\left(\mathbf{q}_{i}(t)\right) \ddot{\mathbf{q}}_{i}(t)+\mathbf{C}_{i}\left(\mathbf{q}_{i}(t), \dot{\mathbf{q}}_{i}(t)\right) \dot{\mathbf{q}}_{i}(t)+\mathbf{g}_{i}\left(\mathbf{q}_{i}(t)\right)+\mathbf{z}_{i}\left(\mathbf{q}_{i}(t), \dot{\mathbf{q}}_{i}(t)\right)=\tau_{i}(t)-\mathbf{J}_{i}\left(\mathbf{q}_{i}(t)\right)^{\mathrm{T}} \mathbf{h}_{i}(t)
$$

na qual $\mathbf{M}_{i}(\cdot)$ é a matriz de inércia, $\mathbf{C}_{i}(\cdot, \cdot)$ é a matriz dos termos centrífugos e de Coriolis, $\mathbf{g}_{i}(\cdot)$ é o vetor dos termos gravitacionais e, $\mathbf{z}_{i}(\cdot, \cdot)$ é o vetor dos termos friccionais [MURRAY et al., 1993]. Note que a única diferença para a equação dinâmica do manipulador livre é o ultimo termo.

A existência de interações cinemáticas e dinâmicas entre os manipuladores torna necessária a descrição global do sistema cooperativo. Utilizando a equação anterior, pode-se representar a dinâmica dos $m$ manipuladores através de uma única equação 
$\mathbf{M}(\mathbf{q}(t)) \ddot{\mathbf{q}}(t)+\mathbf{C}(\mathbf{q}(t), \dot{\mathbf{q}}(t)) \dot{\mathbf{q}}(t)+\mathbf{g}(\mathbf{q}(t))+\mathbf{z}(\mathbf{q}(t), \dot{\mathbf{q}}(t))=\tau(t)-\mathbf{J}(\mathbf{q}(t))^{\mathrm{T}} \mathbf{h}(t)$

na qual

$\mathbf{M}(\mathbf{q}(t))=\left[\begin{array}{cccc}\mathbf{M}_{1}\left(\mathbf{q}_{1}(t)\right) & \mathbf{0}_{n_{1} \times n_{2}} & \cdots & \mathbf{0}_{n_{1} \times n_{m}} \\ \mathbf{0}_{n_{2} \times n_{1}} & \mathbf{M}_{2}\left(\mathbf{q}_{2}(t)\right) & \cdots & \mathbf{0}_{n_{2} \times n_{m}} \\ \vdots & \vdots & \ddots & \vdots \\ \mathbf{0}_{n_{m} \times n_{1}} & \mathbf{0}_{n_{m} \times n_{2}} & \cdots & \mathbf{M}_{m}\left(\mathbf{q}_{m}(t)\right)\end{array}\right], \quad \mathbf{q}(t)=\left[\begin{array}{c}\mathbf{q}_{1}(t) \\ \mathbf{q}_{2}(t) \\ \vdots \\ \mathbf{q}_{m}(t)\end{array}\right]$,

$\mathbf{C}(\mathbf{q}(t), \dot{\mathbf{q}}(t))=\left[\begin{array}{cccc}\mathbf{C}_{1}\left(\mathbf{q}_{1}(t), \dot{\mathbf{q}}_{1}(t)\right) & \mathbf{0}_{n_{1} \times n_{2}} & \cdots & \mathbf{0}_{n_{1} \times n_{m}} \\ \mathbf{0}_{n_{2} \times n_{1}} & \mathbf{C}_{2}\left(\mathbf{q}_{2}(t), \dot{\mathbf{q}}_{2}(t)\right) & \cdots & \mathbf{0}_{n_{2} \times n_{m}} \\ \vdots & \vdots & \ddots & \vdots \\ \mathbf{0}_{n_{m} \times n_{1}} & \mathbf{0}_{n_{m} \times n_{2}} & \cdots & \mathbf{C}_{m}\left(\mathbf{q}_{m}(t), \dot{\mathbf{q}}_{m}(t)\right)\end{array}\right]$,

$\mathbf{g}(\mathbf{q}(t))=\left[\begin{array}{c}\mathbf{g}_{1}\left(\mathbf{q}_{1}(t)\right) \\ \mathbf{g}_{2}\left(\mathbf{q}_{2}(t)\right) \\ \vdots \\ \mathbf{g}_{m}\left(\mathbf{q}_{m}(t)\right)\end{array}\right], \quad \mathbf{z}(\mathbf{q}(t))=\left[\begin{array}{c}\mathbf{z}_{1}\left(\mathbf{q}_{1}(t)\right) \\ \mathbf{z}_{2}\left(\mathbf{q}_{2}(t)\right) \\ \vdots \\ \mathbf{z}_{m}\left(\mathbf{q}_{m}(t)\right)\end{array}\right], \quad \tau(t)=\left[\begin{array}{c}\tau_{1}(t) \\ \boldsymbol{\tau}_{2}(t) \\ \vdots \\ \tau_{m}(t)\end{array}\right]$

$\mathbf{J}(\mathbf{q}(t))=\left[\begin{array}{cccc}\mathbf{J}_{1}\left(\mathbf{q}_{1}(t)\right) & \mathbf{0}_{k \times n_{2}} & \cdots & \mathbf{0}_{k \times n_{m}} \\ \mathbf{0}_{k \times n_{1}} & \mathbf{J}_{2}\left(\mathbf{q}_{2}(t)\right) & \cdots & \mathbf{0}_{k \times n_{m}} \\ \vdots & \vdots & \ddots & \vdots \\ \mathbf{0}_{k \times n_{1}} & \mathbf{0}_{k \times n_{2}} & \cdots & \mathbf{J}_{m}\left(\mathbf{q}_{m}(t)\right)\end{array}\right], \quad \mathbf{h}(t)=\left[\begin{array}{c}\mathbf{h}_{1}(t) \\ \mathbf{h}_{2}(t) \\ \vdots \\ \mathbf{h}_{m}(t)\end{array}\right]$,

$\mathbf{O}_{i x j}$ é uma matriz de zeros com $i$ linhas e $j$ colunas e, $\mathbf{I}_{i}$ é uma matriz identidade de posto $i$.

Já a dinâmica do objeto manipulado pode ser escrita como

$m_{o} \ddot{\mathbf{p}}_{\mathbf{o}}(t)+m_{o}\left[\begin{array}{c}g_{o 1}(t) \\ \vdots \\ g_{o j}(t)\end{array}\right]=\sum_{i=1}^{m}\left[\begin{array}{c}h_{i 1}(t) \\ \vdots \\ h_{i j}(t)\end{array}\right]$,

$\mathbf{I n}_{\mathbf{0}} \dot{\boldsymbol{\omega}}_{\mathbf{0}}(t)+\boldsymbol{\omega}_{\mathbf{0}}(t) \times \mathbf{I n}_{\mathbf{0}} \boldsymbol{\omega}_{\mathbf{0}}(t)=\sum_{i=1}^{m}\left(\left[\begin{array}{c}h_{i(j+1)}(t) \\ \vdots \\ h_{i k}(t)\end{array}\right]+\mathbf{a}_{\mathbf{o} i} \times\left[\begin{array}{c}h_{i 1}(t) \\ \vdots \\ h_{i j}(t)\end{array}\right]\right)$

nas quais $m_{o}$ é a massa do objeto, $\left[g_{o l} \ldots g_{o j}\right]^{\mathrm{T}}$ é o vetor das acelerações provocadas pela força da gravidade, $\mathbf{I n}_{\mathbf{0}}$ é o tensor de inércia do objeto referente ao CM [HIBBELER, 1995], x representa o produto vetorial e, $\mathbf{a}_{\mathbf{o} i}$ é o vetor partindo do CM do objeto para o ponto de contato com efetuador do manipulador $i$ (Figura 3.1). A Figura 3.1 mostra também as forças aplicadas pelos manipuladores e as posições dos efetuadores e do objeto manipulado em relação ao sistema de coordenadas global. 


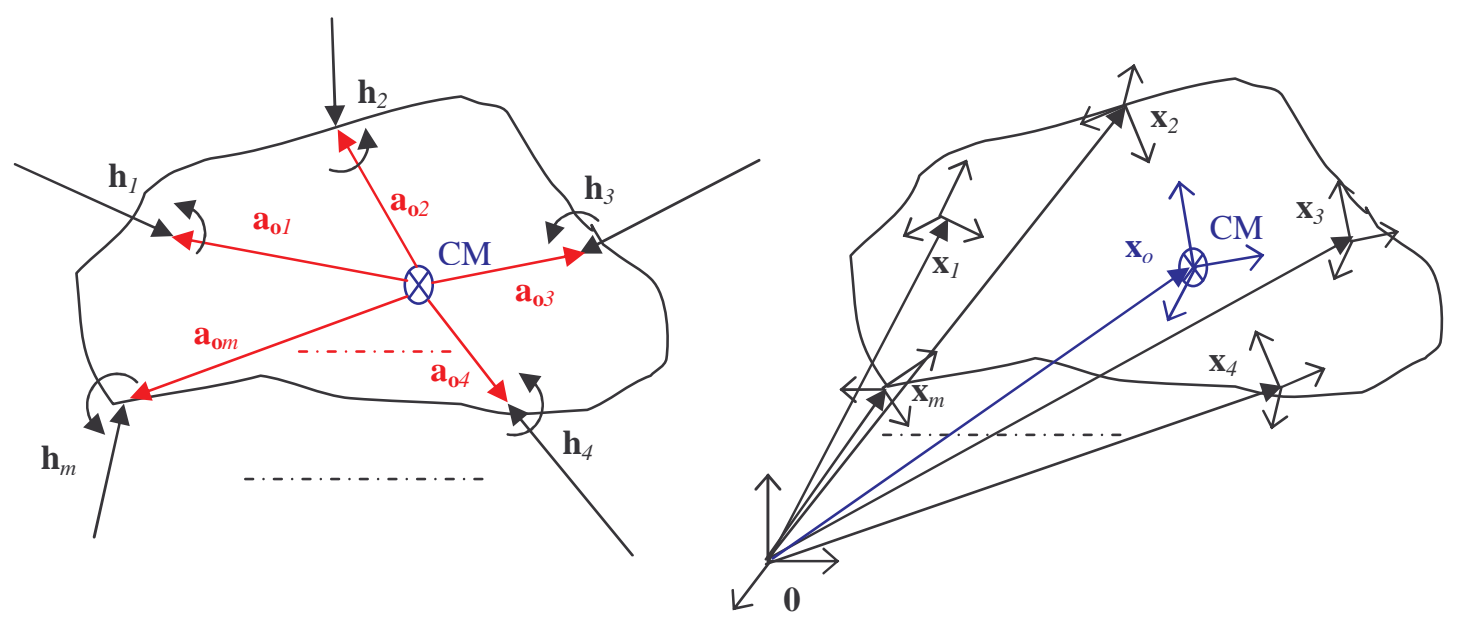

FIGURA 3.1. Forças aplicadas pelos manipuladores e posições dos efetuadores e do objeto manipulado.

A eq. (3.6) pode ser reescrita na seguinte forma

$$
\mathbf{M}_{\mathbf{o}} \dot{\mathbf{v}}_{\mathbf{0}}(t)+\mathbf{c}_{\mathbf{o}}\left(\mathbf{v}_{\mathbf{0}}(t)\right)+\mathbf{g}_{\mathbf{0}}=\sum_{i=1}^{m} \mathbf{J}_{\mathbf{o} i}\left(\mathbf{x}_{\mathbf{o}}(t), \mathbf{x}_{i}(t)\right)^{\mathrm{T}} \mathbf{h}_{i}(t)
$$

ou

$$
\mathbf{M}_{\mathbf{0}} \dot{\mathbf{v}}_{\mathbf{o}}(t)+\mathbf{c}_{\mathbf{o}}\left(\mathbf{v}_{\mathbf{o}}(t)\right)+\mathbf{g}_{\mathbf{o}}=\mathbf{J}_{\mathbf{o}}\left(\mathbf{x}_{\mathbf{o}}(t), \mathbf{x}(t)\right)^{\mathrm{T}} \mathbf{h}(t)
$$

nas quais

$$
\begin{aligned}
& \mathbf{M}_{\mathbf{o}}=\left[\begin{array}{cccc}
m_{0} & \cdots & 0 & \mathbf{0}_{1 \times(k-j)} \\
\vdots & \ddots & \vdots & \vdots \\
0 & \cdots & m_{0} & \mathbf{0}_{1 \times(k-j)} \\
\mathbf{0}_{(k-j) \times 1} & \cdots & \mathbf{0}_{(k-j) \times 1} & \mathbf{I n}_{\mathbf{o}}
\end{array}\right], \quad \mathbf{c}_{\mathbf{o}}\left(\mathbf{v}_{\mathbf{o}}(t)\right)=\left[\begin{array}{c}
\mathbf{0}_{j \times 1} \\
\boldsymbol{\omega}_{\mathbf{0}}(t) \times \mathbf{I n}_{\mathbf{0}} \boldsymbol{\omega}_{\mathbf{0}}(t)
\end{array}\right], \\
& \mathbf{g}_{\mathbf{o}}=m_{o}\left[\begin{array}{c}
g_{o 1} \\
\vdots \\
g_{o j} \\
\mathbf{0}_{(k-j) \times 1}
\end{array}\right], \\
& \mathbf{x}(t)=\left[\begin{array}{c}
\mathbf{J}_{\mathbf{o} i}\left(\mathbf{x}_{\mathbf{o}}(t), \mathbf{x}_{i}(t)\right)=\left[\begin{array}{cc}
\mathbf{I}_{j} & \mathbf{a}_{\mathbf{o} i} \times \\
\mathbf{0}_{(k-j) \times j} & \mathbf{I}_{k-j}
\end{array}\right], \\
\mathbf{x}_{1}(t) \\
\mathbf{x}_{2}(t) \\
\vdots \\
\mathbf{x}_{m}(t)
\end{array}\right],
\end{aligned}
$$

Observe que a matriz $\mathbf{J}_{\mathbf{o} i}(\cdot)$ é sempre não-singular. A matriz $\mathbf{J}_{\mathbf{o} i}(\cdot)^{\mathrm{T}}$ projeta as forças aplicadas no ponto de contato entre o efetuador $i$ e o objeto para o CM deste. Pode-se notar 
ainda, que $\mathbf{J}_{\mathbf{o} i}(\cdot)$ é a matriz Jacobiana de transformação entre as velocidades do CM do objeto e as velocidades do efetuador $i$. Assim

$\mathbf{v}_{i}(t)=\mathbf{J}_{\mathbf{o} i}\left(\mathbf{x}_{\mathbf{o}}(t), \mathbf{x}(t)\right) \mathbf{v}_{\mathbf{o}}(t), \quad i=1, \ldots, m$

ou, ainda, como $\mathbf{x}_{i}(t)$ é uma função das posições das juntas do manipulador $i$ e a posição do objeto pode ser escrita como uma função de $\mathbf{x}_{i}(t)$,

$$
\mathbf{v}_{i}(t)=\mathbf{J}_{\mathbf{o} i}\left(\mathbf{q}_{i}(t)\right) \mathbf{v}_{\mathbf{o}}(t), \quad i=1, \ldots, m
$$

e

$$
\mathbf{v}(t)=\mathbf{J}_{\mathbf{0}}(\mathbf{q}(t)) \mathbf{v}_{\mathbf{o}}(t)
$$

na qual $\mathbf{v}(t)=\left[\begin{array}{llll}\mathbf{v}_{1}(t)^{\mathrm{T}} & \mathbf{v}_{2}(t)^{\mathrm{T}} & \cdots & \mathbf{v}_{m}(t)^{\mathrm{T}}\end{array}\right]^{\mathrm{T}}$.

Utilizando as eqs. (3.5) e (3.7), pode-se representar a dinâmica do sistema cooperativo (robôs e objeto) em uma única equação

$$
\mathbf{M}_{\mathbf{x}}(\mathbf{q}(t)) \dot{\mathbf{v}}_{\mathbf{x}}(t)+\mathbf{c}_{\mathbf{x}}\left(\mathbf{q}(t), \mathbf{v}_{\mathbf{x}}(t)\right)+\mathbf{g}_{\mathbf{x}}(\mathbf{q}(t))+\mathbf{z}_{\mathbf{x}}(\mathbf{q}(t), \dot{\mathbf{q}}(t))=\tau_{\mathbf{x}}(t)-\mathbf{J}_{\mathbf{x}}(\mathbf{q}(t))^{\mathrm{T}} \mathbf{h}(t)
$$

na qual

$$
\begin{array}{cc}
\mathbf{v}_{\mathbf{x}}(t)=\left[\begin{array}{c}
\dot{\mathbf{q}}_{1}(t) \\
\dot{\mathbf{q}}_{2}(t) \\
\vdots \\
\dot{\mathbf{q}}_{m}(t) \\
\mathbf{v}_{\mathbf{o}}(t)
\end{array}\right], \quad \mathbf{M}_{\mathbf{x}}\left(\mathbf{x}_{\mathbf{x}}(t)\right)=\left[\begin{array}{ccccc}
\mathbf{M}_{1}\left(\mathbf{q}_{1}(t)\right) & \mathbf{0}_{n_{1} \times n_{2}} & \cdots & \mathbf{0}_{n_{1} \times n_{m}} & \mathbf{0}_{n_{1} \times k} \\
\mathbf{0}_{n_{2} \times n_{1}} & \mathbf{M}_{2}\left(\mathbf{q}_{2}(t)\right) & & \mathbf{0}_{n_{2} \times n_{m}} & \mathbf{0}_{n_{2} \times k} \\
\vdots & & \ddots & & \vdots \\
\mathbf{0}_{n_{m} \times n_{1}} & \mathbf{0}_{n_{m} \times n_{2}} & & \mathbf{M}_{m}\left(\mathbf{q}_{m}(t)\right) & \mathbf{0}_{n_{m} \times k} \\
\mathbf{0}_{k \times n_{1}} & \mathbf{0}_{k \times n_{2}} & \cdots & \mathbf{0}_{k \times n_{m}} & \mathbf{M}_{\mathbf{o}}
\end{array}\right], \\
\mathbf{c}_{\mathbf{x}}\left(\mathbf{q}(t), \mathbf{v}_{\mathbf{x}}(t)\right)=\left[\begin{array}{c}
\mathbf{C}_{1}\left(\mathbf{q}_{1}(t), \dot{\mathbf{q}}_{1}(t)\right) \dot{\mathbf{q}}_{1}(t) \\
\mathbf{C}_{2}\left(\mathbf{q}_{2}(t), \dot{\mathbf{q}}_{2}(t)\right) \dot{\mathbf{q}}_{2}(t) \\
\vdots \\
\mathbf{C}_{m}\left(\mathbf{q}_{m}(t), \dot{\mathbf{q}}_{m}(t)\right) \dot{\mathbf{q}}_{m}(t) \\
\mathbf{c}_{\mathbf{o}}\left(\mathbf{v}_{\mathbf{o}}(t)\right)
\end{array}\right], & \mathbf{g}_{\mathbf{x}}(\mathbf{q}(t))=\left[\begin{array}{c}
\mathbf{g}_{1}\left(\mathbf{q}_{1}(t)\right) \\
\mathbf{g}_{2}\left(\mathbf{q}_{2}(t)\right) \\
\vdots \\
\mathbf{g}_{m}\left(\mathbf{q}_{m}(t)\right) \\
\mathbf{g}_{o}
\end{array}\right],
\end{array}
$$




$$
\begin{aligned}
& \mathbf{z}_{\mathbf{x}}(\mathbf{q}(t), \dot{\mathbf{q}}(t))=\left[\begin{array}{c}
\mathbf{z}_{1}\left(\mathbf{q}_{1}(t), \dot{\mathbf{q}}_{1}(t)\right) \\
\mathbf{z}_{2}\left(\mathbf{q}_{2}(t), \dot{\mathbf{q}}_{2}(t)\right) \\
\vdots \\
\mathbf{z}_{m}\left(\mathbf{q}_{m}(t), \dot{\mathbf{q}}_{m}(t)\right) \\
\mathbf{0}_{k \times 1}
\end{array}\right] \quad, \quad \boldsymbol{\tau}_{\mathbf{x}}(t)=\left[\begin{array}{c}
\boldsymbol{\tau}_{1}(t) \\
\boldsymbol{\tau}_{2}(t) \\
\vdots \\
\boldsymbol{\tau}_{m}(t) \\
\mathbf{0}_{k \times 1}
\end{array}\right], \\
& \mathbf{J}_{\mathbf{x}}(\mathbf{q}(t))=\left[\begin{array}{ccccc}
\mathbf{J}_{1}\left(\mathbf{q}_{1}(t)\right) & \mathbf{0}_{k \times n_{2}} & \cdots & \mathbf{0}_{k \times n_{m}} & -\mathbf{J}_{\mathbf{o} 1}\left(\mathbf{q}_{1}(t)\right) \\
\mathbf{0}_{k \times n_{1}} & \mathbf{J}_{2}\left(\mathbf{q}_{2}(t)\right) & & \mathbf{0}_{k \times n_{m}} & -\mathbf{J}_{\mathbf{0} 2}\left(\mathbf{q}_{2}(t)\right) \\
\vdots & & \ddots & & \vdots \\
\mathbf{0}_{k \times n_{1}} & \mathbf{0}_{k \times n_{2}} & & \mathbf{J}_{m}\left(\mathbf{q}_{m}(t)\right) & -\mathbf{J}_{\mathbf{o} m}\left(\mathbf{q}_{m}(t)\right)
\end{array}\right]
\end{aligned}
$$

\subsection{CINEMÁTICA DO SISTEMA COOPERATIVO}

Como o sistema cooperativo forma uma cadeia fechada, restrições geométricas aparecem nas equações cinemáticas. De fato, pode-se calcular a posição do objeto como uma função $\left(\varphi_{i}\right)$ das posições das juntas de qualquer manipulador $i$, ou seja:

$$
\mathbf{x}_{\mathbf{o}}(t)=\boldsymbol{\varphi}_{i}\left(\mathbf{q}_{i}(t)\right) \quad, \quad i=1, . ., m .
$$

Assim, para todos os manipuladores, as restrições geométricas podem ser reunidas na seguinte expressão

$$
\boldsymbol{\varphi}(\mathbf{q}(t))=\left[\begin{array}{c}
\boldsymbol{\varphi}_{1}\left(\mathbf{q}_{1}(t)\right)-\mathbf{x}_{\mathbf{o}}(t) \\
\boldsymbol{\varphi}_{2}\left(\mathbf{q}_{2}(t)\right)-\mathbf{x}_{\mathbf{o}}(t) \\
\vdots \\
\boldsymbol{\varphi}_{m}\left(\mathbf{q}_{m}(t)\right)-\mathbf{x}_{\mathbf{o}}(t)
\end{array}\right]=\mathbf{0}_{(k x m) x 1}
$$

As restrições nas velocidades do objeto podem ser obtidas através das eqs. (3.8a) e

$\mathbf{v}_{\mathbf{0}}(t)=\mathbf{J}_{\mathbf{o} i}\left(\mathbf{q}_{i}(t)\right)^{-1} \mathbf{v}_{i}(t)=\mathbf{J}_{\mathbf{o} i}\left(\mathbf{q}_{i}(t)\right)^{-1} \mathbf{J}_{i}\left(\mathbf{q}_{i}(t)\right) \dot{\mathbf{q}}_{i}(t)=\mathbf{D}_{i}\left(\mathbf{q}_{i}(t)\right) \dot{\mathbf{q}}_{i}(t), i=1, \ldots, m$.

sendo $\mathbf{D}_{i}\left(\mathbf{q}_{i}(t)\right)=\mathbf{J}_{\boldsymbol{o} i}\left(\mathbf{q}_{i}(t)\right)^{-1} \mathbf{J}_{i}\left(\mathbf{q}_{i}(t)\right)$ a matriz Jacobiana de transformação das velocidades das juntas do manipulador $i$ para as velocidades no CM do objeto. As restrições nas velocidades podem ser reunidas como

$\boldsymbol{\varphi}_{\mathbf{v}}(\mathbf{q}(t)) \mathbf{v}_{\mathbf{x}}(t)=\mathbf{0}_{(k x m) x 1}$

na qual 
$\boldsymbol{\varphi}_{\mathbf{v}}(\mathbf{q}(t))=\left[\begin{array}{ccccc}\mathbf{D}_{1}\left(\mathbf{q}_{1}(t)\right) & \mathbf{0}_{k \times n_{2}} & \cdots & \mathbf{0}_{k \times n_{m}} & -\mathbf{I}_{k} \\ \mathbf{0}_{k \times n_{1}} & \mathbf{D}_{2}\left(\mathbf{q}_{2}(t)\right) & \cdots & \mathbf{0}_{k \times n_{m}} & -\mathbf{I}_{k} \\ \vdots & \vdots & \ddots & \vdots & \vdots \\ \mathbf{0}_{k \times n_{1}} & \mathbf{0}_{k \times n_{2}} & \cdots & \mathbf{D}_{m}\left(\mathbf{q}_{m}(t)\right) & -\mathbf{I}_{k}\end{array}\right]$

As restrições nas acelerações podem ser obtidas através da diferenciação da eq. (3.13) [CARIGNAN \& AKIN, 1988]

$\boldsymbol{\varphi}_{\mathbf{a}}(\mathbf{q}(t))=\dot{\varphi}_{\mathbf{v}}(\mathbf{q}(t)) \mathbf{v}_{\mathbf{x}}(t)+\boldsymbol{\varphi}_{\mathbf{v}}(\mathbf{q}(t)) \dot{\mathbf{v}}_{\mathbf{x}}(t)=\mathbf{0}_{(k x m) x 1}$.

As eqs. (3.11), (3.13) e (3.14) fornecem as restrições, respectivamente, nas posições, velocidades e acelerações do objeto. Da eq. (3.12), uma importante relação pode ser obtida através da lei dos trabalhos virtuais (veja eqs. 3.1 - 3.3)

$\mu_{i}(t)=\mathbf{D}_{i}\left(\mathbf{q}_{i}(t)\right)^{\mathrm{T}} \mathbf{h}_{\mathbf{r o}}(t) \quad, \quad i=1, \ldots, m$.

que resulta na relação entre uma força resultante no $\mathrm{CM}$ do objeto $\left(\mathbf{h}_{\mathbf{r o}}(t)\right)$ e a sua contribuição nas forças generalizadas nas juntas do manipulador $i$. Pode-se escrever as contribuições causadas por esta força em todos os manipuladores como

$$
\boldsymbol{\mu}(t)=\mathbf{D}(\mathbf{q}(t))^{\mathrm{T}} \mathbf{h}_{\mathbf{r o}}(t)
$$

na qual $\boldsymbol{\mu}(\cdot)^{\mathrm{T}}=\left[\boldsymbol{\mu}_{l}(\cdot)^{\mathrm{T}} \ldots \boldsymbol{\mu}_{m}(\cdot)^{\mathrm{T}}\right] \mathrm{e}$

$$
\mathbf{D}(\mathbf{q}(t))=\left[\begin{array}{llll}
\mathbf{D}_{1}\left(\mathbf{q}_{1}(t)\right) & \mathbf{D}_{2}\left(\mathbf{q}_{2}(t)\right) & \cdots & \mathbf{D}_{m}\left(\mathbf{q}_{m}(t)\right)
\end{array}\right]
$$

\subsection{CÁlCULO DAS FORÇAS NO OBJETO}

Isolando as acelerações da eq. (3.9) e substituindo na eq. (3.14)

$$
\begin{aligned}
\boldsymbol{\varphi}_{\mathbf{v}}(\mathbf{q}(t)) \mathbf{M}_{\mathbf{x}}(\mathbf{q}(t))^{-1} \mid \tau_{\mathbf{x}}(t)- & \mathbf{J}_{\mathbf{x}}(\mathbf{q}(t))^{\mathrm{T}} \mathbf{h}(t)-\mathbf{c}_{\mathbf{x}}\left(\mathbf{q}(t), \mathbf{v}_{\mathbf{x}}(t)\right)+ \\
& \left.-\mathbf{g}_{\mathbf{x}}(\mathbf{q}(t))-\mathbf{z}_{\mathbf{x}}\left(\mathbf{q}(t), \mathbf{v}_{\mathbf{x}}(t)\right)\right]=-\dot{\boldsymbol{\varphi}}_{\mathbf{v}}(\mathbf{q}(t)) \mathbf{v}_{\mathbf{x}}(t) .
\end{aligned}
$$

Isolando as forças nos efetuadores da eq. (3.18), tem-se

$$
\begin{aligned}
\mathbf{h}(t)=\left(\boldsymbol{\varphi}_{\mathbf{x}}(\mathbf{q}(t)) \mathbf{M}_{\mathbf{x}}\left(\mathbf{x}_{\mathbf{x}}(t)\right)^{-1} \mathbf{J}_{\mathbf{x}}\left(\mathbf{x}_{\mathbf{x}}(t)\right)^{\mathrm{T}}\right)^{-1} \boldsymbol{\varphi}_{\mathbf{x}}(\mathbf{q}(t)) \mathbf{M}_{\mathbf{x}}\left(\mathbf{x}_{\mathbf{x}}(t)\right)^{-1}\left[\tau_{\mathbf{x}}(t)+\right. \\
\left.-\mathbf{c}_{\mathbf{x}}\left(\mathbf{x}_{\mathbf{x}}(t), \dot{\mathbf{x}}_{\mathbf{x}}(t)\right)-\mathbf{g}_{\mathbf{x}}\left(\mathbf{x}_{\mathbf{x}}(t)\right)-\mathbf{z}_{\mathbf{x}}\left(\mathbf{x}_{\mathbf{x}}(t), \dot{\mathbf{x}}_{\mathbf{x}}(t)\right)\right]+\dot{\varphi}_{\mathbf{x}}(\mathbf{q}(t)) \dot{\mathbf{x}}_{\mathbf{x}}(t) .
\end{aligned}
$$


Através da equação anterior é possível calcular as forças aplicadas pelos manipuladores no objeto. Esta equação pode ser empregada quando se necessita calcular as forças durante a simulação do sistema cooperativo. Para isto, o termo entre parêntesis da equação anterior deve ser não-singular [CARIGNAN \& AKIN, 1988].

É importante observar que a força aplicada pelo efetuador $i$ não é função apenas dos torques aplicados no manipulador $i$. As forças aplicadas pelos efetuadores acoplam a dinâmica dos diversos manipuladores. Além disso, deve-se notar que nem toda força aplicada no objeto contribui para o movimento. Por exemplo, se duas forças forem aplicadas na mesma direção, mas em sentidos opostos, somente a diferença destas forças irá contribuir para o movimento. Assim, se $1000 \mathrm{~N}$ e $-999 \mathrm{~N}$ ou 1 N e 0 N são aplicados no objeto em uma mesma direção, apenas $1 \mathrm{~N}$ contribuirá para o movimento. A diferença é que, no primeiro caso, uma força de esmagamento igual a $999 \mathrm{~N}$ será aplicada no objeto, enquanto que no segundo, ela será igual a $0 \mathrm{~N}$.

Além de não contribuir para o movimento, a força de esmagamento pode danificar o objeto que está sendo manipulado, fato que leva a maioria dos controladores para sistemas cooperativos a tentar minimizá-la. O controle da força de esmagamento também pode resultar em uma redução no gasto de energia e contribuir para a estabilidade no controle de posições. A seguir, a decomposição entre forças de movimento e esmagamento serão estudadas.

Seja $\mathbf{h}_{\mathbf{0}}(t)$ a projeção da força $\mathbf{h}(t)$ no CM do objeto dada por

$\mathbf{h}_{\mathbf{o}}(t)=\mathbf{J}_{\mathbf{o q}}(\mathbf{q}(t))^{\mathrm{T}} \mathbf{h}(t)$

na qual a matriz $\mathbf{J}_{\mathbf{o q}}(\mathbf{q}(t))$, que projeta o vetor ( $m \times k$ )-dimensional $\mathbf{h}(t)$ dos pontos de contato entre os efetuadores e o objeto para o espaço $(m \times k)$-dimensional das forças $\mathbf{h}_{\mathbf{0}}(t)$ no $\mathrm{CM}$ do objeto, é dada por

$\mathbf{J}_{\mathbf{o q}}(\mathbf{q}(t))=\left[\begin{array}{cccc}\mathbf{J}_{\mathbf{0} 1}\left(\mathbf{q}_{1}(t)\right) & \mathbf{0}_{k \times k} & \cdots & \mathbf{0}_{k \times k} \\ \mathbf{0}_{k \times k} & \mathbf{J}_{\mathbf{o} 2}\left(\mathbf{q}_{2}(t)\right) & \cdots & \mathbf{0}_{k \times k} \\ \vdots & \vdots & \ddots & \vdots \\ \mathbf{0}_{k \times k} & \mathbf{0}_{k \times k} & \cdots & \mathbf{J}_{\mathbf{o} m}\left(\mathbf{q}_{m}(t)\right)\end{array}\right]$.

$\mathrm{O}$ vetor $k$-dimensional das forças resultantes no $\mathrm{CM}$ do objeto é dado por

$$
\mathbf{h}_{\mathbf{r o}}(t)=\sum_{i=1}^{m} \mathbf{h}_{\mathbf{o} i}(t)=\mathbf{J}_{\mathbf{o}}(\mathbf{q}(t))^{\mathrm{T}} \mathbf{h}(t)=\mathbf{A}^{\mathrm{T}} \mathbf{J}_{\mathbf{o q}}(\mathbf{q}(t))^{\mathrm{T}} \mathbf{h}(t)=\mathbf{A}^{\mathrm{T}} \mathbf{h}_{\mathbf{o}}(t)
$$


na qual $\mathbf{J}_{\mathbf{o}}(\mathbf{q}(t))$ é definida na eq. (3.7) e, $\mathbf{A}^{\mathrm{T}}=\left[\begin{array}{l}\mathbf{I}_{\mathrm{k}} \\ \mathbf{I}_{\mathrm{k}}\end{array} \ldots \mathbf{I}_{\mathrm{k}}\right]$ é uma matriz $k x(m x k)$ que projeta o vetor ( $m \times k)$-dimensional $\mathbf{h}_{\mathbf{o}}(t)$ para o espaço $k$-dimensional das forças resultantes $\mathbf{h}_{\mathbf{r o}}(t)$ no CM do objeto.

A matriz $\mathbf{A}^{\mathrm{T}}$ tem um espaço nulo não-trivial [WEN \& KREUTZ-DELGADO, 1992], que será aqui chamado de subespaço de esmagamento $\boldsymbol{X}_{\boldsymbol{e}}$. Assim,

$\boldsymbol{X}_{\boldsymbol{e}}=\boldsymbol{N}\left(\mathbf{A}^{\mathrm{T}}\right)$

sendo $N\left(\mathbf{A}^{\mathrm{T}}\right)$ o espaço nulo de $\mathbf{A}^{\mathrm{T}}$. O complemento ortogonal de $\boldsymbol{X}_{\boldsymbol{e}}$ será chamado aqui de subespaço de movimento $\boldsymbol{X}_{\boldsymbol{m}}$, dado por [NAKAMURA, 1991]

$\boldsymbol{X}_{\boldsymbol{m}}=$ complemento $\left(\boldsymbol{N}\left(\mathbf{A}^{\mathrm{T}}\right)\right)=\operatorname{Im}(\mathbf{A})$

sendo $\operatorname{Im}(\mathbf{A})$ a imagem de $\mathbf{A}$. A dimensão de $\boldsymbol{X}_{m}$ é $k$ e, como $\boldsymbol{X}_{m} \oplus \boldsymbol{X}_{\boldsymbol{e}}=\mathfrak{R}^{m k}$, a dimensão de $\boldsymbol{X}_{e}$ é $k \cdot(m-1)$. A Figura 3.2 mostra de maneira esquemática os subespaços $\boldsymbol{X}_{e}$ e $\boldsymbol{X}_{\boldsymbol{m}}$.

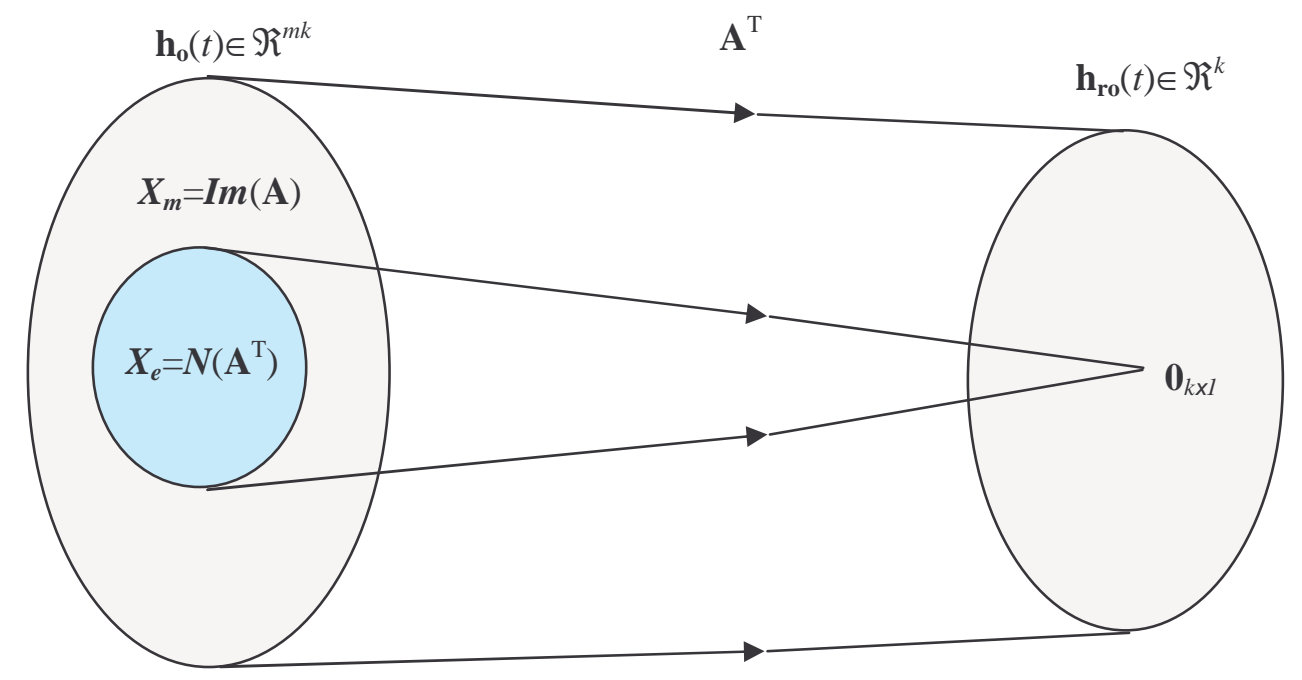

FIGURA 3.2. Subespaços ortogonais de movimento e de esmagamento.

É interessante observar que as componentes de $\mathbf{h}_{\mathbf{0}}(t)$ em $\boldsymbol{X}_{\boldsymbol{e}}$ provocam apenas esmagamento e, em contrapartida, as componentes de $\boldsymbol{X}_{\boldsymbol{m}}$ provocam apenas movimento [WEN \& KREUTZ-DELGADO, 1992]. Assim, existe uma única decomposição ortogonal de $\mathbf{h}_{\mathbf{o}}$

$\mathbf{h}_{\mathbf{o}}(t)=\mathbf{h}_{\mathbf{o m}}(t)+\mathbf{h}_{\mathbf{o e}}(t)$ 
na qual $\mathbf{h}_{\mathbf{o m}}(t) \in \boldsymbol{X}_{\boldsymbol{m}}$, chamada de força de movimento, é a componente que provoca apenas movimento e, $\mathbf{h}_{\mathbf{o e}}(t) \in \boldsymbol{X}_{\boldsymbol{e}}$, chamada de força de esmagamento, é a componente que provoca apenas esmagamento. Vale ressaltar que as duas componentes de $\mathbf{h}_{\mathbf{0}}(t)$ são ortogonais.

Para o cálculo de $\mathbf{h}_{\mathbf{o m}}(t)$ e $\mathbf{h}_{\mathbf{o e}}(t)$, pode-se definir matrizes de projeção de $\mathbf{h}_{\mathbf{0}}(t)$ para os subespaços ortogonais $\boldsymbol{X}_{\boldsymbol{m}}$ e $\boldsymbol{X}_{\boldsymbol{e}}$

$$
\begin{aligned}
& \mathbf{h}_{\text {om }}(t)=\mathbf{P}_{\mathbf{m}} \mathbf{h}_{\mathbf{o}}(t) \\
& \mathbf{h}_{\mathbf{o e}}(t)=\mathbf{P}_{\mathbf{e}} \mathbf{h}_{\mathbf{o}}(t)
\end{aligned}
$$

nas quais as matrizes $\mathbf{P}_{\mathbf{m}}$ e $\mathbf{P}_{\mathbf{e}}$ projetam $\mathbf{h}_{\mathbf{o}}(t)$, respectivamente, em $\boldsymbol{X}_{\boldsymbol{m}}$ e $\boldsymbol{X}_{\boldsymbol{e}}$. A primeira matriz, cujo posto é $k$, é dada por [NAKAMURA, 1991]

$$
\mathbf{P}_{\mathbf{m}}=\mathbf{A}\left(\mathbf{A}^{\mathrm{T}} \mathbf{A}\right)^{-1} \mathbf{A}^{\mathrm{T}}
$$

Das eqs. (3.24), (3.25) e (3.26), pode-se escrever que

$$
\mathbf{h}_{\mathbf{0}}(t)=\mathbf{P}_{\mathbf{m}} \mathbf{h}_{\mathbf{0}}(t)+\mathbf{P}_{\mathbf{e}} \mathbf{h}_{\mathbf{0}}(t)
$$

o que leva a seguinte relação

$\mathbf{P}_{\mathbf{e}}=\mathbf{I}_{m \times k}-\mathbf{A}\left(\mathbf{A}^{\mathrm{T}} \mathbf{A}\right)^{-1} \mathbf{A}^{\mathrm{T}}$

cujo posto é $k \cdot(m-1)$.

É importante notar que, apesar da força de esmagamento não afetar o movimento, o movimento nos manipuladores afeta o esmagamento devido ao componente de esmagamento da força inercial d'Alembert (isto é, os termos dependentes de velocidade em $\mathbf{P}_{\mathbf{e}} \mathbf{h}_{\mathbf{0}}(t)$ ) [WEN \& KREUTZ-DELGADO, 1992]. Assim, a força de esmagamento pode ser decomposta em duas componentes

$$
\mathbf{h}_{\mathbf{o e}}(t)=\mathbf{h}_{\mathbf{o e m}}(t)+\mathbf{h}_{\mathbf{o e c}}(t)
$$

na qual $\mathbf{h}_{\mathbf{o e m}}(t)$ é a componente da força de esmagamento induzida pelo movimento e, $\mathbf{h}_{\mathbf{o e c}}(t)$ é a componente da força de esmagamento que não é induzida pelo movimento. É interessante notar que a componente da força de esmagamento induzida pelo movimento converge para zero se as velocidades dos manipuladores tendem para zero. Essa importante característica é explorada no controle híbrido de movimento e esmagamento proposto em [WEN \& KREUTZ-DELGADO, 1992], descrito na próxima seção. 


\subsection{CONTROLE DO SISTEMA COOPERATIVO SEM FALHAS}

O início da pesquisa em controle de sistemas robóticos cooperativos remonta a década de 1970, quando as tecnologias associadas aos robôs industriais começaram a ser disseminadas. Já no início das pesquisas, notou-se que o controle dos manipuladores envolvidos no sistema cooperativo devia ser realizado de maneira coordenada devido às interações cinemáticas e dinâmicas presentes [VUKOBRATOVIC \& TUNESKI, 1998]. Notou-se também que as forças de esmagamento produzidas pelos manipuladores no objeto deveriam ser minimizadas de modo a evitar danos neste, desgastes nos robôs e consumo desnecessário de energia. Portanto, a idéia básica dos pesquisadores é projetar controladores que aproveitem os gdl's excedentes no controle das posições do objeto para o controle das forças aplicadas.

Várias soluções surgiram para tratar do controle de manipuladores cooperativos totalmente atuados rigidamente conectados a objetos não-deformáveis. Na estratégia mestre/escravo ( [NAKANO et. al., 1974] apud [UCHIYAMA, 1998] ), [LUH \& ZHENG, 1987], um manipulador é utilizado para o controle da posição enquanto que os outros são empregados para o controle das forças aplicadas no objeto. Apesar dos resultados interessantes no acompanhamento de trajetórias dos objetos, esta estratégia sobrecarrega o robô mestre e pode apresentar problemas quando o objeto excede a capacidade dinâmica de carga de um robô individual, que é muitas vezes a justificativa para o uso de mais de um robô.

Para resolver tais problemas, estratégias que buscam a divisão ótima do controle da carga foram propostas, geralmente para o caso de dois manipuladores. Em [CARIGNAN \& AKIN, 1988], busca-se a divisão ótima da carga através da otimização dos torques aplicados. Já em [NAHON \& ANGELES, 1992], busca-se o mesmo objetivo através da otimização das perdas de potência nos manipuladores.

Algumas estratégias buscam resolver o problema do controle olhando não apenas para a posição do objeto, mas formulando novas variáveis ou objetivos para facilitar o controle da tarefa. Assim, [KOIVO \& UNSEREN, 1991] utilizam um modelo reduzido das variáveis das juntas para projetar um controlador posição/força desacoplado. Já [CACCAVALE, 1997] define um novo espaço de variáveis baseado na tarefa a ser executada, utilizando regulação para atingir o objetivo desejado.

Também apareceram estratégias que realizam o controle das posições do objeto ao mesmo tempo que buscam o controle da força de esmagamento [UCHIYAMA, 1998]. Para isto, utilizam equações similares às desenvolvidas na seção anterior para o cálculo da força de esmagamento. Em ([UCHIYAMA \& DAUCHEZ, 1993] apud [UCHIYAMA, 1998]), 
([PERDEREAU \& DROUIN, 1996] apud [UCHIYAMA, 1998]), [WEN \& KREUTZDELGADO, 1992], o controle híbrido de movimento/força de esmagamento no sistema cooperativo é utilizado. Já [BONITZ \& HSIA, 1996] realiza a mesma tarefa através do controle por impedância.

O controle híbrido de movimento e esmagamento proposto em [WEN \& KREUTZDELGADO, 1992] é particularmente interessante por tratar de forma independente o controle das posições e da força de esmagamento. Também é interessante por não utilizar as matrizes de inércia dos manipuladores e do objeto no controle do sistema cooperativo, o que em geral aumenta a robustez a erros de modelagem. Neste trabalho, o controlador proposto em [WEN \& KREUTZ-DELGADO, 1992] é utilizado sempre que houver necessidade de um controlador para o sistema sem falhas. Além disso, sua filosofia é utilizada no projeto dos controladores para o sistema cooperativo com falhas. A seguir, o controle híbrido de movimento e esmagamento proposto em [WEN \& KREUTZ-DELGADO, 1992] é descrito.

\subsubsection{Controle Híbrido de Movimento e Esmagamento Para o Sistema Sem Falhas}

A decomposição entre força de movimento e força de esmagamento explicitada na Seção 3.4 implica que os problemas de controle de movimento e esmagamento ficam desacoplados em uma direção. Somente em uma direção porque qualquer termo de $\boldsymbol{\tau}(t)$ na forma $\mathbf{D}(\mathrm{q}(t))^{\mathrm{T}} \mathbf{h}_{\mathbf{o c}}(t)$, estando a variável $\mathbf{h}_{\mathbf{o c}}(t)$ no subespaço de esmagamento, não afeta $\mathrm{o}$ movimento quando não existem manipuladores em posições singulares. $\mathrm{O}$ movimento dos manipuladores, no entanto, afeta o esmagamento devido ao componente de esmagamento da força inercial d'Alembert (isto é, os termos dependentes de velocidade em $\mathbf{P}_{\mathbf{e}} \mathbf{h}_{\mathbf{o}}(t)$ ). Os termos dependentes do movimento da força de esmagamento tendem para zero quando as velocidades nos manipuladores tendem para zero e, como não são afetados pelos termos que não dependem das velocidades, podem ser tratados como perturbações.

Desta forma, a idéia é
"Projete uma lei de controle de movimento estável sem considerar o controle de força de esmagamento. Então, projete uma lei de controle de força de esmagamento estável, tratando a componente da força de esmagamento provocada pelo movimento como uma perturbação (o qual é independente do controle da força)"
[WEN \& KREUTZ-DELGADO, 1992], página 730, parágrafo 1. 
Assim, considerando as forças exercidas pela força da gravidade, as forças generalizadas aplicadas nas juntas dos manipuladores podem ser decompostas da seguinte forma

$\tau(t)=\tau_{\mathbf{m}}(t)+\tau_{\mathbf{g}}(t)+\tau_{\mathbf{e}}(t)$

na qual $\tau_{\mathbf{m}}(t)$ é responsável pelo controle do movimento do sistema cooperativo, $\tau_{\mathrm{g}}(t)$ é responsável pela compensação dos termos gravitacionais do sistema cooperativo e, $\tau_{\mathrm{e}}(t)$ é responsável pelo controle das forças de esmagamento no objeto.

Para o controle da componente de movimento, diferentes variáveis de controle podem ser escolhidas. Os autores consideram três escolhas: 1) erros nas posições das juntas, o que requer o mapeamento das variáveis do objeto para as variáveis das juntas, 2) erros nas posições dos efetuadores e, 3 ) erro na posição da origem do sistema de coordenadas fixado ao objeto (por exemplo, o CM).

A terceira opção é utilizada aqui pelo interesse em controlar as posições do objeto. Além disso, um número maior de variáveis deve ser controlado para a primeira e a segunda opções. A terceira opção é também interessante quando se consideram os problemas de falhas que afetam o controle das juntas, como, por exemplo, falhas do tipo junta com balanço livre, junta bloqueada e perda de informação dos sensores. Observa-se que, escolhendo as variáveis de controle relacionadas ao objeto, não importa quais valores as coordenadas generalizadas da juntas adquirem, desde que sejam respeitados os limites físicos e evitadas as configurações cinemáticas singulares. Em tarefas em que o controle de trajetórias das juntas deva ser respeitado, como em ambientes em que existe o risco de os manipuladores chocarem com outros objetos ou entre si, o erro das posições das juntas deve ser escolhido como variável de controle.

Assim, escolhendo-se funções candidatas de Lyapunov adequadas [WEN \& KREUTZ-DELGADO, 1992] e utilizando os resultados obtidos para o controle de manipuladores individuais [TAKEGAKI \& ARIMOTO, 1981], chega-se à seguinte lei de controle de movimento para o sistema cooperativo

$$
\tau_{\mathbf{m}}(t)=\mathbf{J}(\mathbf{q}(t))^{\mathrm{T}} \mathbf{f}_{\mathbf{k}}(t)
$$

na qual $\mathbf{f}_{\mathbf{k}}(t)$ é um vetor de tamanho $m k$ escolhido como

$$
\mathbf{K}_{\mathbf{p}} \Delta \mathbf{x}_{\mathbf{o}}(t)+\mathbf{K}_{\mathbf{v}} \Delta \mathbf{v}_{\mathbf{o}}(t)=\mathbf{J}_{\mathbf{o}}(\mathbf{q}(t))^{\mathrm{T}} \mathbf{f}_{\mathbf{k}}(t)
$$

$\Delta \mathbf{x}_{\mathbf{0}}(t)=\left(\mathbf{x}_{\mathbf{0 d}}(t)-\mathbf{x}_{\mathbf{0}}(t)\right)$ é o erro de posição no CM do objeto, $\mathbf{x}_{\mathbf{0 d}}(t)$ é a posição desejada, $\Delta \mathbf{v}_{\mathbf{0}}(t)=\left(\mathbf{v}_{\mathbf{o d}}(t)-\mathbf{v}_{\mathbf{o}}(t)\right)$ é o erro de velocidade, $\mathbf{v}_{\mathbf{o d}}(t)$ é a velocidade desejada, as matrizes $\mathbf{K}_{\mathbf{p}}$ 
e $\mathbf{K}_{\mathbf{v}}$ são diagonais e positivas. Na eq. (3.31), projetam-se forças proporcionais aos erros de posição e velocidade no $\mathrm{CM}$ do objeto com ganhos proporcionais $\mathbf{K}_{\mathbf{p}}$ e derivativos $\mathbf{K}_{\mathbf{v}}$ no espaço das juntas (controle Proporcional-Derivativo).

A compensação dos termos gravitacionais do sistema cooperativo é obtida através da seguinte lei de controle

$\tau_{\mathbf{g}}(t)=\mathbf{g}(\mathbf{q}(t))+\mathbf{J}(\mathbf{q}(t))^{\mathrm{T}} \mathbf{f}_{\mathbf{g}}(t)$

na qual $\mathbf{f}_{\mathrm{g}}(t)$ é um vetor de tamanho $m k$ escolhido como

$\mathbf{g}_{\mathbf{0}}=\mathbf{J}_{\mathbf{o}}(\mathbf{q}(t))^{\mathrm{T}} \mathbf{f}_{\mathbf{g}}(t)$

Na eq. (3.33), o primeiro termo compensa as componentes gravitacionais das juntas e o segundo termo compensa tais componentes do objeto.

Em [WEN \& KREUTZ-DELGADO, 1992], prova-se que, utilizando as componentes das forças generalizadas dadas nas eqs. (3.31) e (3.33), o sistema cooperativo é estável, ou seja as velocidades convergem para zero, para a seguinte classe de trajetórias:

$S=\left\{\mathbf{v}_{\text {od }}, \dot{\mathbf{v}}_{\text {od }} \in L_{2}([0, \infty)), \mathbf{v}_{\text {od }}, \dot{\mathbf{v}}_{\text {od }}\right.$ são uniformemente contínuos $\}$

na qual $L_{2}$ representa o espaço 2 de Lebesgue [GREEN \& LIMEBEER, 1995]

Nas trajetórias do conjunto $S$, as velocidades e acelerações desejadas convergem para zero quando $t \rightarrow \infty$, ou seja, o sistema deve convergir para a situação de repouso. Vale salientar que este conjunto de trajetórias é bastante amplo, cobrindo a grande maioria das trajetórias utilizadas em sistemas reais.

Resta agora o termo da eq. (3.30) responsável pelo controle da força de esmagamento. A idéia básica para esta tarefa é aplicar forças generalizadas nas juntas que provoquem forças no espaço de esmagamento no objeto. Se uma arquitetura com realimentação proporcional for utilizada, ou seja, medindo as forças, calculando as componentes de esmagamento e aplicando componentes proporcionais a estas, a estabilidade é garantida. No entanto, a qualidade do controle fica comprometida já que critérios como desempenho durante transiente e taxa de convergência são inteiramente determinados pelo componente afetado pelo movimento $\left(\mathbf{h}_{\text {oem }}(t)\right)$ da força de esmagamento (eq. 3.29). Além disso, não há redução de ruído neste esquema.

Reconhecendo que o problema é causado pela realimentação das componentes inerciais da força de esmagamento aplicada ao objeto, [WEN \& KREUTZ-DELGADO, 1992] sugerem o pré-processamento da força de esmagamento através de um filtro linear 
estritamente próprio. Uma solução particularmente simples é a escolha de um integrador. Desta forma, a componente $\mathbf{h}_{\mathbf{o e m}}(t)$ é tratada como uma perturbação.

Assim, se o sistema cooperativo converge para o regime estacionário e as componentes gravitacionais são compensadas, o controle realimentado com um integrador contendo zeros somente no plano esquerdo aberto garante que as componentes das forças de esmagamento irão convergir para os valores desejados. A componente responsável pelo controle das forças de esmagamento no objeto é, portanto, dada por

$$
\boldsymbol{\tau}_{\mathbf{e}}(t)=-\mathbf{E}(\mathbf{q}(t))^{\mathrm{T}}\left(\mathbf{h}_{\text {oed }}(t)+\mathbf{K}_{\mathbf{i}} \int_{s=t_{0}}^{s=t}\left(\mathbf{h}_{\text {oed }}(s)-\mathbf{h}_{\text {oe }}(s)\right) d s\right)
$$

na qual

$$
\mathbf{E}(\mathbf{q}(t))=\left[\begin{array}{cccc}
\mathbf{D}_{1}\left(\mathbf{q}_{1}(t)\right) & \mathbf{0}_{k \times n_{2}} & \cdots & \mathbf{0}_{k \times n_{m}} \\
\mathbf{0}_{k \times n_{1}} & \mathbf{D}_{2}\left(\mathbf{q}_{2}(t)\right) & \cdots & \mathbf{0}_{k \times n_{m}} \\
\vdots & \vdots & \ddots & \vdots \\
\mathbf{0}_{k \times n_{1}} & \mathbf{0}_{k \times n_{2}} & \cdots & \mathbf{D}_{m}\left(\mathbf{q}_{m}(t)\right)
\end{array}\right],
$$

$\mathbf{h}_{\text {oed }}(\cdot)$ é o vetor de força de esmagamento desejada e a matriz de ganhos $\mathbf{K}_{\mathbf{i}}$ é diagonal e positiva. Ou seja, calcula-se a força de esmagamento na eq. (3.35) através das forças medidas nos efetuadores dos manipuladores (eqs. 3.20 e 3.25b), calcula-se o termo entre parêntesis, e projeta-o do espaço das forças no $\mathrm{CM}$ do objeto para o espaço das juntas através da matriz $\mathbf{E}(\cdot)$.

Portanto, as eqs. (3.30-3.35) definem a lei de controle. 


\section{Capítulo 4.}

\section{DETECÇÃO E ISOLAÇÃO DE FALHAS}

"The detection and diagnosis of faults in complex process plants is one of
the most important tasks assigned to the computers supervising such
plants. The early indication of incipient failures can help avoid major
plant breakdowns and catastrophes, ones that could otherwise result in
substantial material damage and even human fatalities."
Janos J. Gertler, no primeiro parágrafo do artigo "Survey of model-based
failure detection and isolation in complex plants" [GERTLER, 1988]

"Then, nothing happened for half a billion years until one creature invented computers... and shortly thereafter, the sixth step of evolution was invented as artificial neural networks: artificial learning machines. Life was becoming a going concern and was really in business to start shaping the Universe. Competitors such as rocks and gravity and earth, wind, and fire were taking a distinctly second place."

Derek Stubbs, em 1989 na newsletter Sixth Generation Computing

[FRANKLIN, 1995] 
Sistemas de Detecção e Isolação de Falhas (DIF) desenvolvidos para manipuladores livres ${ }^{1}$ não podem ser diretamente aplicados em robôs cooperativos. Isso ocorre porque a dinâmica de um robô em um sistema cooperativo difere da dinâmica do robô livre (ver Capítulo 3). Neste capítulo, quatro tipos de falhas são considerados para a DIF nos robôs do sistema cooperativo (ver Capítulo 2): falhas do tipo junta com balanço livre, junta bloqueada, informação incorreta da posição da junta e informação incorreta da velocidade da junta. As falhas do tipo junta com balanço livre e junta bloqueada são detectadas através de Redes Neurais Artificiais (RNA's). As falhas do tipo informação incorreta de posição ou velocidade nas juntas são detectadas através do uso das restrições cinemáticas presentes no sistema cooperativo.

Este capítulo está organizado da seguinte forma: na Seção 4.1, uma revisão sobre DIF em sistemas dinâmicos e em robôs manipuladores livres é feita; o Sistema DIF proposto é apresentado na Seção 4.2; na Seção 4.3, o leitor é brevemente introduzido às RNA's utilizadas na DIF; as Seções 4.4 e 4.5 trazem, respectivamente, os esquemas de detecção e isolação das falhas do tipo junta com balanço livre ou bloqueada e informação incorreta da posição ou velocidade da junta; e, finalmente, o fluxograma do Sistema DIF completo é apresentado na Seção 4.6.

\subsection{INTRODUÇÃO: DETECÇÃO E ISOLAÇÃO DE FALHAS}

Segundo a terminologia geralmente aceita, DIF consiste em [GERTLER, 1988]:

(i) Detecção da falha, ou seja, a indicação de que algo errado está acontecendo no sistema, e;

(ii) Isolação da falha, ou seja, a determinação do tipo, local e tempo da falha.

As diferentes metodologias utilizadas para DIF em sistemas dinâmicos são brevemente introduzidas a seguir (Seção 4.1.1). Em seguida, é feita uma revisão sobre Sistemas DIF para robôs manipuladores livres (Seção 4.1.2).

\footnotetext{
${ }^{1}$ Por livre, entende-se que não são aplicadas forças externas no efetuador do manipulador.
} 


\subsubsection{Detecção e Isolação de Falhas em Sistemas Dinâmicos}

Os primeiros métodos de DIF empregavam a redundância física, na qual dois ou mais componentes de um sistema de controle, tais como sensores, atuadores e controladores, são instalados para a execução da mesma tarefa. Na redundância física, um sistema gerenciador deve comparar os sinais de saída do componente para detectar o componente faltoso. Com dois sinais redundantes, um sistema votante pode detectar a existência de um componente faltoso mas não pode identificá-lo. Com três sinais redundantes, um sistema votante pode detectar e isolar o componente faltoso, selecionando qual não deve ser utilizado para o controle da planta.

Redundância física pode proteger o sistema contra falhas nos componentes do sistema de controle, mas não nos componentes da planta. Pode, também, ser uma alternativa bastante cara e muitas vezes inviável, como no caso de falta de espaço físico para a instalação dos componentes redundantes.

Diferentemente da redundância física, Sistemas DIF não necessitam de instrumentação adicional na planta, utilizando-se do processamento de informação das variáveis medidas [PATTON et. al., 1989]. Dentre os Sistemas DIF, aqueles que empregam a chamada redundância analítica são os mais conhecidos [ISERMANN, 1997]. Em contraste com a redundância física, na qual medidas de diferentes sensores são confrontadas, as medidas dos sensores são comparadas com os valores correspondentes analiticamente obtidos na redundância analítica [GERTLER, 1988]. Usando-se o conceito de geração de resíduos, o modelo matemático é utilizado para a reprodução do comportamento dinâmico do sistema livre de falhas. A diferença entre a saída estimada pelo modelo e as medidas do sistema formam os resíduos, que quando propriamente analisados fornecem informações valiosas sobre as falhas .

Para a detectabilidade e diferenciação da falha em métodos que utilizam redundância analítica, as seguintes características devem estar presentes ${ }^{2}$ :

(i) conhecimento do modelo nominal do sistema;

(ii) invariância ou um mínimo de robustez com respeito a entradas desconhecidas.

(iii) existência de relações redundantes;

(iv) observação do comportamento do sistema na presença da falha e;

(v) conclusividade do comportamento faltoso;

\footnotetext{
${ }^{2}$ Para qualquer tipo de Sistema DIF, as características (iv) e (v) devem estar presentes para que as falhas sejam detectadas e isoladas.
} 
A literatura traz uma grande variedade de métodos que utilizam redundância analítica. Basicamente, eles podem ser englobados em: métodos que empregam estimativa de estado, nos quais se destacam o enfoque por paridade de estados e o enfoque por observadores dedicados, e métodos que utilizam estimativa paramétrica [PATTON et. al., 1989], [ISERMANN, 1993].

O preço a ser pago pelos benefícios do modelo matemático do sistema, além é claro do considerável esforço computacional, é a sensibilidade do Sistema DIF com respeito aos erros de modelagem, ruídos e distúrbios, inevitáveis na prática [GERTLER, 1997]. De acordo com FRANK (1990), a sensibilidade aos erros de modelagem é o principal problema nas aplicações dos Sistemas DIF que utilizam redundância analítica.

Para evitar que falsos alarmes apareçam devido aos erros de modelagem e ruídos presentes no sistema, thresholds fixos têm sido aplicados nos resíduos. No entanto, o uso de thresholds fixos apresenta dois problemas principais: a sensibilidade do Sistema DIF fica reduzida e a determinação dos thresholds é difícil de ser estabelecida, já que o resíduo varia com o sinal de entrada, com a magnitude e a natureza dos distúrbios no sistema. Escolhendose thresholds fixos muito pequenos, aumenta-se o número de alarmes falsos. Por outro lado, escolhendo-se thresholds fixos muito grandes, reduz-se consideravelmente a sensibilidade do Sistema DIF.

Muitos trabalhos têm sido desenvolvidos em Sistemas DIF robustos [PATTON et al., 1989], [MANGOUBI, 1998], [CHEN \& PATTON, 1999]. Várias técnicas robustas de projeto de estimadores de estado para geração de resíduos foram propostas [FRANK, 1987], [CHOW \& WILLSKY, 1984]. Mais recentemente, nesta mesma linha, pode-se citar os métodos que utilizam equações de paridade robustas [GERTLER, 1991], o enfoque por estimativa robusta $\mathrm{H}_{\infty}$ [MANGOUBI et al., 1992], [SADRNIA et al., 1997] e o uso de observadores de estados robustos baseados na teoria de modos deslizantes [CAMINHAS, 1997].

Por outro lado, foram desenvolvidos vários enfoques que aumentam a robustez do Sistema DIF pela escolha apropriada de thresholds ou fazendo-os adaptativos ao sinal de entrada do sistema, como foi proposto por CLARK no livro de PATTON et al. (1989) ou no método RMI (Reachable Measurement Intervals), desenvolvido por HORAK (1988) para sistemas de aeronaves. RMI provê condições para se achar os extremos possíveis das saídas medidas para cada entrada e estado do sistema sob condições livres de falhas, dadas faixas de variações paramétricas nos coeficientes das matrizes das equações dinâmicas. RMI, contudo, é concebido para sistemas com dinâmica linear e requer procedimentos especiais custosos para tratar sistemas dinâmicos não-lineares. 
Alternativamente, aparecem Sistemas DIF baseados em técnicas de Inteligência Artificial (IA), tais como sistemas especialistas, lógica difusa e RNA's. Basicamente, técnicas de Inteligência Artificial podem ser utilizadas em Sistemas DIF para três funções distintas. Na primeira, as técnicas de IA são usadas para a produção de classificadores baseados nas variáveis medidas do processo. Na segunda, o conceito de geração de resíduos é utilizado, sendo que as técnicas de IA são empregadas para reproduzir o comportamento dinâmico do sistema e/ou para a classificação do vetor de resíduos. Neste último caso, indiretamente, a técnica empregada produz thresholds variáveis baseados nas medidas do sistema. As técnicas de IA podem ainda ser empregadas para produzir a estimativa paramétrica do sistema.

RNA's têm sido empregadas em DIF especialmente em sistemas estáticos e menos intensivamente em sistemas dinâmicos [KORBICZ, 1997]. Na maioria das aplicações, as RNA's têm sido utilizadas como classificadores baseados nas variáveis medidas do processo. Em geral, neste caso, as entradas do sistema não são utilizadas. Em tais soluções, as RNA's podem ser implementadas com aprendizado supervisionado, não-supervisionado ou em conjunto com a lógica difusa [CAMINHAS et al., 1996], [CAMINHAS, 1997]. No aprendizado supervisionado, um perceptron multicamadas (do inglês multilayer perceptron MLP) é geralmente empregado tendo vetores $p$-dimensionais contendo as variáveis medidas do processo como padrões de entrada, e o estado das diferentes classes na saída (diferentes falhas e sistema em operação normal). As diferentes classes devem ter regiões separáveis no espaço de entradas $p$-dimensional. Para cada padrão de entrada, um vetor $q$-dimensional descrevendo os estados das diferentes classes deve ser utilizado para o aprendizado da RNA. Nas aplicações em que não se conhece o comportamento das variáveis medidas quando submetidas às falhas, RNA's com aprendizado não-supervisionado devem ser empregadas. Um modelo típico de tais redes é a dos mapas auto-organizáveis de Kohonen [KOHONEN, 1995]. Em tais redes, os diferentes padrões são separados em grupos (clusters) que posteriormente devem ser associados às diferentes falhas e à operação normal.

Contudo, tais procedimentos geralmente não são válidos em sistemas dinâmicos pois as variáveis de saída medidas comumente sofrem os efeitos das entradas do sistema. Isto ocorre especialmente em sistemas dinâmicos não-lineares [KORBICZ, 1997]. Se a classificação é feita empregando-se as entradas do sistema dinâmico em conjunto com as medidas das saídas, a dimensão do espaço para classificação se torna muitas vezes demasiadamente elevada, tornando a classificação impraticável.

O conceito de geração de resíduos pode ser utilizado para superar tais dificuldades. Neste enfoque, o modelo matemático ou uma RNA é utilizada para a reprodução do 
comportamento dinâmico do sistema livre de falhas. As saídas do modelo matemático ou da RNA são comparadas com os valores das variáveis medidas do sistema, gerando assim o vetor de resíduos que é aplicado em uma RNA que tem por objetivo a classificação das falhas [KÖPPEN-SELIGER \& FRANK, 1996].

\subsubsection{Detecção e Isolação de Falhas em Manipuladores Livres}

Em geral, os métodos utilizados para DIF em robôs manipuladores livres empregam redundância analítica. Utilizam, portanto, o modelo matemático do manipulador livre de falhas para gerar estimativas das variáveis medidas. As diferenças entre as estimativas e as variáveis medidas reais geram o vetor de resíduos. Se não existem falhas no robô, os resíduos devem ter valores próximos de zero. No caso de falhas, os resíduos devem assumir valores significativamente diferentes de zero.

Analisar simplesmente se os resíduos são diferentes de zero é inviável para a detecção da falha em sistemas robóticos. Este procedimento leva a um grande número de alarmes falsos já que os erros de modelagem inerentes ao sistema sem falhas aumentam devido a fatores como linearização das equações do sistema, ruídos de medida e incertezas dos parâmetros do modelo.

O que acontece tipicamente em sistemas DIF para manipuladores livres é que thresholds fixos são estipulados para mascarar as incertezas do modelo e os ruídos de medida. Geralmente, o threshold fixo é determinado empiricamente tomando-se cuidado para que seu valor não seja grande demais para esconder as falhas. Entretanto, os efeitos de erros de modelagem flutuam dinamicamente conforme o manipulador se move e quando ocorrem falhas. Desta forma, alarmes falsos ainda podem aparecer pois o threshold fixo não é projetado para todas as situações dinâmicas possíveis.

Como exemplo prático deste problema, vale lembrar o Sistema DIF utilizado no robô manipulador do ônibus espacial americano na missão STS-49 de maio de 1992. Neste vôo, uma sequência de 13 alarmes falsos foram anunciados porque condições operacionais especiais, tais como entradas no controlador manual e carga no manipulador não-usuais, não foram previstas na modelagem do sistema [VISINSKY et al., 1994]. Portanto, os thresholds devem ser variáveis para que os efeitos dos erros de modelagem e ruídos possam ser mascarados.

O método ThMB (Model-Based Threshold Algorithm), baseado nos conceitos de RMI (Seção 4.1.1), foi desenvolvido para tratar do problema de DIF em robôs manipuladores. ThMB explora as similaridades entre RMI e redundância analítica. Este 
método utiliza a idéia de se encontrar a máxima variância possível devido às faixas dos erros paramétricos em cada iteração [VISINSKY et al., 1995]. Utilizando tais dados, thresholds dependentes dos estados e das entradas são construídos no intuito de se alcançar robustez na análise dos resíduos.

Técnicas de IA podem ser utilizadas na criação de thresholds adaptativos. Neste enfoque, em geral, resíduos gerados através de observadores de estado são classificados através de técnicas de IA. SCHNEIDER \& FRANK (1996) utilizaram lógica difusa e NAUGHTON et al. (1996) utilizaram um MLP com treinamento por retropropagação dos erros para produzir thresholds variáveis.

O trabalho de SCHNEIDER \& FRANK (1996) preocupa-se basicamente com os erros de modelagem causados pelos efeitos da fricção. Como os efeitos da fricção são difíceis de serem modelados em robôs manipuladores, construiu-se um conjunto de regras difusas para variar os thresholds em função dos dados de velocidade e aceleração nas juntas. Seu método produz, assim, thresholds dinâmicos. Neste caso, o conhecimento de um especialista é necessário para a confecção das regras.

Já em [NAUGHTON et al., 1996], um MLP com treinamento por retropropagação dos erros é empregado na classificação dos resíduos. A classificação equivale a thresholds variáveis via extrapolação do conhecimento adquirido através dos dados de treinamento. Treinando o MLP com dados do vetor de resíduos como entrada e das falhas como saída desejada, a RNA pode classificar os resíduos. No entanto, neste caso, o Sistema DIF consegue apenas detectar as falhas no conjunto de trajetórias utilizado no treinamento, apesar de os autores acreditarem que trajetórias não-treinadas podem ser usadas se o conjunto de treinamento empregado for maior.

Técnicas de controle robusto podem ser também utilizadas para tratar do problema dos erros de modelagem em Sistemas DIF para robôs livres. Em [DIXON et. al., 2000], falhas nos atuadores do manipulador são detectadas através da predição do erro do sinal filtrado do torque.

Os métodos descritos acima têm as seguintes características: 1) o modelo nominal do sistema é considerado linear e, 2) as falhas são modeladas como entradas aditivas externas, ou seja, dependentes apenas do tempo e não dos estados e das entradas do sistema. Apesar de ser conveniente do ponto de vista analítico o estudo de problemas DIF em estruturas lineares, a dinâmica do manipulador é inerentemente não-linear e a maioria das falhas reais são funções não-lineares dos estados e das entradas [VEMURI \& POLYCARPOU, 1997]. Além disso, em [VISINSKY et al., 1995], os dados de aceleração nas juntas precisam ser medidos por acelerômetros, sensor caro e pouco comum nos 
manipuladores industriais. Acelerômetros são também utilizados em [ALDRIDGE, 1996], desta vez em conjunto com sensores de torque. Neste enfoque [ALDRIDGE, 1996], os acelerômetros são colocados nos elos e no efetuador do robô, o que permite a detecção de falhas nos sensores de posição das juntas através de redundância analítica.

Para superar os problemas advindos da linearização do modelo do robô, a extensão das técnicas de redundância analítica para sistemas não-lineares é proposta em [LEUSCHEN, 2001], [LEUSCHEN et al., 2002]. Já em [VEMURI \& POLYCARPOU, 1997], uma RNA é empregada para mapear o vetor de falhas, ou seja, o vetor que representa a função no tempo das variáveis medidas afetadas pela falha. Este método é interessante pois a falha não é considerada como uma entrada aditiva externa e, sim, como uma função das variáveis do sistema. A tarefa da RNA é mapear o vetor de falhas, tendo como entradas as velocidades e as posições das juntas. Assim, o sistema pode não só detectar, mas também reproduzir a função da falha. O método utiliza um observador para, baseado no modelo matemático e na função de falha estimada pela RNA, gerar uma estimativa das variáveis medidas. $\mathrm{O}$ erro entre o valor estimado e o valor medido é utilizado para o ajuste dos pesos da rede. O trabalho não propõe nenhum esquema para isolação da falha, sugerindo que algum método de classificação de padrões seja utilizado. Salienta-se que, neste enfoque, os erros de modelagem podem comprometer o mapeamento do vetor de falhas durante o treinamento da RNA.

Todos os métodos citados anteriormente utilizam o modelo matemático do manipulador. Empregam técnicas robustas para o mapeamento da dinâmica do manipulador ou para a análise dos resíduos através de thresholds variáveis. No entanto, como dito na seção anterior, erros de modelagem são inevitáveis na prática e podem comprometer a DIF, gerando alarmes falsos ou encobrindo os efeitos das falhas.

Em [TERRA \& TINÓS, 2001], [TINÓS, 1999], o modelo matemático do manipulador não é utilizado. Durante a geração dos resíduos, um MLP é utilizado para reproduzir a dinâmica do robô manipulador individual. O vetor de resíduos é gerado pela diferença entre as velocidades reais medidas nas juntas e os valores estimados pelo MLP. Na segunda fase, uma rede com função de base radial (Radial Base Function - RBF) é empregada para classificar o vetor de resíduos. De acordo com o comportamento dos resíduos (assinatura da falha), a rede RBF identifica os diferentes tipos de falhas.

Aqui, a detecção e a isolação de falhas que afetam a dinâmica dos manipuladores do sistema cooperativo, tais como falhas do tipo junta com balanço livre e junta bloqueada, é baseada no enfoque apresentado em [TINÓS, 1999]. A seguir, o Sistema DIF para os manipuladores cooperativos é apresentado. 


\subsection{DETECÇÃO E ISOLAÇÃO DE FALHAS EM MANIPULADORES COOPERATIVOS}

As restrições cinemáticas podem ser utilizadas para a detecção e isolação de falhas do tipo informação incorreta de posição ou velocidade da junta para robôs em cadeias cinemáticas fechadas. Em [NOTASH, 2000], as restrições cinemáticas são utilizadas para a detecção de falhas do tipo informação incorreta de posição das juntas e reconfiguração em robôs manipuladores paralelos. Robôs manipuladores paralelos são, em geral, conectados a plataformas móveis através de juntas esféricas passivas e geralmente são empregados em simuladores de vôo. Enquanto que o cálculo da cinemática direta é geralmente fácil em manipuladores cooperativos, esta tarefa é difícil nos manipuladores paralelos devido ao fato de as juntas esféricas passivas não possuírem sensores. Aqui, as falhas de informação incorreta de posição ou velocidade das juntas são detectadas através das equações cinemáticas do sistema cooperativo e suas restrições (Seção 4.5).

O problema de detecção e isolação de falhas que afetam a dinâmica de robôs manipuladores cooperativos, como falhas do tipo junta passiva e junta bloqueada, é tratado em [TINÓS et al., 2000], [TINÓS et al., 2001]. Como no esquema para os robôs livres [TINÓS, 1999], o vetor de resíduos é gerado pela diferença entre as velocidades reais medidas nas juntas no instante $t+\Delta t$ e os valores estimados pelo MLP. Ao invés de reproduzir a dinâmica de cada robô sem falhas individualmente, o MLP reproduz a dinâmica de todo o sistema cooperativo sem falhas (eq. 3.5).

Como as forças e momentos $\mathbf{h}(t)$ aplicados pelos efetuadores no objeto são dependentes das posições, velocidades e torques nas juntas (eq. 3.19), essas variáveis obtidas no instante $t$ são usadas como entradas do MLP. Isto é interessante quando as forças e momentos nos efetuadores não são medidos. Note, no entanto, que o mapeamento fica dependente das características do objeto manipulado (massa, momentos de inércia, etc.) já que a força calculada depende desses parâmetros. Se outro objeto é manipulado, o MLP precisa ser treinado novamente.

A fase seguinte é a classificação dos resíduos pela rede RBF. Se dois tipos de falhas têm assinaturas idênticas, ou seja, se os resíduos ocuparem a mesma região no espaço de entradas da rede RBF, as falhas podem ser detectas mas não corretamente isoladas. Este é o caso, por exemplo, de falhas do tipo junta bloqueada e junta com balanço livre. Por isso, o Sistema DIF é treinado para detectar e isolar apenas um tipo de falha: junta bloqueada [TINÓS et al., 2000] ou junta com balanço livre [TINÓS et al., 2001]. 
Aqui, diferentemente do que ocorre em [TINÓS et al., 2000], [TINÓS et al., 2001], a dinâmica de cada manipulador sem falhas é mapeada por um MLP diferente (Seção 4.4). Para isso, as forças e momentos nos efetuadores precisam ser medidos. Isto não é um problema pois, geralmente, sensores de força são empregados em sistemas cooperativos para que os controladores minimizem a força de esmagamento no objeto. Para evitar o problema de assinaturas idênticas das duas falhas, entradas auxiliares indicando se as velocidades das juntas são próximas de zero são empregadas na entrada da rede RBF junto com os resíduos. Assim, as falhas do tipo junta com balanço livre e junta bloqueada podem ser isoladas por uma mesma rede RBF.

Antes da descrição dos elementos do Sistema DIF, as RNA's serão brevemente introduzidas. Por motivos de simplicidade, a seguinte suposição será considerada:

Suposição 4.1: somente uma falha ocorre de cada vez, ou seja, duas ou mais falhas não podem ocorrer simultaneamente.

\subsection{AS REDES NEURAIS ARTIFICIAIS}

As redes neurais artificiais (RNA's) têm sido aplicadas em uma infinidade de problemas. O adjetivo "neural" é usado porque muito da inspiração de tais sistemas vem da Neurociência [HERTZ et al., 1991]. As RNA's empregam como unidade de processamento fundamental o neurônio artificial, inspirado no funcionamento básico dos neurônios biológicos.

Neste trabalho, as RNA's são utilizadas para duas tarefas distintas: aproximação de funções não-lineares (mapeamento da dinâmica dos robôs) e classificação de padrões (análise dos resíduos). O MLP com aprendizado por retropropagação do erro (backpropagation) é uma das RNA's mais utilizadas para a aproximação de funções nãolineares contínuas. Para a classificação de padrões em DIF, no entanto, o MLP apresenta alguns problemas. Como é visto a seguir, tais problemas levam à utilização da rede RBF para a classificação dos resíduos. 


\subsubsection{Perceptron Multicamadas (MLP)}

O MLP pode ser visto como um veículo prático para realizar mapeamentos de funções nãolineares de maneira geral [HAYKIN, 1994]. A relação entrada/saída do MLP define um mapeamento continuamente diferenciável de um espaço de entrada Euclidiano $p$-dimensional para um espaço de saída Euclidiano $q$-dimensional.

Para um MLP com uma única camada escondida, apresentando-se o $n$-ésimo ${ }^{3}$ padrão de entrada $\xi(n)=\left[\xi_{I}(n) \xi_{2}(n) \ldots \xi_{p}(n)\right]^{\mathrm{T}}$, a ativação do neurônio de saída $k$ e a ativação do neurônio $j$ da camada escondida são dadas respectivamente por

$$
\begin{aligned}
& \hat{\psi}_{k}(n)=\varphi\left(v_{k}(n)\right)=\varphi\left(\sum_{j=0}^{m} \omega_{k j}(n) h_{j}(n)\right) \\
& h_{j}(n)=\varphi\left(v_{j}(n)\right)=\varphi\left(\sum_{i=0}^{p} \omega_{j i}(n) \xi_{i}(n)\right)
\end{aligned}
$$

sendo $\varphi(\cdot)$ a função de ativação não-linear do neurônio, $\omega_{c b}(\cdot)$ o peso entre a saída do neurônio $b$ (camada anterior) e a entrada do neurônio $c$ (camada posterior), $i=1, \ldots, p$ o índice dos neurônios da camada de entrada, $j=1, \ldots, m$ o índice dos neurônios da camada escondida, e $k=1, \ldots, q$ o índice dos neurônios da camada de saída. Geralmente, a função de ativação nãolinear empregada no MLP é a sigmóide, dada por

$$
\varphi\left(v_{a}(n)\right)=\frac{1}{1+e^{-v_{a}(n)}}
$$

na qual $v_{a}(\cdot)$ é o nível de ativação interna no neurônio. Um MLP com apenas uma camada escondida é representado na Figura 4.1.

\footnotetext{
${ }^{3}$ Por abuso de notação, as variáveis $n, m, j, k, h$, e $q$ adquirem outro significado na Seção 4.3.
} 


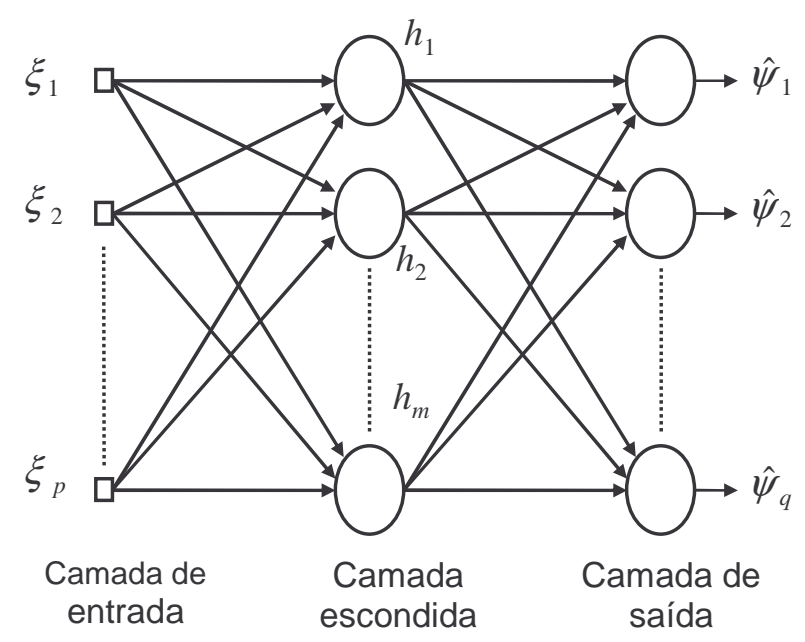

FIGURA 4.1. MLP com uma única camada escondida.

A seguir, o algoritmo para treinamento do MLP por retropropagação do erro será brevemente descrito. Apresentando-se o $n$-ésimo padrão de treinamento $\left(n=1, \ldots, n_{p}\right)$ na entrada do MLP, o erro instantâneo na saída $k$ é dado por

$e_{k}(n)=\psi_{k}(n)-\hat{\psi}_{k}(n)$

na qual $\psi_{k}(n)$ é a variável que deve ser estimada pela saída $\hat{\psi}_{k}(n)$ do MLP. A soma dos erros quadráticos instantâneos nas saídas do MLP para o padrão $n$ é dada por

$e(n)=\frac{1}{2} \sum_{k=1}^{q} e_{k}^{2}(n)$

e o erro médio quadrático (EMQ) sobre o conjunto de treinamento é dado por

$E M Q=\frac{1}{n_{p}} \sum_{n=1}^{n_{p}} e(n)$

Utilizando-se a regra Delta [HERTZ et al., 1991], as conexões entre a camada escondida e a camada de saída são ajustadas por

$\Delta \omega_{k j}(n)=-\eta(n) \frac{\partial e(n)}{\partial \omega_{k j}(n)}$

na qual $\eta$ é a taxa de aprendizagem e $\Delta \omega_{k j}(\cdot)$ é a correção aplicada ao peso $\omega_{k j}(\cdot)$. Da equação anterior e da eq. (4.5), chega-se à lei de ajuste dos pesos

$\Delta \omega_{k j}(n)=\eta(n) \delta_{k}(n) h_{j}(n)$ 
na qual

$$
\delta_{k}(n)=e_{k}(n) \dot{\varphi}_{k}\left(v_{k}(n)\right) \text {. }
$$

Do mesmo modo, para as conexões entre a camada de entrada e a camada escondida, tem-se que o ajuste de pesos é dado por

$$
\Delta \omega_{j i}(n)=\eta(n) \delta_{j}(n) \xi_{i}(n)
$$

na qual

$$
\delta_{j}(n)=\dot{\varphi}_{j}\left(v_{j}(n)\right) \sum_{k=1}^{q} \delta_{k}(n) \omega_{k j}(n)
$$

A definição da taxa de aprendizagem tem um papel importante no treinamento por retropropagação do erro. Se a taxa é muito baixa, o algoritmo demorará a convergir. Se por outro lado a taxa é muito alta, o algoritmo pode se tornar instável. Um método simples para aumentar a velocidade de convergência e evitar a instabilidade é modificar a lei de ajuste de pesos adicionando um termo de momentum que é proporcional ao ajuste de pesos feito na época anterior [HAYKIN, 1994]. Outro fator que ajuda no treinamento quando se trabalha com a função sigmóide é a normalização entre 0 e 1 dos padrões de entrada e saída, já que os mínimos e máximos de saída de uma função de ativação sigmoidal estão dentro desta faixa de valores.

Neste trabalho, o MLP tem apenas uma camada escondida. O seguinte teorema estabelece que uma RNA direta (feedforward) com uma única camada escondida e com um número suficiente de unidades escondidas é capaz de aproximar qualquer função contínua $f$ : $\mathfrak{R}^{p} \rightarrow \mathfrak{R}^{q}$ com uma precisão desejada $\varepsilon>0$ [FLASHNER \& EFRATI, 1997].

Teorema 4.1: [CYBENKO, 1989] Seja $\varphi$ qualquer função de ativação sigmoidal contínua. Então, dada qualquer função contínua com valores reais $f($ (.) em um subespaço compacto $s \subset \mathfrak{R}^{n_{p}}$ e $\varepsilon>0$, existem vetores $\boldsymbol{\omega}_{1}, \boldsymbol{\omega}_{2}, \ldots, \boldsymbol{\omega}_{m}, \boldsymbol{\alpha}, \boldsymbol{\theta}$ e uma função parametrizada $G(., \omega, \alpha, \theta): \rightarrow \Re$ tal que

$$
\begin{aligned}
& |G(\boldsymbol{\xi}, \boldsymbol{\omega}, \boldsymbol{\alpha}, \boldsymbol{\theta})-f(\boldsymbol{\xi})|<\varepsilon \\
& G(\boldsymbol{\xi}, \boldsymbol{\omega}, \boldsymbol{\alpha}, \boldsymbol{\theta})=\sum_{j=1}^{m} \alpha_{j} \varphi\left(\boldsymbol{\omega}_{j}^{\mathrm{T}} \boldsymbol{\xi}+\theta_{j}\right)
\end{aligned}
$$

nas quais $\boldsymbol{\xi} \in \mathfrak{R}^{p}, \boldsymbol{\omega}_{j}=\left[\omega_{j 1} \ldots \omega_{j p}\right]^{T}, \boldsymbol{\alpha}=\left[\alpha_{1 \ldots} \alpha_{m}\right]^{T}$ e $\boldsymbol{\theta}=\left[\theta_{1} \ldots \theta_{m}\right]^{T}$. 
Este teorema pode ser interpretado da seguinte forma: uma falha na função de mapeamento do MLP é resultado de uma escolha de parâmetros inadequada ou de um número insuficiente de unidades escondidas [FLASHNER \& EFRATI, 1997].

Para o problema de classificação, o MLP produz bordas de decisão que separam os padrões das diferentes classes. Bordas de decisão são superfícies, ou linhas para o caso de dois neurônios na entrada, no espaço de entradas onde a saída dos dois, ou mais, neurônios com maior ativação na última camada são iguais para um mesmo padrão. As bordas de decisão produzidas pelo MLP com treinamento por retropropagação do erro são posicionadas muito perto da superfície que separa os padrões de treinamento pertencentes às diferentes classes.

Esta característica do MLP pode gerar uma classificação ruim dos padrões nãotreinados em problemas como DIF em que as superfícies que separam as diferentes classes são difíceis de serem estipuladas através de um conjunto limitado de padrões. Este problema poderia ser evitado se as bordas de decisão estivessem em posições mais conservadoras. Além disso, nas áreas do espaço de entradas não ocupadas pelos padrões do conjunto de treinamento, a classificação é arbitrária já que os pontos de saída desejados somente refletem as ativações da rede para os padrões empregados no treinamento [LEONARD \& KRAMER, 1991]. Portanto, o MLP com treinamento por retropropagação pode produzir bordas de decisão que são não-intuitivas e não-robustas.

\subsubsection{Rede com Função de Base Radial (RBF)}

Funções de base radial são simplesmente uma classe de funções. MOODY \& DARKEN (1989) propuseram seu uso em um novo tipo de RNA chamada rede RBF. Esta RNA é inspirada em neurônios que têm ativações localmente sintonizadas, chamados de neurônios seletivos. Estes neurônios respondem somente para determinadas faixas de sinais de entrada e são encontrados em diversas partes do corpo humano e de outros animais. Em princípio, as redes RBF podem ser multicamadas e terem funções de ativação não-lineares na camada de saída. Contudo, redes RBF têm tradicionalmente sido associadas com funções radiais em uma única camada escondida e funções de saída lineares [ORR, 1996].

A rede RBF utilizada neste trabalho possui três camadas distintas. Na primeira, os padrões de entrada são apresentados. Não existem pesos entre a primeira e a segunda camadas, sendo os padrões de entrada repassados para os neurônios da segunda camada (camada escondida). As unidades desta camada têm função de ativação radial. Cada 
neurônio $j$ da camada escondida é chamado unidade radial $j$ e é responsável pela criação de um campo receptivo no espaço de entradas centrado em um vetor $\boldsymbol{\mu}_{j}$, chamado de centro da unidade radial. A unidade radial $j$ tem ativação de acordo com a distância entre o vetor de entrada e o centro da unidade radial. Quanto mais próximos forem os dois vetores, maior será a ativação do neurônio. Entre a segunda e a terceira camada existem pesos e esta última camada apresenta ativação linear. A $k$-ésima $(k=1, \ldots, q)$ saída da rede RBF para o $n$-ésimo $\left(n=1, \ldots, n_{p}\right)$ vetor de entrada $\xi_{n}$ é dada por

$\hat{\psi}_{k}(n)=\sum_{j=0}^{m} \omega_{k j} h_{j}(n)$

na qual $h_{j}(\cdot)$ é a ativação da unidade radial $j$ da camada escondida e $\omega_{k j}$ é o peso entre a unidade radial $j$ e o neurônio de saída $k$. A ativação das unidades da camada escondida é definida por uma função radial. Uma função radial de ativação comumente utilizada é a função Gaussiana. Aplicando esta função na unidade radial $j$, a ativação desta unidade para o $n$-ésimo vetor de entrada é dada por

$h_{j}(n)=\exp \left(-\frac{\left\|\xi(n)-\boldsymbol{\mu}_{j}\right\|^{2}}{2 \rho^{2}}\right)$

na qual $\rho$ determina o tamanho do campo receptivo da unidade radial $j$ e $\|$.$\| define a norma$ do vetor (aqui, a norma Euclidiana). A ativação da função Gaussiana pode ser vista na Figura 4.2 .

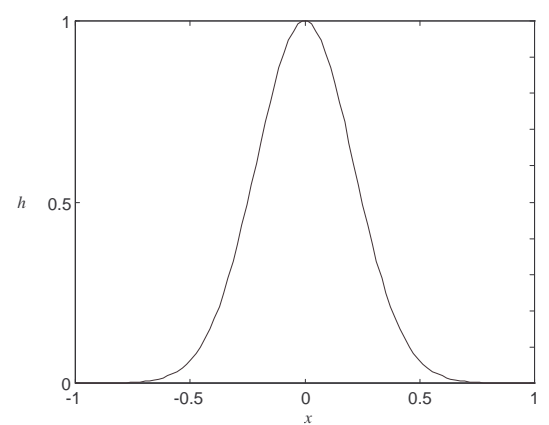

FIGURA 4.2. Resposta da função Gaussiana com o centro em $0(\mu=0)$ e $\rho=0,3$. Note que a ativação máxima ocorre em $x=\mu$.

Neste trabalho, a função de ativação utilizada nas unidades radiais é a função de Cauchy. Esta função foi escolhida por apresentar um decaimento mais suave conforme os padrões se distanciam do centro da unidade radial. Assim, mesmo os padrões nas regiões do espaço de entradas que não são ocupadas pelos padrões de treinamento serão classificados de 
acordo com a distância até o centro mais próximo sem a necessidade de se aumentar o tamanho do campo receptivo. A função de Cauchy é dada por

$h_{j}(n)=\frac{1}{1+\left\|\mathbf{R}^{-1}\left(\xi(n)-\boldsymbol{\mu}_{j}\right)\right\|^{2}}$

na qual $\mathbf{R}$ é uma matriz diagonal formada pelos parâmetros individuais que definem o tamanho do campo receptivo em cada dimensão do espaço de entradas, ou seja

$$
\mathbf{R}=\left[\begin{array}{cccc}
\rho_{1} & 0 & 0 & 0 \\
0 & \rho_{2} & 0 & 0 \\
0 & 0 & \ddots & 0 \\
0 & 0 & 0 & \rho_{p}
\end{array}\right]
$$

Desta forma, o campo receptivo não precisa necessariamente ter o mesmo tamanho em todas as dimensões do espaço de entradas. Se uma determinada variável do vetor de entradas tem um poder discriminatório menor, o tamanho do campo receptivo em sua dimensão pode ser maior, priorizando-se assim as outras variáveis.

Para os problemas DIF, a rede RBF pode produzir bordas de decisão que são mais robustas e intuitivas que as do MLP já que a classificação é feita considerando-se a proximidade entre o padrão a ser classificado e os centros das unidades radiais. É claro que este resultado depende da escolha adequada das unidades radiais e de seus parâmetros.

As redes RBF ainda apresentam outras vantagens sobre o MLP, tais como inexistência de mínimos locais no cálculo dos pesos e um menor tempo de treinamento [LOONEY, 1997]. Entre as desvantagens das redes RBF, pode-se citar: maior ocupação de memória devido ao alto número de unidades escondidas (unidades radiais), menor velocidade de operação devido ao maior número de unidades escondidas, e possível escolha subótima das unidades radiais e de seus parâmetros.

Neste ponto, uma questão que surge é: por que não utilizar também a rede RBF para a aproximação da função dinâmica do sistema no problema DIF? Realmente, a rede RBF apresenta bons resultados no mapeamento de sistemas não-lineares com poucas variáveis medidas [NELLES \& ISERMANN, 1995]. Contudo, se a dimensão do espaço de entradas é grande, um número de unidades radiais bastante alto é requerido para tratar a complexidade do problema [WARWICK \& CRADDOCK, 1996]. Isto pode resultar em uma baixa generalização e/ou em um esforço computacional extremamente alto durante a fase de treinamento da rede RBF.

Considere agora o problema do treinamento da rede RBF. Se a rede RBF possui apenas uma camada escondida e as unidades radiais são fixadas, isto é, o número de 
unidades radiais e seus parâmetros são constantes, então esta RNA pode ser vista como um modelo linear. Neste caso, o treinamento pode ser feito de maneira desacoplada: primeiro determinam-se o número de unidades radiais e seus parâmetros e depois calculam-se os pesos da segunda camada de acordo com as ativações das unidades radiais e com as saídas desejadas. Assim, evita-se o uso de algoritmos de otimização não-lineares, como os do tipo gradiente descendente, que apresentam um esforço computacional relativamente alto para cálculo dos pesos. Outra vantagem é que evitam-se os mínimos locais no cálculo dos pesos.

A determinação do número de unidades radiais e seus parâmetros é a primeira etapa do treinamento. O método RBF original utiliza como centros todos os padrões de treinamento. Entretanto, como o número de padrões geralmente é muito grande em DIF, este método é raramente utilizado. Além disso, utilizando-se um número grande de unidades radiais pode haver problemas de sobreajuste, ou seja, a classificação será sensível à escolha do conjunto de treinamento. Isso resultará em uma baixa generalização, em que padrões nãotreinados podem ser mal-classificados.

Neste trabalho, o mapa auto-organizável de Kohonen (MAOK) é empregado para a seleção das unidades radiais da rede RBF [TINÓS \& TERRA, 2001]. O uso do MAOK para o treinamento de redes RBF não é um enfoque novo. Em OJALA \& VUORIMAA (1995), o MAOK é usado para a seleção inicial dos centros das unidades radiais e, então, o algoritmo Learning Vector Quantization (LVQ2.1) [KOHONEN, 1995] é utilizado para sintonizar os centros das unidades radiais e os pesos da rede.

Em [TINÓS \& TERRA, 2001], algumas mudanças são feitas para adequar o MAOK para o treinamento da rede RBF aplicada ao problema DIF. Apesar deste algoritmo ser não-supervisionado, ou seja, não necessita do conhecimento das saídas desejadas, ele será aplicado em um problema supervisionado. Assim, aproveitando as características do problema, o conjunto de treinamento será separado de acordo com as diferentes classes. Este procedimento é adotado para evitar que padrões de treinamento pertencentes às diferentes classes sejam sintonizados em uma mesma unidade radial. Portanto, o algoritmo descrito abaixo deve ser executado para cada classe.

Inicialmente, todos os padrões de treinamento são considerados como centros das unidades radiais. Utilizando os padrões pertencentes a uma determinada classe, calculam-se as ativações das unidades radias (eq. 4.16) para cada padrão de treinamento da mesma classe. A unidade com a maior ativação é selecionada de acordo com

$$
h_{c}(t)=\underset{j}{\arg \max }\left\{h_{j}(t)\right\}
$$


na qual $c$ é a unidade radial selecionada, $j=1, \ldots, m_{k}, m_{k}$ é o número de padrões na classe $k$, $k=1, \ldots, q, q$ é o número de classes, $t=1, \ldots, t_{\max }$ é o índice do tempo discreto e $t_{\max }$ deve ser múltiplo de $m_{k}$. Em cada amostra $t$, um padrão diferente do subconjunto de treinamento deve ser apresentado. Para que o algoritmo apresente uma convergência conveniente, o subconjunto de treinamento deve ser apresentado diversas vezes. O passo seguinte é atualizar as posições dos centros das unidades radiais de acordo com

$$
\boldsymbol{\mu}_{j}(t+1)=\boldsymbol{\mu}_{j}(t)+\alpha(t) \beta(t)\left[\xi(t)-\boldsymbol{\mu}_{j}(t)\right]
$$

na qual $\alpha(t)$ é uma função de decaimento no tempo que define a taxa de aprendizagem e, $\beta(t)$ é uma função da distância vetorial entre o centro da unidade radial $j\left(\boldsymbol{\mu}_{j}\right)$ e o centro da unidade radial selecionada $\left(\boldsymbol{\mu}_{c}\right)$. Aqui, esta função é dada por

$$
\beta(t)=\left\{\begin{array}{cl}
\frac{1}{1+\left\|\mathbf{R}^{-1}\left(\boldsymbol{\mu}_{c}-\boldsymbol{\mu}_{j}\right)\right\|^{2}}, & \text { se }\left\|\mathbf{R}^{-1}\left(\boldsymbol{\mu}_{c}-\boldsymbol{\mu}_{j}\right)\right\|<\sigma(t), \\
0, & \text { se }\left\|\mathbf{R}^{-1}\left(\boldsymbol{\mu}_{c}-\boldsymbol{\mu}_{j}\right)\right\| \geq \sigma(t)
\end{array}\right.
$$

na qual a função de espalhamento $\sigma(t)$ decai com o tempo e define o tamanho da vizinhança ao redor do centro $\boldsymbol{\mu}_{c}$ da unidade radial selecionada $c$.

Se o número de iterações $t_{\max }$ é suficientemente grande e os parâmetros de treinamento são apropriadamente escolhidos, os centros das unidades radiais em um mesmo grupo deverão se mover até as proximidades do seu centro. Ou seja, os centros deverão se mover para o local em que a média das ativações das unidades radiais para todos os padrões de um mesmo grupo seja a maior. Após o treinamento, vários centros de um mesmo grupo estarão na mesma posição ou em posições muito próximas. Pode-se, portanto, vincular as unidades radiais que estão na mesma posição ou em posições muito próximas a uma única, já que as ativações de duas unidades radiais com o mesmo centro são iguais. Agindo desta forma, a complexidade da rede RBF diminui pois o número de parâmetros adaptativos (pesos) decresce.

Este procedimento também é importante para se evitar problemas de singularidade na matriz usada para a determinação dos pesos ótimos. Se existem dois centros muito próximos, a inversa da matriz utilizada para cálculo dos pesos sofre problemas de maucondicionamento. A união das unidades radiais com centros muito próximos é feita verificando se a norma euclidiana da distância entre os centros das duas unidades radiais é muito pequena. Se a resposta for afirmativa, uma unidade radial é removida.

Repetindo o procedimento descrito acima para todas as classes, as unidades radiais de cada subconjunto são agrupadas em uma única rede RBF e a matriz de pesos ótima é 
calculada. Minimizando a soma dos erros quadráticos, a matriz de pesos ótima é dada por [ORR, 1996]

$\hat{\mathbf{W}}=\left(\mathbf{H}^{\mathrm{T}} \mathbf{H}\right)^{-1} \mathbf{H}^{\mathrm{T}} \boldsymbol{\Psi}$

na qual a matriz $\left(n_{p} \times m\right) \mathbf{H}$ é formada pelas ativações $h_{j}$ das unidades radiais para os $n_{p}$ padrões e, a matriz de saída $\left(n_{p} \times q\right) \Psi$ é formada pelas saídas desejadas do conjunto de treinamento.

\subsection{DETECÇÃO E ISOLAÇÃO DE FALHAS DO TIPO JUNTAS COM BALANÇO LIVRE OU BLOQUEADAS}

Aqui, falhas do tipo junta com balanço livre e bloqueadas são detectadas e isoladas por RNA's. Primeiro, na Seção 4.4.1, MLP's mapeiam a dinâmica dos manipuladores do sistema cooperativo sem falhas (Geração de Resíduos) e, em seguida, na Seção 4.4.2, os resíduos são classificados através de uma rede RBF (Análise de Resíduos).

\subsubsection{Geração de Resíduos}

Para a geração dos resíduos, a dinâmica de cada manipulador livre de falhas (eq. 3.4) é reproduzida por um MLP diferente. Como geralmente não se medem as acelerações nas juntas dos robôs industriais, as velocidades são relacionadas às acelerações no instante $t$. Considerando um período amostral $(\Delta t)$ suficientemente pequeno, pode-se utilizar a integração de Euler. Substituindo

$\ddot{\mathbf{q}}_{i}(t)=\frac{\dot{\mathbf{q}}_{i}(t+\Delta t)-\dot{\mathbf{q}}_{i}(t)}{\Delta t}$

na qual o índice $i$ refere-se às variáveis do manipulador $i$, na eq. (3.4)

$$
\begin{aligned}
\dot{\mathbf{q}}_{i}(t+\Delta t)= & \mathbf{M}_{i}\left(\mathbf{q}_{i}(t)\right)^{-1}\left[\boldsymbol{\tau}_{i}(t)-\mathbf{J}_{i}\left(\mathbf{q}_{i}(t)\right)^{\mathrm{T}} \mathbf{h}_{i}(t)-\mathbf{c}_{i}\left(\mathbf{q}_{i}(t), \dot{\mathbf{q}}_{i}(t)\right)-\mathbf{g}_{i}\left(\mathbf{q}_{i}(t)\right)-\mathbf{z}_{i}\left(\mathbf{q}_{i}(t), \dot{\mathbf{q}}_{i}(t)\right)\right] \Delta t \\
& +\dot{\mathbf{q}}_{i}(t)
\end{aligned}
$$

Assim, pode-se escrever que a dinâmica do manipulador $i$ livre de falhas é dada por

$\dot{\mathbf{q}}_{i}(t+\Delta t)=\mathbf{f}_{i}\left(\mathbf{q}_{i}(t), \dot{\mathbf{q}}_{i}(t), \tau_{i}(t), \mathbf{h}_{i}(t)\right)$ 
na qual $\mathbf{f}_{i}$ (.) é uma função vetorial não-linear que representa a dinâmica do manipulador $i$ sem falhas. Quando uma falha $\phi$ ocorre, então a dinâmica do manipulador $i$ torna-se

$$
\begin{aligned}
\dot{\mathbf{q}}_{i}(t+\Delta t) & =\mathbf{f}_{i}\left(\mathbf{q}_{i}(t), \dot{\mathbf{q}}_{i}(t), \tau_{i}(t), \mathbf{h}_{i}(t)\right)+\mathbf{r}_{\phi_{i}}\left(\mathbf{q}_{i}(t), \dot{\mathbf{q}}_{i}(t), \boldsymbol{\tau}_{i}(t), \mathbf{h}_{i}(t)\right) \\
& =\mathbf{f}_{i}\left(\mathbf{q}_{i}(t), \dot{\mathbf{q}}_{i}(t), \boldsymbol{\tau}_{i}(t), \mathbf{h}_{i}(t)\right)+\mathbf{r}_{\phi_{i}}(t+\Delta t)
\end{aligned}
$$

na qual $\mathbf{r}_{\phi i}($.$) é um vetor função não-linear representando os efeitos dinâmicos da falha \phi$ sobre as velocidades do manipulador $i$.

Desta forma, os dados de entrada do MLP $i$ são as posições, velocidades e forças generalizadas nas juntas e as forças medidas no efetuador do manipulador $i$ no instante $t$. As saídas do MLP $i$ são as estimativas das velocidades medidas no instante $(t+\Delta t)$. Assim, as entradas e as saídas desejadas do MLP $i$ na iteração $n$ são respectivamente:

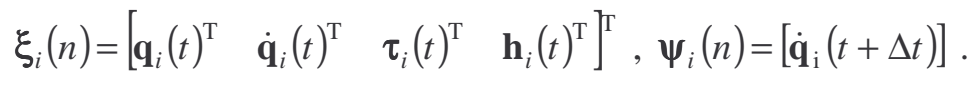

É importante observar que o período amostral está implícito no mapeamento realizado pelo MLP $i$. O vetor de resíduos é formado pelos resíduos individuais gerados pelos $m$ MLP's:

$$
\begin{aligned}
\hat{\mathbf{r}}(t+\Delta t) & =\left[\begin{array}{c}
\hat{\mathbf{r}}_{1}(t+\Delta t) \\
\hat{\mathbf{r}}_{2}(t+\Delta t) \\
\vdots \\
\hat{\mathbf{r}}_{m}(t+\Delta t)
\end{array}\right]=\left[\begin{array}{c}
\dot{\mathbf{q}}_{1}(t+\Delta t)-\hat{\boldsymbol{\Psi}}_{1}(t+\Delta t) \\
\dot{\mathbf{q}}_{2}(t+\Delta t)-\hat{\boldsymbol{\psi}}_{2}(t+\Delta t) \\
\vdots \\
\dot{\mathbf{q}}_{m}(t+\Delta t)-\hat{\boldsymbol{\Psi}}_{m}(t+\Delta t)
\end{array}\right]=\dot{\mathbf{q}}(t+\Delta t)-\hat{\boldsymbol{\psi}}(t+\Delta t) \\
& =\mathbf{r}(t+\Delta t)+\mathbf{e}(t+\Delta t)
\end{aligned}
$$

na qual $\hat{\boldsymbol{\psi}}_{i}(t+\Delta t)$ é o vetor de saídas do MLP $i, \mathbf{r}()=.\left[\mathbf{r}_{\phi 1}(.)^{\mathrm{T}} \mathbf{r}_{\phi 2}(.)^{\mathrm{T}} \ldots \mathbf{r}_{\phi m}(.)^{\mathrm{T}}\right]^{\mathrm{T}}$ se ocorre uma falha $\phi, \mathbf{r}()=.\mathbf{0}$ se não existem falhas e, e(.) é o vetor função dos erros de mapeamento dos MLP's. Quando não existem falhas no sistema cooperativo, o vetor de resíduos varia exclusivamente devido aos erros de mapeamento dos MLP's. Por isso, é interessante que os erros de mapeamento sejam baixos. Se os erros de mapeamento dos MLP's forem altos, o vetor de falhas poderá ser encoberto, ocasionando erros na DIF. Como os erros de treinamento e os ruídos de medida são inevitáveis em sistemas reais, utiliza-se a rede RBF para classificar o vetor de resíduos. O esquema de geração dos resíduos do manipulador $i$ pode ser visto na Figura 4.3.

É importante observar que o mapeamento realizado pelo MLP é estático, o que somente é possível porque os estados são considerados mensuráveis, o período amostral é pequeno e os sinais de controle são usados como entradas do MLP. De fato, este procedimento só é válido se os estados são mensuráveis. Se os estados não são mensuráveis, 
mas as saídas medidas têm informação suficiente sobre os estados (isto é, o sistema é observável), RNA's com valores passados das saídas medidas e das entradas atuais [SORSA \& KOIVO, 1993] ou RNA's dinâmicas [MARCU \& MIREA, 1997], ou seja, RNA's estáticas com elementos dinâmicos, devem ser empregadas.

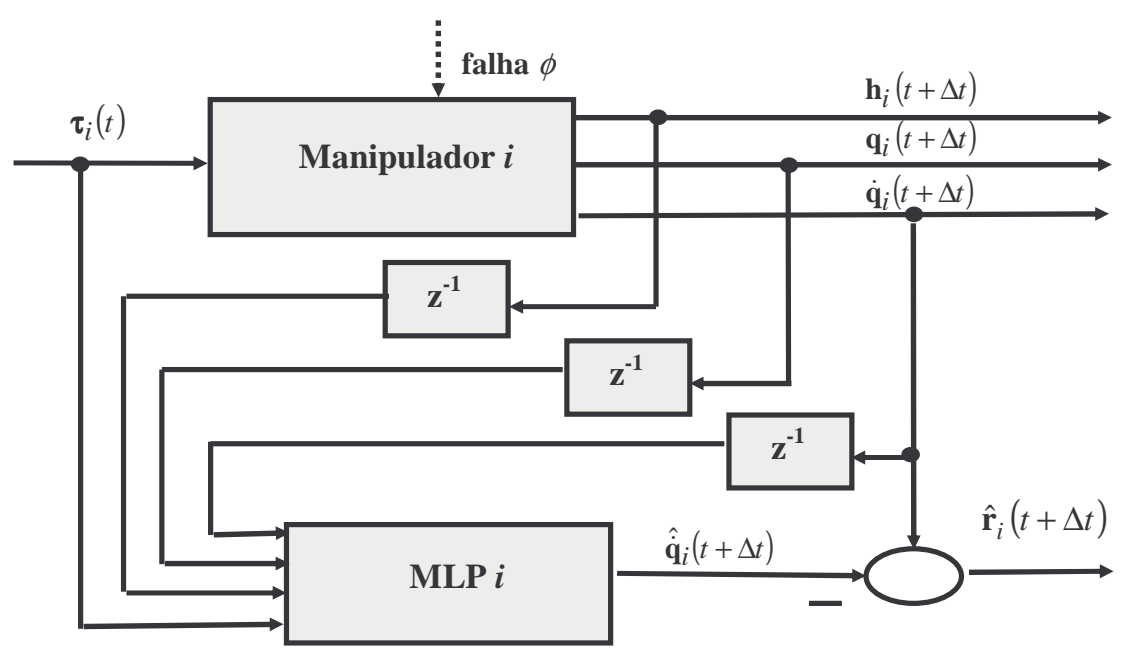

FIGURA 4.3. Geração dos resíduos.

\subsubsection{Análise de Resíduos}

A análise de resíduos é feita através da rede RBF. Como o vetor de resíduos das falhas do tipo junta com balanço livre e do tipo junta bloqueada podem ocupar a mesma região no espaço de entradas da rede RBF, um vetor de entradas auxiliar $\zeta(\cdot)$ que fornece informações sobre as velocidades das juntas é utilizado. Seu uso é motivado pelo fato de que, quando ocorrem falhas do tipo junta bloqueada, a velocidade da junta afetada é zero. Como existem ruídos nas medidas de velocidade das juntas, a componente $i=1, \ldots, n$, na qual $n$ é a soma do número de juntas em todos os robôs, do vetor $\zeta(\cdot)$ é definida como

$\zeta_{i}(t)=\left\{\begin{array}{c}1 \text { se }\left|\dot{q}_{i}(t)\right|>\delta_{i} \\ 0 \text { caso contrario }\end{array}\right.$

na qual $\delta_{i}$ é um threshold que pode ser escolhido como uma função da variância do ruído das medidas de velocidade nas juntas. A arquitetura do sistema de análise dos resíduos pode ser vista na Figura 4.4. A saída da rede RBF apresenta um vetor $q$-dimensional, na qual as $q-1$ primeiras saídas indicam as ocorrências das $q-1$ falhas e a última saída indica a operação 
sem falhas. A rede RBF deve separar o espaço de entradas em $q$ regiões associadas à operação normal do robô manipulador ou às diferentes falhas.

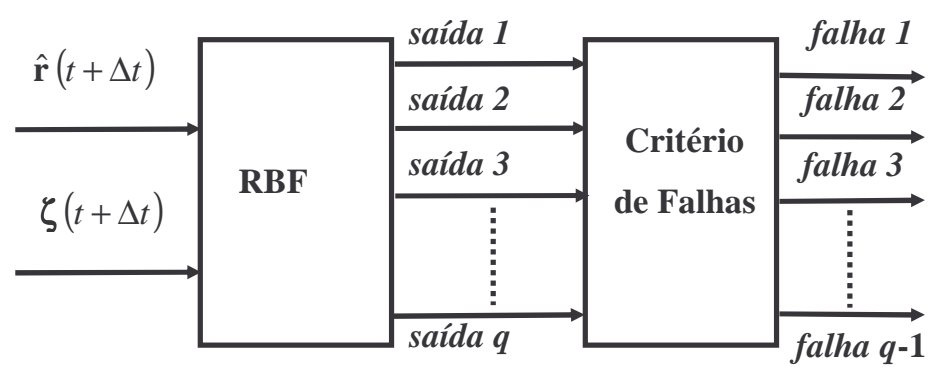

FIGURA 4.4. Análise dos resíduos.

A rede RBF é treinada para que suas saídas apresentem sinal igual a 1, caso o padrão de entrada esteja na classe relacionada à respectiva saída, e 0, caso contrário. Assim, se ocorre uma falha 2 (por exemplo, falha do tipo junta 2 do manipulador 1 com balanço livre) durante o treinamento, o neurônio de saída 2 é relacionado à ativação igual a 1 e os outros neurônios às ativações iguais a 0 . Durante a operação, como o padrão analisado geralmente é diferente do padrão treinado, ou seja, eles não são iguais mas sim próximos, os sinais devem ser próximos de 1 ou de 0 . Assim, para que a falha seja detectada, um critério de falhas deve ser adotado. Uma alternativa é a verificação do máximo valor entre as $q$ saídas para o padrão apresentado. Por exemplo, se $q=5$ (quatro falhas e operação normal) e as saídas são respectivamente, 0,$01 ; 0,10 ; 0,95 ; 0.02$ e; 0.05 , a falha 3 é anunciada.

Aqui, para evitar que padrões classificados erroneamente causem alarmes falsos, o neurônio de saída correspondente à falha deve ter uma sequência com um número prédefinido de amostras de ativações maiores que as ativações das outras saídas para que a falha seja anunciada. Assim, se é considerado que o número de amostras para a detecção deve ser 3, então a falha 1 é detectada quando o neurônio de saída 1 apresentar 3 ativações consecutivas maiores que as ativações dos outros neurônios de saída. Se o número de amostras escolhido não é alto, a sensibilidade do Sistema DIF não é significativamente afetada já que, em geral, o período amostral é baixo. 


\subsection{DETECÇÃO E ISOLAÇÃO DE FALHAS DO TIPO INFORMAÇÃO INCORRETA DE POSIÇÃO OU VELOCIDADE DAS JUNTAS}

Falhas do tipo informação incorreta de posição ou velocidade nas juntas dos manipuladores são detectadas através das equações cinemáticas do sistema cooperativo e suas restrições (Capítulo 3). As restrições impõem uma cadeia cinemática fechada, ou seja, é possível calcular as posições e velocidades do objeto através de mais de um modo. Primeiro, o problema de detecção de falhas do tipo informação incorreta de posição das juntas é apresentado (Seção 4.5.1). Em seguida, a detecção de falhas do tipo informação incorreta de velocidade das juntas é apresentada (Seção 4.5.2).

\subsubsection{DIF de Falhas do Tipo Informação Incorreta de Posição das Juntas}

Dois casos devem aqui ser considerados: quando $m>2$, isto é, o número de manipuladores no sistema cooperativo é maior que 2 , e quando $m=2$, isto é, existem dois manipuladores no sistema cooperativo.

\subsubsection{Informacão Incorreta de Posicão das Juntas Quando $m>2$ :}

Como a posição do objeto $\mathbf{x}_{\mathbf{0}}$ pode ser calculada através das posições das juntas de qualquer manipulador (eq. 3.10), é possível identificar o manipulador com a informação incorreta de posição da junta. Este robô, chamado aqui de manipulador $f$, fornece a estimativa incorreta de $\mathbf{x}_{\mathbf{0}}$, ou seja, uma que é diferente das estimativas fornecidas pelos outros $m-1$ manipuladores. Desta forma, a falha é detectada no manipulador $f$ se

$\left\|\hat{\mathbf{x}}_{\mathbf{o} f}\left(\boldsymbol{\theta}_{f}\right)-\hat{\mathbf{x}}_{\mathbf{o} i}\left(\boldsymbol{\theta}_{i}\right)\right\|>\gamma_{p 1} \quad$ para todo $i=1, \ldots, m$ e $i \neq f$

na qual $\hat{\mathbf{x}}_{\mathbf{o} i}\left(\boldsymbol{\theta}_{i}\right)$ é a estimativa de $\mathbf{x}_{\mathbf{0}}$ usando-se as medidas de posição das juntas $\boldsymbol{\theta}_{i}$ do manipulador $i$, e $\gamma_{p l}$ é um threshold usado para evitar que falsos alarmes apareçam devido à presença de ruídos nas medidas de posição das juntas. O threshold $\gamma_{p 1}$ pode ser escolhido como uma função da variância do ruído de medida da posição das juntas. Observe que $\boldsymbol{\theta}_{i}$ é utilizado aqui ao invés de $\mathbf{q}_{i}$. Enquanto que $\mathbf{q}_{i}$ representa os valores reais das posições das juntas, $\theta_{i}$ representa os valores fornecidos pelos sensores.

O próximo passo é a estimar a posição de cada junta $j=1, \ldots, n_{f}$ no manipulador $f$ através de 
$\hat{q}_{f j}=\chi_{p j}\left(\boldsymbol{\theta}_{f}, \hat{\mathbf{x}}_{\mathbf{o}}\right)$

na qual $\hat{q}_{f j}$ é a estimativa da posição da junta $j$ no manipulador $f, \chi_{p j}(\cdot, \cdot)$ é a função cinemática empregada para estimar a posição da junta $j$, e

$\hat{\mathbf{x}}_{\mathbf{o}}=\frac{1}{m-1} \sum_{i=1, i \neq f}^{m} \hat{\mathbf{x}}_{\mathbf{o}_{i}}\left(\boldsymbol{\theta}_{i}\right)$

Calculando novamente a estimativa do vetor $\mathbf{x}_{\mathbf{0}}$ para o manipulador $f$ com a estimativa $\hat{q}_{f j}$, a falha na junta $j$ do manipulador $f$ é detectada quando

$\left\|\hat{\mathbf{x}}_{\mathbf{o}}-\hat{\mathbf{x}}_{\mathbf{o} f}\left(\boldsymbol{\theta}_{f}, \hat{q}_{f j}\right)\right\|<\gamma_{p 2}$

na qual $\hat{\mathbf{x}}_{\mathbf{o} f}\left(\boldsymbol{\theta}_{f}, \hat{q}_{f j}\right)$ é o vetor das posições do objeto estimado para o manipulador $f$ substituindo a medida de posição da junta $j$ por sua estimativa $\hat{q}_{f j}$ e usando as posições medidas das outras juntas, e $\gamma_{p 2}$ é um threshold usado para evitar que falsos alarmes apareçam devido à presença de ruídos nas medidas de posição das juntas. Da mesma forma que $\gamma_{p 1}$, o threshold $\gamma_{p 2}$ pode ser escolhido como uma função da variância do ruído de medida da posição das juntas.

Para cada instante amostral, o procedimento para detectar e isolar falhas do tipo junta com informação incorreta de posição para $m>2$ pode ser resumido da seguinte forma:

(i) Calcule a estimativa da posição do objeto $\hat{\mathbf{x}}_{\mathbf{o} i}\left(\boldsymbol{\theta}_{i}\right)$ para todos os manipuladores;

(ii) Teste a eq. (4.29) para todos os manipuladores $(f=1, \ldots, m)$. Se o teste não é satisfeito para nenhum manipulador, siga para o passo (v). Caso contrário, defina o manipulador $f$ como aquele que satisfaz o teste e vá para o passo seguinte;

(iii) Calcule a estimativa da posição de todas as juntas do manipulador $f$ através da eq. (4.30);

(iv) Teste a eq. (4.32) para todas as estimativas produzidas no passo (iii). Se o teste é satisfeito para a junta $j$, anuncie a falha nesta junta;

(v) O procedimento é finalizado para o instante amostral corrente. 


\subsubsection{Informacão Incorreta de Posicão das Juntas Quando $m=2$ :}

No caso em que $m=2$, o manipulador com a falha não pode ser identificado somente pela análise das estimativas de $\mathbf{x}_{\mathbf{0}}$ em cada manipulador. Contudo, a falha pode ser detectada pela comparação das duas estimativas de $\mathbf{x}_{\mathbf{0}}$. A falha é detectada quando

$\left\|\hat{\mathbf{x}}_{\mathbf{0} 1}\left(\boldsymbol{\theta}_{1}\right)-\hat{\mathbf{x}}_{\mathbf{0} 2}\left(\boldsymbol{\theta}_{2}\right)\right\|>\gamma_{p 1}$

Como não é possível identificar em qual manipulador ocorreu a falha, a estimativa das posições das juntas é feita para todas as juntas dos dois manipuladores. O valor da estimativa de $\mathbf{x}_{\mathbf{0}}$ obtido para cada manipulador é utilizado para estimar as posições das juntas do outro manipulador. Para o robô 1 , a posição da junta $j=1, \ldots, n_{1}$ é estimada por

$\hat{q}_{1 j}=\chi_{p j}\left(\boldsymbol{\theta}_{1}, \hat{\mathbf{x}}_{\mathbf{0} 2}\left(\boldsymbol{\theta}_{2}\right)\right)$

e para o robô 2 , a posição da junta $j=1, \ldots, n_{2}$ é estimada por

$\hat{q}_{2 j}=\chi_{p j}\left(\boldsymbol{\theta}_{2}, \hat{\mathbf{x}}_{\mathbf{0} 1}\left(\boldsymbol{\theta}_{1}\right)\right)$

Calculando novamente a estimativa de $\mathbf{x}_{\mathbf{0}}$ para cada nova estimativa da posição da junta de cada manipulador, a falha na junta $j$ do manipulador 1 é detectada quando

$\left\|\hat{\mathbf{x}}_{\mathbf{0} 1}\left(\boldsymbol{\theta}_{1}, \hat{q}_{1 j}\right)-\hat{\mathbf{x}}_{\mathbf{0} 2}\left(\boldsymbol{\theta}_{2}\right)\right\|<\gamma_{p 2}$

na qual $\hat{\mathbf{x}}_{\mathbf{0} 1}\left(\boldsymbol{\theta}_{1}, \hat{q}_{1 j}\right)$ é a estimativa de $\mathbf{x}_{\mathbf{0}}$ obtida para o manipulador 1 , substituindo-se a posição medida da junta $j$ por sua estimativa $\hat{q}_{1 j}$ e utilizando as posições medidas das outras juntas. Para o manipulador 2, a falha na junta $j$ é obtida quando

$\| \hat{\mathbf{x}}_{\mathbf{0} 1}\left(\boldsymbol{\theta}_{1}\right)-\hat{\mathbf{x}}_{\mathbf{o} 2}\left(\boldsymbol{\theta}_{2}, \hat{q}_{2 j}\right) \mid<\gamma_{p 2}$

na qual $\hat{\mathbf{x}}_{\mathbf{0} 2}\left(\boldsymbol{\theta}_{2}, \hat{q}_{2 j}\right)$ é a estimativa de $\mathbf{x}_{\mathbf{0}}$ obtida para o manipulador 2, substituindo-se a posição medida da junta $j$ por sua estimativa $\hat{q}_{2 j}$ e utilizando as posições medidas das outras juntas.

Para cada instante amostral, o procedimento para detectar e isolar falhas do tipo junta com informação incorreta de posição para $m=2$ pode ser resumido da seguinte forma:

(i) Calcule a estimativa da posição do objeto $\hat{\mathbf{x}}_{\mathbf{o} i}\left(\boldsymbol{\theta}_{i}\right)$ para todos os manipuladores; 
(ii) Teste a eq. (4.33). Se o teste não é satisfeito, siga para o passo (v). Caso contrário, vá para o passo seguinte;

(iii) Calcule a estimativa da posição de todas as juntas dos dois manipuladores através das eqs. (4.34) e (4.35);

(iv) Teste as eqs. (4.36) e (4.37) para todas as estimativas produzidas no passo (iii). Se, para o manipulador $i=1,2$, o teste é satisfeito para a junta $j$, anuncie a falha nesta junta;

(v) O procedimento é finalizado para o instante amostral corrente.

\subsubsection{DIF de Falhas do Tipo Informação Incorreta de Velocidade das Juntas}

Do mesmo modo que na seção anterior, dois casos devem aqui ser considerados: quando $m>2$, isto é, o número de manipuladores no sistema cooperativo é maior que 2 , e quando $m=2$, isto é, existem dois manipuladores no sistema cooperativo.

\subsubsection{Informacão Incorreta de Velocidade das Juntas Quando $m>2$ :}

Utilizando a eq. (3.12), é possível identificar o manipulador $f$ com a informação incorreta de velocidade da junta. A falha é detectada no manipulador $f$ se

$\left\|\hat{\mathbf{v}}_{\mathbf{o} f}\left(\dot{\boldsymbol{\theta}}_{f}, \boldsymbol{\theta}_{f}\right)-\hat{\mathbf{v}}_{\mathbf{o} i}\left(\dot{\boldsymbol{\theta}}_{i}, \boldsymbol{\theta}_{i}\right)\right\|>\gamma_{v 1} \quad$ para todo $i=1, \ldots, m$ e $i \neq f$

na qual $\hat{\mathbf{v}}_{\mathbf{o} i}\left(\dot{\boldsymbol{\theta}}_{i}, \boldsymbol{\theta}_{i}\right)$ é a estimativa de $\mathbf{v}_{\mathbf{0}}$ usando-se as medidas de velocidade das juntas $\dot{\boldsymbol{\theta}}_{i} \mathrm{e}$ de posição das juntas $\boldsymbol{\theta}_{i}$ do manipulador $i$ (eq. 3.12), e $\gamma_{v l}$ é um threshold usado para evitar que falsos alarmes apareçam devido à presença de ruídos nas medidas de velocidade das juntas. O threshold $\gamma_{v l}$ pode ser escolhido como uma função da variância do ruído de medida da velocidade das juntas.

O próximo passo é a estimar a velocidade de cada junta $j=1, \ldots, n_{f}$ no manipulador $f$ através de

$\hat{\dot{q}}_{f j}=\chi_{v j}\left(\dot{\theta}_{f}, \boldsymbol{\theta}_{f}, \hat{\mathbf{v}}_{\mathbf{o}}\right)$

na qual $\hat{\dot{q}}_{f j}$ é a estimativa da velocidade da junta $j$ no manipulador $f, \chi_{v j}(\cdot, \cdot$,$) é a função$ cinemática empregada para estimar a velocidade da junta $j$, e 
$\hat{\mathbf{v}}_{\mathbf{o}}=\frac{1}{m-1} \sum_{i=1, i \neq f}^{m} \hat{\mathbf{v}}_{\mathbf{o} i}\left(\dot{\boldsymbol{\theta}}_{i}, \boldsymbol{\theta}_{i}\right)=\frac{1}{m-1} \sum_{i=1, i \neq f}^{m} \mathbf{D}_{i}\left(\boldsymbol{\theta}_{i}\right) \dot{\boldsymbol{\theta}}_{i}$

Calculando novamente a estimativa do vetor $\mathbf{v}_{\mathbf{0}}$ para o manipulador $f$ com a estimativa $\hat{\dot{q}}_{f j}$, a falha na junta $j$ do manipulador $f$ é detectada quando

$\left\|\hat{\mathbf{v}}_{\mathbf{o}}-\hat{\mathbf{v}}_{\mathbf{o} f}\left(\dot{\boldsymbol{\theta}}_{f}, \boldsymbol{\theta}_{f}, \hat{\dot{q}}_{f j}\right)\right\|<\gamma_{v 2}$

na qual $\hat{\mathbf{v}}_{\mathbf{o} f}\left(\dot{\boldsymbol{\theta}}_{f}, \boldsymbol{\theta}_{f}, \hat{\dot{q}}_{f j}\right)$ é o vetor das velocidades do objeto estimado para o manipulador $f$ substituindo a medida de velocidade da junta $j$ por sua estimativa $\hat{\dot{q}}_{f j}$ e usando as velocidades medidas das outras juntas, e $\gamma_{v 2}$ é um threshold usado para evitar que falsos alarmes apareçam devido à presença de ruídos nas medidas de velocidade das juntas. Da mesma forma que $\gamma_{v 1}$, o threshold $\gamma_{v 2}$ pode ser escolhido como uma função da variância do ruído de medida da velocidade das juntas.

Para cada instante amostral, o procedimento para detectar e isolar falhas do tipo junta com informação incorreta de posição para $m>2$ pode ser resumido da seguinte forma:

(i) Calcule a estimativa da velocidade do objeto $\hat{\mathbf{v}}_{\mathbf{o} i}\left(\dot{\boldsymbol{\theta}}_{i}, \boldsymbol{\theta}_{i}\right)$ para todos os manipuladores;

(ii) Teste a eq. (4.38) para todos os manipuladores $(f=1, \ldots, m)$. Se o teste não é satisfeito para nenhum manipulador, siga para o passo (v). Caso contrário, defina o manipulador $f$ como aquele que satisfaz o teste e vá para o passo seguinte;

(iii) Calcule a estimativa da velocidade de todas as juntas do manipulador $f$ através da eq. (4.39);

(iv) Teste a eq. (4.41) para todas as estimativas produzidas no passo (iii). Se o teste é satisfeito para a junta $j$, anuncie a falha nesta junta;

(v) O procedimento é finalizado para o instante amostral corrente.

\subsubsection{Informação Incorreta de Velocidade das Juntas Quando $m=2$ :}

No caso em que $m=2$, o manipulador com a falha não pode ser identificado somente pela análise das estimativas de $\mathbf{v}_{\mathbf{0}}$ em cada manipulador. Contudo, a falha pode ser detectada pela comparação das duas estimativas de $\mathbf{v}_{\mathbf{0}}$. A falha é detectada quando

$$
\left\|\hat{\mathbf{v}}_{\mathbf{0} 1}\left(\dot{\boldsymbol{\theta}}_{1}, \boldsymbol{\theta}_{1}\right)-\hat{\mathbf{v}}_{\mathbf{0} 2}\left(\dot{\boldsymbol{\theta}}_{2}, \boldsymbol{\theta}_{2}\right)\right\|>\gamma_{v 1}
$$


Como não é possível identificar em qual manipulador ocorreu a falha, a estimativa das velocidades das juntas é feita para todas as juntas dos dois manipuladores. O valor da estimativa de $\mathbf{v}_{\mathbf{0}}$ obtida para cada manipulador é utilizado para estimar as velocidades das juntas do outro manipulador. Para o robô 1 , a velocidade da junta $j=1, \ldots, n_{1}$ é estimada por

$\hat{\dot{q}}_{1 j}=\chi_{v j}\left(\dot{\boldsymbol{\theta}}_{1}, \boldsymbol{\theta}_{1}, \hat{\mathbf{v}}_{\mathbf{0} 2}\left(\dot{\boldsymbol{\theta}}_{2}, \boldsymbol{\theta}_{2}\right)\right)$

e para o robô 2 , a velocidade da junta $j=1, \ldots, n_{2}$ é estimada por

$\hat{\dot{q}}_{2 j}=\chi_{v j}\left(\dot{\boldsymbol{\theta}}_{2}, \boldsymbol{\theta}_{2}, \hat{\mathbf{v}}_{\mathbf{0} 1}\left(\dot{\boldsymbol{\theta}}_{1}, \boldsymbol{\theta}_{1}\right)\right)$

Calculando novamente a estimativa de $\mathbf{v}_{\mathbf{0}}$ para cada nova estimativa da velocidade da junta de cada manipulador, a falha na junta $j$ do manipulador 1 é detectada quando

$\left\|\hat{\mathbf{v}}_{\mathbf{0} 1}\left(\dot{\boldsymbol{\theta}}_{1}, \boldsymbol{\theta}_{1}, \hat{\dot{q}}_{1 j}\right)-\hat{\mathbf{v}}_{\mathbf{0} 2}\left(\dot{\boldsymbol{\theta}}_{2}, \boldsymbol{\theta}_{2}\right)\right\|<\gamma_{v 2}$

na qual $\hat{\mathbf{v}}_{\mathbf{0} 1}\left(\dot{\boldsymbol{\theta}}_{1}, \boldsymbol{\theta}_{1}, \hat{\dot{q}}_{1 j}\right)$ é a estimativa de $\mathbf{v}_{\mathbf{0}}$ obtida para o manipulador 1 , substituindo-se a velocidade medida da junta $j$ por sua estimativa $\hat{\dot{q}}_{1 j}$ e utilizando as velocidades medidas das outras juntas. Para o manipulador 2, a falha na junta $j$ é obtida quando

$\left\|\hat{\mathbf{v}}_{\mathbf{0} 1}\left(\dot{\boldsymbol{\theta}}_{1}, \boldsymbol{\theta}_{1}\right)-\hat{\mathbf{v}}_{\mathbf{0} 2}\left(\dot{\boldsymbol{\theta}}_{2}, \boldsymbol{\theta}_{2}, \hat{\dot{q}}_{2 j}\right)\right\|<\gamma_{v 2}$

na qual $\hat{\mathbf{v}}_{\mathbf{0} 2}\left(\dot{\boldsymbol{\theta}}_{2}, \boldsymbol{\theta}_{2}, \hat{\dot{q}}_{2 j}\right)$ é a estimativa de $\mathbf{v}_{\mathbf{o}}$ obtida para o manipulador 2 , substituindo-se a velocidade medida da junta $j$ por sua estimativa $\hat{\dot{q}}_{2 j}$ e utilizando as velocidades medidas das outras juntas.

Para cada instante amostral, o procedimento para detectar e isolar falhas do tipo junta com informação incorreta de velocidade para $m=2$ pode ser resumido da seguinte forma:

(i) Calcule a estimativa da velocidade do objeto $\hat{\mathbf{v}}_{\mathbf{o} i}\left(\dot{\boldsymbol{\theta}}_{i}, \boldsymbol{\theta}_{i}\right)$ para todos os manipuladores;

(ii) Teste a eq. (4.42). Se o teste não é satisfeito, siga para o passo (v). Caso contrário, vá para o passo seguinte;

(iii) Calcule a estimativa da velocidade de todas as juntas dos dois manipuladores através das eqs. (4.43) e (4.44); 
(iv) Teste as eqs. (4.45) e (4.46) para todas as estimativas produzidas no passo (iii). Se, para o manipulador $i=1,2$, o teste é satisfeito para a junta $j$, anuncie a falha nesta junta;

(v) O procedimento é finalizado para o instante amostral corrente.

\subsection{FLUXOGRAMA DO SISTEMA DIF}

O fluxograma do Sistema DIF completo é mostrado na Figura 4.5. As falhas do tipo informação incorreta de posições das juntas devem ser detectadas antes pois as posições das juntas são utilizadas para estimar as velocidades durante a detecção das falhas do tipo informação incorreta de velocidade (eqs. 4.38-4.46). Se o contrário fosse feito, as falhas do tipo informação incorreta de posição e velocidade das juntas seriam confundidas. Este também é o motivo de se detectar as falhas do tipo junta com balanço livre ou bloqueada por último; lembre-se que os MLP's utilizados na detecção destas falhas utilizam os dados de posição e velocidade das juntas (eq. 4.26). 


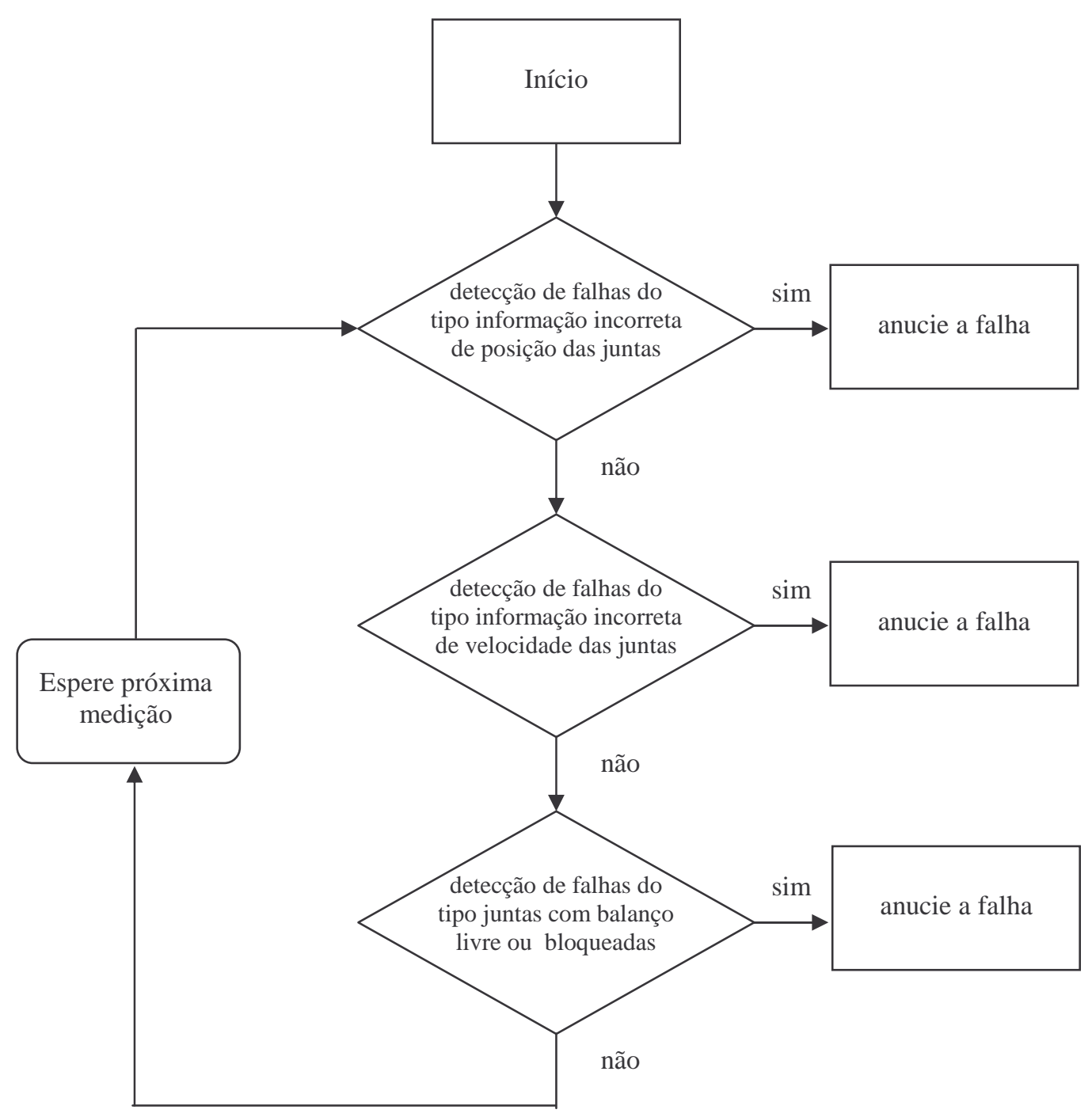

FIGURA 4.5. Fluxograma do Sistema DIF. 


\section{Capítulo 5.}

\section{CONTROLE E RECONFIGURAÇÃO DO SISTEMA COOPERATIVO COM FALHAS}


Feita a detecção e isolação da falha (Capítulo 4), pode-se reconfigurar o sistema de controle para que o sistema cooperativo continue trabalhando mesmo após a falha. O problema do controle do sistema com falhas é estudado neste capítulo. Controladores para robôs manipuladores cooperativos com falhas do tipo junta com balanço livre (ou junta passiva) e junta bloqueada são propostos respectivamente nas Seções 5.2 e 5.3. Para as falhas do tipo informação incorreta de posição ou velocidade das juntas, as medidas afetadas são substituídas pelas estimativas produzidas pelo Sistema DIF (Seção 5.4). Neste caso, o controlador utilizado para o sistema cooperativo sem falhas continua sendo utilizado. $\mathrm{Na}$ Seção 5.5, alguns comentários sobre a reconfiguração são apresentados juntamente com um método para cálculo da capacidade dinâmica de carga em manipuladores cooperativos com juntas passivas.

Vale salientar que os esquemas para controle após falhas propostos aqui podem ser aplicados nos casos em que juntas com balanço livre, juntas bloqueadas ou informações incorretas de posições e velocidades nas juntas não são vistas como falhas e, sim, como características inerentes ao sistema. Juntas com balanço livre, ou passivas, servem como exemplo de tal conceito. Quando o número de gdl's do manipulador é muito grande, como em robôs tipo cobra, ou em que necessita-se economizar energia, peso e/ou tamanho, como em robôs espaciais, pode-se optar por sistemas com juntas passivas por estes terem menos atuadores.

A seguir, na Seção 5.1, uma revisão dos sistemas de controle para robôs manipuladores com falhas é feita.

\subsection{INTRODUÇÃO: CONTROLE DE ROBÔS MANIPULADORES COM FALHAS}

Sistemas de controle que garantam a execução das tarefas mesmo após a ocorrência de falhas são geralmente indispensáveis em robôs utilizados em ambientes distantes, inóspitos e/ou não-estruturados, como foi visto no Capítulo 1.

A maioria dos trabalhos em tolerância a falhas em robôs tem se concentrado naqueles algoritmos que ativam a parte duplicada quando uma falha é detectada [VISINSKY et al., 1994]. Por exemplo, se um motor falha, o sistema detecta e isola tal falha, desliga o componente faltoso e ativa o motor redundante. Este procedimento faz uso da redundância física, já comentada nos capítulos anteriores.

Redundância física pode proteger o sistema contra falhas nos componentes do sistema de controle, como controlador, atuadores e sensores, mas não nos componentes da 
planta. Além disso, em robótica, o uso de redundância física é quase sempre limitado pelos fatores custo, tamanho e potência [VISINSKY et al., 1994].

Como alternativas à redundância física, redundância cinemática e redundância funcional têm sido utilizadas com o intuito de prover tolerância a falhas ao robô. No primeiro caso, o robô é provido com um número maior de gdl's do que o requerido para a realização da sua tarefa. Por exemplo, um robô com sete juntas pode ser utilizado para manipular uma carga em um espaço tridimensional livre de obstáculos, no qual somente seis gdl's são necessários. Em caso de falha em uma das juntas, esta é bloqueada e o manipulador ainda assim tem condições de concluir sua tarefa [LEWIS \& MACIEJEWSKI, 1997], [PAREDIS \& KHOSLA, 1996a]. Robôs cinematicamente redundantes podem ainda ser empregados para evitar as áreas do espaço das juntas e as configurações do robô em que as falhas do tipo junta com balanço livre têm consequências mais desastrosas [ENGLISH \& MACIEJEWSKI, 1998], [PAREDIS \& KHOSLA, 1996b].

Já a redundância funcional utiliza dados funcionais equivalentes para substituir as medidas que foram afetadas por falhas. Se um sensor de posição falha, por exemplo, os dados de posição daquela junta podem ser substituídos por valores obtidos pela integração numérica das velocidades medidas [VISINSKY et al., 1994].

Redundância funcional pode ser aplicada somente para certos tipos de falhas, como falhas nos sensores. Já redundância cinemática ou física requer certas características construtivas especiais. Tais características muitas vezes não podem ser alcançadas devido aos custos ou às limitações impostas pela tarefa.

Para o caso de falhas que afetem os atuadores, como falhas do tipo juntas com balanço livre, é possível reconfigurar as leis de controle para tratar do sistema após a DIF [BERGERMAN et al., 2000], [TERRA et al., 2001]. Quando uma falha do tipo junta com balanço livre ocorre, esta se torna passiva e o manipulador torna-se um sistema subatuado já que o número de atuadores em funcionamento é menor que o número de juntas ativas (com atuação). O manipulador subatuado em cadeia aberta está sujeito a restrições nas acelerações que, geralmente, não são integráveis. Portanto, o manipulador subatuado é, em geral, nãoholonômico com restrições de segunda ordem não-integráveis [ORIOLO \& NAKAMURA, 1991]. Este sistema não pode ser estabilizado através de leis de controle por realimentação baseadas no trabalho de Brockett ([BROCKETT, 1983], [LI \& CANNY, 1992] apud [LIU et al., 1999]). Portanto, a pesquisa em manipuladores livres subatuados tem se concentrado em sistemas utilizando freios ou chaveamento entre leis de controle. Se uma falha que impossibilite o uso do atuador de uma junta qualquer do manipulador foi detectada e isolada, 
o sistema de controle do manipulador com freios pode ser reconfigurado para, através das juntas que ainda têm atuação, controlar a junta não-atuada [BERGERMAN, 1996].

A pesquisa em manipuladores subatuados iniciou-se com o estudo e controle de um manipulador de dois elos equipado com um motor e um freio [ARAI \& TACHI, 1991]. Em seguida, PAPADOPOULOS \& DUBOWSKY (1991) e MUKHERJEE \& CHEN (1993) estudaram o problema do controle de manipuladores montados em satélites espaciais e ORIOLO \& NAKAMURA (1991) estudaram o problema dos manipuladores sem restrições não-holonômicas. A modelagem e análise de manipuladores subatuados também foram estudadas [YU et al., 1995]. Em BERGERMAN (1996), os problemas de modelagem, controlabilidade, controle e planejamento de trajetórias em manipuladores subatuados foram estudados. Todos estes trabalhos têm em comum o fato de que as juntas não-atuadas (passivas) são equipadas com freios. Recentemente começaram a surgir os primeiros trabalhos em controle de manipuladores subatuados sem freios [ARAI, 1997], [LYNCH et al., 1997], [CHUNG et al., 1995].

De acordo com o conhecimento do autor, somente LIU, XU \& BERGERMAN [LIU \& XU, 1997], [BERGERMAN et al., 1997], [LIU et al., 1999] estudaram o problema do controle de robôs cooperativos com juntas passivas.

Dois controladores foram propostos em [LIU et al., 1999] para o caso em que o número de juntas ativas $\left(n_{a}\right)$ é igual ou maior que o número de coordenadas de posição $(k)$ em sistemas cooperativos formados por 2 manipuladores. As juntas ativas são aquelas que possuem atuadores ativos. Os dois controladores propostos em [LIU et al., 1999] são comentados a seguir.

O primeiro controlador foi utilizado para o controle de posição do tipo set-point, ou seja, a carga deve mover-se entre dois pontos com velocidade desejada igual a zero [LIU et al., 1999]. Este controlador é baseado na lei de controle Proporcional-Derivativa (PD) clássica com compensação dos termos gravitacionais. Para isso, uma matriz Jacobiana $\mathbf{Q}(\mathbf{q})$, que relaciona as velocidades das juntas ativas e a velocidade do objeto para o caso em que $m=2$, é utilizada para projetar forças resultantes na carga no espaço das juntas ativas. Neste caso, nenhuma componente da força de esmagamento é controlada.

O segundo controlador foi utilizado para o problema do acompanhamento de trajetórias [LIU et al., 1999] e é derivado a partir do procedimento de redução desenvolvido em [MCCLAMROCH \& WANG, 1988]. Como somente $k$ juntas são usadas para o controle de movimento do objeto, os autores propõem a utilização das $n_{a}-k$ juntas restantes, quando existirem, para minimizar a diferença entre as forças de esmagamento e seus valores desejados. É interessante notar que o problema do controle de movimento não é 
desvinculado do controle de esmagamento em [LIU et al., 1999], já que este pode projetar forças fora do subespaço de esmagamento (ver Apêndice A). Como o controle de esmagamento influencia o controle de movimento, podem ocorrer instabilidade e erros inaceitáveis tanto para o controle de movimento quanto para o controle de esmagamento.

A seguir, são estudados os problemas de reconfiguração e controle do sistema cooperativo para quatro tipos de falhas: balanço livre em uma ou mais juntas (Seção 5.1), uma ou mais juntas bloqueadas (Seção 5.2) e informações incorretas de posições ou velocidades das juntas (Seção 5.3).

\subsection{CONTROLE DO SISTEMA COOPERATIVO COM JUNTAS PASSIVAS (OU COM FALHAS DO TIPO JUNTAS COM BALANÇO LIVRE)}

Considere que o sistema cooperativo com $m$ manipuladores conectados a um objeto rígido possua $n$ juntas. Considere agora que dessas $n$ juntas, $n_{p}$ sejam passivas e $n_{a}=n-n_{p}$ sejam ativas. Particionando a equação dinâmica dos manipuladores (eq. 3.5) para que apareçam as variáveis relacionadas às juntas ativas e passivas, tem-se a seguinte equação na qual os termos friccionais são ignorados e os termos de dependência entre parêntesis não são mostrados por simplicidade,

$$
\left[\begin{array}{ll}
\mathbf{M}_{\mathbf{a a}} & \mathbf{M}_{\mathbf{a p}} \\
\mathbf{M}_{\mathbf{p a}} & \mathbf{M}_{\mathbf{p p}}
\end{array}\right]\left[\begin{array}{c}
\ddot{\mathbf{q}}_{\mathbf{a}} \\
\ddot{\mathbf{q}}_{\mathbf{p}}
\end{array}\right]+\left[\begin{array}{cc}
\mathbf{C}_{\mathbf{a a}} & \mathbf{C}_{\mathrm{ap}} \\
\mathbf{C}_{\mathbf{p a}} & \mathbf{C}_{\mathbf{p p}}
\end{array}\right]\left[\begin{array}{c}
\dot{\mathbf{q}}_{\mathbf{a}} \\
\dot{\mathbf{q}}_{\mathbf{p}}
\end{array}\right]+\left[\begin{array}{l}
\mathbf{g}_{\mathbf{a}} \\
\mathbf{g}_{\mathbf{p}}
\end{array}\right]=\left[\begin{array}{c}
\boldsymbol{\tau}_{\mathbf{a}} \\
\mathbf{0}_{n_{p} x 1}
\end{array}\right]-\left[\begin{array}{c}
\mathbf{J}_{\mathbf{a}}{ }^{\mathrm{T}} \\
\mathbf{J}_{\mathbf{p}}{ }^{\mathrm{T}}
\end{array}\right] \mathbf{h} .
$$

na qual o índice $a$ refere-se às quantidades relacionadas às juntas ativas e o índice $p$ àquelas relacionadas às juntas passivas.

Apesar do manipulador subatuado livre ser um sistema dinâmico não-holonômico, os manipuladores cooperativos conectados rigidamente a um objeto não-deformável possuem a propriedade holonômica quando $n_{a} \geq k$. Portanto, é possível garantir convergência assintótica para uma posição do objeto desejada através de leis de controle desde que o número de juntas ativas do sistema não seja menor que o número de variáveis que devem ser controladas, ou seja, o número de coordenadas de movimento do objeto [LIU et al., 1999]. Assim, considere a seguinte suposição:

Suposiçãa 5.1: o número de juntas ativas do sistema é igual ou maior que o número de coordenadas de movimento do objeto, ou seja, $n_{a} \geq k$. 
Vale lembrar que, para o controle das posições do objeto, $k=6$ se o objeto move-se em um espaço tridimensional e $k=3$ se o objeto move-se em um plano (duas posições e uma orientação).

Neste momento, surge a seguinte questão: é possível controlar de modo satisfatório o sistema cooperativo com juntas passivas através dos controladores desenvolvidos para o sistema cooperativo totalmente atuado? Se $n_{a}>k$, existe redundância no posicionamento do objeto, ou seja, existem mais juntas ativas que o número de variáveis de posição e orientação do objeto. Assim, pode-se supor que o controle para o sistema totalmente atuado pode executar a tarefa em robôs cooperativos com juntas passivas. No entanto, vale lembrar que tal redundância geralmente é utilizada na minimização ou controle de certas variáveis, como forças aplicadas e força de esmagamento no objeto (ver Capítulo 3). Como, em geral, tais procedimentos custam a propriedade da redundância, a passividade das juntas pode gerar consequências catastróficas se o sistema de controle não for reconfigurado.

A seguir, é definida uma nova lei de controle para o sistema cooperativo com juntas passivas baseada no controlador desenvolvido por [WEN \& KREUTZ-DELGADO, 1992] para o sistema totalmente atuado. Tal lei de controle é interessante por tratar separadamente os controles de movimento e esmagamento do objeto. Mas, primeiro, uma nova matriz Jacobiana $\mathbf{Q}(\mathbf{q})$ será definida para um caso geral de $m>1$ manipuladores no sistema cooperativo.

\subsubsection{Matriz Jacobiana $Q(q)$ Para o Sistema Cooperativo Com Juntas Passivas}

Da eq. (3.12), tem-se para $m>1$ manipuladores que

$$
m \mathbf{v}_{\mathbf{o}}=\mathbf{D}_{1}\left(\mathbf{q}_{1}\right) \dot{\mathbf{q}}_{1}+\mathbf{D}_{2}\left(\mathbf{q}_{2}\right) \dot{\mathbf{q}}_{2}+\cdots+\mathbf{D}_{m}\left(\mathbf{q}_{m}\right) \dot{\mathbf{q}}_{m}
$$

na qual, por simplicidade, a dependência em $t$ não aparece.

Considerando a partição entre juntas passivas e ativas, tem-se que

$$
\begin{aligned}
m \mathbf{v}_{\mathbf{o}}= & \mathbf{D}_{\mathbf{a} 1}\left(\mathbf{q}_{1}\right) \dot{\mathbf{q}}_{\mathbf{a}}+\mathbf{D}_{\mathbf{p} 1}\left(\mathbf{q}_{1}\right) \dot{\mathbf{q}}_{\mathbf{p}}+\mathbf{D}_{\mathrm{a} 2}\left(\mathbf{q}_{2}\right) \dot{\mathbf{q}}_{\mathbf{a}}+\mathbf{D}_{\mathbf{p} 2}\left(\mathbf{q}_{2}\right) \dot{\mathbf{q}}_{\mathbf{p}}+\cdots+ \\
& +\mathbf{D}_{\mathbf{a} m}\left(\mathbf{q}_{m}\right) \dot{\mathbf{q}}_{\mathbf{a}}+\mathbf{D}_{\mathbf{p} m}\left(\mathbf{q}_{m}\right) \dot{\mathbf{q}}_{\mathbf{p}}
\end{aligned}
$$

ou seja,

$$
m \mathbf{v}_{\mathbf{o}}=\sum_{i=1}^{m} \mathbf{D}_{\mathbf{a} i}\left(\mathbf{q}_{i}\right) \dot{\mathbf{q}}_{\mathbf{a}}+\sum_{i=1}^{m} \mathbf{D}_{\mathbf{p} i}\left(\mathbf{q}_{i}\right) \dot{\mathbf{q}}_{\mathbf{p}}=\mathbf{D}_{\mathbf{a}}(\mathbf{q}) \dot{\mathbf{q}}_{\mathbf{a}}+\mathbf{D}_{\mathbf{p}}(\mathbf{q}) \dot{\mathbf{q}}_{\mathbf{p}}
$$

nas qual as matrizes $\mathbf{D}_{\mathbf{a}}$ e $\mathbf{D}_{\mathbf{p}}$ podem ser calculadas através de 
$\begin{cases}\operatorname{col}_{l_{a}}\left(\mathbf{D}_{\mathbf{a}}(\mathbf{q})\right)=\operatorname{col}_{j}(\mathbf{D}(\mathbf{q})) & \text { se junta } j \text { é ativa } \\ \operatorname{col}_{l_{p}}\left(\mathbf{D}_{\mathbf{p}}(\mathbf{q})\right)=\operatorname{col}_{j}(\mathbf{D}(\mathbf{q})) & \text { se junta } j \text { é passiva }\end{cases}$

na qual $\operatorname{col}_{j}(\mathbf{D}(\mathbf{q}))$ refere-se à coluna $j$ da matriz $\mathbf{D}(\mathbf{q})$ (eq. 3.17), o índice $j=1, \ldots, n$ refere-se às juntas dos manipuladores, o índice $l_{a}=1, \ldots, n_{a}$ refere-se às juntas ativas dos manipuladores e o índice $l_{p}=1, \ldots, n_{p}$ refere-se às juntas passivas dos manipuladores.

Agora, dois casos podem ser considerados a partir da eq. (3.12).

Quando $m$ é par, tem-se a seguinte restrição cinemática no sistema cooperativo

$$
\sum_{i=1}^{m}(-1)^{i+1} \mathbf{D}_{i}\left(\mathbf{q}_{i}\right) \dot{\mathbf{q}}_{i}=\mathbf{0}_{k x 1}
$$

Particionando a eq. (5.5) entre juntas ativas e passivas

$$
\sum_{i=1}^{m}(-1)^{i+1} \mathbf{D}_{\mathbf{a} i}\left(\mathbf{q}_{i}\right) \dot{\mathbf{q}}_{\mathbf{a}}+\sum_{i=1}^{m}(-1)^{i+1} \mathbf{D}_{\mathbf{p} i}\left(\mathbf{q}_{i}\right) \dot{\mathbf{q}}_{\mathbf{p}}=\mathbf{R}_{\mathbf{a}}(\mathbf{q}) \dot{\mathbf{q}}_{\mathbf{a}}+\mathbf{R}_{\mathbf{p}}(\mathbf{q}) \dot{\mathbf{q}}_{\mathbf{p}}=\mathbf{0}_{k x 1}
$$

na qual as matrizes $\mathbf{R}_{\mathbf{a}}$ e $\mathbf{R}_{\mathrm{p}}$ podem ser calculadas através de

$$
\begin{aligned}
& \left\{\begin{array}{cl}
\operatorname{col}_{l_{a}}\left(\mathbf{R}_{\mathbf{a}}(\mathbf{q})\right)=\operatorname{col}_{j}(\mathbf{R}(\mathbf{q})) & \text { se junta } j \text { é ativa } \\
\operatorname{col}_{l_{p}}\left(\mathbf{R}_{\mathbf{p}}(\mathbf{q})\right)=\operatorname{col}_{j}(\mathbf{R}(\mathbf{q})) & \text { se junta } j \text { é passiva }
\end{array}\right. \\
& \text { sendo } \mathbf{R}(\mathbf{q})=\left[\begin{array}{lllll}
\mathbf{D}_{1}\left(\mathbf{q}_{1}\right) & -\mathbf{D}_{2}\left(\mathbf{q}_{2}\right) & \mathbf{D}_{3}\left(\mathbf{q}_{3}\right) & \cdots & -\mathbf{D}_{m}\left(\mathbf{q}_{m}\right)
\end{array}\right] \text {. }
\end{aligned}
$$

Da eq. (5.6), obtém-se a seguinte relação entre as velocidades das juntas ativas e as velocidades das juntas passivas quando $m$ é par

$$
\dot{\mathbf{q}}_{\mathbf{p}}=-\mathbf{R}_{\mathbf{p}}(\mathbf{q})^{\#} \mathbf{R}_{\mathbf{a}}(\mathbf{q}) \dot{\mathbf{q}}_{\mathrm{a}}
$$

na qual a matriz $\mathbf{R}_{\mathbf{p}}(\mathbf{q})$ com dimensão $k \times n_{p}$ deve ter posto pleno e número de linhas igual ou superior ao número de colunas $\left(k \geq n_{p}\right)$. Observe que se $k<n_{p}$, não existe unicidade para a solução de $\dot{\mathbf{q}}_{\mathbf{p}}$. Assim, considere as seguintes suposições neste trabalho:

Suposição 5.2 o número de coordenadas de movimento do objeto $k$ é igual ou maior que o número de juntas passivas do sistema $n_{p}$, ou seja, $k \geq n_{p}$.

Suposição 5.3 A matriz $\boldsymbol{R}_{p}(\boldsymbol{q})$ tem posto pleno.

Os exemplos apresentados em [LIU et al., 1999] com sistemas cooperativos formados por dois manipuladores planares com 2 gdl's cada e por dois manipuladores Puma indicam que as regiões em que a matriz $\mathbf{R}_{\mathbf{p}}(\mathbf{q})$ não tem posto pleno são limitadas. 
Quando $m$ é ímpar, tem-se a seguinte restrição cinemática no sistema cooperativo

$\sum_{i=1}^{m}(-1)^{i+1} \mathbf{D}_{i}\left(\mathbf{q}_{i}\right) \dot{\mathbf{q}}_{i}=\mathbf{v}_{\mathbf{o}}$.

Particionando a eq. (5.8) entre juntas ativas e passivas

$\mathbf{v}_{\mathbf{o}}=\mathbf{R}_{\mathbf{a}}(\mathbf{q}) \dot{\mathbf{q}}_{\mathrm{a}}+\mathbf{R}_{\mathbf{p}}(\mathbf{q}) \dot{\mathbf{q}}_{\mathrm{p}}$

e, daí, considerando as Suposições 5.2 e 5.3,

$$
\dot{\mathbf{q}}_{\mathbf{p}}=\mathbf{R}_{\mathbf{p}}(\mathbf{q})^{\#}\left(\mathbf{v}_{\mathbf{o}}-\mathbf{R}_{\mathbf{a}}(\mathbf{q}) \dot{\mathbf{q}}_{\mathbf{a}}\right)
$$

A eq. (5.10) relaciona a velocidade das juntas ativas e a velocidade das juntas passivas quando $m$ é ímpar.

Substituindo as eqs. (5.7), quando $m$ é par, e (5.10), quando $m$ é ímpar, na eq. (5.4), então a relação entre as velocidades das juntas ativas e a velocidade do objeto pode ser estabelecida

$$
\mathbf{v}_{\mathbf{o}}=\mathbf{Q}(\mathbf{q}) \dot{\mathbf{q}}_{\mathbf{a}}
$$

na qual

$$
\mathbf{Q}(\mathbf{q})=\frac{1}{m}\left(\mathbf{D}_{\mathbf{a}}(\mathbf{q})-\mathbf{D}_{\mathbf{p}}(\mathbf{q}) \mathbf{R}_{\mathbf{p}}(\mathbf{q})^{\#} \mathbf{R}_{\mathbf{a}}(\mathbf{q})\right)
$$

se $m$ é par, e

$$
\mathbf{Q}(\mathbf{q})=\left(m \mathbf{I}_{k}-\mathbf{D}_{\mathbf{p}}(\mathbf{q}) \mathbf{R}_{\mathbf{p}}(\mathbf{q})^{\#}\right)^{-1}\left(\mathbf{D}_{\mathbf{a}}(\mathbf{q})-\mathbf{D}_{\mathbf{p}}(\mathbf{q}) \mathbf{R}_{\mathbf{p}}(\mathbf{q})^{\#} \mathbf{R}_{\mathbf{a}}(\mathbf{q})\right)
$$

se $m$ é ímpar.

É interessante notar que a relação cinemática de primeira ordem descrita pela eq. (5.11) independe da dinâmica do sistema. Esta relação não pode ser encontrada em um manipulador subatuado livre. Observe que, se existe um único manipulador (ou seja, $m=1$ ), $\mathbf{D}_{\mathbf{p}}(\mathbf{q})=\mathbf{R}_{\mathbf{p}}(\mathbf{q})$ e $\mathbf{D}_{\mathbf{a}}(\mathbf{q})=\mathbf{R}_{\mathbf{a}}(\mathbf{q})$, o que faz com que $\mathbf{Q}(\mathbf{q})=\mathbf{0}_{k x n a}$.

A matriz $\mathbf{Q}(\mathbf{q})$ caracteriza as propriedades cinemáticas do sistema cooperativo com juntas passivas. Por exemplo, a manipulabilidade do sistema com juntas passivas, estudada em [BICCHI \& PRATTICHIZZO, 2000], pode ser obtida através da análise da matriz $\mathbf{Q}(\mathbf{q})$ [LIU et al., 1999]. Quando a passividade das juntas é característica desejada no sistema cooperativo, a análise da manipulabilidade pode servir para a escolha de quais juntas devem ser passivas [HIRANO et al., 2002]. A matriz Q(q) determina também o desempenho do 
controlador do sistema cooperativo, já que, usando a lei dos trabalhos virtuais, $\mathbf{Q}(\mathbf{q})^{\mathrm{T}}$ projeta as forças resultantes no objeto para o espaço das juntas ativas.

Considere agora que a matriz (de projeção) $\mathbf{Q}(\mathbf{q})$ tem posto pleno. Se $n_{a}=k$, ou seja, o número de juntas ativas é igual ao número de coordenadas de movimento do objeto, existe um único conjunto de velocidades das juntas atuadas e, consequentemente, uma única matriz de projeção para cada velocidade do objeto. Se $n_{a}>k$, entretanto, cada velocidade do objeto pode ser calculada pela projeção de mais de um conjunto de velocidades das juntas ativas. Ou seja, a matriz $\mathbf{Q}(\mathbf{q})$ apresentada nas eqs. (5.12) e (5.13) é apenas uma das soluções possíveis para a eq. (5.11) quando $n_{a}>k$. De fato, a matriz $\mathbf{Q}(\mathbf{q})$ obtida em [LIU et al., 1999] para $m=2$ é diferente da matriz obtida na eq. (5.12) quando $n_{a}>k$.

A dedução da matriz Q(q) em [LIU et al., 1999] é similar àquela apresentada aqui, exceto que a eq. (3.12) para $i=1$ ou 2 é empregada em substituição da eq. (5.4), ou seja, ao invés de utilizar as velocidades das juntas de todos os manipuladores, as velocidades das juntas de apenas um manipulador são utilizadas. Consequentemente, em geral, a matriz $\mathbf{Q}(\mathbf{q})^{\mathrm{T}}$ obtida em [LIU et al., 1999] projeta forças generalizadas das juntas ativas de um manipulador muito maiores que aqueles do outro manipulador para uma mesma força resultante. Isso pode não ser interessante já que, muitas vezes, um único robô não tem capacidade de carga suficiente para manipular o objeto. $\mathrm{O}$ mesmo não ocorre com a matriz $\mathbf{Q}(\mathbf{q})$ calculada aqui (eqs. 5.12 e 5.13) pois as velocidades das juntas de todos os manipuladores são utilizadas na eq. (5.4). Além disso, vale ressaltar, a matriz $\mathbf{Q}(\mathbf{q})$ calculada em [LIU et al., 1999] só é válida para $m=2$.

Deduzida a matriz $\mathbf{Q}(\mathbf{q})$, um novo controlador para o sistema com juntas passivas baseado no controle híbrido de movimento e esmagamento [WEN \& KREUTZ-DELGADO, 1992] para o sistema totalmente atuado é desenvolvido a seguir.

\subsubsection{Controle Híbrido de Movimento e Esmagamento Para o Sistema Cooperativo Com Juntas Passivas}

Como dito na Seção 3.4, a decomposição entre forças de movimento e esmagamento implica o desacoplamento dos problemas de controle de movimento e esmagamento em uma direção. Somente em uma direção porque qualquer termo das forças generalizadas nas juntas que provoque forças apenas no subespaço de esmagamento não afeta o movimento quando não existem manipuladores em posições singulares. O movimento dos manipuladores, no 
entanto, afeta o esmagamento devido ao componente de esmagamento da força inercial d'Alembert (isto é, os termos dependentes de velocidade em $\mathbf{P}_{\mathbf{e}} \mathbf{h}_{\mathbf{o}}(t)$ ).

Portanto, como em [WEN \& KREUTZ-DELGADO, 1992] para o sistema totalmente atuado (Seção 3.5.1), projeta-se aqui uma lei de controle de movimento para o sistema cooperativo com juntas passivas estável sem considerar o controle de força de esmagamento. Então, projeta-se uma lei de controle de esmagamento estável tratando as componentes da força de esmagamento provocadas pelo movimento como perturbações.

Assim, considerando as Suposições 5.1-5.3, a lei de controle para as juntas ativas é dada por

$\tau_{\mathrm{a}}=\tau_{\mathrm{amg}}+\tau_{\mathrm{ae}}$

na qual o primeiro termo é responsável pelo controle de movimento e compensação dos termos gravitacionais e, o segundo termo, pelo controle da força de esmagamento.

A seguir, um controlador estável para o movimento do sistema cooperativo com juntas passivas com compensação dos termos gravitacionais é projetado.

\subsubsection{Controle de Movimento com Compensacão dos Termos Gravitacionais:}

Pode-se escrever a eq. (5.1) da seguinte forma:

$\overline{\mathbf{M}} \ddot{\overline{\mathbf{q}}}+\overline{\mathbf{C}} \dot{\overline{\mathbf{q}}}+\overline{\mathbf{g}}=\overline{\boldsymbol{\tau}}-\overline{\mathbf{J}}^{\mathrm{T}} \mathbf{h}$

na qual

$$
\overline{\mathbf{M}}=\left[\begin{array}{ll}
\mathbf{M}_{\mathrm{aa}} & \mathbf{M}_{\mathrm{ap}} \\
\mathbf{M}_{\mathbf{p a}} & \mathbf{M}_{\mathbf{p p}}
\end{array}\right], \overline{\mathbf{q}}=\left[\begin{array}{l}
\mathbf{q}_{\mathbf{a}} \\
\mathbf{q}_{\mathbf{p}}
\end{array}\right], \overline{\mathbf{C}}=\left[\begin{array}{ll}
\mathbf{C}_{\mathbf{a a}} & \mathbf{C}_{\mathrm{ap}} \\
\mathbf{C}_{\mathbf{p a}} & \mathbf{C}_{\mathbf{p p}}
\end{array}\right], \overline{\mathbf{g}}=\left[\begin{array}{l}
\mathbf{g}_{\mathbf{a}} \\
\mathbf{g}_{\mathbf{p}}
\end{array}\right], \overline{\boldsymbol{\tau}}=\left[\begin{array}{c}
\boldsymbol{\tau}_{\mathbf{a}} \\
\mathbf{0}_{n_{p} x 1}
\end{array}\right] \text { e } \overline{\mathbf{J}}^{\mathrm{T}}=\left[\begin{array}{l}
\mathbf{J}_{\mathbf{a}}{ }^{\mathrm{T}} \\
\mathbf{J}_{\mathbf{p}}{ }^{\mathrm{T}}
\end{array}\right] .
$$

Os termos da eq. (5.15) podem ser obtidos através de uma matriz de permutação $\mathbf{P}_{\text {ap }}$ ortogonal (isto é, $\mathbf{P}_{\mathrm{ap}} \mathbf{P}_{\mathrm{ap}}{ }^{\mathrm{T}}=\mathbf{P}_{\mathrm{ap}}{ }^{\mathrm{T}} \mathbf{P}_{\mathrm{ap}}=\mathbf{I}$ ). Assim,

$$
\overline{\mathbf{q}}=\mathbf{P}_{\mathrm{ap}} \mathbf{q} \quad, \quad \overline{\mathbf{M}}=\mathbf{P}_{\mathrm{ap}} \mathbf{M} \mathbf{P}_{\mathrm{ap}}{ }^{\mathrm{T}} \quad, \quad \overline{\mathbf{C}}=\mathbf{P}_{\mathrm{ap}} \mathbf{C} \mathbf{P}_{\mathrm{ap}}{ }^{\mathrm{T}}, \quad \overline{\mathbf{g}}=\mathbf{P}_{\mathrm{ap}} \mathbf{g} \quad, \quad \bar{\tau}=\mathbf{P}_{\mathrm{ap}} \tau
$$

A lei de controle de movimento proposta aqui é dada por

$$
\tau_{\mathrm{amg}}=\tau_{\mathrm{am}}+\tau_{\mathrm{ag}}
$$

na qual $\boldsymbol{\tau}_{\mathrm{am}}$ é o componente responsável pelo controle de movimento e $\boldsymbol{\tau}_{\mathrm{ag}}$ é o componente responsável pela compensação dos torques gravitacionais. 
Para o componente responsável pelo controle de movimento, a matriz $\mathbf{Q}(\mathbf{q})$ é utilizada para projetar forças resultantes proporcionais aos erros de posição e velocidade no espaço das juntas ativas. Assim,

$$
\tau_{\mathrm{am}}=\mathbf{Q}^{\mathrm{T}}\left(\mathbf{T}^{-\mathrm{T}} \mathbf{K}_{\mathbf{p}} \Delta \mathbf{x}_{\mathbf{o}}+\mathbf{K}_{\mathbf{v}} \Delta \mathbf{v}_{\mathbf{o}}\right)
$$

na qual $\Delta \mathbf{x}_{\mathbf{0}}=\left(\mathbf{x}_{\mathbf{o d}}-\mathbf{x}_{\mathbf{0}}\right)$ é o erro de posição do CM do objeto, $\Delta \mathbf{v}_{\mathbf{0}}=\left(\mathbf{v}_{\mathbf{o d}}-\mathbf{v}_{\mathbf{0}}\right)$ é o erro de velocidade, $\mathbf{x}_{\mathbf{o d}}$ é a posição desejada, $\mathbf{v}_{\mathbf{o d}}$ é a velocidade desejada, as matrizes $\mathbf{K}_{\mathbf{p}}$ e $\mathbf{K}_{\mathbf{v}}$ são diagonais e positivas e $\mathbf{T}^{-\mathrm{T}}=\left(\mathbf{T}^{\mathrm{T}}\right)^{-1}$. A matriz $\mathbf{T}$ relaciona as derivadas das representações mínimas das orientações do objeto com as suas velocidades angulares (ver Capítulo 3).

A componente $\boldsymbol{\tau}_{\mathrm{ag}}$ deve compensar os torques provocados pelos termos gravitacionais das juntas ativas, passivas e do objeto. A compensação dos termos gravitacionais das juntas passivas é obtida pela projeção de $\mathbf{g}_{\mathbf{p}}$ nas juntas ativas através das matrizes de projeção dadas nas eqs. (5.7) e (5.10). A compensação dos termos gravitacionais no objeto é obtida através da matriz de projeção entre as velocidades das juntas ativas e as velocidades dos efetuadores v. Particionando

$\mathbf{v}=\mathbf{J} \dot{\mathbf{q}}$

entre juntas ativas e passivas, então

$\mathbf{v}=\mathbf{J}_{\mathbf{a}} \dot{\mathbf{q}}_{\mathbf{a}}+\mathbf{J}_{\mathbf{p}} \dot{\mathbf{q}}_{\mathbf{p}}$

Substituindo as eqs. (5.7), para $m$ par, e (5.10-11), para $m$ ímpar, na eq. (5.19), obtém-se a matriz de projeção entre as velocidades das juntas ativas e as velocidades dos efetuadores

$\mathbf{v}=\left(\mathbf{J}_{\mathbf{a}}-\mathbf{J}_{\mathbf{p}} \mathbf{A}_{\mathbf{o}}\right) \dot{\mathbf{q}}_{\mathbf{a}}$

na qual

$$
\mathbf{A}_{\mathbf{o}}=\left\{\begin{array}{ll}
\mathbf{R}_{\mathbf{p}}{ }^{\#} \mathbf{R}_{\mathbf{a}} & \text { para } m \text { par } \\
\mathbf{R}_{\mathbf{p}}{ }^{\#}\left(\mathbf{R}_{\mathbf{a}}-\mathbf{Q}\right) & \text { para } m \text { impar }
\end{array} .\right.
$$

Deste modo, $\boldsymbol{\tau}_{\mathrm{ag}}$ é dado por

$$
\boldsymbol{\tau}_{\mathrm{ag}}=\mathbf{g}_{\mathrm{a}}-\mathbf{A}_{\mathbf{o}}{ }^{\mathrm{T}} \mathbf{g}_{\mathbf{p}}+\left(\mathbf{J}_{\mathrm{a}}{ }^{\mathrm{T}}-\mathbf{A}_{\mathbf{o}}{ }^{\mathrm{T}} \mathbf{J}_{\mathbf{p}}{ }^{\mathrm{T}}\right) \mathbf{f}_{\mathrm{g}}
$$

na qual

$$
\mathbf{g}_{\mathbf{o}}+\mathbf{c}_{\mathbf{o}}=\mathbf{J}_{\mathbf{o}}{ }^{\mathrm{T}} \mathbf{f}_{\mathrm{g}}
$$


As eqs. (5.17) e (5.22) definem as componentes da lei de controle de movimento dada pela eq. (5.16).

Considere agora a seguinte suposição

Suposição 5.4. As trajetórias desejadas pertencem ao conjunto $S$, definido como

$S=\left\{\mathbf{v}_{\text {od }}, \dot{\mathbf{v}}_{\text {od }} \in L_{2}([0, \infty)) ; \mathbf{v}_{\text {od }}, \dot{\mathbf{v}}_{\text {od }}\right.$ contínuas e uniformes $\}$

ou seja, as velocidades e acelerações desejadas são contínuas e convergem para zero quando $t \rightarrow \infty$.

Para o controle de movimento, os seguintes resultados são obtidos:

Teorema 5.1. Assuma que as Suposições 5.1-5.4 são satisfeitas e que a lei de controle de movimento dada pelas eqs. (5.16), (5.17) e (5.22) seja utilizada. Então:

(i) O sistema cooperativo é assintoticamente estável, isto é, as velocidades do objeto são convergentes para zero quando $t \rightarrow \infty$.

(ii) O erro de posição converge para a variedade descrita por:

$$
\mathbf{Q}^{\mathrm{T}} \mathbf{T}^{-\mathrm{T}} \mathbf{K}_{\mathbf{p}} \boldsymbol{\Delta} \mathbf{x}_{\mathbf{o}}+\left(\mathbf{J}_{\mathbf{a}}{ }^{\mathrm{T}}-\mathbf{A}_{\mathbf{o}}{ }^{\mathrm{T}} \mathbf{J}_{\mathbf{p}}{ }^{\mathrm{T}}\right) \mathbf{J}_{\mathbf{o q}}{ }^{-\mathrm{T}} \mathbf{h}_{\text {oec }}=\mathbf{0}_{n_{a} \times 1}
$$

\section{Prova:}

Dois casos serão aqui analisados. O primeiro é o problema de controle do tipo setpoint no qual as velocidades desejadas são iguais a zero. O segundo é o problema do seguimento de trajetórias pertencentes a $S$. Observe que o primeiro problema é um caso particular do segundo.

Para o problema de controle do tipo set-point no qual as velocidades desejadas são iguais a zero, considere a seguinte função candidata de Lyapunov

$V=\frac{1}{2} \mathbf{v}_{\mathbf{o}}{ }^{\mathrm{T}} \mathbf{M}_{\mathbf{o}} \mathbf{v}_{\mathbf{o}}+\frac{1}{2} \dot{\overline{\mathbf{q}}}^{\mathrm{T}} \overline{\mathbf{M}} \dot{\overline{\mathbf{q}}}+\frac{1}{2} \Delta \mathbf{x}_{\mathbf{o}}{ }^{\mathrm{T}} \mathbf{K}_{\mathbf{p}} \Delta \mathbf{x}_{\mathbf{o}}$

na qual o primeiro termo é a energia cinética do objeto e o segundo termo é a energia cinética dos manipuladores.

Derivando a eq. (5.25) em relação ao tempo,

$$
\dot{V}=\mathbf{v}_{\mathbf{o}}{ }^{\mathrm{T}} \mathbf{M}_{\mathbf{o}} \dot{\mathbf{v}}_{\mathbf{o}}+\dot{\overline{\mathbf{q}}}^{\mathrm{T}} \overline{\mathbf{M}} \ddot{\overline{\mathbf{q}}}+\frac{1}{2} \dot{\overline{\mathbf{q}}}^{\mathrm{T}} \dot{\mathbf{M}} \dot{\overline{\mathbf{q}}}+\Delta \mathbf{x}_{\mathbf{o}}{ }^{\mathrm{T}} \mathbf{K}_{\mathbf{p}} \Delta \dot{\mathbf{x}}_{\mathbf{o}}
$$


Substituindo as eqs. (3.7b) e (5.15) na eq. (5.26)

$\dot{V}=-\mathbf{v}_{\mathbf{o}}{ }^{\mathrm{T}}\left(\mathbf{c}_{\mathbf{o}}+\mathbf{g}_{\mathbf{0}}\right)+\mathbf{v}_{\mathbf{o}}{ }^{\mathrm{T}} \mathbf{J}_{\mathbf{o}}{ }^{\mathrm{T}} \mathbf{h}-\dot{\overline{\mathbf{q}}}^{\mathrm{T}} \overline{\mathbf{g}}+\dot{\overline{\mathbf{q}}}^{\mathrm{T}}\left(\frac{1}{2} \dot{\overline{\mathbf{M}}}-\overline{\mathbf{C}}\right) \dot{\overline{\mathbf{q}}}+\dot{\overline{\mathbf{q}}}^{\mathrm{T}} \overline{\boldsymbol{\tau}}+\Delta \mathbf{x}_{\mathbf{o}}{ }^{\mathrm{T}} \mathbf{K}_{\mathbf{p}} \boldsymbol{\Delta} \dot{\mathbf{x}}_{\mathbf{o}}-\dot{\overline{\mathbf{q}}}^{\mathrm{T}} \overline{\mathbf{J}}^{\mathrm{T}} \mathbf{h}$

e, como $\mathbf{v}=\mathbf{J}_{\mathbf{0}} \mathbf{v}_{\mathbf{o}}=\overline{\mathbf{J}} \dot{\overline{\mathbf{q}}}$ (eqs. 3.8b e 5.19), então

$\dot{V}=-\mathbf{v}_{\mathbf{o}}{ }^{\mathrm{T}}\left(\mathbf{c}_{\mathbf{o}}+\mathbf{g}_{\mathbf{o}}\right)-\dot{\overline{\mathbf{q}}}^{\mathrm{T}} \overline{\mathbf{g}}+\dot{\overline{\mathbf{q}}}^{\mathrm{T}}\left(\frac{1}{2} \dot{\overline{\mathbf{M}}}-\overline{\mathbf{C}}\right) \dot{\overline{\mathbf{q}}}+\dot{\overline{\mathbf{q}}}^{\mathrm{T}} \overline{\boldsymbol{\tau}}+\Delta \mathbf{x}_{\mathbf{o}}{ }^{\mathrm{T}} \mathbf{K}_{\mathbf{p}} \Delta \dot{\mathbf{x}}_{\mathbf{0}}$

Agora o termo $\dot{\overline{\mathbf{q}}}^{\mathrm{T}}\left(\frac{1}{2} \dot{\overline{\mathbf{M}}}-\overline{\mathbf{C}}\right) \dot{\overline{\mathbf{q}}}$ será analisado. Lembrando que $\overline{\mathbf{q}}=\mathbf{P}_{\text {ap }} \mathbf{q}$, na qual $\mathbf{P}_{\text {ap }}$ é a matriz de permutação, então

$\dot{\mathbf{q}}^{\mathrm{T}}\left(\frac{1}{2} \dot{\overline{\mathbf{M}}}-\overline{\mathbf{C}}\right) \dot{\overline{\mathbf{q}}}=\dot{\mathbf{q}}^{\mathrm{T}} \mathbf{P}_{\mathrm{ap}}{ }^{\mathrm{T}} \mathbf{P}_{\mathrm{ap}}\left(\frac{1}{2} \dot{\mathbf{M}}-\mathbf{C}\right) \mathbf{P}_{\mathrm{ap}}{ }^{\mathrm{T}} \mathbf{P}_{\mathrm{ap}} \dot{\mathbf{q}}=\dot{\mathbf{q}}^{\mathrm{T}}\left(\frac{1}{2} \dot{\mathbf{M}}-\mathbf{C}\right) \dot{\mathbf{q}}$

Como a matriz $(\dot{\mathbf{M}}-2 \mathbf{C})$ é anti-simétrica (Teorema 6.3.1, página 143, [SPONG \& VIDYASAGAR, 1989]), ou seja, $(\dot{\mathbf{M}}-2 \mathbf{C})^{\mathrm{T}}=-(\dot{\mathbf{M}}-2 \mathbf{C})$ possui elementos na diagonal principal iguais a zero [NOBLE \& DANIEL, 1986], então

$\dot{\overline{\mathbf{q}}}^{\mathrm{T}}\left(\frac{1}{2} \dot{\overline{\mathbf{M}}}-\overline{\mathbf{C}}\right) \dot{\overline{\mathbf{q}}}=\frac{1}{2} \dot{\overline{\mathbf{q}}}^{\mathrm{T}}(\dot{\overline{\mathbf{M}}}-2 \overline{\mathbf{C}}) \dot{\overline{\mathbf{q}}}=0$

Substituindo a eq. (5.28) na eq. (5.27)

$\dot{V}=-\mathbf{v}_{\mathbf{o}}{ }^{\mathrm{T}}\left(\mathbf{c}_{\mathbf{o}}+\mathbf{g}_{\mathbf{o}}\right)-\dot{\overline{\mathbf{q}}}^{\mathrm{T}} \overline{\mathbf{g}}+\dot{\overline{\mathbf{q}}}^{\mathrm{T}} \bar{\tau}+\Delta \mathbf{x}_{\mathbf{o}}{ }^{\mathrm{T}} \mathbf{K}_{\mathbf{p}} \Delta \dot{\mathbf{x}}_{\mathbf{o}}$

Expandindo a eq. anterior (eq. 5.15),

$\dot{V}=-\mathbf{v}_{\mathbf{o}}{ }^{\mathrm{T}}\left(\mathbf{c}_{\mathbf{o}}+\mathbf{g}_{\mathbf{o}}\right)-\dot{\mathbf{q}}_{\mathrm{a}}^{\mathrm{T}} \mathbf{g}_{\mathrm{a}}-\dot{\mathbf{q}}_{\mathbf{p}}^{\mathrm{T}} \mathbf{g}_{\mathbf{p}}+\dot{\mathbf{q}}_{\mathrm{a}}^{\mathrm{T}} \boldsymbol{\tau}_{\mathrm{a}}+\Delta \mathbf{x}_{\mathbf{o}}{ }^{\mathrm{T}} \mathbf{K}_{\mathbf{p}} \Delta \dot{\mathbf{x}}_{\mathbf{o}} \quad$.

Aplicando a lei de controle dada pelas eqs. (5.16), (5.17) e (5.22), então

$\dot{V}=\mathbf{v}_{\mathbf{o}}{ }^{\mathrm{T}} \mathbf{K}_{\mathbf{v}} \boldsymbol{\Delta} \mathbf{v}_{\mathbf{o}}+\mathbf{v}_{\mathbf{o}}{ }^{\mathrm{T}} \mathbf{T}^{-\mathrm{T}} \mathbf{K}_{\mathbf{p}} \boldsymbol{\Delta} \mathbf{x}_{\mathbf{o}}+\boldsymbol{\Delta} \mathbf{x}_{\mathbf{o}}{ }^{\mathrm{T}} \mathbf{K}_{\mathbf{p}} \boldsymbol{\Delta} \dot{\mathbf{x}}_{\mathbf{o}}$

Substituindo $\Delta \mathbf{v}_{\mathbf{0}}=-\mathbf{v}_{\mathbf{0}}, \Delta \dot{\mathbf{x}}_{\mathbf{0}}=-\dot{\mathbf{x}}_{\mathbf{0}}$ (lembre-se que as velocidades desejadas do objeto são iguais a zero) e $\mathbf{T}^{-1} \mathbf{v}_{\mathbf{o}}=\dot{\mathbf{x}}_{\mathbf{o}}$ na eq. (5.31)

$\dot{V}=-\mathbf{v}_{\mathbf{o}}{ }^{\mathrm{T}} \mathbf{K}_{\mathbf{v}} \mathbf{v}_{\mathbf{o}} \leq 0 \quad$, 
o que implica, de acordo com o Princípio da Invariância [LASALLE, 1960], a convergência assintótica de $\mathbf{v}_{\mathbf{0}}$ para zero. Assim, o objeto sempre vai para uma situação de repouso quando o controlador descrito pelas eqs. (5.16), (5.17) e (5.22) é utilizado.

Para o problema de seguimento de trajetórias pertencentes ao conjunto $S$, considere a seguinte função candidata de Lyapunov

$$
V=\frac{1}{2} \Delta \mathbf{v}_{\mathbf{o}}{ }^{\mathrm{T}} \mathbf{M}_{\mathbf{o}} \Delta \mathbf{v}_{\mathbf{o}}+\frac{1}{2} \Delta \dot{\overline{\mathbf{q}}}^{\mathrm{T}} \overline{\mathbf{M}} \Delta \dot{\overline{\mathbf{q}}}+\frac{1}{2} \Delta \mathbf{x}_{\mathbf{o}}{ }^{\mathrm{T}} \mathbf{K}_{\mathbf{p}} \Delta \mathbf{x}_{\mathbf{o}}
$$

na qual $\Delta \dot{\overline{\mathbf{q}}}=\left(\dot{\overline{\mathbf{q}}}_{\mathbf{d}}-\dot{\overline{\mathbf{q}}}\right)$, sendo $\dot{\overline{\mathbf{q}}}_{\mathbf{d}}$ obtido através da projeção de $\mathbf{v}_{\mathbf{o d}}$ no espaço das juntas, ou seja, lembrando que $\overline{\mathbf{q}}=\mathbf{P}_{\text {ap }} \mathbf{q}$, então ${ }^{1}$

$$
\dot{\overline{\mathbf{q}}}_{\mathbf{d}}=\mathbf{P}_{\mathrm{ap}} \dot{\mathbf{q}}_{\mathbf{d}}=\mathbf{P}_{\mathrm{ap}}\left[\begin{array}{c}
\mathbf{D}_{1}\left(\mathbf{q}_{1}\right)^{-1} \\
\vdots \\
\mathbf{D}_{m}\left(\mathbf{q}_{m}\right)^{-1}
\end{array}\right] \mathbf{v}_{\text {od }}=\mathbf{A}_{\mathbf{q}} \mathbf{v}_{\text {od }}
$$

Observe que $\Delta \dot{\overline{\mathbf{q}}}$ não é usado nas leis de controle, aparecendo aqui somente para a demonstração da estabilidade do sistema.

Derivando a eq. (5.33) em relação ao tempo,

$$
\dot{V}=\Delta \mathbf{v}_{\mathbf{o}}{ }^{\mathrm{T}} \mathbf{M}_{\mathbf{0}} \Delta \dot{\mathbf{v}}_{\mathbf{o}}+\Delta \dot{\overline{\mathbf{q}}}^{\mathrm{T}} \overline{\mathbf{M}} \Delta \ddot{\overline{\mathbf{q}}}+\frac{1}{2} \Delta \dot{\overline{\mathbf{q}}}^{\mathrm{T}} \dot{\overline{\mathbf{M}}} \Delta \dot{\overline{\mathbf{q}}}+\Delta \mathbf{x}_{\mathbf{o}}{ }^{\mathrm{T}} \mathbf{K}_{\mathbf{p}} \Delta \dot{\mathbf{x}}_{\mathbf{o}}
$$

Substituindo as eqs. (3.7b) e (5.15) na eq. (5.35),

$$
\begin{aligned}
\dot{V} & =\Delta \mathbf{v}_{\mathbf{o}}{ }^{\mathrm{T}}\left(\mathbf{c}_{\mathbf{o}}+\mathbf{g}_{\mathbf{0}}\right)+\Delta \mathbf{v}_{\mathbf{o}}{ }^{\mathrm{T}} \mathbf{M}_{\mathbf{o}} \dot{\mathbf{v}}_{\mathbf{o d}}+\Delta \dot{\overline{\mathbf{q}}}^{\mathrm{T}} \overline{\mathbf{M}}_{\ddot{\mathbf{q}}_{\mathbf{d}}}+\Delta \dot{\overline{\mathbf{q}}}^{\mathrm{T}}(\overline{\mathbf{g}}+\overline{\mathbf{C}} \dot{\overline{\mathbf{q}}})-\Delta \dot{\overline{\mathbf{q}}}^{\mathrm{T}} \bar{\tau}+ \\
& +\frac{1}{2} \Delta \dot{\overline{\mathbf{q}}}^{\mathrm{T}} \dot{\overline{\mathbf{M}}} \Delta \dot{\overline{\mathbf{q}}}+\Delta \mathbf{x}_{\mathbf{o}}{ }^{\mathrm{T}} \mathbf{K}_{\mathbf{p}} \Delta \dot{\mathbf{x}}_{\mathbf{o}}
\end{aligned}
$$

e aplicando a lei de controle de movimento dada pelas eq. (5.16), (5.17) e (5.22), então

$$
\begin{aligned}
\dot{V} & =\Delta \mathbf{v}_{\mathbf{o}}{ }^{\mathrm{T}}\left(\mathbf{c}_{\mathbf{o}}+\mathbf{g}_{\mathbf{o}}\right)+\Delta \mathbf{v}_{\mathbf{o}}{ }^{\mathrm{T}} \mathbf{M}_{\mathbf{o}} \dot{\mathbf{v}}_{\mathbf{o d}}+\Delta \dot{\overline{\mathbf{q}}}^{\mathrm{T}} \overline{\mathbf{M}} \ddot{\overline{\mathbf{q}}}_{\mathbf{d}}+\Delta \dot{\overline{\mathbf{q}}}^{\mathrm{T}} \overline{\mathbf{C}} \dot{\overline{\mathbf{q}}}-\Delta \dot{\mathbf{q}}_{\mathbf{a}}{ }^{\mathrm{T}} \mathbf{Q}^{\mathrm{T}}\left(\mathbf{T}^{-\mathrm{T}} \mathbf{K}_{\mathbf{p}} \Delta \mathbf{x}_{\mathbf{o}}+\mathbf{K}_{\mathbf{v}} \boldsymbol{\Delta} \mathbf{v}_{\mathbf{o}}\right)+ \\
& +\Delta \mathbf{v}_{\mathbf{o}}{ }^{\mathrm{T}} \mathbf{J}_{\mathbf{o}}{ }^{\mathrm{T}} \mathbf{f}_{\mathbf{g}}+\frac{1}{2} \Delta \dot{\overline{\mathbf{q}}}^{\mathrm{T}} \dot{\overline{\mathbf{M}}} \Delta \dot{\overline{\mathbf{q}}}+\Delta \mathbf{x}_{\mathbf{o}}{ }^{\mathrm{T}} \mathbf{K}_{\mathbf{p}} \Delta \dot{\mathbf{x}}_{\mathbf{o}} \\
\dot{V} & =\Delta \mathbf{v}_{\mathbf{o}}{ }^{\mathrm{T}} \mathbf{M}_{\mathbf{o}} \dot{\mathbf{v}}_{\mathbf{o d}}+\Delta \dot{\overline{\mathbf{q}}}^{\mathrm{T}} \overline{\mathbf{M}} \ddot{\overline{\mathbf{q}}}_{\mathbf{d}}+\Delta \dot{\overline{\mathbf{q}}}^{\mathrm{T}} \overline{\mathbf{C}} \dot{\overline{\mathbf{q}}}+\frac{1}{2} \Delta \dot{\overline{\mathbf{q}}}^{\mathrm{T}} \dot{\overline{\mathbf{M}}} \Delta \dot{\overline{\mathbf{q}}}-\Delta \mathbf{v}_{\mathbf{o}}{ }^{\mathrm{T}} \mathbf{K}_{\mathbf{v}} \boldsymbol{\Delta} \mathbf{v}_{\mathbf{o}}
\end{aligned}
$$

\footnotetext{
${ }^{1}$ Observe que a eq. (5.34) é válida quando as matrizes $\mathbf{D}_{i}$ são quadradas, ou seja, quando nenhum manipulador é cinematicamente redundante. No caso em que o manipulador $i$ é cinematicamente redundante, um método de cinemática inversa para manipuladores redundantes pode ser utilizado (por exemplo, através da solução de um problema de otimização linear com restrições [SCIAVICCO \& SICILIANO, 1996]).
} 
Somando $\left(\Delta \dot{\overline{\mathbf{q}}}^{\mathrm{T}} \overline{\mathbf{C}} \dot{\overline{\mathbf{q}}}_{\mathbf{d}}-\Delta \dot{\overline{\mathbf{q}}}^{\mathrm{T}} \overline{\mathbf{C}} \dot{\overline{\mathbf{q}}}_{\mathbf{d}}\right)$ na eq. (5.36) e substituindo $\Delta \mathbf{v}_{\mathbf{0}}=\left(\mathbf{v}_{\mathbf{o d}^{-}}-\mathbf{v}_{\mathbf{o}}\right)$ e $\Delta \mathbf{q}=\left(\mathbf{q}_{\mathbf{d}^{-}} \mathbf{q}\right)$, então

$$
\begin{aligned}
\dot{V}= & \mathbf{v}_{\mathbf{o d}}{ }^{\mathrm{T}} \mathbf{M}_{\mathbf{o}} \dot{\mathbf{v}}_{\mathbf{o d}}-\mathbf{v}_{\mathbf{o}}{ }^{\mathrm{T}} \mathbf{M}_{\mathbf{o}} \dot{\mathbf{v}}_{\mathbf{o d}}+\dot{\overline{\mathbf{q}}}_{\mathbf{d}}{ }^{\mathrm{T}} \overline{\mathbf{M}} \ddot{\overline{\mathbf{q}}}_{\mathbf{d}}-\dot{\overline{\mathbf{q}}}^{\mathrm{T}} \overline{\mathbf{M}} \ddot{\overline{\mathbf{q}}}_{\mathbf{d}}+\dot{\overline{\mathbf{q}}}_{\mathbf{d}}{ }^{\mathrm{T}} \overline{\mathbf{C}} \dot{\overline{\mathbf{q}}}_{\mathbf{d}}+ \\
& -\dot{\overline{\mathbf{q}}}^{\mathrm{T}} \overline{\mathbf{C}} \dot{\overline{\mathbf{q}}}_{\mathbf{d}}-\mathbf{v}_{\mathbf{o d}}{ }^{\mathrm{T}} \mathbf{K}_{\mathbf{v}} \mathbf{v}_{\mathbf{o d}}+2 \mathbf{v}_{\mathbf{o d}}{ }^{\mathrm{T}} \mathbf{K}_{\mathbf{v}} \mathbf{v}_{\mathbf{o}}-\mathbf{v}_{\mathbf{o}}{ }^{\mathrm{T}} \mathbf{K}_{\mathbf{v}} \mathbf{v}_{\mathbf{o}}
\end{aligned}
$$

Como $\dot{\overline{\mathbf{q}}}=\mathbf{A}_{\mathbf{q}} \mathbf{v}_{\mathbf{o}}$ e $\dot{\overline{\mathbf{q}}}_{\mathbf{d}}=\mathbf{A}_{\mathbf{q}} \mathbf{v}_{\text {od }}$, na qual $\mathbf{A}_{\mathbf{q}}$ é dada na eq. (5.34), então

$$
\begin{aligned}
\dot{V} & =\mathbf{v}_{\mathbf{~ o d}}{ }^{\mathrm{T}} \mathbf{M}_{\mathbf{o}} \dot{\mathbf{v}}_{\mathbf{o d}}-\mathbf{v}_{\mathbf{o}}{ }^{\mathrm{T}} \mathbf{M}_{\mathbf{o}} \dot{\mathbf{v}}_{\mathbf{o d}}+\mathbf{v}_{\text {od }}{ }^{\mathrm{T}} \mathbf{A}_{\mathbf{q}}{ }^{\mathrm{T}} \overline{\mathbf{M}} \ddot{\overline{\mathbf{q}}}_{\mathbf{d}}-\mathbf{v}_{\mathbf{o}}{ }^{\mathrm{T}} \mathbf{A}_{\mathbf{q}}{ }^{\mathrm{T}} \overline{\mathbf{M}} \ddot{\overline{\mathbf{q}}}_{\mathbf{d}}+\mathbf{v}_{\mathbf{o d}}{ }^{\mathrm{T}} \mathbf{A}_{\mathbf{q}}{ }^{\mathrm{T}} \overline{\mathbf{C}} \mathbf{A}_{\mathbf{q}} \mathbf{v}_{\text {od }}+ \\
& -\mathbf{v}_{\mathbf{o}}{ }^{\mathrm{T}} \mathbf{A}_{\mathbf{q}}{ }^{\mathrm{T}} \overline{\mathbf{C}} \mathbf{A}_{\mathbf{q}} \mathbf{v}_{\mathbf{o d}}-\mathbf{v}_{\mathbf{o d}}{ }^{\mathrm{T}} \mathbf{K}_{\mathbf{v}} \mathbf{v}_{\mathbf{o d}}+2 \mathbf{v}_{\mathbf{o d}}{ }^{\mathrm{T}} \mathbf{K}_{\mathbf{v}} \mathbf{v}_{\mathbf{o}}-\mathbf{v}_{\mathbf{o}}{ }^{\mathrm{T}} \mathbf{K}_{\mathbf{v}} \mathbf{v}_{\mathbf{o}}
\end{aligned}
$$

Já que a matriz $\mathbf{K}_{\mathbf{v}}$ é simétrica e positiva definida, então é possível utilizar a decomposição por autovalores e escrever que

$$
\lambda_{\min }\left(\mathbf{K}_{\mathbf{v}}\right)\left\|\mathbf{v}_{\mathbf{o}}\right\|^{2} \leq \mathbf{v}_{\mathbf{o}}{ }^{\mathrm{T}} \mathbf{K}_{\mathbf{v}} \mathbf{v}_{\mathbf{o}} \leq \lambda_{\max }\left(\mathbf{K}_{\mathbf{v}}\right)\left\|\mathbf{v}_{\mathbf{o}}\right\|^{2}
$$

na qual $\lambda_{\min }\left(\mathbf{K}_{\mathbf{v}}\right)$ e $\lambda_{\max }\left(\mathbf{K}_{\mathbf{v}}\right)$ são, respectivamente, o menor e o maior autovalores da matriz $\mathbf{K}_{\mathbf{v}}$. Assim, fazendo $k_{v}=\lambda_{\min }\left(\mathbf{K}_{\mathbf{v}}\right)$, pode-se escrever que

$$
\begin{aligned}
\dot{V} \leq & \mathbf{v}_{\text {od }}{ }^{\mathrm{T}} \mathbf{v}_{1}+\mathbf{v}_{\mathbf{o}}{ }^{\mathrm{T}} \boldsymbol{v}_{2}+\mathbf{v}_{3}{ }^{\mathrm{T}} \mathbf{v}_{\mathbf{o}}-k_{v}\left\|\mathbf{v}_{\text {od }}\right\|^{2}-k_{v}\left\|\mathbf{v}_{\mathbf{o}}\right\|^{2}+ \\
& +\mathbf{v}_{\text {od }}{ }^{\mathrm{T}} \mathbf{A}_{\mathbf{q}}{ }^{\mathrm{T}} \overline{\mathbf{C}} \mathbf{A}_{\mathbf{q}} \mathbf{v}_{\text {od }}-\mathbf{v}_{\mathbf{o}}{ }^{\mathrm{T}} \mathbf{A}_{\mathbf{q}}{ }^{\mathrm{T}} \overline{\mathbf{C}} \mathbf{A}_{\mathbf{q}} \mathbf{v}_{\mathbf{o d}}
\end{aligned}
$$

na qual

$$
\begin{aligned}
& \mathbf{v}_{1}=\mathbf{M}_{\mathbf{o}} \dot{\mathbf{v}}_{\mathbf{o d}}+\mathbf{A}_{\mathbf{q}}{ }^{\mathrm{T}} \overline{\mathbf{M}} \ddot{\overline{\mathbf{q}}}_{\mathbf{d}} ; \\
& \mathbf{v}_{2}=-\mathbf{M}_{\mathbf{0}} \dot{\mathbf{v}}_{\text {od }}-\mathbf{A}_{\mathbf{q}}{ }^{\mathrm{T}} \overline{\mathbf{M}} \ddot{\overline{\mathbf{q}}}_{\mathbf{d}} ; \\
& \mathbf{v}_{3}=2 \mathbf{K}_{\mathbf{v}}{ }^{\mathrm{T}} \mathbf{v}_{\mathbf{o d}} .
\end{aligned}
$$

Como, as trajetórias desejadas pertencem ao conjunto $S$ e os termos dependentes do modelo em $\boldsymbol{v}_{1}, \boldsymbol{v}_{2}$ são contínuos e limitados, então $\boldsymbol{v}_{1}, \boldsymbol{v}_{2}, \boldsymbol{v}_{3} \in L_{2}([0, \infty))$. Integrando a eq. (5.38) entre os instantes $t_{0}$ e $t$, pode-se escrever que

$$
\begin{aligned}
V(t)-V\left(t_{0}\right) \leq \mid & \int_{t_{o}}^{t} \mathbf{v}_{\mathbf{o d}}(t)^{\mathrm{T}} \mathbf{v}_{1}(t) \mathrm{dt}|+| \int_{t_{o}}^{t} \mathbf{v}_{\mathbf{o}}(t)^{\mathrm{T}} \mathbf{v}_{2}(t) \mathrm{dt}|+| \int_{t_{o}}^{t} \mathbf{v}_{3}(t)^{\mathrm{T}} \mathbf{v}_{\mathbf{o}}(t) \mathrm{dt} \mid+ \\
& +\left|\int_{t_{0}}^{t} \mathbf{v}_{\mathbf{o d}}{ }^{\mathrm{T}} \mathbf{A}_{\mathbf{q}}{ }^{\mathrm{T}} \overline{\mathbf{C}} \mathbf{A}_{\mathbf{q}} \mathbf{v}_{\mathbf{o d}} \mathrm{dt}\right|+\left|\int_{t_{0}}^{t} \mathbf{v}_{\mathbf{o}}{ }^{\mathrm{T}} \mathbf{A}_{\mathbf{q}}{ }^{\mathrm{T}} \overline{\mathbf{C}} \mathbf{A}_{\mathbf{q}} \mathbf{v}_{\mathbf{o d}} \mathrm{dt}\right|+ \\
& -\left.\int_{t_{o}}^{t} k_{v}\left\|\left.\mathbf{v}_{\mathbf{o d}}(t)\right|^{2} \mathrm{dt}-\int_{t_{o}}^{t} k_{v}\right\| \mathbf{v}_{\mathbf{o}}(t)\right|^{2} \mathrm{dt}
\end{aligned}
$$


Lembrando agora que qualquer produto interno satisfaz a Desigualdade de CauchySchwarz [GREEN \& LIMEBEER, 1995], ou seja,

$$
\left|\langle\mathbf{x}, \mathbf{y}\rangle_{\left[t_{o}, t\right]}\right|=\left|\int_{t_{0}}^{t} \mathbf{x}^{\mathrm{T}} \mathbf{y} \mathrm{dt}\right| \leq\|\mathbf{x}\|_{L_{2}}\|\mathbf{y}\|_{L_{2}}
$$

na qual $\|\cdot\|_{L_{2}}$ representa a norma $L_{2}$ (Lebesgue) de horizonte finito dada por

$$
\|\mathbf{x}\|_{L_{2}}=\left\{\int_{t_{0}}^{t}\|\mathbf{x}\|^{2} \mathrm{dt}\right\}^{1 / 2},
$$

a eq. (5.39) torna-se

$$
\begin{aligned}
V(t)-V\left(t_{0}\right) \leq & \left\|\mathbf{v}_{1}\right\|_{L_{2}}\left\|\mathbf{v}_{\mathbf{o d}}\right\|_{L_{2}}+\left\|\mathbf{v}_{2}\right\|_{L_{2}}\left\|\mathbf{v}_{\mathbf{o}}\right\|_{L_{2}}+\left\|\mathbf{v}_{3}\right\|_{L_{2}}\left\|\mathbf{v}_{\mathbf{o}}\right\|_{L_{2}}+\left\|\mathbf{A}_{\mathbf{q}} \mathbf{v}_{\mathbf{o d}}\right\|_{L_{2}}\left\|\overline{\mathbf{C}} \mathbf{A}_{\mathbf{q}} \mathbf{v}_{\mathbf{o d}}\right\|_{L_{2}}+ \\
& +\left\|\mathbf{A}_{\mathbf{q}} \mathbf{v}_{\mathbf{o}}\right\|_{L_{2}}\left\|\overline{\mathbf{C}} \mathbf{A}_{\mathbf{q}} \mathbf{v}_{\mathbf{o d}}\right\|_{L_{2}}-k_{v}\left\|\mathbf{v}_{\mathbf{o d}}\right\|_{L_{2}}^{2}-k_{v}\left\|\mathbf{v}_{\mathbf{o}}\right\|_{L_{2}}^{2}
\end{aligned}
$$

A seguinte relação é válida para o termo $\left\|\mathbf{A}_{\mathbf{q}} \mathbf{v}_{\text {od }}\right\|\left\|\overline{\mathbf{C}_{L_{2}}} \mathbf{A}_{\mathbf{q}} \mathbf{v}_{\mathbf{~ o d}}\right\|_{L_{2}}$ $\left\|\mathbf{A}_{\mathbf{q}} \mathbf{v}_{\text {od }}\right\|_{L_{2}}\left\|\overline{\mathbf{C}} \mathbf{A}_{\mathbf{q}} \mathbf{v}_{\text {od }}\right\|_{L_{2}} \leq\left\|\mathbf{A}_{\mathbf{q}} \mathbf{v}_{\text {od }}\right\|_{L_{2}}\|\overline{\mathbf{C}}\|_{L_{\infty}}\left\|\mathbf{A}_{\mathbf{q}}\right\|_{L_{\infty}}\left\|\mathbf{v}_{\text {od }}\right\|_{L_{2}}$

sendo \|\|$_{L_{\infty}}$ a norma $L_{\infty}$ [GREEN \& LIMEBEER, 1995]. Como $\overline{\mathbf{C}}=\overline{\mathbf{C}}\left(\mathbf{v}_{\mathbf{o}}\right)$, então a seguinte relação é válida

$$
\left\|\mathbf{A}_{\mathbf{q}} \mathbf{v}_{\text {od }}\right\|\left\|_{L_{2}}\right\| \overline{\mathbf{C}} \mathbf{A}_{\mathbf{q}} \mathbf{v}_{\mathbf{o d}}\left\|_{L_{2}} \leq k_{1}\right\| \mathbf{A}_{\mathbf{q}} \mathbf{v}_{\text {od }}\left\|_{L_{2}}\right\| \mathbf{A}_{\mathbf{q}} \mathbf{v}_{\text {od }}\left\|_{L_{2}}\right\| \mathbf{v}_{\mathbf{o}} \|_{L_{2}}
$$

na qual $k_{1}$ é uma constante positiva.

Fazendo o mesmo para o termo $\left\|\mathbf{A}_{\mathbf{q}} \mathbf{v}_{\text {od }}\right\|_{L_{2}}\left\|\overline{\mathbf{C}} \mathbf{A}_{\mathbf{q}} \mathbf{v}_{\mathbf{o}}\right\|_{L_{2}}$, então pode-se escrever que

$$
\left\|\mathbf{A}_{\mathbf{q}} \mathbf{v}_{\text {od }}\right\|_{L_{2}}\left\|\overline{\mathbf{C}} \mathbf{A}_{\mathbf{q}} \mathbf{v}_{\mathbf{o}}\right\|_{L_{2}} \leq k_{1}\left\|\mathbf{A}_{\mathbf{q}} \mathbf{v}_{\mathbf{~ o d}}\right\|_{L_{2}}\left\|\mathbf{A}_{\mathbf{q}}\right\|_{L_{\infty}}\left\|\mathbf{v}_{\mathbf{o}}\right\|_{L_{2}}^{2}
$$

Substituindo as relações dadas em (5.41a) e (5.41b) na eq. (5.40), então é possível escrever que

$$
V(t)-V\left(t_{0}\right) \leq k_{2}\left\|\mathbf{v}_{\mathbf{o d}}\right\|_{L_{2}}+k_{3}\left\|\mathbf{v}_{\mathbf{o}}\right\|_{L_{2}}+k_{4}\left\|\mathbf{v}_{\mathbf{o}}\right\|_{L_{2}}^{2}-k_{v}\left\|\mathbf{v}_{\mathbf{o d}}\right\|_{L_{2}}^{2}-k_{v}\left\|\mathbf{v}_{\mathbf{o}}\right\|_{L_{2}}^{2} \quad .
$$

na qual

$k_{2}=\left\|\boldsymbol{v}_{1}\right\|_{L_{2}} ;$ 


$$
\begin{aligned}
& k_{3}=k_{1}\left\|\mathbf{A}_{\mathbf{q}} \mathbf{v}_{\text {od }}\right\|_{L_{2}}^{2}\left\|\mathbf{v}_{\text {od }}\right\|_{L_{2}} ; \\
& k_{4}=k_{1}\left\|\mathbf{A}_{\mathbf{q}} \mathbf{v}_{\text {od }}\right\|_{L_{2}}\left\|\mathbf{A}_{\mathbf{q}}\right\|_{L_{2}} ;
\end{aligned}
$$

Os termos $k_{2}, k_{3}, k_{4}$ e $k_{v}$ da eq. (5.42) são todos positivos e uniformemente limitados para as trajetórias pertencentes ao conjunto $S$. Considerando $k_{v}>k_{4}$ (o que pode ocorrer tanto pela escolha apropriada da matriz $\mathbf{K}_{\mathbf{v}}$ quanto pelo uso de um $t_{0}$ suficientemente grande, desde que $V\left(t_{o}\right)$ seja limitada), então pode se escrever que

$$
V(t)-V\left(t_{0}\right) \leq k_{2}\left\|\mathbf{v}_{\mathbf{o d}}\right\|_{L_{2}}+k_{3}\left\|\mathbf{v}_{\mathbf{o}}\right\|_{L_{2}}-k_{v}\left\|\mathbf{v}_{\mathbf{o d}}\right\|_{L_{2}}^{2}-k_{5}\left\|\mathbf{v}_{\mathbf{o}}\right\|_{L_{2}}^{2} \quad .
$$

na qual $k_{5}=\left(k_{v}-k_{4}\right)>0$.

Completando os quadrados da eq. (5.43)

$$
V(t)-V\left(t_{0}\right) \leq-k_{v}\left(\left\|\mathbf{v}_{\mathbf{o d}}\right\|_{L_{2}}-\frac{k_{2}}{2 k_{v}}\right)^{2}-k_{5}\left(\left\|\mathbf{v}_{\mathbf{o}}\right\|_{L_{2}}-\frac{k_{3}}{2 k_{5}}\right)^{2}+\frac{k_{2}{ }^{2}}{4 k_{v}}+\frac{k_{3}^{2}}{4 k_{5}} .
$$

Como $k_{v}$ e $k_{5}$ são sempre positivos, $V(t)-V\left(t_{0}\right)$ é limitado superiormente pelo soma do terceiro e quarto termos da eq. (5.44), ou seja,

$$
V(t)-V\left(t_{0}\right) \leq+\frac{k_{2}^{2}}{4 k_{v}}+\frac{k_{3}^{2}}{4 k_{5}}
$$

Escolhendo $t_{0}$ de tal modo que $V\left(t_{o}\right)$ é limitado e sabendo que $V(t)$ é por definição maior ou igual a zero, a eq. (5.44) implica que $V(t)$ é uniformemente limitado para $t>0$ já que $k_{2}, k_{3}$, e $k_{5}$ são todos uniformemente limitados.

Se $V(t)$ é uniformemente limitado, então pela eq. (5.33), $\Delta \mathbf{x}_{\mathbf{0}}, \boldsymbol{\Delta} \mathbf{v}_{\mathbf{0}}, \Delta \dot{\overline{\mathbf{q}}}$ são uniformemente limitados, o que implica que $\mathbf{x}_{\mathbf{0}}, \mathbf{v}_{\mathbf{0}}, \dot{\overline{\mathbf{q}}}$ são uniformemente limitados já que os são $\mathbf{x}_{\text {od }}, \mathbf{v}_{\text {od }}, \dot{\overline{\mathbf{q}}}_{\mathbf{d}}$.

Assim, como $\mathbf{v}_{\mathbf{0}}$ é uniformemente contínuo, então $\Delta \mathbf{v}_{\mathbf{0}}, \mathbf{v}_{\mathbf{0}}, \dot{\mathbf{v}}_{\mathbf{0}} \rightarrow \mathbf{0}$ quando $t \rightarrow \infty$, ou seja, o objeto sempre irá para uma situação de repouso e o erro de velocidade sempre convergirá para zero quando o controlador descrito pelas eqs. (5.16), (5.17) e (5.22) é utilizado, o que completa a primeira parte da prova.

Considere agora o item $b$. Substituindo a equação dinâmica das juntas passivas (eq. 5.15) e a lei de controle de movimento (eqs. 5.16, 5.17 e 5.22) na eq. dinâmica das juntas ativas (eq. 5.15) para $\dot{\mathbf{q}}=\ddot{\mathbf{q}}=\mathbf{0}$, então 


$$
\mathbf{Q}^{\mathrm{T}} \mathbf{T}^{-\mathrm{T}} \mathbf{K}_{\mathbf{p}} \boldsymbol{\Delta} \mathbf{x}_{\mathbf{o}}+\left(\mathbf{J}_{\mathbf{a}}{ }^{\mathrm{T}}-\mathbf{A}_{\mathbf{o}}{ }^{\mathrm{T}} \mathbf{J}_{\mathbf{p}}{ }^{\mathrm{T}}\right) \mathbf{h}+\left(\mathbf{J}_{\mathbf{a}}{ }^{\mathrm{T}}-\mathbf{A}_{\mathbf{o}}{ }^{\mathrm{T}} \mathbf{J}_{\mathbf{p}}{ }^{\mathrm{T}}\right) \mathbf{f}_{\mathbf{g}}=\mathbf{0}_{n_{a} \times 1}
$$

Substituindo agora a eq. (5.23) na eq. (3.7b) para $\mathbf{v}_{\mathbf{0}}=\dot{\mathbf{v}}_{\mathbf{0}}=\mathbf{0}$,

$$
\mathbf{J}_{\mathbf{o}}{ }^{\mathrm{T}} \mathbf{f}_{\mathbf{g}}=-\mathbf{J}_{\mathbf{o}}{ }^{\mathrm{T}} \mathbf{h}
$$

Como $\mathbf{J}_{\mathbf{0}}$ é uma matriz de tamanho ( $\left.m k \times k\right)$, a eq. (5.47) não implica necessariamente que $\mathbf{f}_{\mathbf{g}}=-\mathbf{h}$. Se o vetor $\mathbf{f}_{\mathbf{g}}$ é escolhido de modo a não provocar esmagamento no CM do objeto, então a eq. (5.47) implica que, em repouso,

$$
\mathbf{f}_{\mathrm{g}}=-\mathbf{J}_{\mathrm{oq}}{ }^{-\mathrm{T}} \mathbf{h}_{\mathrm{om}}
$$

na qual $\mathbf{h}_{\mathbf{o m}} \in \boldsymbol{X}_{\boldsymbol{m}}$ é a força de movimento (eq. 3.24) e a matriz $\mathbf{J}_{\mathbf{o q}}{ }^{\mathrm{T}}$ projeta as forças dos efetuadores no CM do objeto (eq. 3.20). Substituindo a eq. (5.48) na eq. (5.46) e lembrando que $\mathbf{h}=\mathbf{J}_{\mathbf{o q}}{ }^{-\mathrm{T}} \mathbf{h}_{\mathbf{o}}$ (eq. 3.20), então

$$
\mathbf{Q}^{\mathrm{T}} \mathbf{T}^{-\mathrm{T}} \mathbf{K}_{\mathbf{p}} \boldsymbol{\Delta} \mathbf{x}_{\mathbf{o}}+\left(\mathbf{J}_{\mathbf{a}}{ }^{\mathrm{T}}-\mathbf{A}_{\mathbf{o}}{ }^{\mathrm{T}} \mathbf{J}_{\mathbf{p}}{ }^{\mathrm{T}}\right) \mathbf{J}_{\mathbf{o q}}{ }^{-\mathrm{T}} \mathbf{h}_{\mathbf{o}}-\left(\mathbf{J}_{\mathbf{a}}{ }^{\mathrm{T}}-\mathbf{A}_{\mathbf{o}}{ }^{\mathrm{T}} \mathbf{J}_{\mathbf{p}}{ }^{\mathrm{T}}\right) \mathbf{J}_{\mathbf{o q}}{ }^{-\mathrm{T}} \mathbf{h}_{\mathbf{o m}}=\mathbf{0}_{n_{a} \times 1}
$$

Como $\mathbf{h}_{\mathbf{o}}=\mathbf{h}_{\mathbf{o m}}+\mathbf{h}_{\mathbf{o e}}$ (eq. 3.24) e sabendo que a força de esmagamento pode ser decomposta em $\mathbf{h}_{\mathbf{o e}}=\mathbf{h}_{\text {oem }}+\mathbf{h}_{\text {oec }}$ (eq. 3.29), sendo a componente induzida pelo movimento $\mathbf{h}_{\text {oem }}=\mathbf{0}$ para a situação de repouso, então

$$
\mathbf{Q}^{\mathrm{T}} \mathbf{T}^{-\mathrm{T}} \mathbf{K}_{\mathbf{p}} \boldsymbol{\Delta} \mathbf{x}_{\mathbf{o}}+\left(\mathbf{J}_{\mathbf{a}}{ }^{\mathrm{T}}-\mathbf{A}_{\mathbf{o}}{ }^{\mathrm{T}} \mathbf{J}_{\mathbf{p}}{ }^{\mathrm{T}}\right) \mathbf{J}_{\mathbf{o q}}{ }^{-\mathrm{T}} \mathbf{h}_{\mathbf{o e c}}=\mathbf{0}_{n_{a} \times 1}
$$

o que completa a segunda parte da prova.

O Teorema 5.1 indica que o erro de posição varia com a componente do esmagamento $\mathbf{h}_{\text {oec }}$. A seguir, o controle desta componente do esmagamento é tratado.

\subsubsection{Controle de Esmagamento do Objeto:}

O controle do esmagamento é feito através de componentes nas forças generalizadas das juntas ativas que projetam forças no objeto pertencentes ao subespaço de esmagamento. 
Para o sistema cooperativo sem juntas passivas, a componente responsável pelo controle de esmagamento é dada por (eq. 3.35)

$\tau_{\mathrm{e}}=-\mathbf{E}^{\mathrm{T}} \overline{\mathbf{h}}_{\text {oec }}$

na qual a matriz $\mathbf{E}^{\mathrm{T}}$, que tem tamanho $(n \times m k)$, projeta as $m k$ componentes da força de esmagamento $\overline{\mathbf{h}}_{\mathbf{o e c}} \in \boldsymbol{X}_{e}$ no espaço das juntas.

Como $\overline{\mathbf{h}}_{\text {oec }}$ tem $m k$ componentes e a dimensão de $\boldsymbol{X}_{e}$ é $k \times(m-1)$, é possível escrever que

$$
\overline{\mathbf{h}}_{\text {oec }}=\widetilde{\mathbf{A}}^{\mathrm{T}} \boldsymbol{\gamma}_{\mathbf{e}}
$$

na qual as colunas da matriz com posto pleno $\tilde{\mathbf{A}}^{\mathrm{T}}$ projetam o espaço nulo de $\mathbf{A}^{\mathrm{T}}$, ou seja, $\operatorname{Im}\left(\tilde{\mathbf{A}}^{\mathrm{T}}\right)=\boldsymbol{X}_{e}$ (ver Seção 3.4) e as novas variáveis desejadas são as $k \times(m-1)$ componentes do vetor $\gamma_{\mathrm{e}}$. Por exemplo, o vetor $\boldsymbol{\gamma}_{\mathrm{e}}$ tem três componentes em um sistema cooperativo planar com dois manipuladores pois as três componentes da força de esmagamento produzidas por um robô têm o mesmo módulo que aquelas produzidas pelo outro robô.

Desta forma

$\tau_{\mathbf{e}}=-\mathbf{E}^{\mathrm{T}} \tilde{\mathbf{A}}^{\mathrm{T}} \boldsymbol{\gamma}_{\mathbf{e}}$

Para o sistema com juntas passivas, a eq. (5.52) pode ser particionada como

$$
\left[\begin{array}{c}
\boldsymbol{\tau}_{\mathrm{ae}} \\
\mathbf{0}_{n_{p} \times 1}
\end{array}\right]=\left[\begin{array}{l}
-\mathbf{E}_{\mathbf{a}}{ }^{\mathrm{T}} \\
-\mathbf{E}_{\mathbf{p}}{ }^{\mathrm{T}}
\end{array}\right] \tilde{\mathbf{A}}^{\mathrm{T}} \boldsymbol{\gamma}_{\mathbf{e}} .
$$

Repare que $n_{p}$ restrições são impostas pelas juntas passivas nas componentes do vetor $\gamma_{\mathrm{e}}$.

Dois casos devem agora ser considerados a partir da análise da eq. (5.53): quando existem ou não robôs cinematicamente redundantes no sistema cooperativo.

Quando não existem robôs redundantes, ou seja, $n=m k$, então nem todas as componentes do vetor $\boldsymbol{\gamma}_{\mathrm{e}}$ podem ser independentemente controladas. Como $n_{p}$ restrições são impostas (eq. 5.53), o número de componentes do vetor $\boldsymbol{\gamma}_{\mathbf{e}}$, cujo tamanho é $k \times(m-1)$, que podem ser independentemente controladas é

$$
n_{e}= \begin{cases}k(m-1)-n_{p}=n_{a}-k & \text { se } n_{a}>k \\ 0 & \text { se } n_{a} \leq k\end{cases}
$$

A Tabela 5.1 mostra o valor de $n_{e}$ para sistemas cooperativos com $m$ manipuladores, $k$ componentes de movimento (ou força) na carga, $n_{a}$ juntas ativas e $n_{p}$ juntas 
passivas. Repare que para o sistema cooperativo sem juntas passivas é possível controlar todos as componentes do vetor $\gamma_{\mathrm{e}}$.

TABELA 5.1. Número de componentes independentemente controladas $\left(n_{e}\right)$ do vetor $\gamma_{\mathrm{e}}$ para $m=2$ ou 3 manipuladores planares.

\begin{tabular}{l|llllllll}
\hline$m$ & 2 & 2 & 2 & 2 & 3 & 3 & $\ldots$ & 3 \\
$k$ & 3 & 3 & 3 & 3 & 3 & 3 & $\ldots$ & 3 \\
$n_{a}$ & 6 & 5 & 4 & 3 & 9 & 8 & $\ldots$ & 3 \\
$n_{p}$ & 0 & 1 & 2 & 3 & 0 & 1 & $\ldots$ & 6 \\
\hline$n_{e}$ & 3 & 2 & 1 & 0 & 6 & 5 & $\ldots$ & 0 \\
\hline número de componentes de $\boldsymbol{\gamma}_{\mathbf{e}}$ & 3 & 3 & 3 & 3 & 6 & 6 & $\ldots$ & 6 \\
\hline
\end{tabular}

Pode-se, portanto, formular o problema do controle de $n_{e}$ componentes do vetor $\boldsymbol{\gamma}_{\mathbf{e}}$ quando $n_{\mathrm{a}}>k$. Particionando o vetor $\gamma_{\mathrm{e}}$ através de uma matriz de permutação $\mathbf{P}_{\text {ed }}$ como

$\mathbf{P}_{\mathrm{ed}} \gamma_{\mathrm{e}}=\left[\begin{array}{c}\gamma_{\mathrm{ec}} \\ \gamma_{\mathrm{en}}\end{array}\right]$

na qual $\boldsymbol{\gamma}_{\mathrm{ec}}$ é o vetor das $n_{e}$ componentes independentemente controladas e o vetor $\boldsymbol{\gamma}_{\mathrm{en}}$ tem suas $n_{p}$ componentes calculadas através das equações das juntas passivas (eq. 5.53) como funções do vetor $\boldsymbol{\gamma}_{\text {ec }}$. Ou seja, para o instante $t$

$\boldsymbol{\gamma}_{\mathrm{en}}(t)=f\left(\boldsymbol{\gamma}_{\mathrm{ec}}(t)\right)$

Resta, agora, o cálculo do vetor $\boldsymbol{\gamma}_{\mathbf{e c}}$. Utilizando o integrador sugerido por [WEN \& KREUTZ-DELGADO, 1992] (ver Seção 3.5.1), então para o instante $t$

$\boldsymbol{\gamma}_{\mathrm{ec}}(t)=\boldsymbol{\gamma}_{\mathrm{ecd}}(t)+\mathbf{K}_{\mathbf{i}} \int_{s=t_{0}}^{s=t}\left(\gamma_{\mathrm{ecd}}(s)-\boldsymbol{\gamma}_{\mathrm{ec}}(s)\right) d s$

na qual $\boldsymbol{\gamma}_{\text {ecd }}(t)$ é o vetor dos valores desejados e $\mathbf{K}_{\mathbf{i}}$ é uma matriz diagonal e positiva.

Portanto, o controle do esmagamento para $n_{\mathrm{a}}>k$ é dado por

$\tau_{\mathbf{a e}}(t)=-\mathbf{E}_{\mathbf{a}}(\mathbf{q}(t))^{\mathrm{T}} \tilde{\mathbf{A}}^{\mathrm{T}} \boldsymbol{\gamma}_{\mathbf{e}}(t)$

na qual $\boldsymbol{\gamma}_{\mathbf{e}}(t)$ é definido nas eqs. (5.55-57).

As componentes de $\gamma_{\text {ec }}(t)$ que são independentemente controladas devem ser escolhidas de acordo com a aplicação do sistema cooperativo. Por exemplo, se o objeto manipulado é frágil em uma determinada direção, esta deve ser utilizada para escolher as componentes independentemente controladas. Além disso, note que as colunas da matriz $\mathbf{E}_{\mathbf{p}}{ }^{\mathrm{T}}$ 
que multiplicam $\boldsymbol{\gamma}_{\mathrm{en}}$ na eq. (5.53) não podem ser colunas de zeros. Isso também é válido para as colunas de $\mathbf{E}_{\mathbf{a}}{ }^{\mathrm{T}}$ que multiplicam $\boldsymbol{\gamma}_{\mathbf{e c}}$ na eq. (5.58).

Quando existem manipuladores redundantes no sistema cooperativo, ou seja, $n>m k$, todas as componentes do vetor $\boldsymbol{\gamma}_{\mathrm{e}}$ podem ser independentemente controladas se:

(i) a junta passiva está em um manipulador redundante;

(ii) as colunas da matriz $\mathbf{E}_{\mathbf{p}}{ }^{\mathrm{T}}$ que multiplicam $\boldsymbol{\gamma}_{\mathrm{en}}$ na eq. (5.53) são colunas de zeros ${ }^{2}$, e;

(iii) $n_{a} \geq m k$.

Caso contrário, o número de componentes do vetor $\boldsymbol{\gamma}_{\mathbf{e}}$ que podem ser independentemente controladas é

$n_{e_{-} r}=\left\{\begin{array}{lr}k(m-1)-n_{p} & \text { se } n_{a}>k \\ 0 & \text { se } n_{a} \leq k\end{array}\right.$.

Em ambos os casos, a lei de controle definida pela eq. (5.58) pode ser utilizada.

É importante salientar que o replanejamento das trajetórias pode ser utilizado para reduzir os valores de $\boldsymbol{\gamma}_{\text {en }}$ através da redução das componentes do vetor da força de esmagamento causadas pelo movimento $\left(\mathbf{h}_{\text {oem }}\right)$ na eq. (3.29). O sistema cooperativo deve mover o objeto mais lentamente quando existem juntas passivas, o que ocasionará uma redução das componentes da força de esmagamento influenciadas pelo movimento. No entanto, tal solução minimiza o problema durante o período transitório em que o objeto está se movimentando, mas não quando o objeto está em repouso.

\subsection{CONTROLE DO SISTEMA COOPERATIVO COM JUNTAS BLOQUEADAS}

Considere agora que, das $n$ juntas do sistema cooperativo, $n_{b}$ sejam bloqueadas e $n_{a}=n-n_{b}$ sejam ativas, ou seja, com atuação e não-bloqueadas. Particionando a equação dinâmica dos manipuladores (eq. 3.5) para que apareçam as variáveis relacionadas às juntas ativas e bloqueadas, tem-se a seguinte equação na qual os termos friccionais são ignorados e os termos de dependência entre parêntesis não são mostrados por simplicidade,

\footnotetext{
${ }^{2}$ Este requisito pode ser imposto já que a Matriz Jacobiana $\mathbf{J}_{i}$ não é única em um manipulador redundante. Observe, no entanto, que esta imposição inviabiliza o controle de movimento do sistema com juntas passivas já que a Suposição 5.3 não é mais válida.
} 


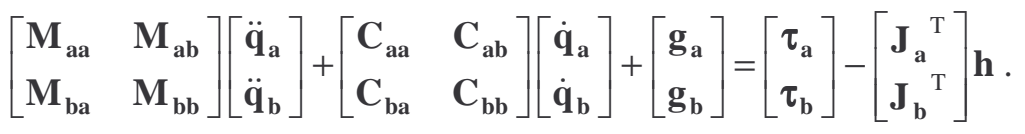

na qual o índice $a$ refere-se às quantidades relacionadas às juntas ativas e o índice $b$ àquelas relacionadas às juntas bloqueadas. Para as juntas bloqueadas, é seguinte relação é válida

$\tau_{\mathrm{b}}=\mathbf{M}_{\mathrm{ba}} \ddot{\mathbf{q}}_{\mathrm{a}}+\mathbf{M}_{\mathrm{bb}} \ddot{\mathbf{q}}_{\mathrm{b}}+\mathbf{C}_{\mathrm{ba}} \dot{\mathbf{q}}_{\mathrm{a}}+\mathbf{C}_{\mathrm{bb}} \dot{\mathbf{q}}_{\mathrm{b}}+\mathbf{J}_{\mathrm{b}}{ }^{\mathrm{T}} \mathbf{h}$

que quando substituída na eq. (5.60) leva a

$\ddot{\mathbf{q}}_{\mathbf{b}}=\mathbf{0}_{n_{b} x 1}$ e $\dot{\mathbf{q}}_{\mathbf{b}}=\mathbf{0}_{n_{b} x 1}$.

O interesse aqui é projetar um controlador para o sistema cooperativo com juntas bloqueadas semelhante àquele desenvolvido na seção 5.3 para robôs com juntas passivas. Portanto, primeiro a Matriz Jacobiana que relaciona as velocidades nas juntas ativas com as velocidades no $\mathrm{CM}$ do objeto será deduzida através de procedimento semelhante àquele adotado na seção 5.2.1.

Particionando a eq. (3.12) entre as relações relativas às juntas bloqueadas e ativas, tem-se

$$
\begin{aligned}
m \mathbf{v}_{\mathbf{o}}= & \mathbf{D}_{\mathbf{a} 1}\left(\mathbf{q}_{1}\right) \dot{\mathbf{q}}_{\mathbf{a}}+\mathbf{D}_{\mathbf{b} 1}\left(\mathbf{q}_{1}\right) \dot{\mathbf{q}}_{\mathbf{b}}+ \\
& +\mathbf{D}_{\mathbf{a} 2}\left(\mathbf{q}_{2}\right) \dot{\mathbf{q}}_{\mathbf{a}}+\mathbf{D}_{\mathbf{b} 2}\left(\mathbf{q}_{2}\right) \dot{\mathbf{q}}_{\mathbf{b}}+\cdots+\mathbf{D}_{\mathbf{a} m}\left(\mathbf{q}_{m}\right) \dot{\mathbf{q}}_{\mathbf{a}}+\mathbf{D}_{\mathbf{b} m}\left(\mathbf{q}_{m}\right) \dot{\mathbf{q}}_{\mathbf{b}}
\end{aligned}
$$

Utilizando a restrição imposta pela eq. (5.62), então

$\mathbf{v}_{\mathbf{o}}=\frac{1}{m} \mathbf{D}_{\mathbf{a}} \dot{\mathbf{q}}_{\mathbf{a}}$

na qual a matriz $\mathbf{D}_{a}$ é dada pela eq. (5.4). Da equação anterior,

$$
\mathbf{v}_{\mathbf{o}}=\mathbf{Q}_{\mathbf{b}} \dot{\mathbf{q}}_{\mathbf{a}}
$$

na qual

$$
\mathbf{Q}_{\mathbf{b}}=\frac{1}{m} \mathbf{D}_{\mathbf{a}}
$$

é a Matriz Jacobiana de transformação entre as velocidades nas juntas ativas e a velocidade no $\mathrm{CM}$ do objeto para o caso em que existem juntas bloqueadas.

Quando uma ou mais juntas são bloqueadas, o espaço de trabalho do sistema cooperativo fica reduzido. Este é um problema que afeta o planejamento da trajetória do objeto. Dependendo da tarefa e das configurações cinemáticas dos manipuladores, principalmente no que diz respeito à redundância cinemática de cada robô, a tarefa deve ser 
replanejada ou mesmo interrompida. O problema da determinação do espaço de trabalho e do planejamento de trajetórias do sistema cooperativo com falhas do tipo junta bloqueada deve ser tratado considerando-se individualmente o espaço de trabalho e o planejamento de trajetórias de cada robô com junta bloqueadas e não é estudado neste trabalho.

O controlador para o sistema com juntas bloqueadas é projetado da mesma forma que o controlador para o sistema com juntas passivas. Primeiro, são projetadas as componentes das forças generalizadas nas juntas para o controle do movimento e para a compensação dos termos gravitacionais. Então, um controle da força de esmagamento que não afeta o movimento é considerado. Assim, a lei de controle para as juntas ativas é dada por

$$
\tau_{\mathrm{a}}=\tau_{\mathrm{amg}}+\tau_{\mathrm{ae}}
$$

na qual $\boldsymbol{\tau}_{\mathrm{am}}$ é o componente responsável pelo controle de movimento e $\boldsymbol{\tau}_{\mathrm{ag}}$ é o componente responsável pela compensação dos torques gravitacionais.

A seguinte lei para o controle do movimento é proposta aqui

$$
\tau_{\mathrm{amg}}=\tau_{\mathrm{am}}+\tau_{\mathrm{ag}}
$$

na qual

$$
\begin{aligned}
& \tau_{\mathrm{am}}=\mathbf{Q}_{\mathbf{b}}{ }^{\mathrm{T}}{ }\left(\mathbf{T}^{-\mathrm{T}} \mathbf{K}_{\mathbf{p}} \Delta \mathbf{x}_{\mathbf{o}}+\mathbf{K}_{\mathbf{v}} \Delta \mathbf{v}_{\mathbf{o}}\right) \\
& \boldsymbol{\tau}_{\mathrm{ag}}=\mathbf{g}_{\mathbf{a}}+\mathbf{J}_{\mathrm{a}}{ }^{\mathrm{T}} \mathbf{f}_{\mathbf{g}} \\
& \text { sendo } \mathbf{f}_{\mathrm{g}} \text { dado na eq. (5.23). }
\end{aligned}
$$

Para o controle de movimento, os seguintes resultados são obtidos:

Teorema 5.2. Assuma que as Suposições 5.1 e 5.4 são satisfeitas e que a lei de controle de movimento dada pelas eqs. (5.68-70) seja utilizada. Então:

(i) O sistema cooperativo é assintoticamente estável, isto é, as velocidades do objeto são convergentes para zero quando $t \rightarrow \infty$.

(ii) O erro de posição converge para a variedade descrita por:

$$
\mathbf{Q}_{\mathbf{b}}{ }^{\mathrm{T}} \mathbf{T}^{-\mathrm{T}} \mathbf{K}_{\mathbf{p}} \boldsymbol{\Delta} \mathbf{x}_{\mathbf{o}}+\mathbf{J}_{\mathbf{a}}{ }^{\mathrm{T}} \mathbf{J}_{\mathbf{o q}}{ }^{-\mathrm{T}} \mathbf{h}_{\mathbf{o e c}}=\mathbf{0}_{n_{a} \times 1}
$$

Prova: 
Para o problema de controle do tipo set-point no qual as velocidades desejadas são iguais a zero, considere a seguinte função candidata de Lyapunov

$$
V=\frac{1}{2} \mathbf{v}_{\mathbf{o}}{ }^{\mathrm{T}} \mathbf{M}_{\mathbf{o}} \mathbf{v}_{\mathbf{o}}+\frac{1}{2} \dot{\mathbf{q}}_{\mathbf{a}}{ }^{\mathrm{T}} \mathbf{M}_{\mathrm{aa}} \dot{\mathbf{q}}_{\mathbf{a}}+\frac{1}{2} \Delta \mathbf{x}_{\mathbf{o}}{ }^{\mathrm{T}} \mathbf{K}_{\mathbf{p}} \Delta \mathbf{x}_{\mathbf{o}}
$$

na qual o primeiro termo é a energia cinética do objeto e o segundo termo é a energia cinética dos manipuladores.

Derivando a eq. (5.71) em relação ao tempo

$$
\dot{V}=\mathbf{v}_{\mathbf{o}}{ }^{\mathrm{T}} \mathbf{M}_{\mathbf{o}} \dot{\mathbf{v}}_{\mathbf{o}}++\dot{\mathbf{q}}_{\mathrm{a}}{ }^{\mathrm{T}} \mathbf{M}_{\mathrm{aa}} \ddot{\mathbf{q}}_{\mathrm{a}}+\frac{1}{2} \dot{\mathbf{q}}_{\mathrm{a}}{ }^{\mathrm{T}} \dot{\mathbf{M}}_{\mathrm{aa}} \dot{\mathbf{q}}_{\mathrm{a}}+\Delta \mathbf{x}_{\mathbf{o}}{ }^{\mathrm{T}} \mathbf{K}_{\mathbf{p}} \Delta \dot{\mathbf{x}}_{\mathbf{o}}
$$

Analisando a equação acima similarmente à análise feita para o sistema com juntas passivas (eq. 5.27-30), tem-se que

$$
\dot{V}=-\mathbf{v}_{\mathbf{o}}{ }^{\mathrm{T}}\left(\mathbf{c}_{\mathbf{o}}+\mathbf{g}_{\mathbf{o}}\right)-\dot{\mathbf{q}}_{\mathrm{a}}^{\mathrm{T}} \mathbf{g}_{\mathbf{a}}+\dot{\mathbf{q}}_{\mathrm{a}}^{\mathrm{T}} \boldsymbol{\tau}_{\mathbf{a}}+\Delta \mathbf{x}_{\mathbf{o}}{ }^{\mathrm{T}} \mathbf{K}_{\mathbf{p}} \Delta \dot{\mathbf{x}}_{\mathbf{o}}
$$

Aplicando a lei de controle descrita pelas eqs. (5.68-70) na eq. (5.73),

então

$$
\dot{V}=-\mathbf{v}_{\mathbf{o}}{ }^{\mathrm{T}} \mathbf{K}_{\mathbf{v}} \mathbf{v}_{\mathbf{o}} \leq 0,
$$

o que implica, de acordo com o Princípio da Invariância [LASALLE, 1960], a convergência assintótica de $\mathbf{v}_{\mathbf{0}}$ para zero. Assim, o objeto sempre vai para uma situação de repouso quando o controlador descrito pelas eqs. (5.68-70) é utilizado.

Para o problema de seguimento de trajetórias pertencentes ao conjunto $S$, considere a seguinte função candidata de Lyapunov

$$
V=\frac{1}{2} \Delta \mathbf{v}_{\mathbf{o}}{ }^{\mathrm{T}} \mathbf{M}_{\mathbf{o}} \boldsymbol{\Delta} \mathbf{v}_{\mathbf{o}}+\frac{1}{2} \boldsymbol{\Delta} \dot{\mathbf{q}}_{\mathbf{a}}{ }^{\mathrm{T}} \mathbf{M}_{\mathrm{aa}} \Delta \dot{\mathbf{q}}_{\mathrm{a}}+\frac{1}{2} \boldsymbol{\Delta} \mathbf{x}_{\mathbf{o}}{ }^{\mathrm{T}} \mathbf{K}_{\mathbf{p}} \boldsymbol{\Delta} \mathbf{x}_{\mathbf{o}}
$$

na qual $\Delta \dot{\mathbf{q}}_{\mathbf{a}}=\left(\dot{\mathbf{q}}_{\text {ad }}-\dot{\overline{\mathbf{q}}}_{\mathbf{a}}\right)$, sendo $\dot{\mathbf{q}}_{\text {ad }}$ obtido através da projeção de $\mathbf{v}_{\text {od }}$ no espaço das juntas. Assim, pode-se escrever que (ver eq. 5.34)

$$
\dot{\overline{\mathbf{q}}}_{\mathbf{a d}}=\mathbf{P}_{\mathbf{a b}} \dot{\mathbf{q}}_{\mathbf{d}}=\mathbf{P}_{\mathbf{a b}}\left[\begin{array}{c}
\mathbf{D}_{1}\left(\mathbf{q}_{1}\right)^{-1} \\
\vdots \\
\mathbf{D}_{m}\left(\mathbf{q}_{m}\right)^{-1}
\end{array}\right] \mathbf{v}_{\mathbf{o d}}=\mathbf{A}_{\mathbf{q b}} \mathbf{v}_{\mathbf{o d}}
$$

Observe que $\Delta \dot{\overline{\mathbf{q}}}_{\mathbf{a}}$ não é usado nas leis de controle, aparecendo aqui somente para a demonstração da estabilidade do sistema.

Derivando a eq. (5.75) em relação ao tempo, 


$$
\dot{V}=\Delta \mathbf{v}_{\mathbf{o}}{ }^{\mathrm{T}} \mathbf{M}_{\mathbf{o}} \Delta \dot{\mathbf{v}}_{\mathbf{o}}+\Delta \dot{\mathbf{q}}_{\mathrm{a}}{ }^{\mathrm{T}} \mathbf{M}_{\mathrm{aa}} \Delta \ddot{\mathbf{q}}_{\mathrm{a}}+\frac{1}{2} \Delta \dot{\mathbf{q}}_{\mathrm{a}}{ }^{\mathrm{T}} \mathbf{M}_{\mathrm{aa}} \Delta \dot{\mathbf{q}}_{\mathrm{a}}+\Delta \mathbf{x}_{\mathbf{o}}{ }^{\mathrm{T}} \mathbf{K}_{\mathrm{p}} \Delta \dot{\mathbf{x}}_{\mathbf{o}}
$$

Substituindo as eqs. (3.7b) e (5.60) na eq. (5.76),

$$
\begin{aligned}
\dot{V}= & \Delta \mathbf{v}_{\mathbf{o}}{ }^{\mathrm{T}}\left(\mathbf{c}_{\mathbf{o}}+\mathbf{g}_{\mathbf{o}}\right)+\Delta \mathbf{v}_{\mathbf{o}}{ }^{\mathrm{T}} \mathbf{M}_{\mathbf{o}} \dot{\mathbf{v}}_{\mathrm{od}}+\Delta \dot{\mathbf{q}}_{\mathrm{a}}{ }^{\mathrm{T}} \mathbf{M}_{\mathrm{aa}} \ddot{\mathbf{q}}_{\mathrm{ad}}+\Delta \dot{\mathbf{q}}_{\mathrm{a}}{ }^{\mathrm{T}}\left(\mathbf{g}_{\mathrm{a}}+\mathbf{C}_{\mathrm{aa}} \dot{\mathbf{q}}_{\mathrm{a}}\right)-\Delta \dot{\mathbf{q}}_{\mathrm{a}}{ }^{\mathrm{T}} \tau_{\mathrm{a}}+ \\
& +\frac{1}{2} \Delta \dot{\mathbf{q}}_{\mathrm{a}}{ }^{\mathrm{T}} \dot{\mathbf{M}}_{\mathrm{aa}} \Delta \dot{\mathbf{q}}_{\mathrm{a}}+\Delta \mathbf{x}_{\mathbf{o}}{ }^{\mathrm{T}} \mathbf{K}_{\mathrm{p}} \Delta \dot{\mathbf{x}}_{\mathbf{o}} .
\end{aligned}
$$

Aplicando a lei de controle descrita pelas eqs. (5.68-70) na eq. (5.77) e a

$$
\begin{aligned}
& \dot{V}=\Delta \mathbf{v}_{\mathbf{o}}{ }^{\mathrm{T}}\left(\mathbf{c}_{\mathbf{o}}+\mathbf{g}_{\mathbf{o}}\right)+\Delta \mathbf{v}_{\mathbf{o}}{ }^{\mathrm{T}} \mathbf{M}_{\mathbf{o}} \dot{\mathbf{v}}_{\mathbf{o d}}+\Delta \dot{\mathbf{q}}_{\mathbf{a}}{ }^{\mathrm{T}} \mathbf{M}_{\mathrm{aa}} \ddot{\mathbf{q}}_{\mathrm{ad}}+\boldsymbol{\Delta} \dot{\mathbf{q}}_{\mathrm{a}}{ }^{\mathrm{T}} \mathbf{C}_{\mathrm{aa}} \dot{\mathbf{q}}_{\mathbf{a}}+\boldsymbol{\Delta} \mathbf{v}_{\mathbf{o}}{ }^{\mathrm{T}} \mathbf{J}_{\mathbf{o}}{ }^{\mathrm{T}} \mathbf{f}_{\mathrm{g}}+ \\
& +\frac{1}{2} \Delta \dot{\mathbf{q}}_{\mathrm{a}}{ }^{\mathrm{T}} \dot{\mathbf{M}}_{\mathrm{aa}} \boldsymbol{\Delta} \dot{\mathbf{q}}_{\mathrm{a}}+\Delta \mathbf{x}_{\mathbf{o}}{ }^{\mathrm{T}} \mathbf{K}_{\mathrm{p}} \boldsymbol{\Delta} \dot{\mathbf{x}}_{\mathbf{o}}-\boldsymbol{\Delta} \dot{\mathbf{q}}_{\mathbf{a}}{ }^{\mathrm{T}} \mathbf{Q}_{\mathbf{b}}{ }^{\mathrm{T}}\left(\mathbf{T}^{-\mathrm{T}} \mathbf{K}_{\mathbf{p}} \boldsymbol{\Delta} \mathbf{x}_{\mathbf{o}}+\mathbf{K}_{\mathbf{v}} \Delta \mathbf{v}_{\mathbf{o}}\right)+ \\
& \dot{V}=\Delta \mathbf{v}_{\mathbf{o}}{ }^{\mathrm{T}} \mathbf{M}_{\mathbf{o}} \dot{\mathbf{v}}_{\mathbf{o d}}+\Delta \dot{\mathbf{q}}_{\mathrm{a}}{ }^{\mathrm{T}} \mathbf{M}_{\mathrm{aa}} \ddot{\mathbf{q}}_{\mathrm{ad}}+\boldsymbol{\Delta} \dot{\mathbf{q}}_{\mathrm{a}}{ }^{\mathrm{T}} \mathbf{C}_{\mathrm{aa}} \dot{\mathbf{q}}_{\mathrm{a}}+\frac{1}{2} \boldsymbol{\Delta} \dot{\mathbf{q}}_{\mathrm{a}}{ }^{\mathrm{T}} \dot{\mathbf{M}}_{\mathrm{aa}} \boldsymbol{\Delta} \dot{\mathbf{q}}_{\mathrm{a}}-\Delta \mathbf{v}_{\mathbf{o}}{ }^{\mathrm{T}} \mathbf{K}_{\mathbf{v}} \boldsymbol{\Delta} \mathbf{v} \mathbf{0} \quad .
\end{aligned}
$$

Observe que a eq. (5.77) é similar à eq. (5.36) do sistema com juntas passivas. Considerando dedução similar àquela feita para o sistema com juntas passivas (eqs. 5.36-5.38), então a seguinte relação é válida

$$
\begin{aligned}
\dot{V} \leq & \mathbf{v}_{\text {od }}{ }^{\mathrm{T}} \boldsymbol{v}_{4}+\mathbf{v}_{\mathbf{o}}{ }^{\mathrm{T}} \boldsymbol{v}_{5}+\boldsymbol{v}_{6}{ }^{\mathrm{T}} \mathbf{v}_{\mathbf{o}}-k_{v}\left\|\mathbf{v}_{\mathbf{o d}}\right\|^{2}-k_{v}\left\|\mathbf{v}_{\mathbf{o}}\right\|^{2}+ \\
& +\mathbf{v}_{\mathbf{o d}}{ }^{\mathrm{T}} \mathbf{A}_{\mathbf{q b}}{ }^{\mathrm{T}} \mathbf{C}_{\mathbf{a a}} \mathbf{A}_{\mathbf{q b}} \mathbf{v}_{\mathbf{o d}}-\mathbf{v}_{\mathbf{o}}{ }^{\mathrm{T}} \mathbf{A}_{\mathbf{q b}}{ }^{\mathrm{T}} \mathbf{C}_{\mathbf{a a}} \mathbf{A}_{\mathbf{q b}} \mathbf{v}_{\mathbf{o d}}
\end{aligned}
$$

na qual

$$
\begin{aligned}
& k_{v}=\lambda_{\min }\left(\mathbf{K}_{\mathbf{v}}\right) ; \\
& \mathbf{v}_{4}=\mathbf{M}_{\mathbf{o}} \dot{\mathbf{v}}_{\mathbf{o d}}+\mathbf{A}_{\mathbf{q b}}{ }^{\mathrm{T}} \mathbf{M}_{\mathbf{a a}} \ddot{\overline{\mathbf{q}}}_{\mathbf{d}} ; \\
& \mathbf{v}_{5}=-\mathbf{M}_{\mathbf{o}} \dot{\mathbf{v}}_{\mathbf{o d}}-\mathbf{A}_{\mathbf{q b}}{ }^{\mathrm{T}} \mathbf{M}_{\mathbf{a a}} \ddot{\overline{\mathbf{q}}}_{\mathbf{d}} ; \\
& \mathbf{v}_{6}=2 \mathbf{K}_{\mathbf{v}}{ }^{\mathrm{T}} \mathbf{v}_{\mathbf{o d}} .
\end{aligned}
$$

Como, as trajetórias desejadas pertencem ao conjunto $S$ e os termos dependentes do modelo em $\boldsymbol{v}_{4}, \boldsymbol{v}_{5}$ são contínuos e limitados, então $\boldsymbol{v}_{4}, \boldsymbol{v}_{5}, \boldsymbol{v}_{6} \in L_{2}([0, \infty))$. A eq. (5.78) é similar à eq. (5.38) para o sistema com juntas passivas. A aplicação de análise similar à adotada para o sistema com juntas passivas (eqs. 5.38-5.45) leva à conclusão que $V(t)$ é uniformemente limitado, assim como $\mathbf{x}_{\mathbf{0}}, \mathbf{v}_{\mathbf{0}}, \dot{\overline{\mathbf{q}}}$.

Assim, como $\mathbf{v}_{\mathbf{0}}$ é uniformemente contínuo, então $\Delta \mathbf{v}_{\mathbf{0}}, \mathbf{v}_{\mathbf{0}}, \dot{\mathbf{v}}_{\mathbf{0}} \rightarrow \mathbf{0}$ quando $t \rightarrow \infty$, ou seja, o objeto sempre irá para uma situação de repouso e o erro de velocidade sempre convergirá para zero quando o controlador descrito pelas eqs. (5.6870) é utilizado é utilizado, o que completa a primeira parte da prova. 
Considere agora o item $b$. Substituindo a lei de controle de movimento (eqs. 5.6870) na eq. dinâmica das juntas ativas (eq. 5.60) para $\dot{\mathbf{q}}=\ddot{\mathbf{q}}=\mathbf{0}$, então

$$
\mathbf{Q}_{\mathbf{b}}{ }^{\mathrm{T}} \mathbf{T}^{-\mathrm{T}} \mathbf{K}_{\mathbf{p}} \mathbf{\Delta} \mathbf{x}_{\mathbf{o}}+\mathbf{J}_{\mathbf{a}}{ }^{\mathrm{T}} \mathbf{h}+\mathbf{J}_{\mathbf{a}}{ }^{\mathrm{T}} \mathbf{f}_{\mathbf{g}}=\mathbf{0}_{n_{a} \times 1}
$$

Substituindo agora a eq. (5.23) na eq. (3.7b) para $\mathbf{v}_{\mathbf{o}}=\dot{\mathbf{v}}_{\mathbf{0}}=\mathbf{0}$,

$\mathbf{J}_{\mathbf{0}}{ }^{\mathrm{T}} \mathbf{f}_{\mathbf{g}}=-\mathbf{J}_{\mathbf{0}}{ }^{\mathrm{T}} \mathbf{h}$

Como $\mathbf{f}_{\mathbf{g}}$ é escolhido de modo a não provocar esmagamento no CM do objeto, então a eq. (5.80) implica que, em repouso,

$$
\mathbf{f}_{\mathbf{g}}=-\mathbf{J}_{\mathrm{oq}}{ }^{-\mathrm{T}} \mathbf{h}_{\mathrm{om}}
$$

na qual $\mathbf{h}_{\mathbf{o m}} \in \boldsymbol{X}_{\boldsymbol{m}}$ é a força de movimento (eq. 3.24) e a matriz $\mathbf{J}_{\mathbf{o q}}{ }^{\mathrm{T}}$ projeta as forças dos efetuadores no CM do objeto (eq. 3.20). Substituindo a eq. (5.81) na eq. (5.79) e lembrando que $\mathbf{h}=\mathbf{J}_{\text {oq }}{ }^{-\mathrm{T}} \mathbf{h}_{\mathbf{o}}$ (eq. 3.20), $\mathbf{h}_{\mathbf{o}}=\mathbf{h}_{\text {om }}+\mathbf{h}_{\text {oe }}$ (eq. 3.24), $\mathbf{h}_{\text {oe }}=\mathbf{h}_{\text {oem }}+\mathbf{h}_{\text {oec }}$ (eq. 3.29) e que $\mathbf{h}_{\text {oem }}=\mathbf{0}$ para a situação de repouso, então

$$
\mathbf{Q}_{\mathbf{b}}{ }^{\mathrm{T}} \mathbf{T}^{-\mathrm{T}} \mathbf{K}_{\mathbf{p}} \mathbf{\Delta} \mathbf{x}_{\mathbf{o}}+\mathbf{J}_{\mathbf{a}}{ }^{\mathrm{T}} \mathbf{J}_{\mathbf{o q}}{ }^{-\mathrm{T}} \mathbf{h}_{\mathbf{o e c}}=\mathbf{0}_{n_{a} \times 1}
$$

o que completa a segunda parte da prova.

Projetada a lei de controle para o movimento do objeto, a mesma equação utilizada para o controle de esmagamento do objeto para o sistema cooperativo com juntas passivas (eq. 5.58) pode ser aplicada para o controle do esmagamento do objeto do sistema cooperativo com juntas bloqueadas. Se a junta bloqueada está em um manipulador redundante e $n_{a} \geq m k$, então todas as componentes do vetor $\boldsymbol{\gamma}_{\mathrm{e}}$ podem ser independentemente controladas quando a matriz $\mathbf{J}_{i}$ do manipulador redundante é apropriadamente escolhida. 


\subsection{CONTROLE DO SISTEMA COOPERATIVO COM INFORMAÇÃO INCORRETA DE POSIÇÃO OU VELOCIDADE DAS JUNTAS}

Como descrito na Seção 4.3, a falhas do tipo informação incorreta de posições e velocidades das juntas são detectadas através das equações cinemáticas do sistema cooperativo. Como foi visto, o Sistema de DIF estima a posição ou velocidade da junta com falha. Estimada a posição ou velocidade detectada como incorreta, esta estimativa é utilizada nos controladores e no planejamento de trajetórias em substituição à medida incorreta. Feita a reconfiguração das variáveis das juntas, um controlador para o sistema sem falhas, como aquele apresentado na Seção 3.5.1, deve ser utilizado.

\subsubsection{Informação Incorreta de Posição das Juntas}

Seja $\mathbf{q}_{\mathbf{c} i}$ o vetor das posições das juntas do manipulador $i$ usado pelos controladores e pelo planejamento de trajetórias. As componentes $q_{c i j}\left(j=1, \ldots, n_{i}\right)$ do vetor $\mathbf{q}_{\mathbf{c} i}$ no instante $t$ são definidas como

$q_{c i j}(t)= \begin{cases}\hat{q}_{i j}(t) & \text { se a medida da posicao da junta } j \text { do manipulador } i \text { e' incorreta } \\ \theta_{i j}(t) & \text { caso contrario }\end{cases}$

na qual $\theta_{i j}(t)$ é a valor medido da posição da junta $j$ do manipulador $i$ e $\hat{q}_{i j}(t)$ é a estimativa da posição da junta $j$ do manipulador $i$ dada nas eqs. (4.30), (4.34) e (4.35).

\subsubsection{Informação Incorreta de Velocidade das Juntas}

Seja $\dot{\mathbf{q}}_{\mathbf{c} i}$ o vetor das velocidades das juntas do manipulador $i$ usado pelos controladores e pelo planejamento de trajetórias. As componentes $\dot{q}_{c i j}\left(j=1, \ldots, n_{i}\right)$ do vetor $\dot{\mathbf{q}}_{\mathbf{c} i}$ no instante $t$ são definidas como

$\dot{q}_{c i j}(t)= \begin{cases}\hat{q}_{i j}(t) & \text { se a medida da velocidade da junta } j \text { do manipulador } i \text { e' incorreta } \\ \dot{\theta}_{i j}(t) & \text { caso contrario }\end{cases}$

na qual $\dot{\theta}_{i j}(t)$ é a valor medido da velocidade da junta $j$ do manipulador $i$ e $\hat{\dot{q}}_{i j}(t)$ é a estimativa da velocidade da junta $j$ do manipulador $i$ dada nas eqs. (4.39), (4.43) e (4.44). 


\subsection{RECONFIGURAÇÃO DO SISTEMA COOPERATIVO COM FALHAS}

Quando ocorre uma falha no sistema cooperativo, as posições e velocidades do objeto geralmente assumem valores muito diferentes daqueles especificados na trajetória desejada se a falha não é rapidamente detectada. Assim, a trajetória desejada precisa ser reconfigurada. Após a DIF, a trajetória pode ser reconfigurada a partir do repouso ou das velocidades correntes.

Quando a trajetória é reconfigurada a partir do repouso, os freios das juntas devem ser acionados após a DIF e, então, o sistema de controle para o sistema com falhas deve ser aplicado. A aplicação dos freios deve ser feita com cuidado pois pode causar danos ao sistema. Uma alternativa é aplicar os freios lentamente, ou seja, ajustar o freio para que sua aplicação provoque uma desaceleração suave.

Quando a trajetória é reconfigurada a partir das velocidades atuais das juntas, o sistema de controle para o sistema com falhas é aplicado diretamente sem que os freios sejam acionados. A escolha de um ou outro esquema deve ser feita levando em consideração os seguintes aspectos:

(i) Presença de freios nas juntas;

(ii) Configuração atual das posições e velocidades das juntas;

(iii) Valores atuais da força de esmagamento;

(iv) Trajetória inicialmente desejada, e;

(v) Parâmetros do robôs, tais como taxa amostral, valores máximos de torque e limites das juntas.

Para os casos das falhas do tipo junta com balanço livre (passiva) ou bloqueada, as variáveis das juntas usadas no controle são aquelas fornecidas pelos sensores e as leis de controle são aquelas desenvolvidas nas Seções 5.2 e 5.3. Para as falhas do tipo informação incorreta de posição ou velocidade das juntas, as leis de controle são aquelas desenvolvidas para o caso do sistema sem falhas (Seção 3.5.1). A Tabela 5.2 apresenta as variáveis das juntas e as leis utilizadas no controle para a operação normal e para a operação com falhas. 
TABELA 5.2. Variáveis e leis usadas no controle do sistema cooperativo.

\begin{tabular}{|c|c|c|c|}
\hline Operação & $\begin{array}{l}\text { Variáveis das juntas } \\
\text { usadas no controle }\end{array}$ & Componentes da lei de controle & Lei de controle \\
\hline Normal & $\begin{array}{l}\mathbf{q}_{\mathrm{c}}=\boldsymbol{\theta} \\
\dot{\mathbf{q}}_{\mathrm{c}}=\dot{\boldsymbol{\theta}}\end{array}$ & $\begin{array}{l}\tau_{\mathrm{m}}=\mathbf{J}^{\mathrm{T}} \mathbf{f}_{\mathrm{k}} \\
\mathbf{K}_{\mathrm{p}} \Delta \mathbf{x}_{\mathbf{o}}+\mathbf{K}_{\mathrm{v}} \Delta \mathbf{v}_{\mathbf{o}}=\mathbf{J}_{\mathbf{o}}{ }^{\mathrm{T}} \mathbf{f}_{\mathbf{k}}\end{array}$ & $\tau=\tau_{\mathrm{m}}+\tau_{\mathrm{g}}+\tau_{\mathrm{e}}$ \\
\hline $\begin{array}{l}\text { Informação } \\
\text { incorreta } \\
\text { da posição } \\
\text { da junta } j\end{array}$ & $\begin{array}{l}\mathbf{q}_{\mathbf{c}}=\left[\begin{array}{c}\mathbf{q}_{\mathbf{c} 1} \\
\vdots \\
\mathbf{q}_{\mathbf{c} m}\end{array}\right] \\
q_{c i k}=\left\{\begin{array}{cc}\hat{q}_{c i k} & \text { se } k=j \\
\theta_{i k} & \text { se } k \neq j\end{array}\right. \\
\dot{\mathbf{q}}_{\mathbf{c}}=\dot{\boldsymbol{\theta}}\end{array}$ & $\begin{array}{l}\tau_{\mathbf{g}}=\mathbf{g}+\mathbf{J}^{\mathrm{T}} \mathbf{f}_{\mathbf{g}} \\
\tau_{\mathbf{e}}=-\mathbf{E}^{\mathrm{T}}\left(\mathbf{h}_{\text {oed }}+\mathbf{K}_{\mathbf{i}} \int_{s=t_{0}}^{s=t}\left(\mathbf{h}_{\text {oed }}(s)-\mathbf{h}_{\text {oe }}(s)\right) d s\right.\end{array}$ & \\
\hline $\begin{array}{l}\text { Informação } \\
\text { incorreta } \\
\text { da } \\
\text { velocidade } \\
\text { da junta j }\end{array}$ & $\begin{array}{l}\mathbf{q}_{\mathbf{c}}=\boldsymbol{\theta} \\
\dot{\mathbf{q}}_{\mathbf{c}}=\left[\begin{array}{c}\dot{\mathbf{q}}_{\mathbf{c} 1} \\
\vdots \\
\dot{\mathbf{q}}_{\mathbf{c} m}\end{array}\right] \\
\dot{q}_{c i k}=\left\{\begin{array}{cc}\hat{\dot{q}}_{c i k} & \text { se } k=j \\
\dot{\theta}_{i k} & \text { se } k \neq j\end{array}\right.\end{array}$ & & \\
\hline $\begin{array}{l}\text { Junta } \\
\text { passiva }\end{array}$ & $\begin{array}{l}\mathbf{q}_{\mathrm{c}}=\boldsymbol{\theta} \\
\dot{\mathbf{q}}_{\mathrm{c}}=\dot{\boldsymbol{\theta}}\end{array}$ & $\begin{array}{l}\tau_{\mathrm{am}}=\mathbf{Q}^{\mathrm{T}}\left(\mathbf{T}^{-\mathrm{T}} \mathbf{K}_{\mathbf{p}} \Delta \mathbf{x}_{\mathbf{o}}+\mathbf{K}_{\mathbf{v}} \mathbf{\Delta} \mathbf{v}_{\mathbf{o}}\right) \\
\tau_{\mathrm{ag}}=\mathbf{g}_{\mathrm{a}}-\mathbf{A}_{\mathbf{o}}{ }^{\mathrm{T}} \mathbf{g}_{\mathbf{p}}+\left(\mathbf{J}_{\mathbf{a}}{ }^{\mathrm{T}}-\mathbf{A}_{\mathbf{o}}{ }^{\mathrm{T}} \mathbf{J}_{\mathbf{p}}^{\mathrm{T}}\right) \mathbf{f}_{\mathbf{g}} \\
\tau_{\mathrm{ae}}=-\mathbf{E}_{\mathbf{a}}{ }^{\mathrm{T}} \tilde{\mathbf{A}}^{\mathrm{T}} \boldsymbol{\gamma}_{\mathrm{e}}\end{array}$ & $\tau_{\mathrm{a}}=\tau_{\mathrm{am}}+\tau_{\mathrm{ag}}+\tau_{\mathrm{ae}}$ \\
\hline $\begin{array}{l}\text { Junta } \\
\text { bloqueada }\end{array}$ & $\begin{array}{l}\mathbf{q}_{\mathrm{c}}=\boldsymbol{\theta} \\
\dot{\mathbf{q}}_{\mathrm{c}}=\dot{\boldsymbol{\theta}}\end{array}$ & $\begin{array}{l}\tau_{\mathrm{am}}=\mathbf{Q}_{\mathbf{b}}^{\mathrm{T}}\left(\mathbf{T}^{-\mathrm{T}} \mathbf{K}_{\mathbf{p}} \Delta \mathbf{x}_{\mathbf{o}}+\mathbf{K}_{\mathbf{v}} \boldsymbol{\Delta} \mathbf{v}_{\mathbf{o}}\right) \\
\tau_{\mathrm{ag}}=\mathbf{g}_{\mathrm{a}}+\mathbf{J}_{\mathbf{a}}^{\mathrm{T}} \mathbf{f}_{\mathbf{g}} \\
\tau_{\mathrm{ae}}=-\mathbf{E}_{\mathbf{a}}^{\mathrm{T}} \tilde{\mathbf{A}}^{\mathrm{T}} \boldsymbol{\gamma}_{\mathrm{e}}\end{array}$ & $\tau_{\mathrm{a}}=\tau_{\mathrm{am}}+\tau_{\mathrm{ag}}+\tau_{\mathrm{ae}}$ \\
\hline
\end{tabular}


Além disso, a capacidade de carga do sistema com falhas deve ser levada em consideração durante a reconfiguração. Existem casos em que, após a falha, o sistema cooperativo não tem capacidade de executar a tarefa originalmente proposta. Um exemplo disso é quando a Capacidade Dinâmica de Carga (CDC) do sistema cooperativo fica reduzida a tal ponto após a falha que não é mais possível executar satisfatoriamente a tarefa inicialmente proposta. Assim, é muitas vezes necessário calcular a CDC do sistema com falhas. A seguir, um método para cálculo da CDC do sistema cooperativo com juntas passivas é apresentado. Este método pode ser também aplicado ao problema do sistema cooperativo com juntas bloqueadas, desde que sejam utilizadas as equações dinâmicas apropriadas.

\subsubsection{Capacidade Dinâmica de Carga em Manipuladores Cooperativos com Juntas Passivas}

Quando os robôs manipuladores perdem um ou mais atuadores, a CDC do sistema geralmente diminui. A CDC de um sistema é definida como a máxima carga que este pode carregar em um dado instante [ZHAO et al., 1998]. Como uma das principais justificativas para o uso de sistemas cooperativos é a manipulação de objetos pesados que excedem a CDC do manipulador individual, a CDC do sistema cooperativo deve ser recalculada quando juntas passivas aparecem. A CDC pode, ainda, ser utilizada durante a fase de projeto de sistemas cooperativos com juntas passivas.

Já que a CDC depende dos valores de posição, velocidade e aceleração do sistema, a trajetória desejada pode ser escolhida de modo a maximizar a CDC de um sistema cooperativo com juntas passivas. Apesar de sua importância no planejamento de trajetórias, a CDC de manipuladores cooperativos foi investigada somente recentemente [WANG \& KUO, 1994], [ZHAO et al., 1998]. A CDC ainda não foi investigada para manipuladores cooperativos com juntas passivas,. Aqui, a CDC do sistema com juntas passivas é obtida através de um algoritmo baseado naquele desenvolvido em [ZHAO et al., 1998] para o sistema totalmente atuado. É importante observar que a CDC é obtida baseada nas características do sistema, tais como tipo da carga e forças generalizadas máximas permitidas nas juntas, e não do controlador ${ }^{1}$.

\footnotetext{
${ }^{1}$ Uma análise mais rigorosa pode ser feita para o cálculo da CDC associada a cada controlador através da análise da estabilidade do sistema quando são considerados limites nos valores das forças generalizadas nas juntas e taxas de amostragem diferentes.
} 
Nos robôs cooperativos rigidamente conectados a um objeto indeformável, restrições cinemáticas aparecem devido ao(s) laço(s) fechado(s) formado(s) pelos manipuladores (Seção 3). Estas restrições e as equações dinâmicas do sistema totalmente atuado são utilizadas em [ZHAO et al., 1998] para formar um problema de programação linear, cuja solução em alguns pontos da trajetória fornece os limites superiores da massa e das componentes do tensor de inércia do objeto.

Aqui, os limites superiores da massa do objeto são obtidos em todo o instante amostral. Quando existem juntas passivas no sistema, restrições nos torques das juntas passivas são acrescentadas no problema de programação linear. Apesar do aumento do número de problemas a serem resolvidos (um para cada instante amostral), o algoritmo é computacionalmente menos custoso que aquele desenvolvido em [ZHAO et al., 1998] pois o tensor de inércia é computado como uma função da massa do objeto. Para isso, a forma do objeto a ser manipulado precisa ser conhecida. A seguir, o método para cálculo da CDC é apresentado.

A dinâmica do objeto em um sistema cooperativo (eqs. 3.6 e 3.7) pode ser escrita como

$\mathbf{h}_{\mathbf{r o}}=\left[\begin{array}{cc}m_{o} \mathbf{I}_{j} & \mathbf{0} \\ \mathbf{0} & \mathbf{I}_{\mathbf{n o}}\end{array}\right]\left[\begin{array}{l}\ddot{\mathbf{p}}_{\mathbf{o}} \\ \dot{\boldsymbol{\omega}}_{\mathbf{0}}\end{array}\right]+\left[\begin{array}{c}m_{o} \mathbf{g}_{\mathbf{v}} \\ \boldsymbol{\omega}_{\mathbf{0}} \times\left(\mathbf{I}_{\mathbf{n} \mathbf{0}} \boldsymbol{\omega}_{\mathbf{0}}\right)\end{array}\right]$.

na qual $\mathbf{h}_{\mathbf{r o}}=\mathbf{J}_{\mathbf{o}}{ }^{\mathrm{T}} \mathbf{h}$ (eq. 3.21), $\mathbf{g}_{\mathbf{v}}=\left[\begin{array}{lll}g_{o l} & \ldots & g_{o j}\end{array}\right]^{\mathrm{T}}$ é o vetor das acelerações provocadas pela força da gravidade, $\mathbf{I}_{j}$ é a matriz identidade com posto $j$ e a dependência do índice $t$ não é mostrada por simplicidade. Considerando objetos em que o tensor de inércia do objeto é igual a $\left(\mathbf{I}_{\text {noc }} m_{o}\right)$, na qual $\mathbf{I}_{\text {noc }}$ é constante, a eq. (5.85) pode ser reescrita como

$\mathbf{h}_{\mathrm{ro}}=\left[\begin{array}{c}\ddot{\mathbf{p}}_{\mathbf{o}}+\mathbf{g}_{\mathbf{v}} \\ \mathbf{I}_{\mathbf{n o c}} \dot{\boldsymbol{\omega}}_{\mathbf{o}}+\boldsymbol{\omega}_{\mathbf{o}} \times\left(\mathbf{I}_{\text {noc }} \boldsymbol{\omega}_{\mathbf{o}}\right)\end{array}\right] m_{o}$.

Como existem $k$ componentes de movimento na carga, as primeiras $k$ (partição $K$ ) componentes do espaço de juntas (com $n$ juntas) são escolhidas como coordenadas generalizadas. Assim, lembrando a lei dos trabalhos virtuais, a dinâmica das juntas na partição $K$ pode ser escrita como

$$
\tau_{\mathbf{k}}+\mathbf{J}_{\mathbf{k}}^{\mathbf{n}-\mathbf{k}}(\mathbf{q})^{\mathrm{T}} \tau_{\mathbf{n}-\mathbf{k}}+\mathbf{D}_{\mathbf{k}}^{\mathbf{o}}(\mathbf{q})^{\mathrm{T}} \mathbf{h}_{\mathrm{ro}}-\mathbf{J}_{\mathbf{k}}^{\mathrm{n}}(\mathbf{q})^{\mathrm{T}}(\mathbf{M}(\mathbf{q}) \ddot{\mathbf{q}}+\mathbf{C}(\mathbf{q}, \dot{\mathbf{q}}) \dot{\mathbf{q}}+\mathbf{g}(\mathbf{q})+\mathbf{z}(\mathbf{q}, \dot{\mathbf{q}}))=\mathbf{0}_{\mathrm{kx} 1}
$$

na qual $\tau_{\mathrm{k}}$ é o vetor dos torques nas juntas pertencentes à partição $K, \tau_{\mathbf{n}-\mathbf{k}}$ é o vetor dos torques nas juntas que não pertencem à partição $K, \mathbf{J}_{\mathbf{k}}^{\mathbf{n}-\mathbf{k}}(\mathbf{q})$ é a matriz Jacobiana que relaciona as velocidades das juntas pertencentes à partição $K$ com as velocidades das juntas 
que não pertencem à partição $K, \mathbf{D}_{\mathbf{k}}^{\mathbf{0}}(\mathbf{q})$ é a matriz Jacobiana que relaciona as velocidades das juntas pertencentes à partição $K$ com as velocidades do objeto e $\mathbf{J}_{\mathbf{k}}^{\mathbf{n}}(\mathbf{q})=\left[\begin{array}{ll}\mathbf{I}_{k} & \mathbf{J}_{\mathbf{k}}^{\mathbf{n}-\mathbf{k}}(\mathbf{q})^{\mathrm{T}}\end{array}\right]^{\mathrm{T}}$ é a matriz Jacobiana que relaciona as velocidades das juntas pertencentes à partição $K$ com as velocidades de todas as juntas do sistema cooperativo.

Substituindo a eq. (5.86) na (5.87),

$\mathbf{J}_{\mathbf{k}}^{\mathbf{n}}(\mathbf{q})^{\mathrm{T}} \boldsymbol{\tau}+\mathbf{a}_{\mathbf{o}} m_{o}-\mathbf{J}_{\mathbf{k}}^{\mathbf{n}}(\mathbf{q})^{\mathrm{T}}(\mathbf{M}(\mathbf{q}) \ddot{\mathbf{q}}+\mathbf{C}(\mathbf{q}, \dot{\mathbf{q}}) \dot{\mathbf{q}}+\mathbf{g}(\mathbf{q})+\mathbf{z}(\mathbf{q}, \dot{\mathbf{q}}))=\mathbf{0}_{\mathrm{kx} 1}$.

na qual $\tau=\left[\begin{array}{ll}\tau_{\mathbf{k}}^{\mathrm{T}} & \tau_{\mathbf{n}-\mathbf{k}}^{\mathrm{T}}\end{array}\right]^{\mathrm{T}}$, e

$\mathbf{a}_{\mathrm{o}}=\mathbf{D}_{\mathrm{k}}^{\mathrm{o}}(\mathbf{q})\left[\begin{array}{c}\ddot{\mathbf{p}}_{\mathrm{o}}+\mathbf{g}_{\mathrm{v}} \\ \mathbf{I}_{\mathrm{noc}} \dot{\boldsymbol{\omega}}_{\mathrm{o}}+\boldsymbol{\omega}_{\mathrm{o}} \times\left(\mathbf{I}_{\mathrm{noc}} \boldsymbol{\omega}_{\mathrm{o}}\right)\end{array}\right]$.

A eq. (5.88) pode ser reescrita como

$\mathbf{A x}=\mathbf{b}$

na qual

$\mathbf{A}=\left\lfloor\mathbf{J}_{\mathbf{k}}^{\mathbf{n}}(\mathbf{q})^{\mathrm{T}} \quad \mathbf{a}_{\mathbf{o}}\right\rfloor$,

$\mathbf{x}=\left[\begin{array}{c}\tau \\ m_{o}\end{array}\right], \mathrm{e}$

$\mathbf{b}=\mathbf{J}_{\mathbf{k}}^{\mathrm{n}}(\mathbf{q})^{\mathrm{T}}(\mathbf{M}(\mathbf{q}) \ddot{\mathbf{q}}+\mathbf{C}(\mathbf{q}, \dot{\mathbf{q}}) \dot{\mathbf{q}}+\mathbf{g}(\mathbf{q})+\mathbf{z}(\mathbf{q}, \dot{\mathbf{q}}))$.

Como o número de restrições $(n+1)$ em $\mathbf{x}$ é maior que o número de equações $(k)$, a eq. (5.89) assemelha-se a um sistema linear com restrições de igualdade. No vetor $\mathbf{x}$, aparecem as seguintes restrições

$m_{o}>0$

e

$\left|\tau_{j}\right|\left\{\begin{array}{ll}\leq \tau_{\max j} & \text { se a junta } j \text { é atuada } \\ =0 & \text { se a junta } j \text { é passiva }\end{array} \quad, j=1, \cdots, n\right.$.

na qual $\tau_{j}$ é o torque aplicado na junta $j$ e $\tau_{\max j}$ é o torque máximo que pode ser aplicado na junta $j$. Observe que o problema das juntas passivas aparece somente nas restrições dadas pela eq. (5.91). As restrições nas juntas passivas não aparecem no método proposto em [ZHAO et al., 1998] já que o sistema é totalmente atuado.

Como a máxima massa do objeto deve ser calculada para a trajetória desejada, a função objetivo do problema de programação linear é dada por 
$f(\mathbf{x})=\mathbf{c}^{\mathrm{T}} \mathbf{x}$

na qual $\mathbf{c}^{\mathrm{T}}=\left[\begin{array}{ll}\mathbf{0}_{n \times 1} & 1\end{array}\right]$.

Assim, o procedimento para calcular a carga máxima que pode ser manipulada pelo sistema cooperativo com juntas passivas pode ser resumido como

(i) A trajetória desejada é definida;

(ii) O problema de programação linear é resolvido para cada instante amostral da trajetória desejada com o objetivo de obter-se os torques ótimos nas juntas e a massa máxima do objeto (CDC) que maximizem a eq. (5.92) sujeita às restrições impostas pelas eqs. (5.89-92).

(iii) A massa máxima do objeto obtida em cada instante amostral (CDC) é armazenada;

(iv) A carga máxima que pode ser manipulada para a trajetória desejada é obtida através do mínimo dos valores de massa do objeto (CDC) armazenados. 


\section{Capítulo 6.}

\section{RESULTADOS}


Neste capítulo são apresentados os resultados do Sistema DIF, do controle do sistema cooperativo com falhas e do sistema de tolerância completo aplicados em simulações e em robôs cooperativos reais. Os seguintes sistemas cooperativos foram simulados:

(i) sistema com dois manipuladores planares com 3 juntas rotacionais cada (Sistema Simulado 1);

(ii) sistema formado por dois robôs do tipo Puma 560 (Sistema Simulado 2), e;

(iii) sistema com três manipuladores planares com 3 juntas rotacionais cada (Sistema Simulado 3).

Os sistemas simulados e o sistema real são apresentados na Seção 6.1. Na mesma seção, o Ambiente de Simulação e Controle do Sistema Cooperativo Real é apresentado. Na Seção 6.2 são apresentados resultados do sistema cooperativo com falhas e sem reconfiguração. A Seção 6.3 traz os resultados do Sistema DIF apresentado no Capítulo 4. Já a Seção 6.4 apresenta os resultados do controle com falhas desenvolvido no Capítulo 5. Os resultados da implementação do sistema de tolerância completo encontram-se na Seção 6.5. Finalmente, na Seção 6.6, os resultados do método para cálculo da CDC do sistema com juntas passivas são apresentados.

\subsection{SISTEMAS COOPERATIVOS UTILIZADOS}

\subsubsection{Sistemas Cooperativos Simulados}

\subsubsection{Sistema Simulado 1: Dois Manipuladores Planares com 3 Juntas Cada:}

Um sistema cooperativo composto de dois manipuladores planares com 3 juntas rotacionais cada rigidamente conectados a um objeto indeformável com as mesmas características do sistema real (Seção 6.1.2) foi utilizado paras testes do Sistema DIF, de controle após falhas, do sistema de tolerância completo e do algoritmo para cálculo da CDC do sistema com juntas passivas. Os manipuladores movem-se em um plano x-y, e, diferentemente do sistema real, a força gravitacional é paralela ao eixo y (ou seja, ortogonal ao eixo de movimento das juntas) durante a simulação. O controlador desenvolvido por [WEN \& KREUTZDELGADO, 1992] foi aqui utilizado para o controle do sistema cooperativo sem falhas. 
Os parâmetros dos robôs, do objeto e do controlador para o sistema sem falhas são apresentados, respectivamente, nas Tabelas B.1, B.2 e B.3 do Apêndice B. O período amostral utilizado é de 0,008 s e ruídos de medidas com distribuição normal foram adicionados às variáveis de posição (média zero e desvio padrão igual a 0,0005) e velocidade (média zero e desvio padrão igual a 0,0008 ) das juntas, e de força nos efetuadores (média zero e desvio padrão igual a 0,00008$)$.

\subsubsection{Sistema Simulado 2: Dois Manipuladores Puma 560}

Um sistema cooperativo composto de dois robôs Puma560 manipulando um cilindro em um espaço tridimensional foi utilizado para os testes do Sistema DIF, do controle do sistema com falhas e do sistema de tolerância completo. No sistema simulado 2, os efetuadores dos manipuladores são rigidamente conectados ao cilindro. Robôs com 6 graus de liberdade, como o Puma560, são comuns em indústrias e outros ambientes pois permitem que o objeto manipulado assuma qualquer posição e orientação dentro do espaço de trabalho tridimensional (três dimensões de posição). Tal caso apresenta uma complexidade significativamente maior em relação aos robôs cooperativos movendo-se em um plano já que o número de variáveis das juntas dobra. Com isso, para o sistema de tolerância a falhas, o número de neurônios empregados nas redes neurais utilizadas na detecção das falhas do tipo junta com balanço livre e junta bloqueada aumenta significativamente, o que torna mais lento o treinamento. Além disso, mais variáveis de controle são utilizadas.

O toolbox Robotics para MATLAB desenvolvido por Corke [CORKE, 1996] foi utilizado para o cálculo dos componentes da equação dinâmica dos robôs (eq. 3.4), incluindo os termos de fricção. Os parâmetros do Puma560 podem ser encontrados em [CORKE \& ARMSTRONG-HÉLOUVRY, 1994]. Os parâmetros do objeto e do controlador para o sistema sem falhas são apresentados, respectivamente, nas Tabelas C.1 e C.2 do Apêndice C. Nas simulações, a força gravitacional é considerada paralela ao eixo z (ou seja, ortogonal ao eixo de movimento das três primeiras juntas) e o controlador desenvolvido por [WEN \& KREUTZ-DELGADO, 1992] é aqui utilizado para o controle do sistema cooperativo sem falhas. O período amostral é de 0,018 s e ruídos de medidas com distribuição normal foram adicionados às variáveis de posição (média zero e desvio padrão igual a $5 \times 10^{-6}$ ) e velocidade (média zero e desvio padrão igual a $8 \times 10^{-6}$ ) das juntas, e de força nos efetuadores (média zero e desvio padrão igual a $8 \times 10^{-7}$ ). 


\subsubsection{Sistema Simulado 3:Três Manipuladores Planares com 3 Juntas Cada}

Um sistema cooperativo composto de três manipuladores planares com 3 juntas rotacionais cada rigidamente conectados a um objeto indeformável foi utilizado paras testes do sistema de controle após falhas (Figura 6.1). Os manipuladores movem-se em um plano x-y e a força gravitacional é paralela ao eixo y (ou seja, ortogonal ao eixo de movimento das juntas). Os parâmetros dos robôs e do objeto são apresentados, respectivamente, nas Tabelas D.1 e D.2 do Apêndice D. O período amostral utilizado é de $0,0025 \mathrm{~s}$.

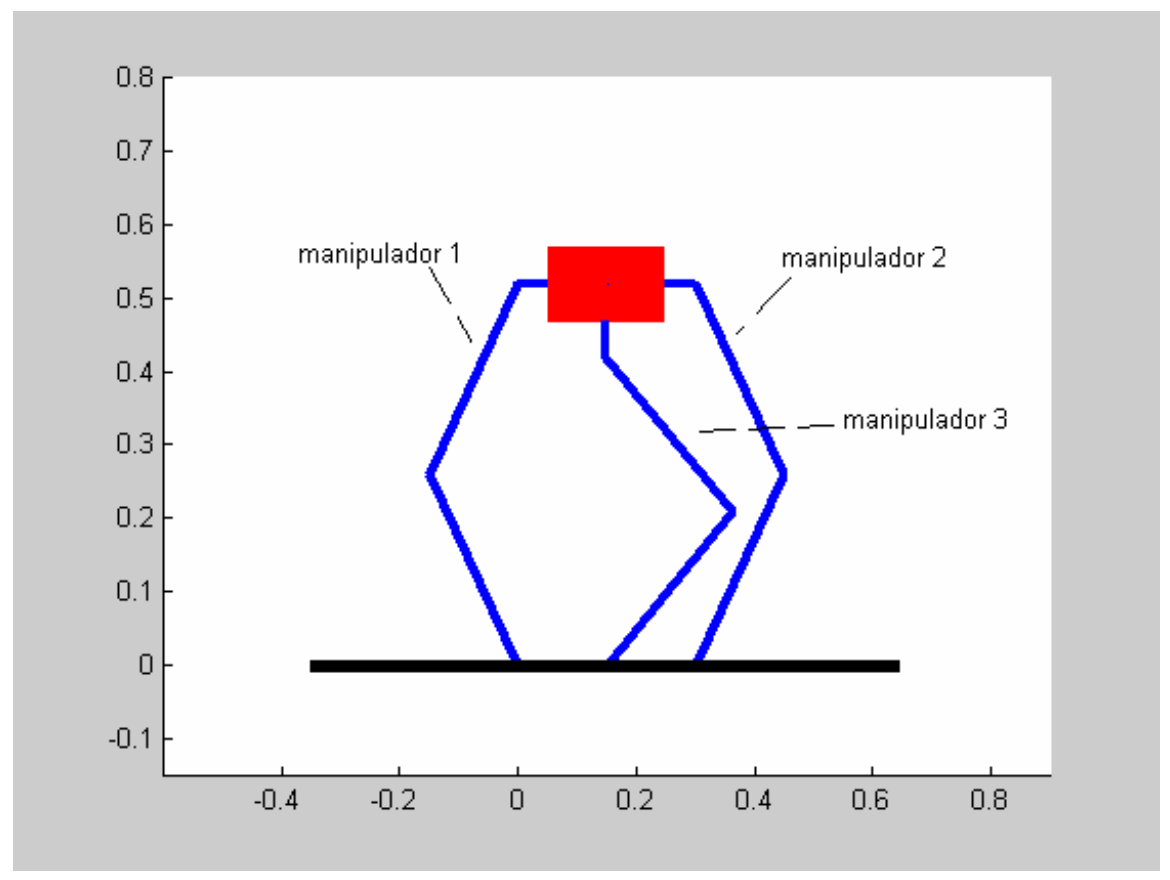

FIGURA 6.1. Sistema Simulado 3.

\subsubsection{Sistema Cooperativo Real}

O sistema real é composto por dois robôs UArmII ${ }^{1}$ (Figura 6.2) e foi utilizado para testes do sistema DIF, de controle após falhas e do sistema de tolerância completo. Cada UArmII é um robô planar com três juntas rotacionais que flutua sobre uma fina camada de ar sobre uma mesa de mármore. O sistema cooperativo é controlado por um PC através do programa MATLAB. Isto é possível porque os drivers para as placas de comando dos UArmII são escritos como arquivos '.mex' do MATLAB.

\footnotetext{
${ }^{1}$ Os manipuladores UArmII foram construídos por H. Ben Brown Jr. da Carnegie Mellon University.
} 
Cada junta do UArmII contém um motor de corrente contínua (CC) brushless com acoplamento direto, encoder e freio pneumático. As juntas podem ser ativamente controladas pelos motores $\mathrm{CC}$, bloqueadas pelos freios ou permitidas a mover-se livremente com torques aplicados iguais a zero. Isto permite simular as falhas do tipo junta com balanço livre ou bloqueada.

As posições das juntas são obtidas através dos encoders e as velocidades são calculadas a partir das posições. Como sensores de força não são empregados, as forças nos efetuadores são calculadas através das equações do sistema. Aqui, o controlador desenvolvido em [WEN \& KREUTZ-DELGADO, 1992] é utilizado para controlar o sistema sem falhas (taxa amostral igual a $0,06 \mathrm{~s}$.).

É importante observar que a inclinação da mesa sobre a qual os robôs flutuam é irregular, ou seja, a mesa não é totalmente plana. Já que as irregularidades da mesa são difíceis de serem modeladas, também os são os torques gravitacionais $\mathbf{g}_{i}$ (eq. 3.4) e o termo $\mathbf{g}_{\mathbf{0}}$ no objeto (eq. 3.7). Se estes termos não são corretamente compensados na lei de controle de movimento, os erros de posição tendem a valores diferentes de zero. Para sanar este problema são incorporados termos integrais nas leis de controle do movimento [SCIAVICCO \& SICILIANO, 1996]. Assim, o termo $\mathbf{f}_{\mathbf{k}}$ da lei de controle de movimento para o sistema real livre de falhas (eq. 3.31) é, agora, dado por

$$
\mathbf{K}_{\mathbf{p}} \Delta \mathbf{x}_{\mathbf{o}}(t)+\mathbf{K}_{\mathbf{v}} \Delta \mathbf{v}_{\mathbf{o}}(t)+\mathbf{K}_{\mathrm{im}} \int_{s=t_{0}}^{s=t} \Delta \mathbf{x}_{\mathbf{o}}(s) d s=\mathbf{J}_{\mathbf{o}}(\mathbf{q}(t))^{\mathrm{T}} \mathbf{f}_{\mathbf{k}}(t) .
$$

na qual $\mathbf{K}_{\mathbf{i m}}$ é uma matriz diagonal e positiva. Para o sistema real com juntas passivas, a lei de controle de movimento no instante $t$ torna-se

$$
\tau_{\mathbf{a m}}(t)=\mathbf{Q}(\mathbf{q}(t))^{\mathrm{T}}\left(\mathbf{T}(\mathbf{q}(t))^{-\mathrm{T}} \mathbf{K}_{\mathbf{p}} \Delta \mathbf{x}_{\mathbf{o}}(t)+\mathbf{K}_{\mathbf{v}} \Delta \mathbf{v}_{\mathbf{o}}(t)+\mathbf{K}_{\mathrm{im}} \int_{s=t_{0}}^{s=t} \Delta \mathbf{x}_{\mathbf{o}}(s) d s\right)
$$

e para o sistema real com juntas bloqueadas

$$
\boldsymbol{\tau}_{\mathbf{a m}}(t)=\mathbf{Q}_{\mathbf{b}}(\mathbf{q}(t))^{\mathrm{T}}\left(\mathbf{T}(\mathbf{q}(t))^{-\mathrm{T}} \mathbf{K}_{\mathbf{p}} \Delta \mathbf{x}_{\mathbf{o}}(t)+\mathbf{K}_{\mathbf{v}} \Delta \mathbf{v}_{\mathbf{o}}(t)+\mathbf{K}_{\mathrm{im}} \int_{s=t_{0}}^{s=t} \Delta \mathbf{x}_{\mathbf{o}}(s) d s\right)
$$

Outro problema que aparece no sistema real é a imprecisão no cálculo das velocidades das juntas a partir das medidas de posição obtidas através dos encoders. Isso ocorre porque as velocidades medidas pelos encoders são baixas devido ao acoplamento direto entre a junta e o rotor do atuador. Para minimizar este problema, o filtro adaptativo 
desenvolvido em [WIJNGAARD, 1996] para aplicações em que o encoder é usado para medir velocidades baixas é empregado no sistema real.
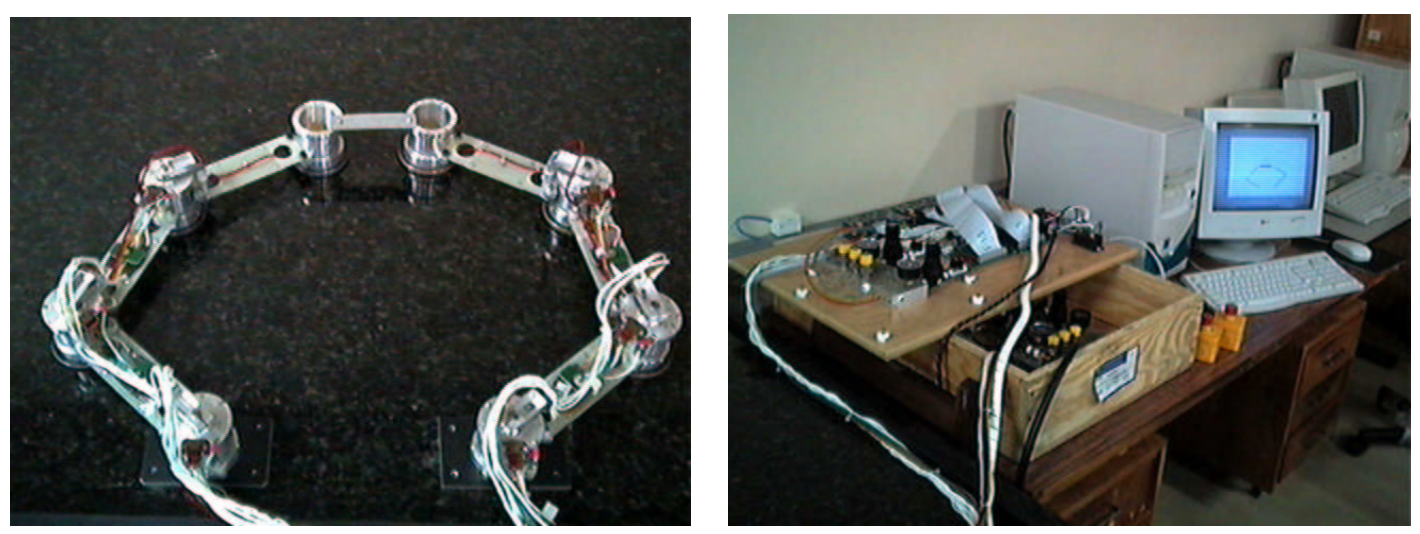

FIGURA 6.2. Sistema Real. Figura à esquerda: robôs cooperativos; Figura à esquerda: sistema de apoio.

Dois objetos diferentes foram manipulados pelos UArmII's. Os parâmetros dos robôs, dos objetos manipulados e do controlador utilizado para o sistema sem falhas são apresentados, respectivamente, nas Tabela E.1, E.2 e E.3 do Apêndice E.

\subsubsection{Ambiente de Simulação e Controle do Sistema Real}

O Ambiente de Simulação e Controle do Sistema Real (ASCSR) permite, através do MATLAB, simular sistemas cooperativos formados por dois manipuladores planares com 3 juntas cada, configurar parâmetros, visualizar os resultados da DIF, e controlar e acompanhar a progressão do sistema real. A maioria das rotinas do ASCSR foi escrita na linguagem de programação do MATLAB (arquivos “.m”). Devido à baixa velocidade de execução dos arquivos “.m”, algumas rotinas de cálculo da dinâmica e da cinemática dos robôs, e as rotinas das RNA's foram implementadas em linguagem $\mathrm{C}$ e, então, transformadas em arquivos executáveis do MATLAB (arquivos “.dll”).

A janela principal do ASCSR pode ser vista na Figura 6.3. 


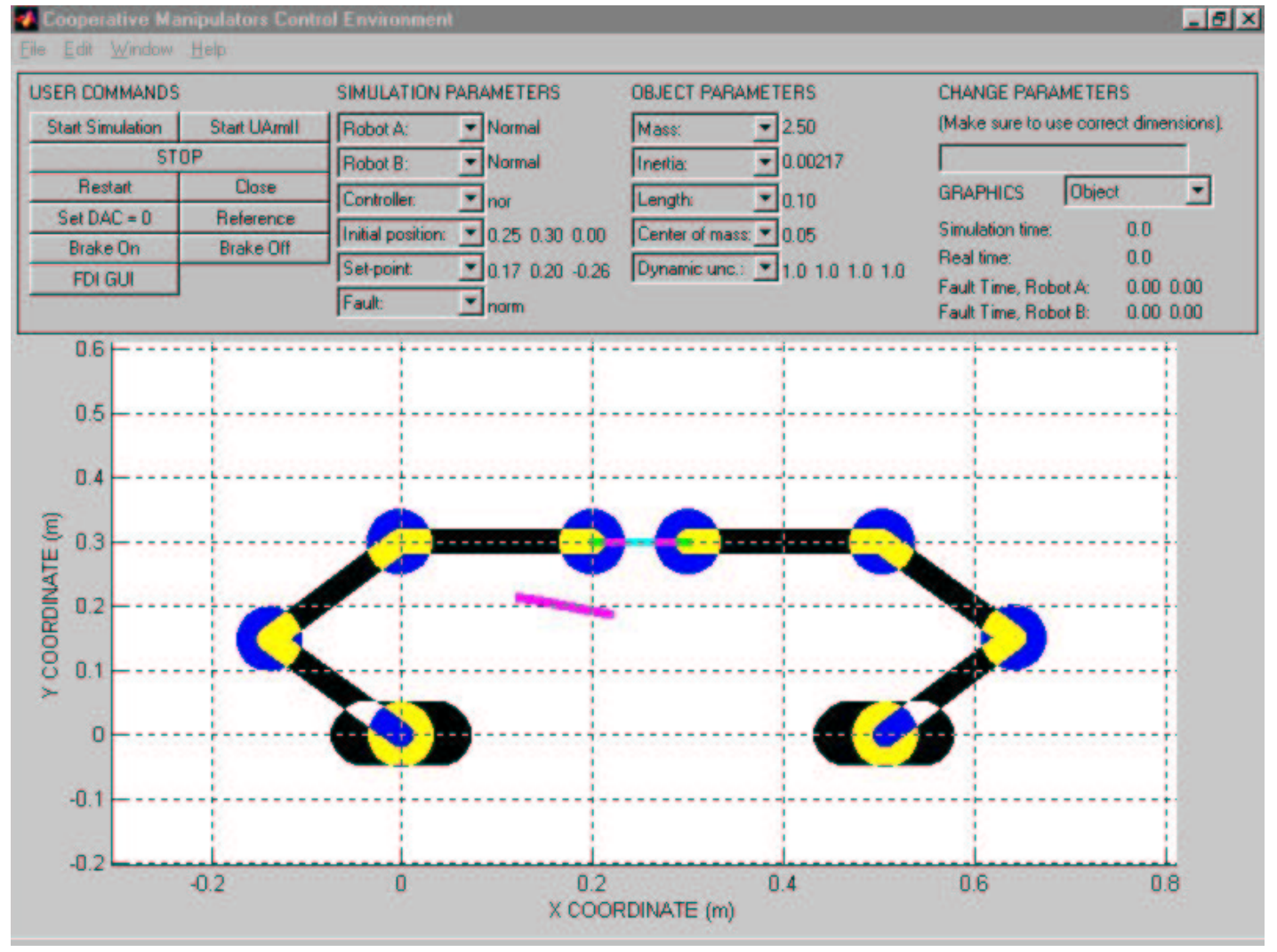

FIGURA 6.3. Janela principal do Ambiente de Simulação e Controle do Sistema Real. O manipulador 1 está no lado esquerdo da figura.

Através da janela principal do ASCSR, é possível acessar a janela da DIF e os gráficos de falhas (Figura 6.4), das variáveis do objeto e dos robôs (Figura 6.5). Através da janela da DIF pode-se configurar os parâmetros para a geração de trajetória durante o treinamento das RNA's, e configurar parâmetros da DIF e da reconfiguração após falhas. Os gráficos de falhas mostram os resíduos, as saídas da rede RBF e os indicadores de falhas. Os gráficos do objeto mostram as suas posições, velocidades e forças. Os gráficos dos robôs mostram as posições, velocidades e torques nas juntas. O Apêndice $\mathrm{F}$ apresenta com detalhes os menus, botões e janelas do ASCSR. 

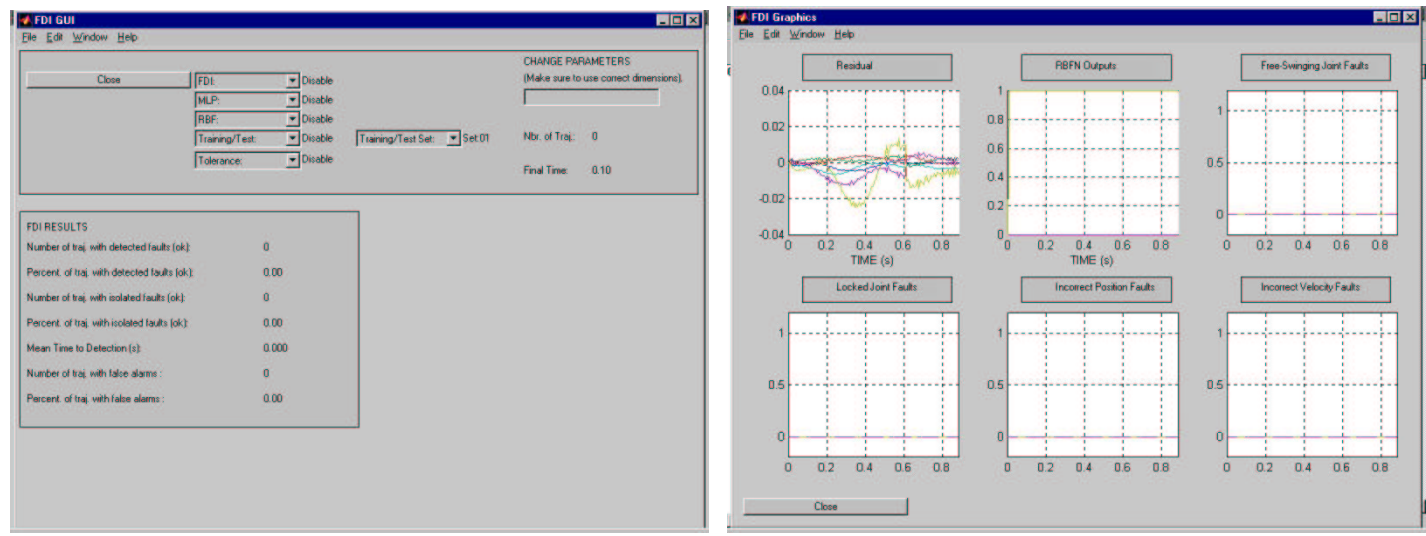

FIGURA 6.4. Janela da DIF (à esquerda) e gráficos de falhas (à direita).
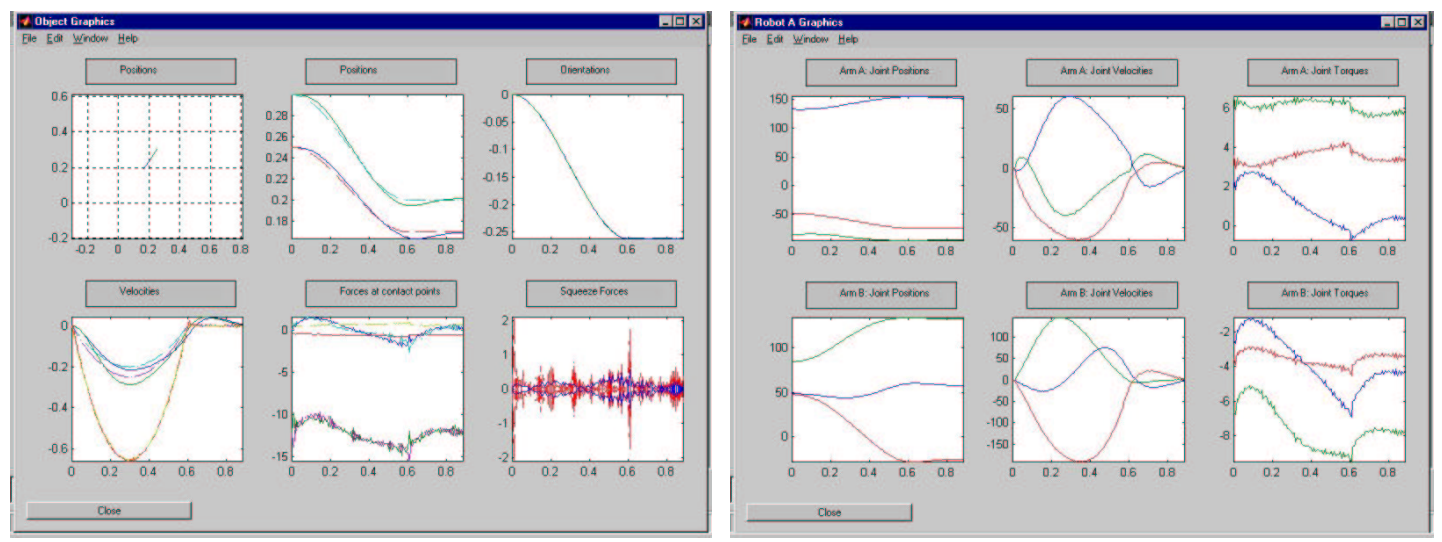

FIGURA 6.5. Gráficos do objeto (à esquerda) e dos robôs (à direita).

Neste trabalho, o ASCSR foi utilizado para simular o Sistema (Simulado) 1 (Seção 6.1.1.1) e para controlar o sistema real (Seção 6.1.2). Uma versão do ASCSR, chamada de AS560, foi desenvolvida para a simulação de dois robôs Puma 560 cooperativos (Sistema Simulado 2, Seção 6.1.1.2). A Figura 6.6 mostra a janela principal do AS560. Como se pode ver na Figura 6.6, os manipuladores Puma 560 são representados através de desenhos simplificados. As orientações dos efetuadores são representadas através de sistemas de coordenadas fixados no fim do terceiro elo. Repare que o objeto manipulado não é mostrado. 


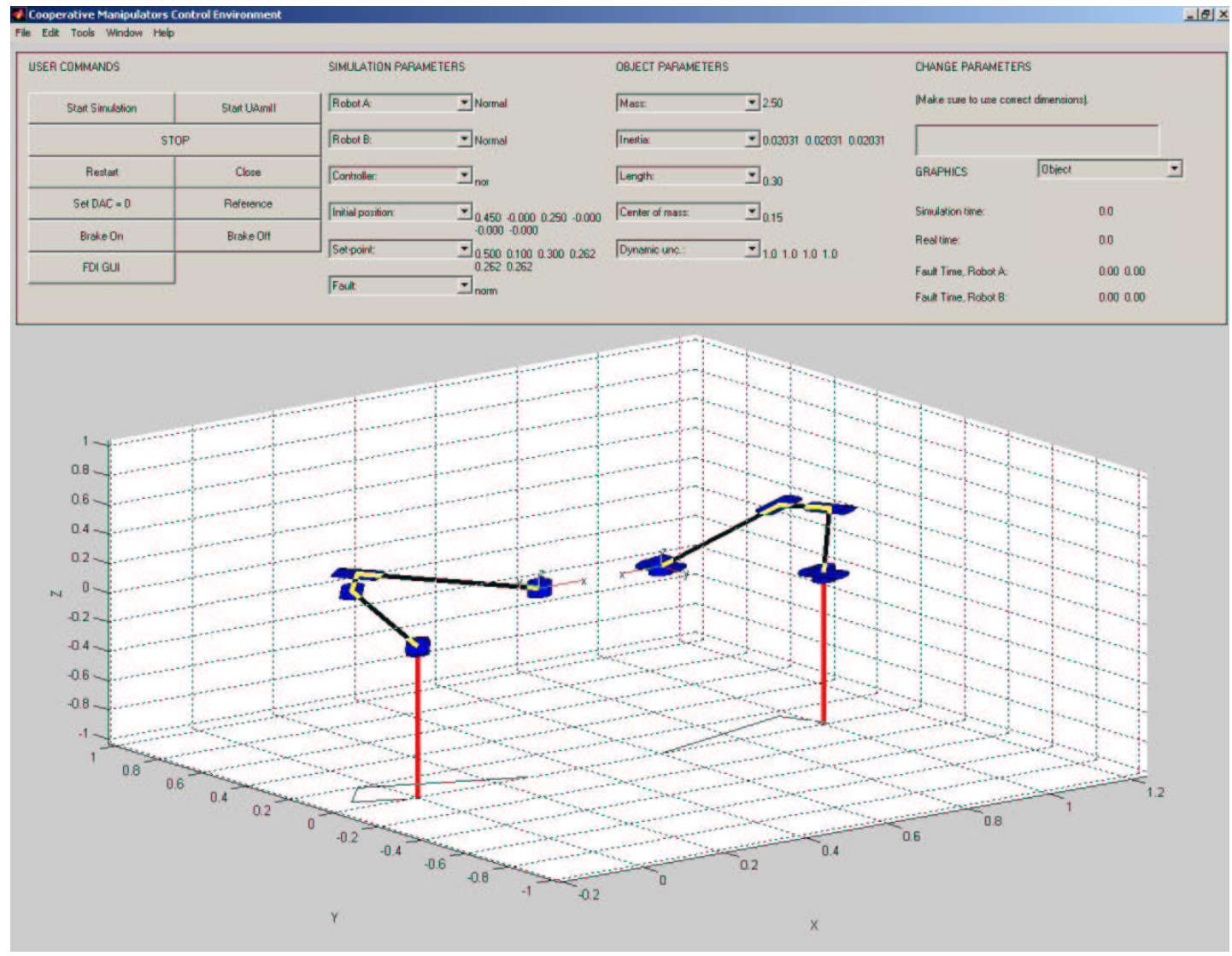

FIGURA 6.6. Janela principal do ambiente de simulação para os manipuladores Puma 560 cooperativos (AS560). As juntas, os elos e a base do robô aparecem, respectivamente, em azul, preto e vermelho. 0 manipulador 1 está no lado esquerdo da figura.

\subsection{SISTEMA COOPERATIVO COM FALHAS (SEM RECONFIGURAÇÃO)}

Quando ocorre uma falha no sistema cooperativo, esta deve ser detectada para que ações sejam tomadas com o objetivo de evitar que os robôs colidam com o chão ou com outros obstáculos, e para que o objeto não seja danificado pela força de esmagamento (Capítulo 2). Esta seção traz dois exemplos de sistemas simulados com falhas do tipo junta com balanço livre e sem reconfiguração. 


\subsubsection{Sistema Simulado 1}

Os resultados desta seção foram obtidos com a simulação do sistema formado por dois robôs planares com 3 juntas rotacionais cada (Sistema Simulado 1). As Figuras 6.7-6.12 mostram os resultados da simulação de uma trajetória do sistema cooperativo com uma falha do tipo junta 1 do robô 1 com balanço livre ocorrendo em 0,1 s. As Figuras 6.7-6.12 mostram, respectivamente, as posições do CM e as orientações do objeto (Figura 6.7), as velocidades do objeto (Figura 6.8), as forças exercidas pelos efetuadores no objeto e a força de esmagamento (Figura 6.9), os ângulos e velocidades das juntas do robô 1 (Figura 6.10), os ângulos e velocidades das juntas do robô 2 (Figura 6.11), e os torques nas juntas dos robôs 1 e 2 (Figura 6.12).

Note que, quando ocorre a falha, os erros de posição e velocidade do objeto aumentam rapidamente (Figuras 6.7 e 6.8) já que não existe tolerância a falhas no sistema cooperativo. As posições e velocidades também mudam rapidamente, o que pode levar o sistema a colidir com o solo ou com outro objeto. Note também que a força de esmagamento aumenta (Figura 6.9), podendo vir a danificar o objeto manipulado. Assim, fica evidente que a falha deve ser rapidamente isolada e o sistema reconfigurado ou freado.
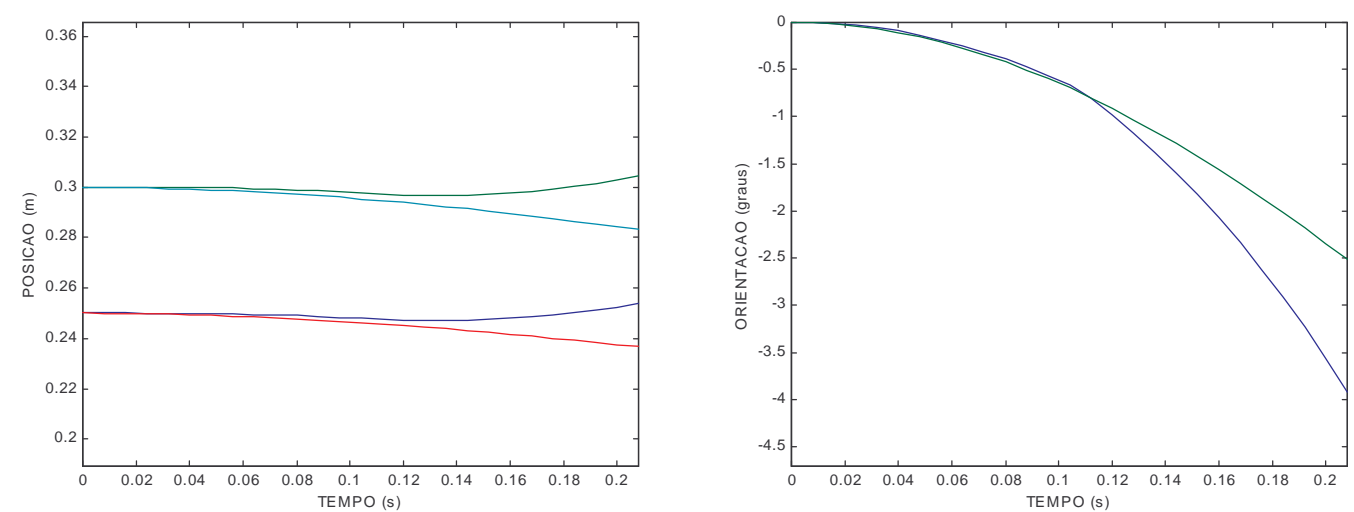

FIGURA 6.7. Falha do tipo junta 1 do manipulador 1 com balanço livre ocorrendo em

$0,1 \mathrm{~s}$ (sistema cooperativo sem tolerância a falhas). Figura à esquerda: linhas contínuas indicam a posição do CM do objeto (coordenada $x$ em azul e coordenada $y$ em verde). Figura à direita: linha contínua indica a orientação do objeto. As linhas tracejadas indicam os valores desejados. 

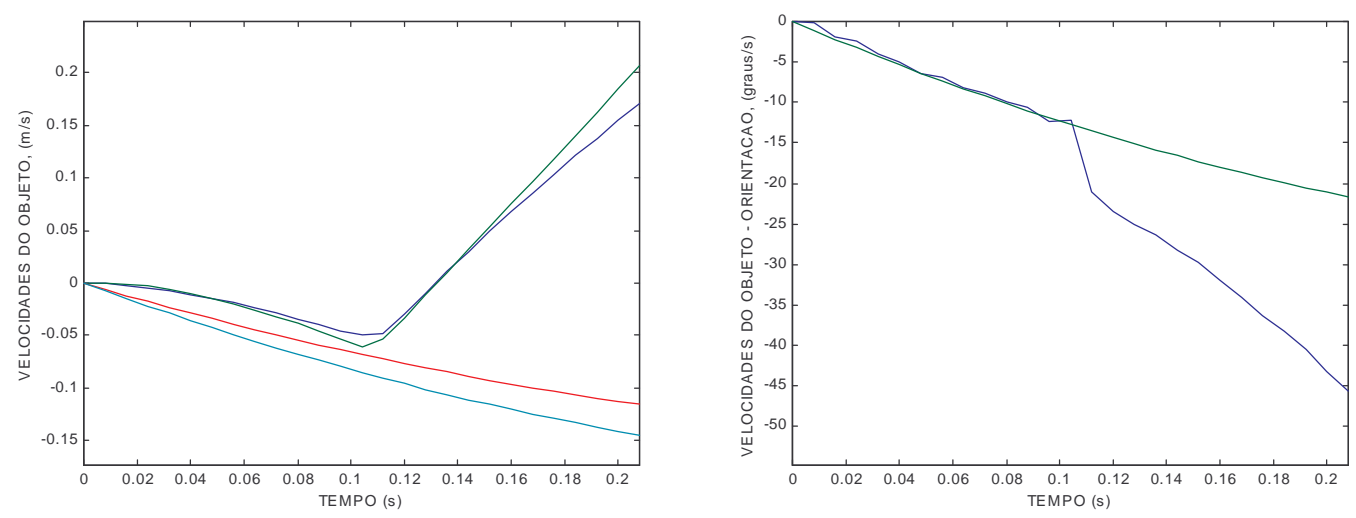

FIGURA 6.8. Figura à esquerda: linhas contínuas indicam a velocidade linear do objeto (coordenada $x$ em azul e coordenada $y$ em verde). Figura à direita: linhas contínuas indicam a velocidade angular do objeto. As linhas tracejadas indicam os valores desejados.
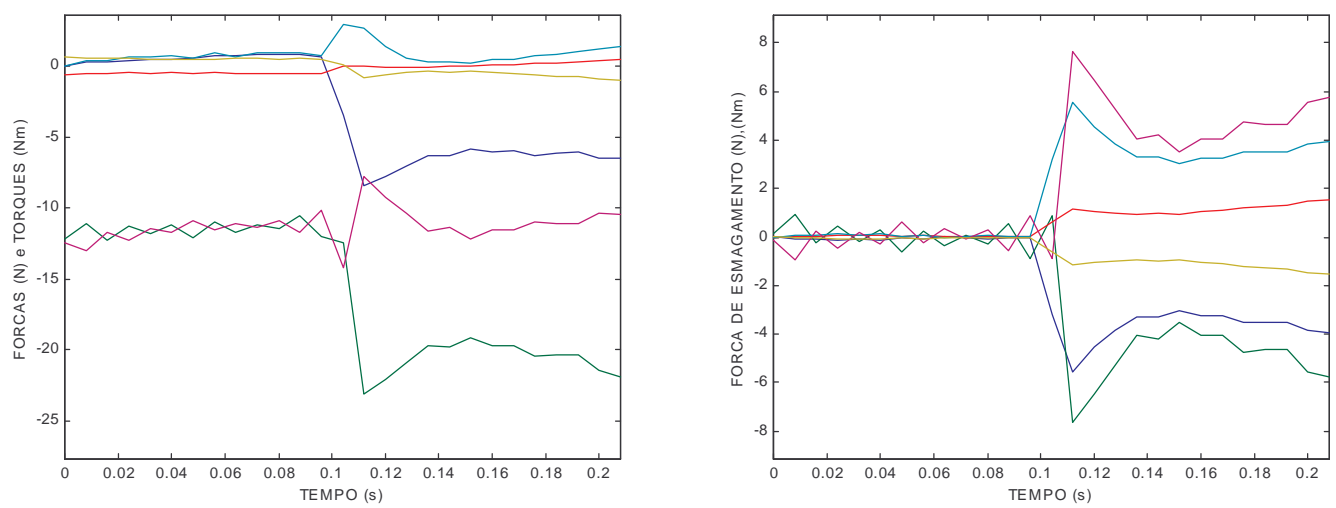

FIGURA 6.9. Figura à esquerda: forças aplicadas no objeto. Linhas contínuas: forças aplicadas pelo manipulador 1 . Linhas tracejadas: forças aplicadas pelo manipulador

2. Figura à direita: força de esmagamento $\left(h_{\circ e}\right)$.
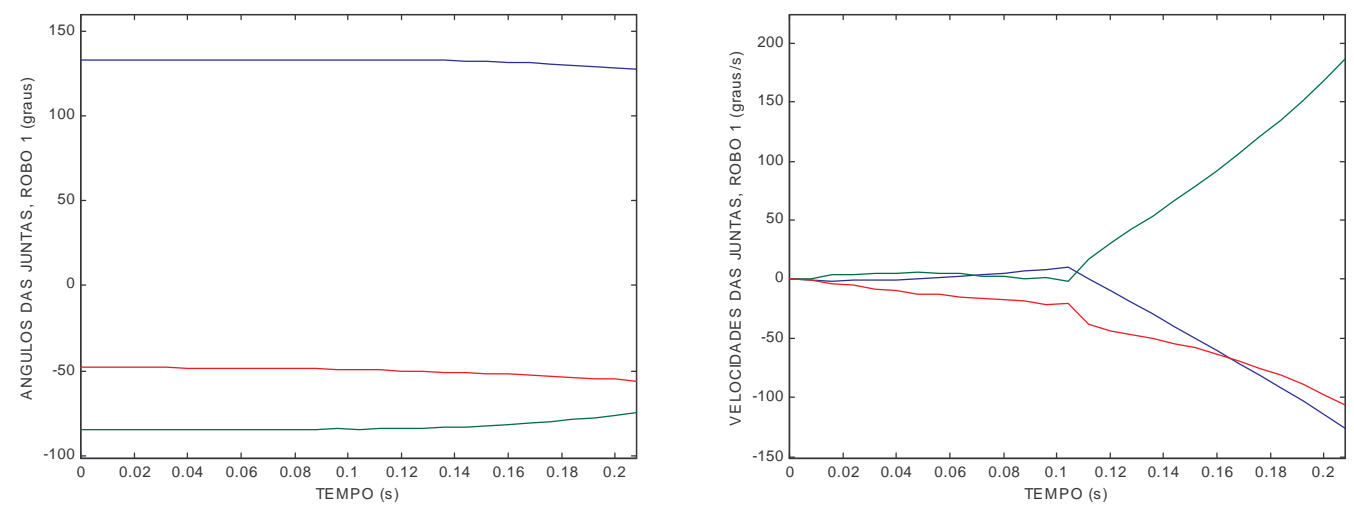

FIGURA 6.10. Figura à esquerda: ângulos das juntas do robô 1; Figura à direita: velocidades das juntas do robô 1 . Junta $1 \mathrm{em}$ azul, junta $2 \mathrm{em}$ verde e junta $3 \mathrm{em}$ vermelho. 

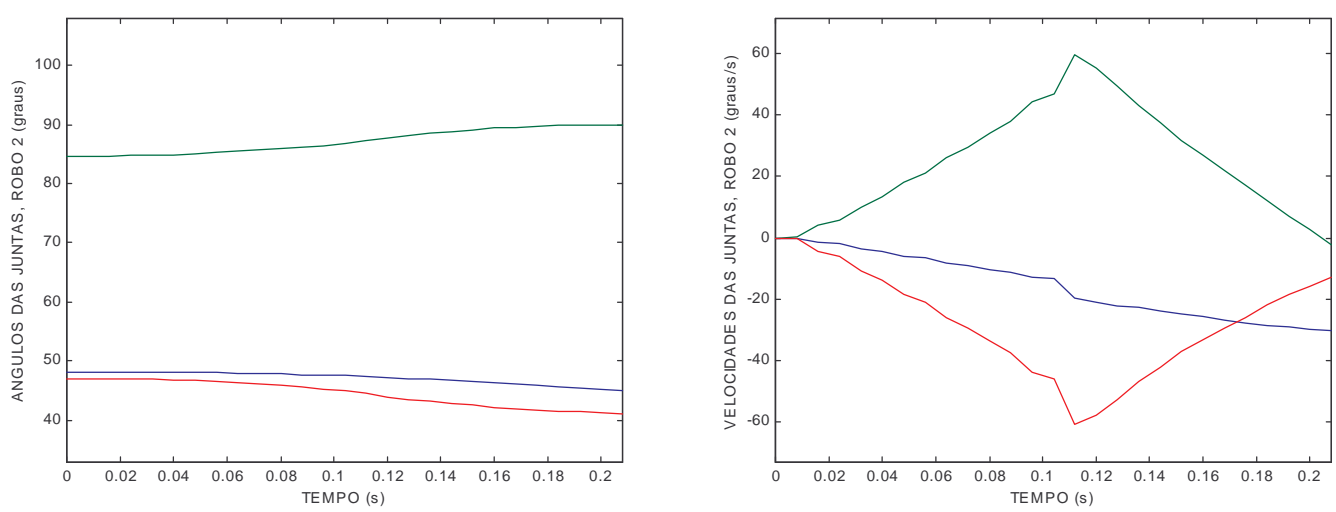

FIGURA 6.11. Figura à esquerda: Ângulos das juntas do robô 2; Figura à direita: Velocidades das juntas do robô 2 . Junta 1 em azul; junta 2 em verde e junta 3 em vermelho.
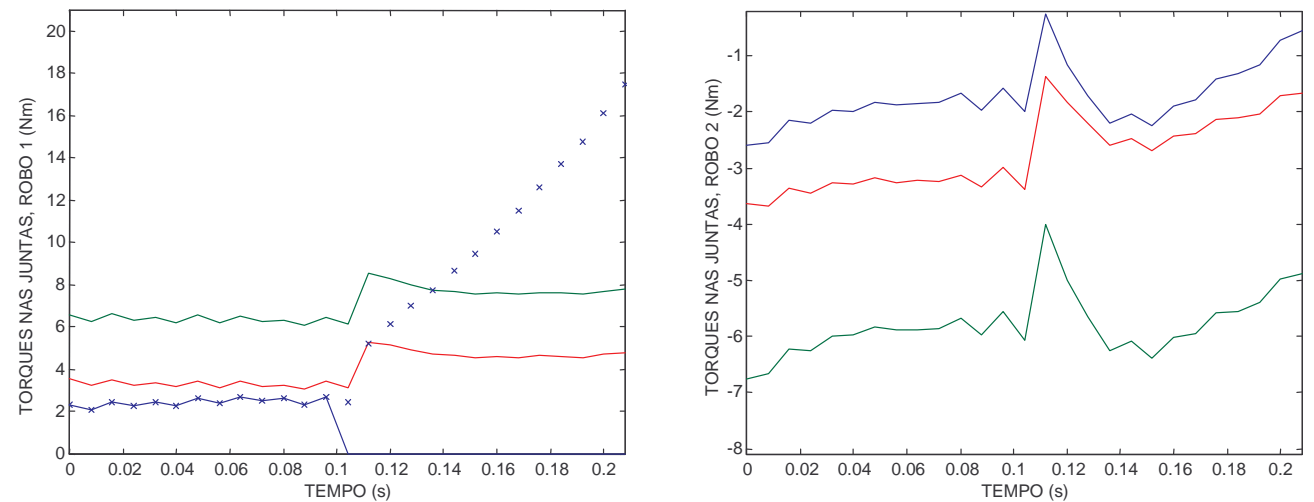

FIGURA 6.12. Figura à esquerda: torques nas juntas do robô 1; Figura à direita: torques nas juntas do robô 2 . Linhas sólidas: torques reais nas junta 1 (azul), 2 (verde) e 3 (vermelho); ' $x$ ': torques calculados na junta 1 do robô 1.

\subsubsection{Sistema Simulado 2}

Os resultados desta seção foram obtidos com a simulação do sistema formado por dois robôs Puma 560 (Sistema Simulado 2). As Figuras 6.13-6.17 mostram os resultados da simulação de uma trajetória do sistema cooperativo com uma falha do tipo junta 2 do robô 2 com balanço livre ocorrendo em 0,8 s. A Figura 6.13. mostra uma representação dos robôs no instante 1,602 s e as Figuras 6.14-17 mostram, respectivamente, as posições do CM e as orientações do objeto (Figura 6.14), as velocidades do objeto (Figura 6.15), as forças exercidas pelos efetuadores no objeto e a força de esmagamento (Figura 6.16), e os torques nas juntas dos robôs 1 e 2 (Figura 6.17). 
Note que, quando ocorre a falha, os erros de posição e as velocidades do objeto aumentam rapidamente (Figuras 6.14 e 6.15) já que não existe tolerância a falhas, podendo levar os robôs a colidirem entre si, com o solo, ou com outro objeto presente no ambiente de trabalho. A Figura 6.13 mostra que, nessa simulação, o efetuator do robô 1 colidiu com a base do mesmo manipulador no instante 1,602 s. Note também que a força de esmagamento aumenta quando ocorre a falha (Figura 6.16), podendo vir a danificar o objeto manipulado. Assim, fica evidente que a falha deva ser rapidamente isolada e o sistema reconfigurado ou bloqueado através de freios.

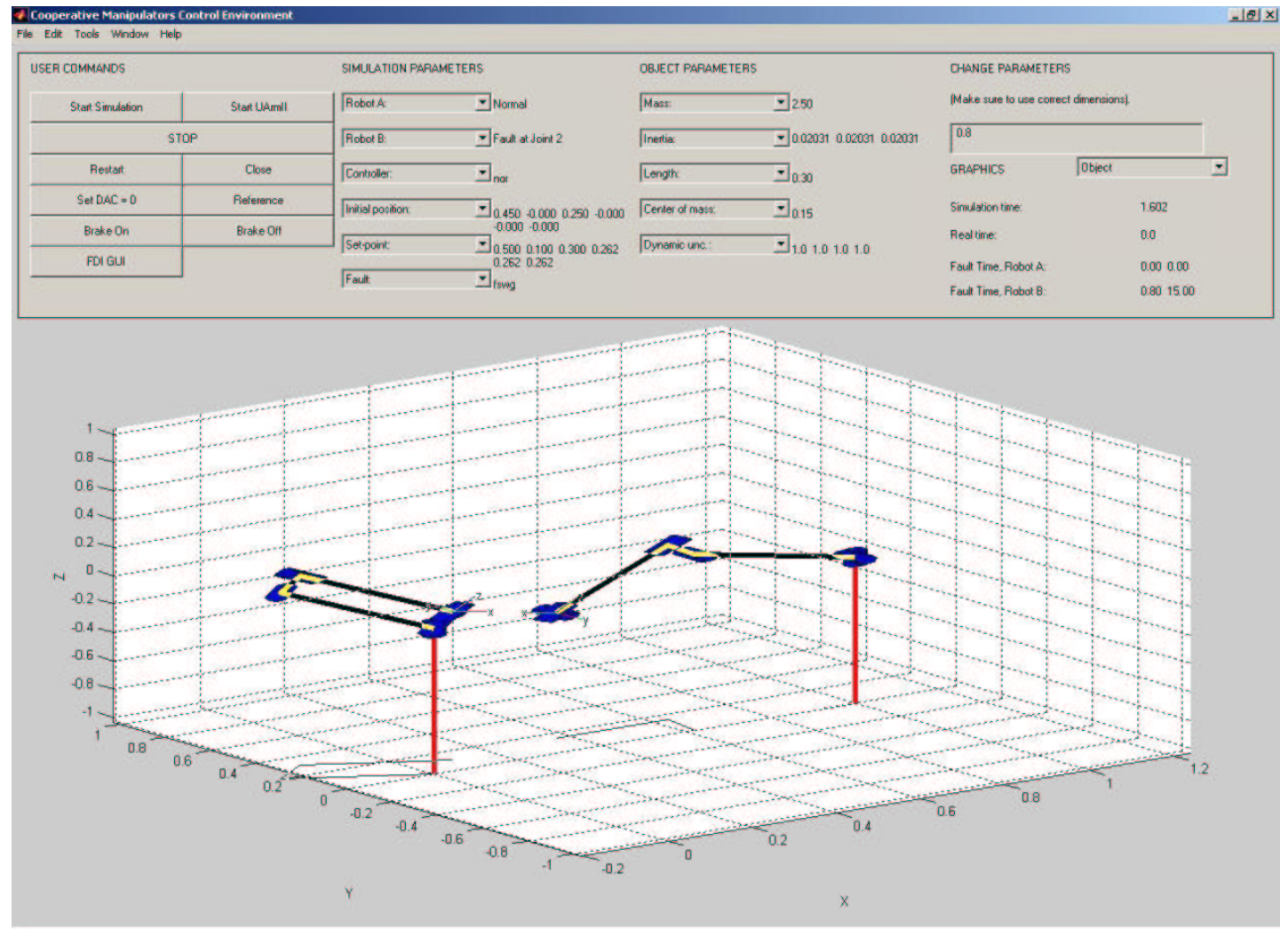

FIGURA 6.13. Robôs Puma 560 em $t=1,602 \mathrm{~s}$ em uma trajetória do sistema sem tolerância simulada com falha do tipo junta 2 do robô 2 com balanço livre ocorrendo em $0,8 \mathrm{~s}$. 0 robô 2 pode ser visto do lado direito da figura. 

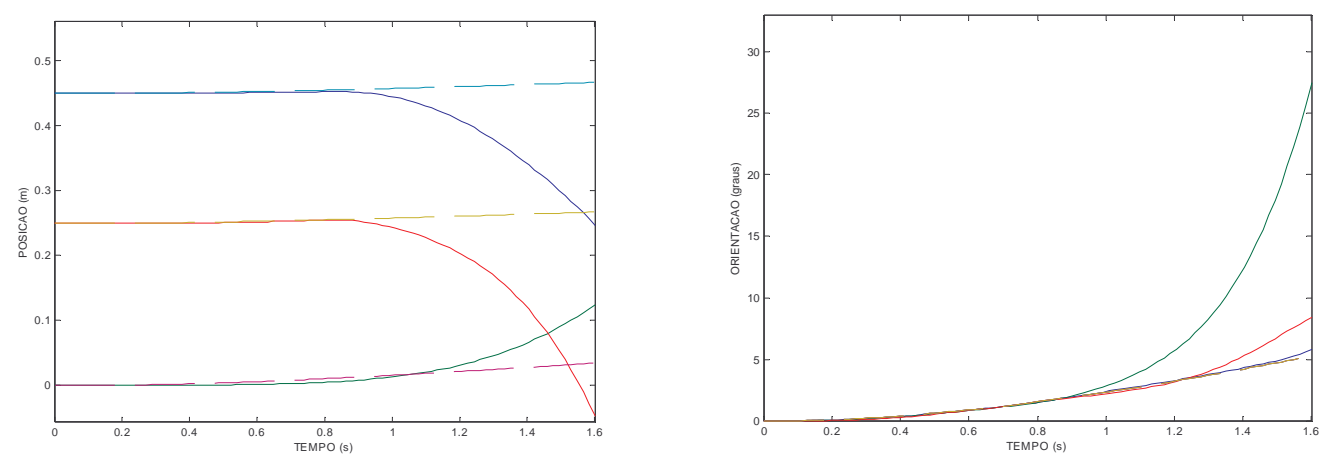

FIGURA 6.14. Figura à esquerda: linhas contínuas indicam a posição do CM do objeto (coordenadas: $x$ em azul, $y$ em verde e $z$ em vermelho). Figura à direita: linhas contínuas indicam a orientação do objeto (roll em azul, pitch em verde e yaw em vermelho). As linhas tracejadas indicam os valores desejados.
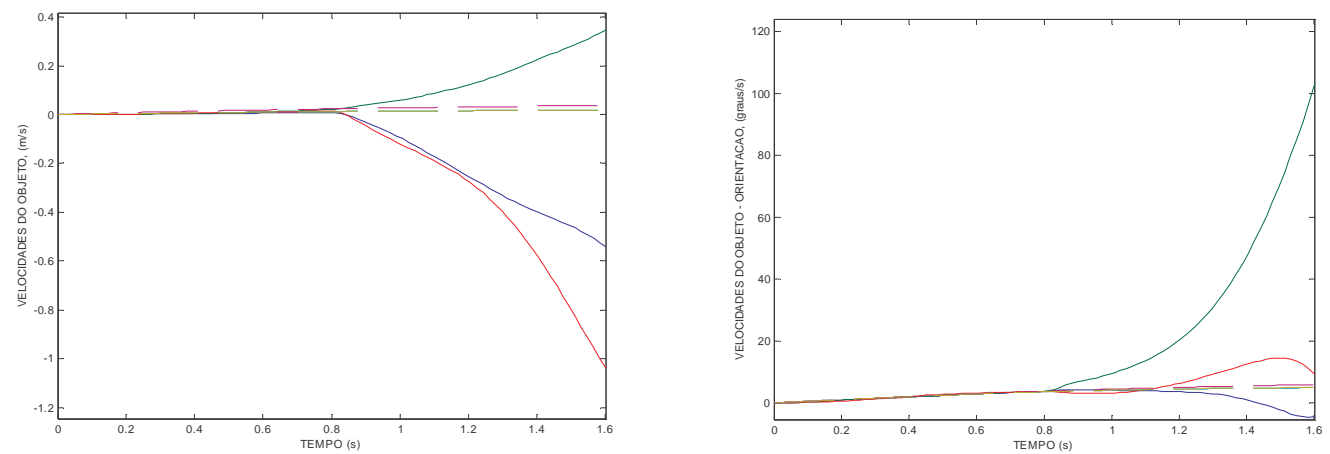

FIGURA 6.15. Figura à esquerda: linhas contínuas indicam as velocidades lineares do objeto (coordenadas: $x$ em azul, $y$ em verde e $z$ em vermelho). Figura à direita: linhas contínuas indicam as velocidades angulares do objeto (coordenadas: $x$ em azul, $y \mathrm{em}$ verde e $z$ em vermelho). As linhas tracejadas indicam os valores desejados.
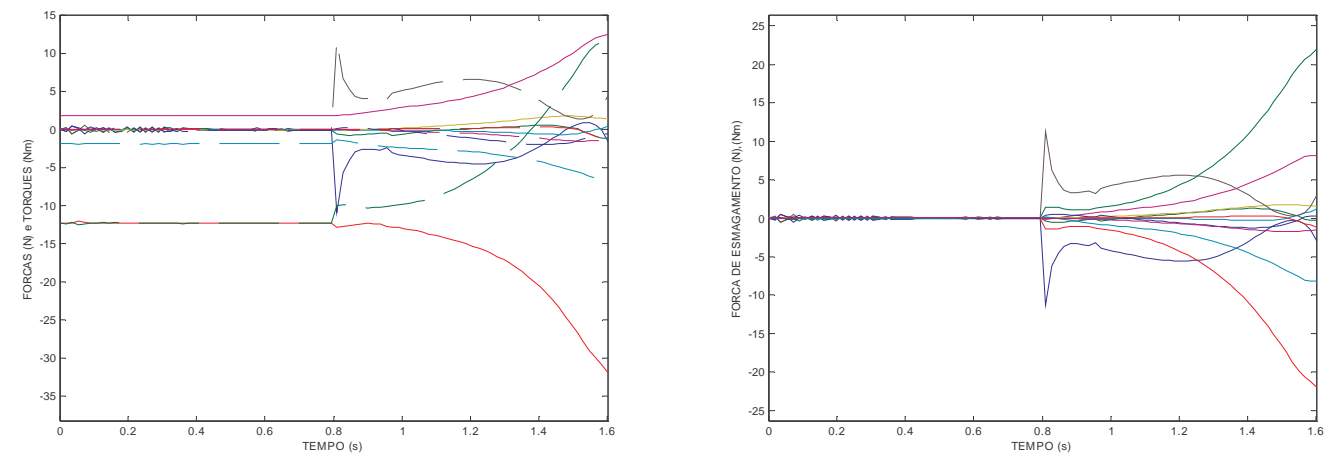

FIGURA 6.16. Figura à esquerda: forças aplicadas no objeto. Linhas contínuas: forças aplicadas pelo manipulador 1. Linhas tracejadas: forças aplicadas pelo manipulador 2. Figura à direita: força de esmagamento $\left(h_{o e}\right)$. 

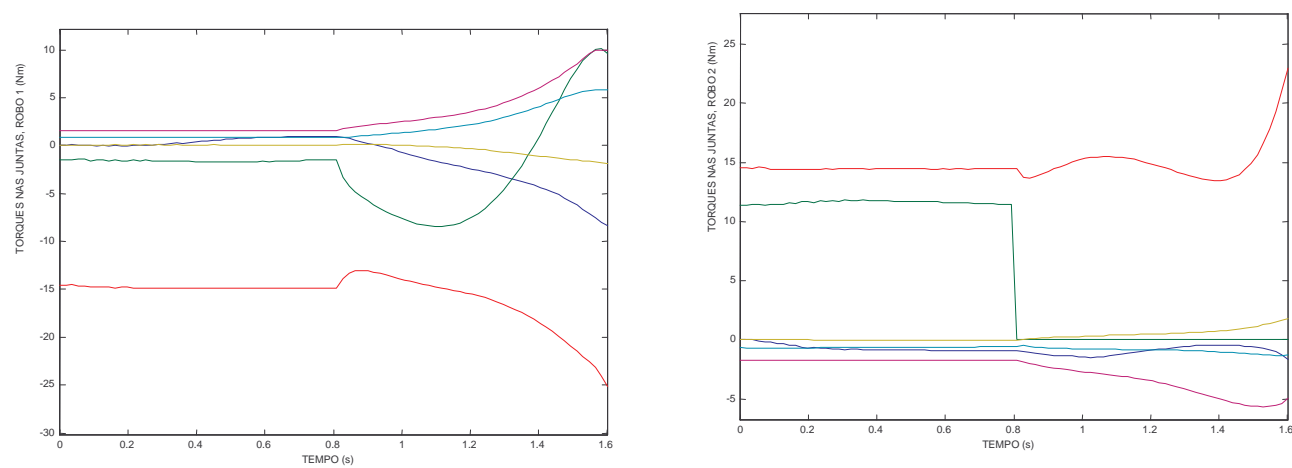

FIGURA 6.17. Figura à esquerda: torques nas juntas do robô 1; Figura à direita: torques nas juntas do robô 2 .

\subsection{DETECÇÃO E ISOLAÇÃO DE FALHAS}

Esta seção traz os resultados do Sistema DIF apresentado no Capítulo 4. Primeiramente, o Sistema DIF foi aplicado no Sistema Simulado 1 (Seção 6.3.1), no qual estão presentes ruídos de medida (ver Seção 6.1.1.1). Então, aumentou-se a complexidade do problema através da simulação do sistema cooperativo formado por robôs Puma 560 (Seção 6.3.2), no qual, além do dobro do número de juntas em relação ao Sistema Simulado 1, os efeitos da fricção nas juntas estão presentes. Finalmente, o Sistema DIF foi aplicado no sistema cooperativo real (Seção 6.3.3).

\subsubsection{Sistema Simulado 1}

Os resultados desta seção foram obtidos com a simulação do sistema formado por dois robôs planares com 3 juntas rotacionais cada (Sistema Simulado 1). Para o treinamento das RNA's do Sistema DIF, definiu-se um espaço de trabalho para o sistema cooperativo. Isto foi necessário devido à necessidade de se normalizar os dados de entrada dos MLP's. Os valores máximos e mínimos das variáveis de posição e orientação do objeto são apresentados na Tabela B.4 do Apêndice B (a Figura B.1 deste mesmo apêndice mostra a representação das posições no espaço de trabalho).

O treinamento dos MLP's foi realizado utilizando-se 7400 padrões obtidos na simulação de 100 trajetórias livres de falhas. A Tabela B.5 do Apêndice B mostra os parâmetros do MLP. Em cada trajetória, o objeto partia de uma posição inicial aleatória e era 
controlado até uma posição desejada também aleatória. O sistema cooperativo foi simulado para todas as trajetórias e os dados resultantes foram apresentados normalizados pelo máximo valor aos MLP's.

Para o treinamento da rede RBF, considera-se que o sistema cooperativo sofre 12 falhas (uma em cada junta) dos tipos junta com balanço livre e bloqueada. Considera-se que o sistema sofre apenas uma falha de cada vez. Utilizou-se para o treinamento 2691 padrões. As Tabelas B.6 e B.7 do Apêndice B mostram, respectivamente, o conjunto de trajetórias e os parâmetros de treinamento da rede RBF. O critério de falhas adotado é o seguinte: para que a falha $i(i=1, \ldots, 12)$ seja detectada, a saída $j=i(j=1, \ldots, 13)$ da rede RBF deve apresentar durante 3 amostras seguidas o sinal com maior valor em relação às outras saídas.

A Figura 6.18 mostra os resíduos e as saídas da rede RBF na simulação do sistema com falha do tipo junta 1 do robô 1 com balanço livre apresentada na Seção 6.1.1. A Figura 6.19 mostra a detecção das falhas do tipo junta 1 do manipulador 1 com balanço livre para a mesma simulação. Observe que, quando ocorre a falha, os resíduos aumentam rapidamente, o que torna possível a deteç̧ão e isolação da falha em aproximadamente $0,02 \mathrm{~s}$.
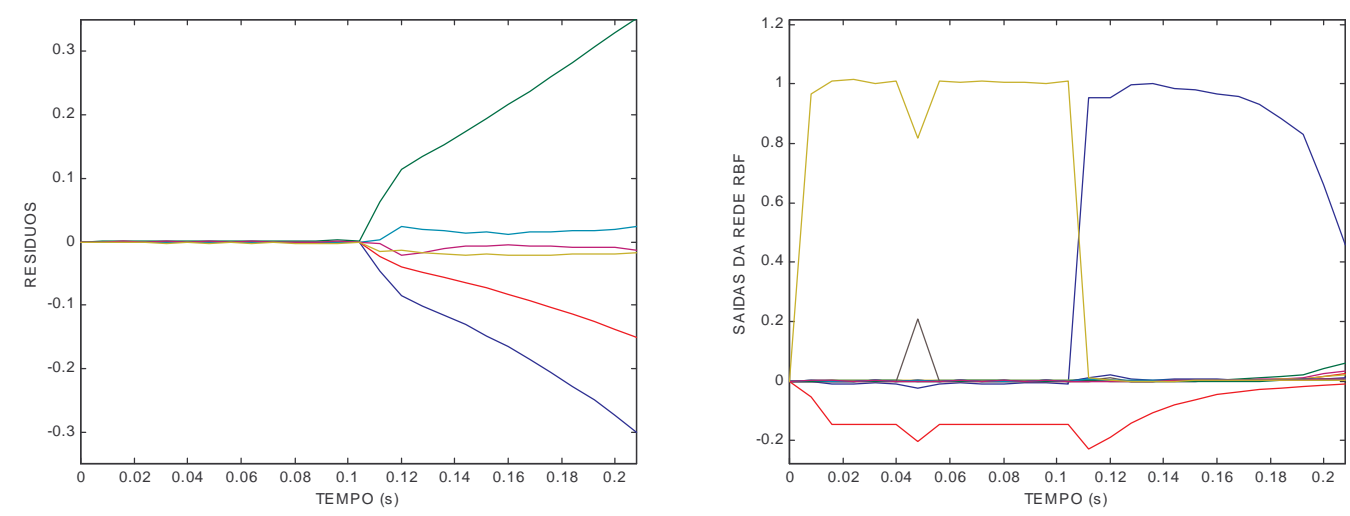

FIGURA 6.18. Figura à esquerda: resíduos ; Figura à direita: saídas da rede RBF (amarelo: saída responsável pela indicação da operação sem falhas; azul: saída responsável pela detecção da falha junta 1 do robô 1 com balanço livre). 


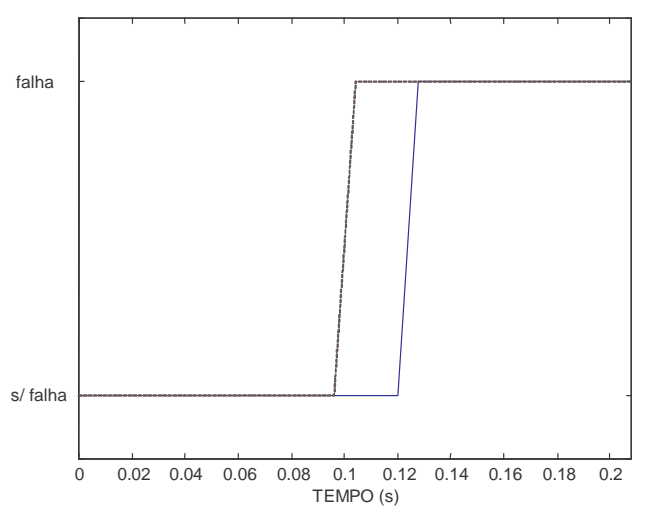

FIGURA 6.19. Detecção da falha do tipo junta 1 do manipulador 1 com balanço livre (linha contínua azul) e falha real (linha tracejada preta).

O passo seguinte foi a definição dos parâmetros para a detecção e isolação de falhas dos tipos informação incorreta de posição e velocidade das juntas. Tais valores foram escolhidos com base nos valores de variância dos ruídos de medida e são apresentados na Tabela B.8 do Apêndice B.

O Sistema DIF completo foi testado considerando-se 8 conjuntos de testes. Os conjuntos de 1 a 4 têm 480 trajetórias com falhas e 20 sem falhas cada. As trajetórias desejadas dos 2 primeiros conjuntos têm os mesmos pontos iniciais e finais, mas com falhas ocorrendo, respectivamente, em 0,15 s e 0,3 s. O mesmo ocorre para os conjuntos 3 e 4 . Os quatro tipos de falhas foram simuladas. Nos conjuntos de 1 a 4 , as medidas de posição e velocidade nas juntas foram substituídas por valores aleatórios para as falhas do tipo informação incorreta de posição e velocidade. Já para os conjuntos de 5 a 8 , estas medidas foram substituídas por zeros. Nos conjuntos de 5 a 8, os mesmos parâmetros das trajetórias dos conjuntos de 1 a 4 foram usados, mas somente 240 trajetórias foram simuladas (somente para as falhas do tipo informação incorreta de posição ou velocidade das juntas).

A Tabela 6.1 apresenta os resultados dos testes do Sistema DIF completo. A segunda e a terceira colunas mostram, respectivamente, o número de falhas detectadas e o número de falhas corretamente isoladas. A quarta coluna mostra o número de alarmes falsos que ocorreram nas trajetórias sem falhas. A quinta coluna mostra o Tempo Médio para Detecção (TMD): o tempo médio que o Sistema DIF leva para detectar a falha depois de sua ocorrência. 
TABELA 6.1: Resultados do teste do Sistema DIF: Sistema Simulado 1.

\begin{tabular}{ccccc}
\hline Conjunto & Falhas detectadas & $\begin{array}{c}\text { Falhas isoladas } \\
\text { corretamente }\end{array}$ & Alarmes falsos & TMD (s) \\
\hline 1 & $479^{* *}(99,8 \%)$ & $469^{* *}(97,7 \%)$ & $0^{*}(0 \%)$ & 0,016 \\
2 & $480^{* *}(100 \%)$ & $461^{* *}(96,0 \%)$ & $0^{*}(0 \%)$ & 0,017 \\
3 & $479^{* *}(99,8 \%)$ & $469^{* *}(97,7 \%)$ & $0^{*}(0 \%)$ & 0,017 \\
4 & $480^{* *}(100 \%)$ & $459^{* *}(95,6 \%)$ & $0^{*}(0 \%)$ & 0,019 \\
5 & $449^{* *}(93,5 \%)$ & $408^{* *}(85,0 \%)$ & $0^{*}(0 \%)$ & 0,024 \\
6 & $457^{* *}(95,2 \%)$ & $408^{* *}(85,0 \%)$ & $0^{*}(0 \%)$ & 0,018 \\
7 & $450^{* *}(93,7 \%)$ & $397^{* *}(82,7 \%)$ & $0^{*}(0 \%)$ & 0,013 \\
8 & $459^{* *}(93,6 \%)$ & $409^{* *}(85,2 \%)$ & $0^{*}(0 \%)$ & 0,021 \\
\hline
\end{tabular}

"Total: 20 trajetórias sem falhas em cada conjunto; ${ }^{* * *}$ Total: 480 trajetórias com falhas em cada conjunto

A Tabela 6.2 mostra os resultados dos testes para cada falha individualmente. Pode-se notar que o número de falhas do tipo informação incorreta de velocidade corretamente isoladas foi menor para os conjuntos de 5 a 8 . Isto ocorreu porque estas falhas nestes conjuntos foram confundidas com as falhas do tipo junta bloqueada devido à substituição das velocidades medidas por zeros. Contudo, nestes casos, falhas do tipo informação incorreta de velocidade das juntas geralmente não ocasionam consequências graves para o controle devido à substituição das velocidades reais por zeros. Salienta-se entretanto que isto ocorre devido à escolha do tipo de trajetória controlada (com velocidade do objeto igual a zero no final da trajetória) e do tipo do controlador. 
TABELA 6.2: Resultados por falha do teste do Sistema DIF: Sistema Simulado 1.

\begin{tabular}{|c|c|c|c|}
\hline Conjunto & Tipo de falha & Falhas detectadas & $\begin{array}{c}\text { Falhas isoladas } \\
\text { corretamente }\end{array}$ \\
\hline 1 & $\mathrm{JBL}$ & $120(100,0 \%)$ & $118(98,33 \%)$ \\
\hline 1 & $\mathrm{JB}^{* *}$ & $119(99,17 \%)$ & $114(95,00 \%)$ \\
\hline 1 & $\operatorname{IIPJ}^{* * *}$ & $120(100,0 \%)$ & $118(98,33 \%)$ \\
\hline 1 & $\mathrm{IIVJ}^{* * * *}$ & $120(100,0 \%)$ & $118(98,33 \%)$ \\
\hline 2 & $\mathrm{JBL}^{*}$ & $120(100,0 \%)$ & $120(100,0 \%)$ \\
\hline 2 & $\mathrm{JB}^{* *}$ & $120(100,0 \%)$ & $105(87,50 \%)$ \\
\hline 2 & IIPJ ${ }^{* * * *}$ & $120(100,0 \%)$ & $118(98,33 \%)$ \\
\hline 2 & IIVJ ${ }^{* * * * *}$ & $120(100,0 \%)$ & $118(98,33 \%)$ \\
\hline 3 & $\mathrm{JBL}^{*}$ & $120(100,0 \%)$ & $118(98,33 \%)$ \\
\hline 3 & $\mathrm{JB}^{* *}$ & $119(99,17 \%)$ & $114(95,00 \%)$ \\
\hline 3 & IIPJ $^{* * *}$ & $120(100,0 \%)$ & $117(97,50 \%)$ \\
\hline 3 & $\mathrm{IIVJ}^{* * * *}$ & $120(100,0 \%)$ & $120(100,0 \%)$ \\
\hline 4 & $\mathrm{JBL}^{*}$ & $120(100,0 \%)$ & $118(98,33 \%)$ \\
\hline 4 & $\mathrm{JB}^{* *}$ & $120(100,0 \%)$ & $104(86,67 \%)$ \\
\hline 4 & IIPJ $^{* * *}$ & $120(100,0 \%)$ & $120(100,0 \%)$ \\
\hline 4 & $\mathrm{IIVJ}^{* * * *}$ & $120(100,0 \%)$ & $118(98,33 \%)$ \\
\hline 5 & IIPJ $^{* * *}$ & $120(100,0 \%)$ & $120(100,0 \%)$ \\
\hline 5 & $\mathrm{IIVJ}^{* * * *}$ & $89(74,17 \%)$ & $52(43,33 \%)$ \\
\hline 6 & IIPJ $^{* * *}$ & $120(100,0 \%)$ & $118(98,33 \%)$ \\
\hline 6 & $\mathrm{IIVJ}^{* * * *}$ & $97(80,83 \%)$ & $65(54,17 \%)$ \\
\hline 7 & IIPJ ${ }^{* * *}$ & $120(100,0 \%)$ & $118(98,33 \%)$ \\
\hline 7 & $\mathrm{IIVJ}^{* * * *}$ & $91(75,83 \%)$ & $46(38,33 \%)$ \\
\hline 8 & IIPJ ${ }^{* * *}$ & $120(100,0 \%)$ & $118(98,33 \%)$ \\
\hline 8 & IIVJ $^{* * * *}$ & $99(82,50 \%)$ & $70(58,33 \%)$ \\
\hline
\end{tabular}

"JBL: Junta com balanço livre; ; JB: Junta bloqueada; ${ }^{* * * *}$ IIPJ: Informação incorreta de posição da junta; IIVJ: Informação incorreta de velocidade da junta;

\subsubsection{Sistema Simulado 2}

Os resultados desta seção foram obtidos com a simulação do sistema formado por dois robôs Puma 560 (Sistema Simulado 2). Para o treinamento das RNA's do Sistema DIF, definiu-se um espaço de trabalho para o sistema cooperativo, cujos valores máximos e mínimos das 
variáveis de posição e orientação do objeto são apresentados na Tabela C.3 do Apêndice C (a Figura C.1 deste mesmo Apêndice mostra a representação das posições no espaço de trabalho).

O treinamento dos MLP's foi realizado utilizando-se 6804 padrões obtidos na simulação de 50 trajetórias do sistema cooperativo. A Tabela C.4 do Apêndice C mostra os parâmetros do MLP. Em cada trajetória, o objeto partia de uma posição inicial aleatória e era controlado até uma posição desejada também aleatória. O sistema cooperativo foi simulado para todas as trajetórias e os dados resultantes foram apresentados normalizados pelos máximos e mínimos valores aos MLP's.

Para o treinamento da rede RBF, considera-se que o sistema cooperativo sofre 24 falhas (uma em cada junta) dos tipos junta com balanço livre e bloqueada. Considera-se que o sistema sofre apenas uma falha de cada vez. Foram utilizados 5291 padrões para o treinamento da rede RBF. As Tabelas C.5 e C.6 do Apêndice C mostram, respectivamente, o conjunto de trajetórias e os parâmetros de treinamento da rede RBF. O critério de falhas adotado é o seguinte: para que a falha $i(i=1, \ldots, 24)$ seja detectada, a saída $j=i(j=1, \ldots, 25)$ da rede RBF deve apresentar durante 3 amostras consecutivas o sinal com maior valor em relação às outras saídas.

O passo seguinte foi a definição dos parâmetros para a detecção e isolação de falhas dos tipos informação incorreta de posição e velocidade das juntas. Tais valores são apresentados na Tabela C.7 do Apêndice C.

O Sistema DIF foi testado considerando-se 4 conjuntos de testes, cada qual com 720 trajetórias com falhas e 15 sem falhas. As medidas de posição e velocidade nas juntas foram substituídas por valores aleatórios para as falhas do tipo informação incorreta de posição ou velocidade das juntas. As trajetórias desejadas dos conjuntos 1 e 2 têm os mesmos pontos iniciais e finais, mas com tempos iniciais das falhas iguais a $0,3 \mathrm{~s}$ e $1,5 \mathrm{~s}$ respectivamente. O conjunto 3 tem trajetórias desejadas diferentes e o tempo inicial das falhas é 0,5 s. Já no conjunto 4, no qual as trajetórias desejadas são diferentes daquelas dos demais conjuntos, o tempo inicial das falhas é $0,3 \mathrm{~s}$. A Tabela 6.3 apresenta os resultados dos quatro conjuntos de testes. A Tabela 6.4 mostra os resultados dos testes para cada falha individualmente. 
TABELA 6.3: Resultados do teste do Sistema DIF: Sistema Simulado 2.

\begin{tabular}{ccccc}
\hline Conjunto & Falhas detectadas & $\begin{array}{c}\text { Falhas isoladas } \\
\text { corretamente }\end{array}$ & Alarmes falsos & TMD (s) \\
\hline 1 & $718^{* *}(99,72 \%)$ & $689^{* *}(95,69 \%)$ & $0^{*}(0 \%)$ & 0,117 \\
2 & $715^{* *}(99,31 \%)$ & $656^{* *}(91,11 \%)$ & $0^{*}(0 \%)$ & 0,118 \\
3 & $719^{* *}(99,86 \%)$ & $691^{* *}(95,97 \%)$ & $0^{*}(0 \%)$ & 0,108 \\
4 & $712^{* *}(98,85 \%)$ & $685^{* *}(95,14 \%)$ & $2^{*}(13,33 \%)$ & 0,112 \\
\hline
\end{tabular}

"Total: 15 trajetórias sem falhas em cada conjunto; ${ }^{* *}$ Total: 720 trajetórias com falhas em cada conjunto

TABELA 6.4: Resultados por falha do teste do Sistema DIF: Sistema Simulado 2.

\begin{tabular}{cccc}
\hline Conjunto & Tipo de falha & Falhas detectadas & $\begin{array}{c}\text { Falhas isoladas } \\
\text { corretamente }^{* * * * *}\end{array}$ \\
\hline 1 & JBL $^{*}$ & $178(98,89 \%)$ & $152(85,39 \%)$ \\
1 & JB $^{* *}$ & $180(100,0 \%)$ & $180(100,0 \%)$ \\
1 & IIPJ $^{* * *}$ & $180(100,0 \%)$ & $175(95,22 \%)$ \\
1 & IIVJ $^{* * * *}$ & $180(100,0 \%)$ & $180(100,0 \%)$ \\
2 & JBL $^{*}$ & $174(96,67 \%)$ & $150(83,33 \%)$ \\
2 & JB $^{* *}$ & $180(100,0 \%)$ & $158(87,78 \%)$ \\
2 & IIPJ $^{* * *}$ & $180(100,0 \%)$ & $171(95,00 \%)$ \\
2 & IIVJ $^{* * * *}$ & $180(100,0 \%)$ & $177(98,33 \%)$ \\
3 & JBL $^{*}$ & $179(99,44 \%)$ & $156(86,67 \%)$ \\
3 & JB $^{* *}$ & $180(100,0 \%)$ & $180(100,0 \%)$ \\
3 & IIPJ $^{* * *}$ & $180(100,0 \%)$ & $176(97,78 \%)$ \\
3 & IIVJ $^{* * * *}$ & $180(100,0 \%)$ & $179(99,44 \%)$ \\
4 & JBL $^{*}$ & $173(96,11 \%)$ & $151(83,89 \%)$ \\
4 & JB $^{* *}$ & $180(100,0 \%)$ & $180(100,0 \%)$ \\
4 & IIPJ $^{* * *}$ & $180(100,0 \%)$ & $175(97,22 \%)$ \\
4 & IIVJ $^{* * * *}$ & $180(100,0 \%)$ & $118(98,33 \%)$ \\
\hline
\end{tabular}

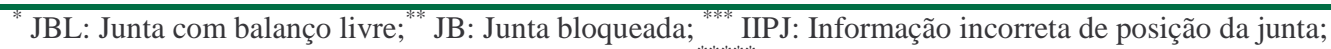

***** IIVJ: Informação incorreta de velocidade da junta; ${ }^{* * * * *}$ Total: 180 trajetórias para cada falha em cada conjunto

Observe que algumas falhas do tipo junta com balanço livre não foram corretamente isoladas. Isto ocorreu porque as falhas estavam em trajetórias em que a velocidade da junta era próxima de zero e, então, foram confundidas com falhas do tipo junta bloqueada. Note que isso ocorreu mais acentuadamente no conjunto 2 , pois as falhas 
ocorreram quando o objeto estava mais perto da posição final e, consequentemente, as juntas tinham velocidades e torques menores.

\subsubsection{Sistema Real}

Os resultados desta seção foram obtidos com o sistema real formado por dois robôs UArmII (Seção 6.1.2). Para o treinamento das RNA's do Sistema DIF, definiu-se um espaço de trabalho para o sistema cooperativo, cujos valores máximos e mínimos das variáveis de posição e orientação do objeto são apresentados na Tabela E.4 do Apêndice E (a Figura E.1 deste mesmo apêndice mostra a representação das posições no espaço de trabalho).

O treinamento dos MLP's foi realizado utilizando-se 3250 padrões obtidos do sistema real. A Tabela E.5 do Apêndice E mostra os parâmetros do MLP. Em cada trajetória do sistema real, o objeto partia de uma posição inicial aleatória e era controlado até uma posição desejada também aleatória. O sistema cooperativo foi simulado para todas as trajetórias e os dados resultantes foram apresentados normalizados pelo máximo valor aos MLP's.

Para o treinamento da rede RBF, considera-se que o sistema cooperativo sofre 12 falhas (uma em cada junta) dos tipos junta com balanço livre e bloqueada. Considera-se que o sistema sofre apenas uma falha de cada vez. Utilizou-se para o treinamento 2506 padrões. As Tabelas E.6 e E.7 do Apêndice E mostram, respectivamente, o conjunto de trajetórias e os parâmetros de treinamento da rede RBF. O critério de falhas adotado é o seguinte: para que a falha $i(i=1, \ldots, 12)$ seja detectada, a saída $j=i(j=1, \ldots, 13)$ da rede RBF deve apresentar durante 4 amostras seguidas o sinal com maior valor em relação às outras saídas.

O passo seguinte foi a definição dos parâmetros para a detecção e isolação de falhas dos tipos informação incorreta de posição e velocidade das juntas. Tais valores são apresentados na Tabela E.8 do Apêndice E.

O Sistema DIF foi testado considerando-se 3 conjuntos de testes, cada qual com 360 trajetórias com falhas e 15 sem falhas. As trajetórias desejadas dos conjuntos 2 e 3 têm os mesmos pontos iniciais e finais, mas com massas do objeto de $0,025 \mathrm{~kg}$ e $0,45 \mathrm{~kg}$ respectivamente. $\mathrm{O}$ conjunto 1 tem trajetórias diferentes e uma massa do objeto de $0,45 \mathrm{~kg}$. As medidas de posição e velocidade nas juntas foram substituídas por valores aleatórios para as falhas do tipo informação incorreta de posição e velocidade. A Tabela 6.5 apresenta os resultados dos três conjuntos de testes. 
TABELA 6.5: Resultados do teste do Sistema DIF: Sistema Real.

\begin{tabular}{ccccc}
\hline Conjunto & Falhas detectadas & $\begin{array}{c}\text { Falhas isoladas } \\
\text { corretamente }\end{array}$ & Alarmes falsos & TMD (s) \\
\hline 1 & $337^{* *}(93,61 \%)$ & $260^{* *}(72,22 \%)$ & $1^{*}(6,67 \%)$ & 0,469 \\
2 & $333^{* *}(92,50 \%)$ & $247^{* *}(68,61 \%)$ & $0^{*}(0 \%)$ & 0,419 \\
3 & $325^{* *}(90,28 \%)$ & $268^{* *}(74,44 \%)$ & $0^{*}(0 \%)$ & 0,458 \\
\hline
\end{tabular}

"Total: 15 trajetórias sem falhas em cada conjunto; ${ }^{* *}$ Total: 360 trajetórias com falhas em cada conjunto

O número de falhas corretamente isoladas é menor no sistema real do que no sistema simulado devido, principalmente, à confusão na isolação de falhas do tipo junta com balanço livre com as do tipo junta bloqueada. Isto ocorre porque as velocidades das juntas com falhas são pequenas já que os torques gravitacionais são pequenos nas juntas. Entretanto, nestes casos, mesmo com falhas do tipo junta com balanço livre, o objeto em geral converge para a posição desejada. Ou seja, a falha não apresenta consequências graves. Isto ocorre, por exemplo, se não é necessário aplicar torques altos na junta com falha em uma determinada trajetória.

\subsection{CONTROLE DO SISTEMA COOPERATIVO COM FALHAS}

Esta seção traz os resultados do controle do sistema com falhas apresentado no Capítulo 5. A Seção 6.4.1 traz três simulações do Sistema 1. Nas duas primeiras, o controlador desenvolvido na Seção 5.2 é comparado com o controlador apresentado em [LIU et al., 1999] para o sistema cooperativo com uma junta passiva. Na terceira, o controlador desenvolvido na Seção 5.3 é aplicado em uma trajetória com uma junta bloqueada. A Seção 6.4.2 traz uma simulação do controlador apresentado no Capítulo 5.2 para o caso limite em que 6 juntas do Sistema Simulado 2 são passivas. Salienta-se que, neste caso, os termos de fricção presentes na simulação não são compensados pelo controlador. Na Seção 6.4.3, apresenta-se uma simulação do Sistema 3 (Seção 6.1.1.3), que foi utilizado para testar a habilidade de controle de mais de dois robôs cooperativos com juntas passivas. Finalmente, na Seção 6.4.4, resultados do controle do sistema real com falhas são apresentados. 


\subsubsection{Sistema Simulado 1}

Os resultados desta seção foram obtidos com a simulação do sistema formado por dois robôs planares com 3 juntas rotacionais cada (Sistema Simulado 1). Os controladores desenvolvidos para o sistema com falhas apresentados no Capítulo 5 foram utilizados na simulação do sistema cooperativo. Os parâmetros dos controladores desenvolvidos para o controle do sistema com falhas podem ser vistos nas Tabelas B.9 e B.10 do Apêndice B.

As Figuras 6.20-25 mostram os resultados de duas simulações de uma mesma trajetória do sistema cooperativo na qual a junta 1 do manipulador 2 é passiva. Na primeira simulação (Figuras 6.20-22), o controlador apresentado em [LIU et al., 1999] para o problema de seguimento de trajetórias com controle da força de esmagamento foi utilizado. Na segunda simulação (Figuras 6.23-25), o controlador desenvolvido para o sistema com juntas passivas (Seção 5.2) foi utilizado. Nesta segunda simulação, as 4 componentes em $x \mathrm{e}$ $y$ da força de esmagamento foram controladas e as componentes do momento de esmagamento não foram controladas (Figura 6.24).

O controlador apresentado neste trabalho apresenta melhores resultados porque a lei de controle de esmagamento apresentada em [LIU et al., 1999] influencia o controle de movimento quando os erros de esmagamento são diferentes de zero (ver Apêndice A). Como não é possível controlar todos as componentes da força de esmagamento, as leis de controle apresentadas em [LIU et al., 1999] para o problema de seguimento de trajetórias quando $n_{a}>k$ ficam acopladas nas duas direções, o que leva os erros de movimento e esmagamento a serem significativamente diferentes de zero (Figuras 6.20 e 6.21).

Diferentemente do controlador desenvolvido em [LIU et al., 1999], os controles de movimento e esmagamento são tratados independentemente no controlador projetado neste trabalho, já que os torques calculados pela lei de controle de esmagamento projetam forças somente no subespaço de esmagamento. Note que o objeto segue a trajetória desejada para o controlador apresentando neste trabalho com um erro pequeno (Figura 6.23), apesar do torque na junta 1 do manipulador 2 ser zero (Figura 6.25). Também pode ser notado que as componentes em $x$ e $y$ da força de esmagamento são controladas (Figura 6.24).

Além disso, os torques produzidos pelo controlador apresentado em [LIU et al., 1999] são geralmente muito maiores (em módulo) que os produzidos pelo controlador desenvolvido na Seção 5.2, como pode ser visto nas Figuras 6.22 e 6.25. Isto ocorre porque somente $k$ juntas são utilizadas para o controle de movimento apresentado em [LIU et al., 1999] no caso do seguimento de trajetórias, o que pode sobrecarregar algumas juntas e representar um consumo desnecessário de energia. 
Observe também que os torques produzidos pelo manipulador 1 foram mais influenciados pelos ruídos do que os torques produzidos pelo manipulador 2 (Figura 6.25). Isso ocorreu porque a matriz $\mathbf{Q}$ projetou torques menores (em módulo) para a juntas do manipulador que continha a junta passiva na lei de controle de movimento $\boldsymbol{\tau}_{\mathrm{am}}$ (eq. 5.17). Como os erros de posição e velocidade são multiplicados pela matriz $\mathbf{Q}$ na eq. (5.17), os ruídos de medida foram amplificados através de ganhos diferentes. Já os torques produzidos pela lei de compensação dos termos gravitacionais $\boldsymbol{\tau}_{\mathrm{ag}}$ (eq. 5.22) são maiores para o manipulador com a junta passiva e são pouco influenciados pelos ruídos de medida. Assim, a soma dos dois componentes produziu torques com valores máximos (em módulo) próximos para os dois manipuladores durante a trajetória apresentada (Figura 6.25).
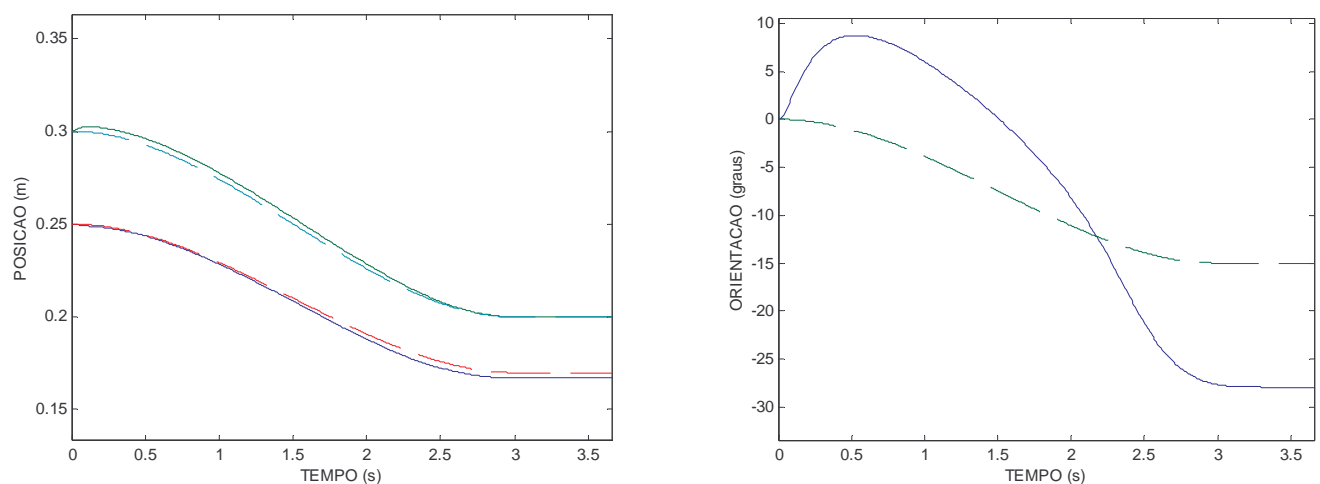

FIGURA 6.20. Simulação de uma trajetória com a junta 1 do manipulador 2 passiva (controlador apresentado em [LIU et al., 1999]). Figura à esquerda: linhas contínuas indicam a posição do CM do objeto (coordenada $x$ em azul e coordenada $y$ em verde). Figura à direita: linhas contínuas indicam a orientação do objeto. As linhas tracejadas indicam os valores desejados.
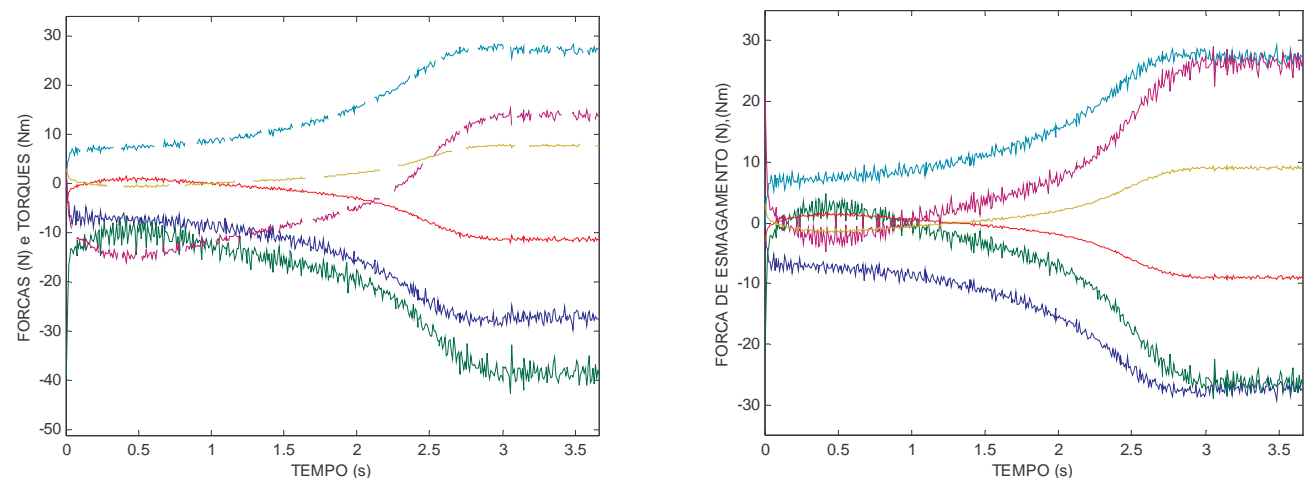

FIGURA 6.21. Simulação de uma trajetória com a junta 1 do manipulador 2 passiva (controlador apresentado em [LIU et al., 1999]). Figura à esquerda: forças aplicadas no objeto. Linhas contínuas: forças aplicadas pelo manipulador 1. Linhas tracejadas: forças aplicadas pelo manipulador 2 . Figura à direita: força de esmagamento $\left(h_{o e}\right)$. 

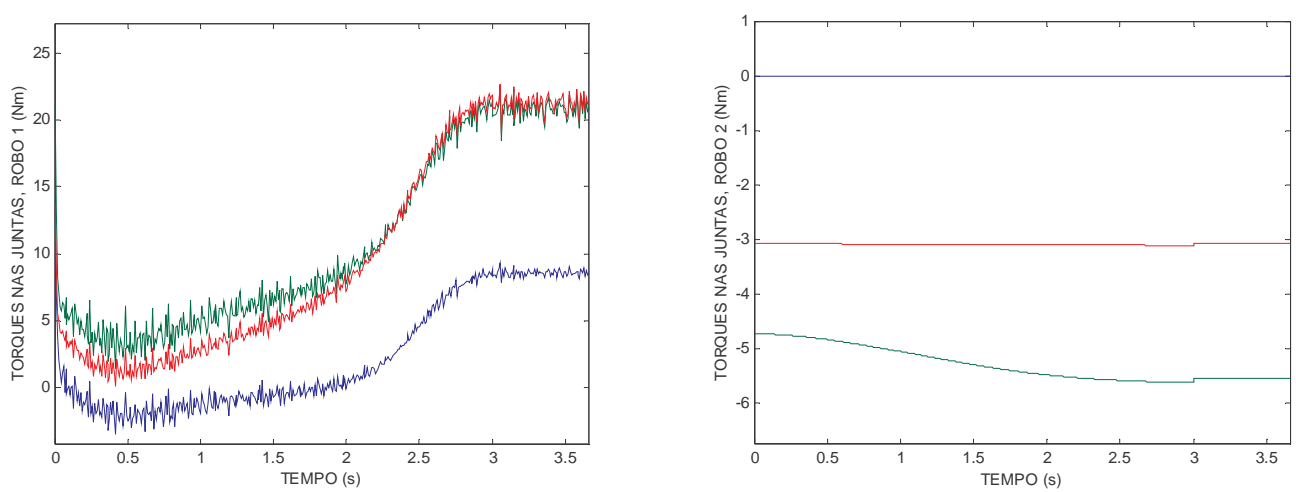

FIGURA 6.22. Simulação de uma trajetória com a junta 1 do robô 2 passiva (controlador apresentado em [LIU et al., 1999]). Torques nas juntas do robô 1 (à esquerda) e do robô 2 (à direita). Junta 1 em azul, 2 em verde e 3 em vermelho.
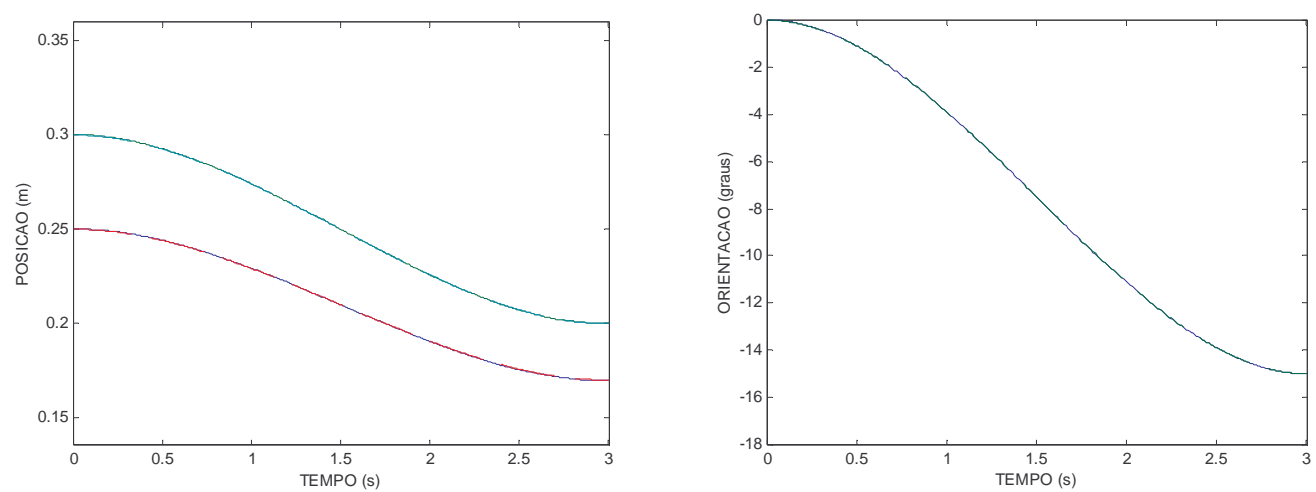

FIGURA 6.23. Simulação de uma trajetória com a junta 1 do robô 2 passiva (controlador desenvolvido na Seção 5.2). Linhas contínuas indicam a posição do CM do objeto (figura à esquerda) e a orientação do objeto (figura à direita). Coordenadas $x$ em azul e $y$ em verde. As linhas tracejadas indicam os valores desejados.
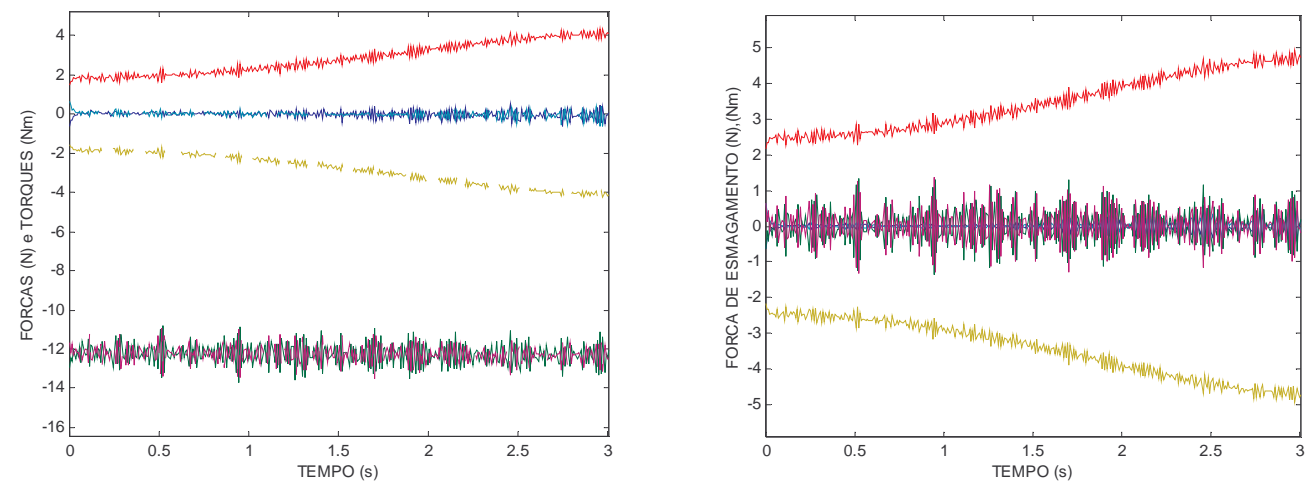

FIGURA 6.24. Simulação de uma trajetória com a junta 1 do robô 2 passiva (controlador desenvolvido na Seção 5.2). Figura à esquerda: forças aplicadas no objeto. Linhas contínuas: forças aplicadas pelo manipulador 1. Linhas tracejadas: forças aplicadas pelo manipulador 2 . Figura à direita: força de esmagamento $\left(h_{o e}\right)$. As duas componentes que provocam torção (momentos) no objeto não são controladas. 

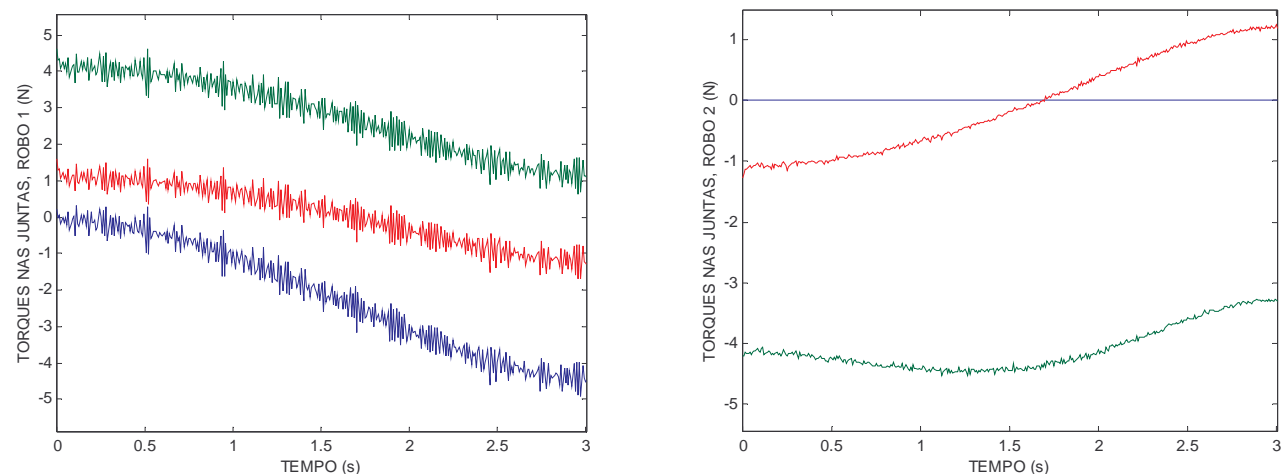

FIGURA 6.25. Simulação de uma trajetória com a junta 1 do manipulador 2 passiva (controlador desenvolvido na Seção 5.2). Figura à esquerda: Torques nas juntas do robô 1; Figura à direita: Torques nas juntas do robô 2 . Torques reais na junta $1 \mathrm{em}$ azul, na junta 2 em verde e na junta 3 em vermelho.

As Figuras 6.26-6.30 mostram os resultados da simulação de uma trajetória do sistema cooperativo na qual a junta 1 do manipulador 1 é bloqueada. Como o espaço de trabalho do sistema cooperativo é reduzido quando juntas bloqueadas aparecem nos manipuladores, a orientação do objeto não foi controlada nesta simulação. Salienta-se que a trajetória desejada é possível para esta configuração pois as posições desejadas do objeto estão dentro do espaço de trabalho dos robôs. Se, por exemplo, a junta 1 do manipulador 2 fosse configurada como bloqueada, esta trajetória não poderia ser acompanhada pois existiriam posições fora do espaço de trabalho do manipulador 2. O controlador desenvolvido para o sistema com juntas bloqueadas apresentado na Seção 5.3 foi utilizado. As Figuras 6.26-6.30 mostram, respectivamente, as posições do $\mathrm{CM}$ e as orientações do objeto (Figura 6.26), as forças exercidas pelos efetuadores no objeto e a força de esmagamento (Figura 6.27), os ângulos e velocidades das juntas do robô 1 (Figura 6.28), os ângulos e velocidades das juntas do robô 2 (Figura 6.29) e os torques nas juntas dos robôs 1 e 2 (Figura 6.30).

Note que o objeto segue a posição desejada do objeto apesar da orientação não ser controlada (Figura 6.26). Também pode ser notado que, apesar de o momento de esmagamento não ser controlado, todas as componentes da força de esmagamento permanecem próximas a zero (Figura 6.27). 

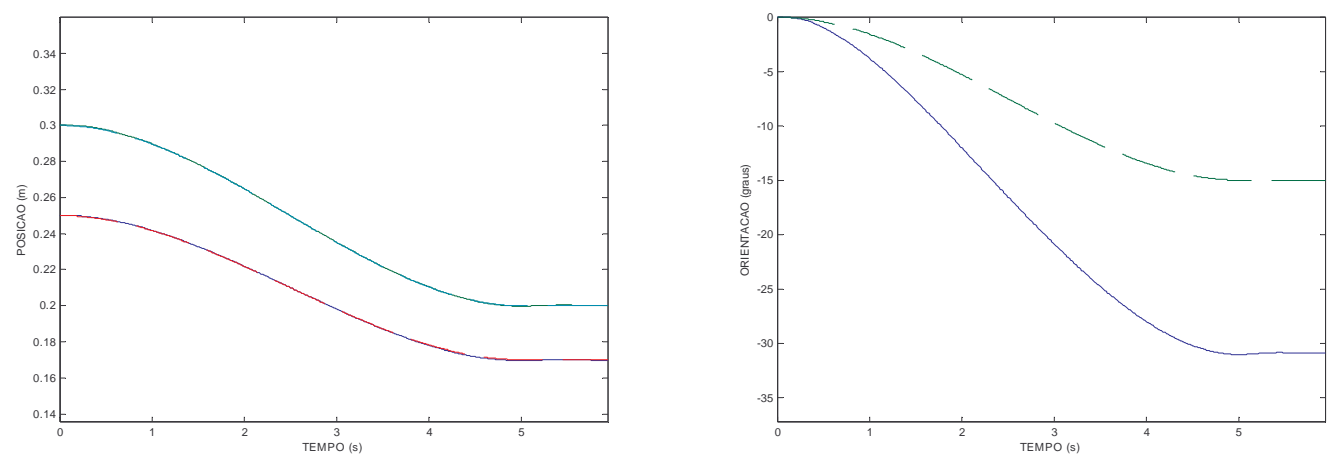

FIGURA 6.26. Simulação de uma trajetória com a junta 1 do manipulador 1 bloqueada. Figura à esquerda: linhas contínuas indicam a posição do $\mathrm{CM}$ do objeto (coordenada $x$ em azul e coordenada $y$ em verde). Figura à direita: linhas contínuas indicam a orientação do objeto. As linhas tracejadas indicam os valores desejados.
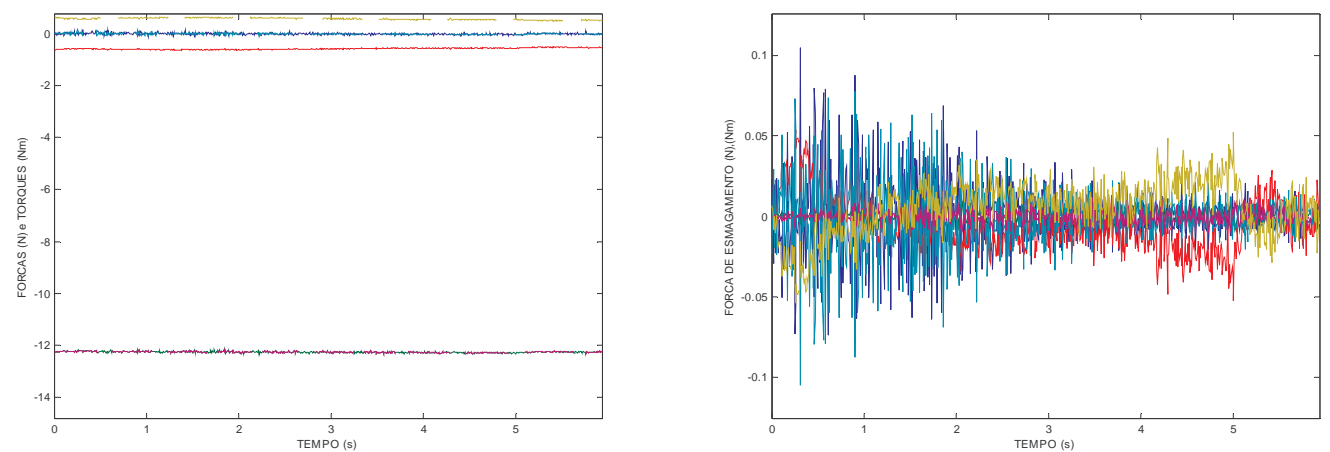

FIGURA 6.27. Simulação de uma trajetória com a junta 1 do manipulador 1 bloqueada.

Figura à esquerda: forças aplicadas no objeto. Linhas contínuas: forças aplicadas pelo manipulador 1. Linhas tracejadas: forças aplicadas pelo manipulador 2 . Figura à direita: força de esmagamento $\left(h_{o e}\right)$.
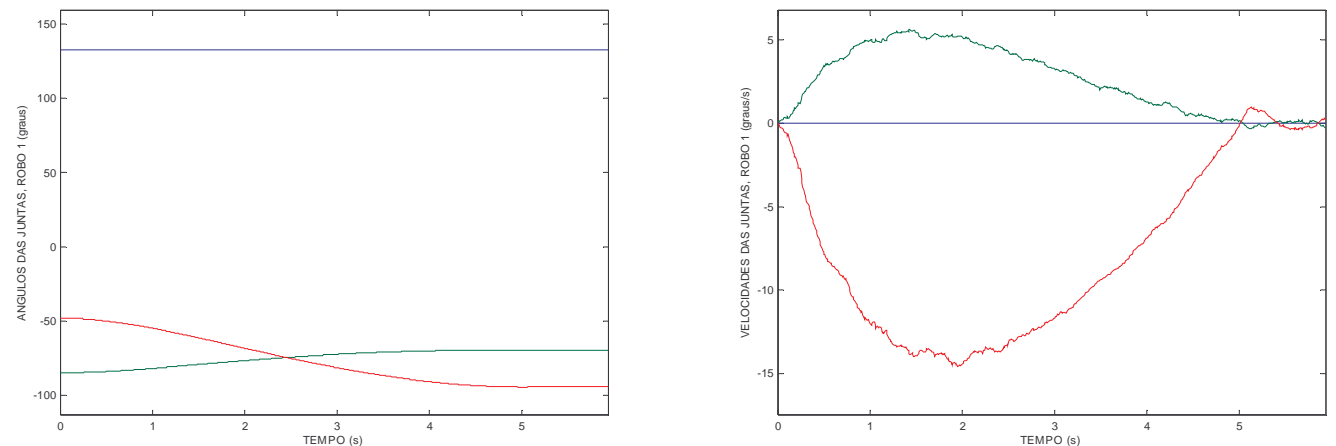

FIGURA 6.28. Simulação de uma trajetória com a junta 1 do manipulador 1 bloqueada.

Figura à esquerda: Ângulos das juntas do robô 1; Figura à direita: Velocidades das juntas do robô 1 . Junta 1 em azul, junta 2 em verde e junta 3 em vermelho. 

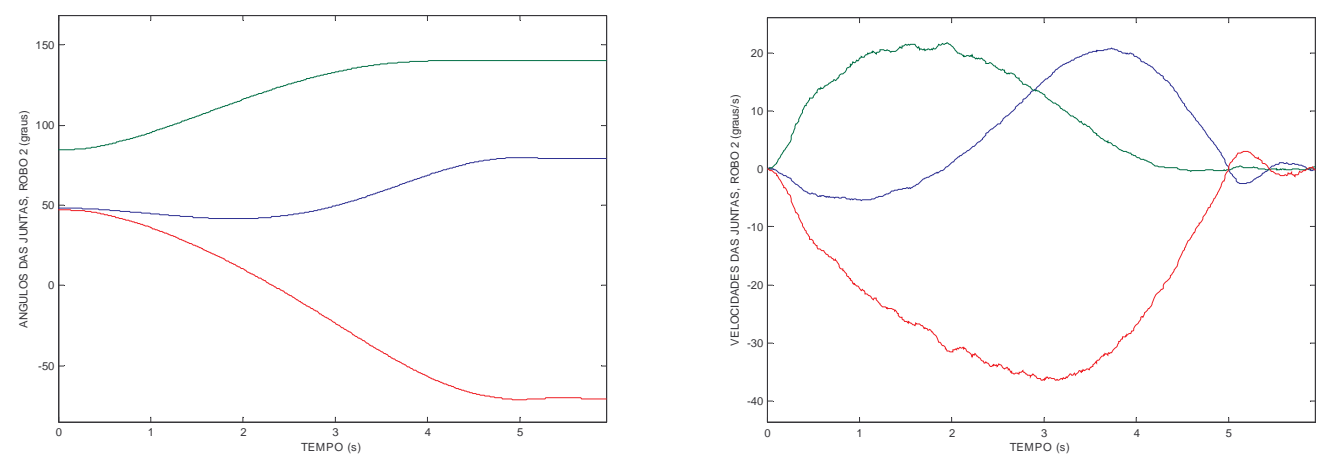

FIGURA 6.29. Simulação de uma trajetória com a junta 1 do manipulador 1 bloqueada. Figura à esquerda: Ângulos das juntas do robô 2; Figura à direita: Velocidades das juntas do robô 2 . Junta $1 \mathrm{em}$ azul; junta $2 \mathrm{em}$ verde e junta $3 \mathrm{em}$ vermelho.
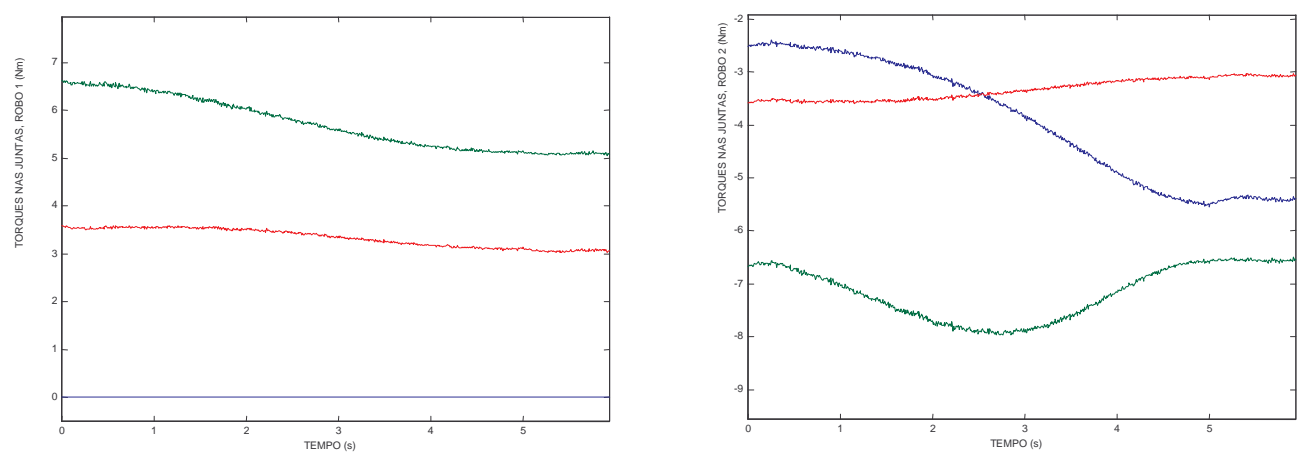

FIGURA 6.30. Simulação de uma trajetória com a junta 1 do manipulador 1 bloqueada. Figura à esquerda: Torques nas juntas do robô 1; Figura à direita: Torques nas juntas do robô 2. Linhas sólidas: torques reais na junta 1 em azul, na junta 2 em verde e na junta 3 em vermelho.

\subsubsection{Sistema Simulado 2}

Os resultados desta seção foram obtidos com a simulação do sistema formado por dois robôs Puma 560 (Sistema Simulado 2). Os controladores desenvolvidos para o sistema com falhas apresentados no Capítulo 5 foram utilizados na simulação do sistema cooperativo. Os parâmetros dos controladores desenvolvidos para o controle do sistema com falhas podem ser vistos nas Tabelas C.8 e C.9 do Apêndice C.

As Figuras 6.31-33 mostram os resultados da simulação de uma trajetória do sistema cooperativo na qual as juntas 1, 2, 4 e 6 do manipulador 1, e 2 e 5 do manipulador 2 são passivas. Note que este é um caso extremo $\left(n_{a}=k\right)$ em que não é possível controlar as forças de esmagamento. O controlador desenvolvido para o sistema com juntas passivas foi 
utilizado. Observe que mesmo com 6 juntas passivas (Figura 6.33), a trajetória desejada foi acompanhada (Figura 6.31).
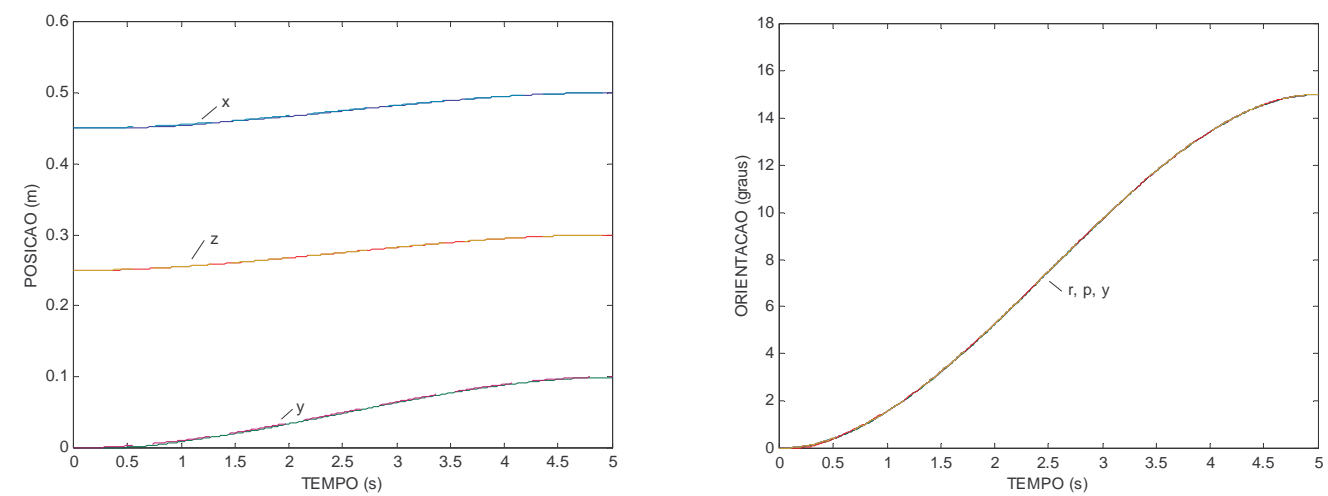

FIGURA 6.31. Simulação de uma trajetória com as juntas 1, 2, 4 e 6 do manipulador 1, e juntas 2 e 5 do manipulador 2 passivas. Figura à esquerda: linhas contínuas indicam a posição do CM do objeto (coordenadas $x$ em azul, $y$ em verde e $z$ em vermelho). Figura à direita: linhas contínuas indicam as três componentes da orientação do objeto ( roll-pitch-yaw). As linhas tracejadas indicam os valores desejados.
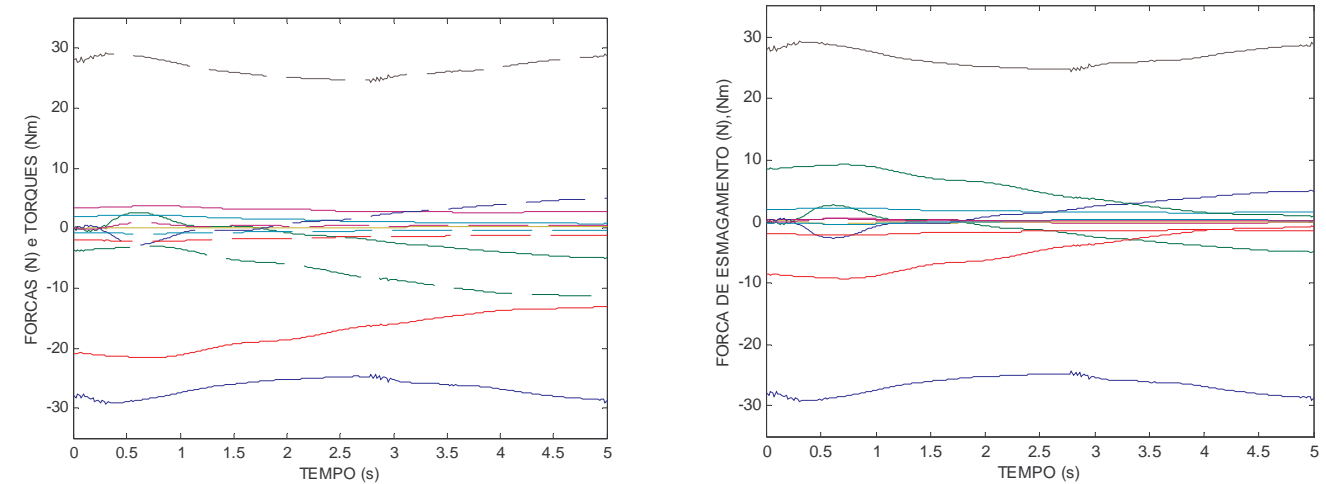

FIGURA 6.32. Simulação de uma trajetória com as juntas 1, 2, 4 e 6 do manipulador 1, e juntas 2 e 5 do manipulador 2 passivas. Figura à esquerda: forças aplicadas no objeto. Linhas contínuas: forças aplicadas pelo manipulador 1. Linhas tracejadas: forças aplicadas pelo manipulador 2. Figura à direita: força de esmagamento $\left(h_{o e}\right)$. 

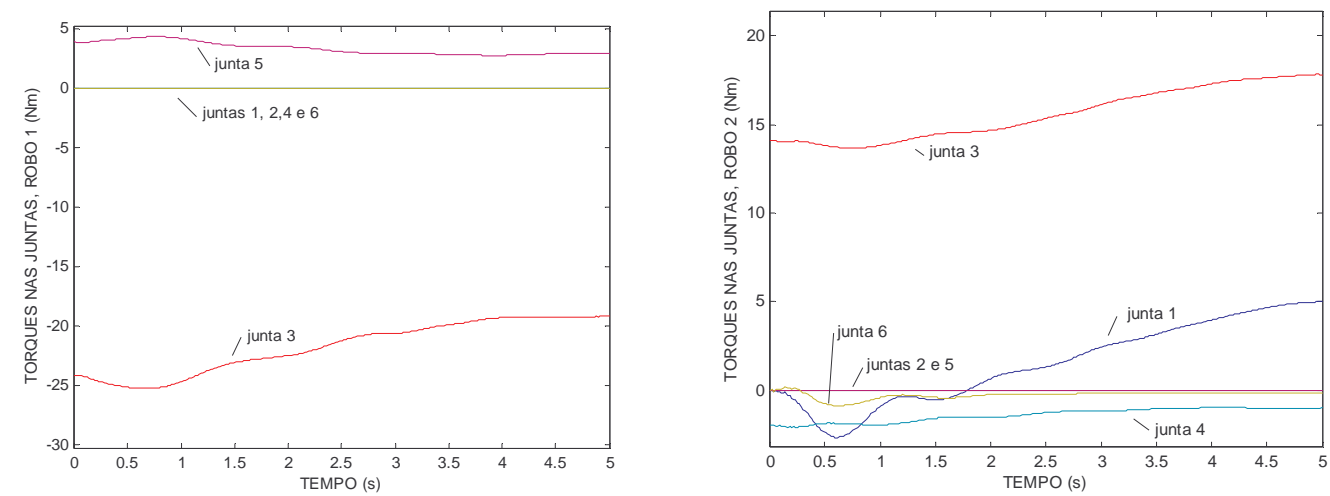

FIGURA 6.33. Simulação de uma trajetória com as juntas 1, 2, 4 e 6 do manipulador 1, e juntas 2 e 5 do manipulador 2 passivas. Figura à esquerda: Torques nas juntas do robô 1 ; Figura à direita: Torques nas juntas do robô 2 .

\subsubsection{Sistema Simulado 3}

Os resultados desta seção foram obtidos com a simulação do sistema formado por três robôs planares com 3 juntas rotacionais cada (Sistema Simulado 3). O controlador desenvolvido para o sistema com juntas passivas apresentado na Seção 5.2 foi utilizado na simulação do sistema cooperativo. Os parâmetros do controlador para o controle do sistema com juntas passivas podem ser vistos na Tabela D.3 do Apêndice D.

As Figuras 6.34-36 mostram os resultados da simulação de uma trajetória do sistema cooperativo na qual a junta 2 do manipulador 1 é passiva. Neste caso, duas componentes da força de esmagamento (formada por 9 componentes) não são controladas (Figura 6.35). Observe que os erros de posição e velocidade (Figura 6.34) são pequenos apesar da presença da junta passiva (Figura 6.36) 

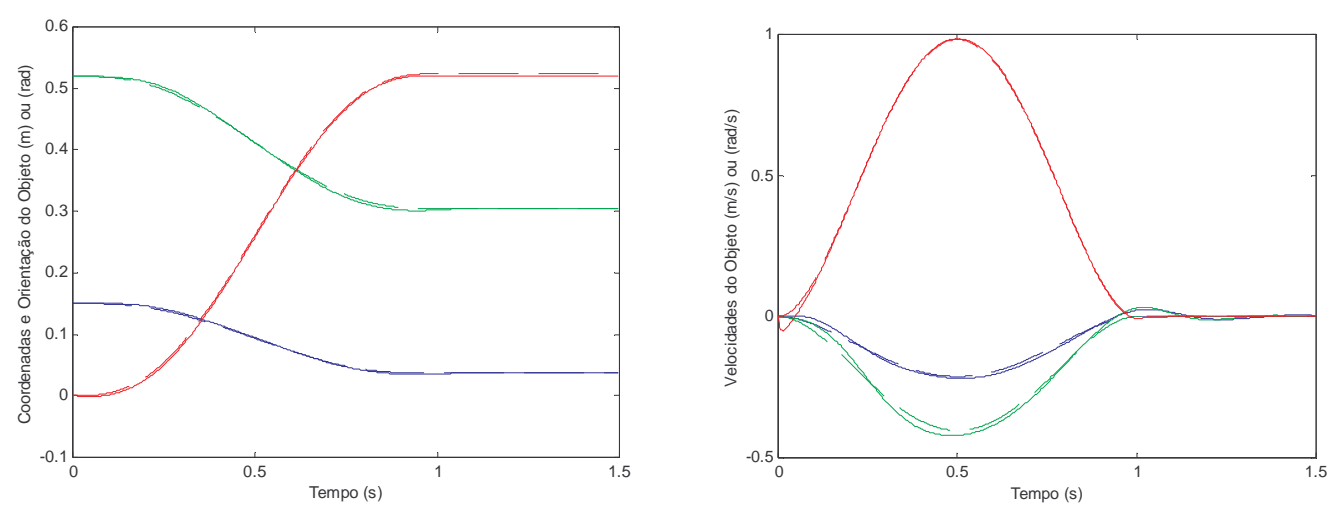

FIGURA 6.34. Simulação de uma trajetória com a junta 2 do manipulador 1 passiva.

Figura à esquerda: linhas contínuas indicam a posição do CM do objeto (coordenadas $x$ em azul, $y$ em verde e orientação em vermelho). Figura à direita: linhas contínuas indicam a velocidade do objeto (velocidade linear na coordenada $x$ em azul, na coordenada $y$ em verde e velocidade angular em vermelho). As linhas tracejadas indicam os valores desejados.
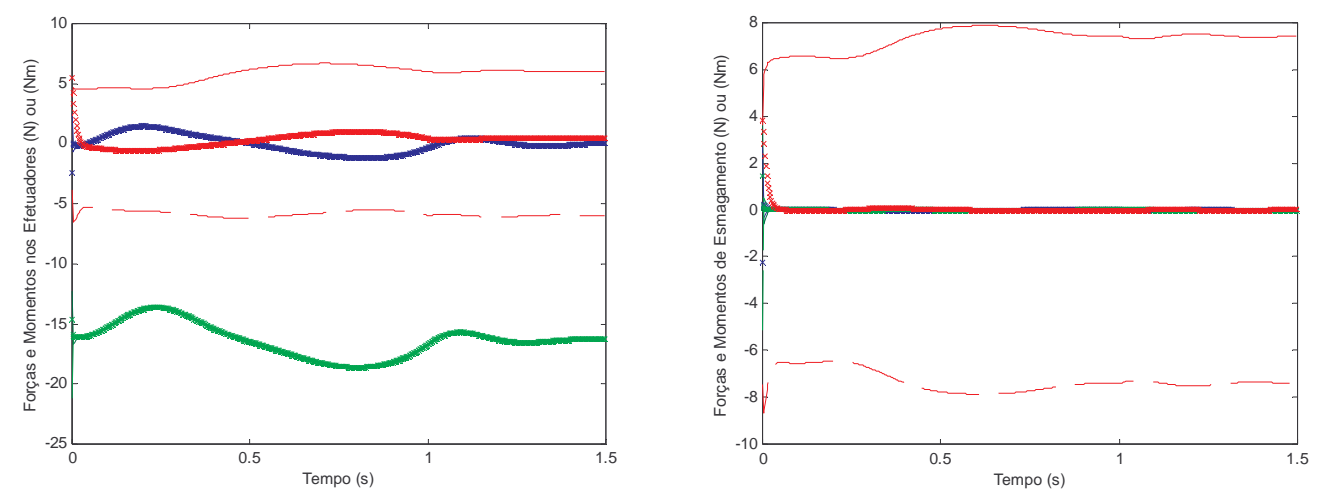

FIGURA 6.35. Forças: coordenada $x$ em azul, coordenada $y$ em verde e torque em vermelho. As linhas contínuas, tracejadas e ' $x$ ' referem-se aos valores aplicados pelos manipuladores 1, 2 e 3 respectivamente. Figura à esquerda: forças aplicadas no objeto. Figura à direita: força de esmagamento $\left(h_{o e}\right)$. As componentes que provocam torção (momentos) no objeto relativas ao manipuladores 1 e 2 não são controladas. 

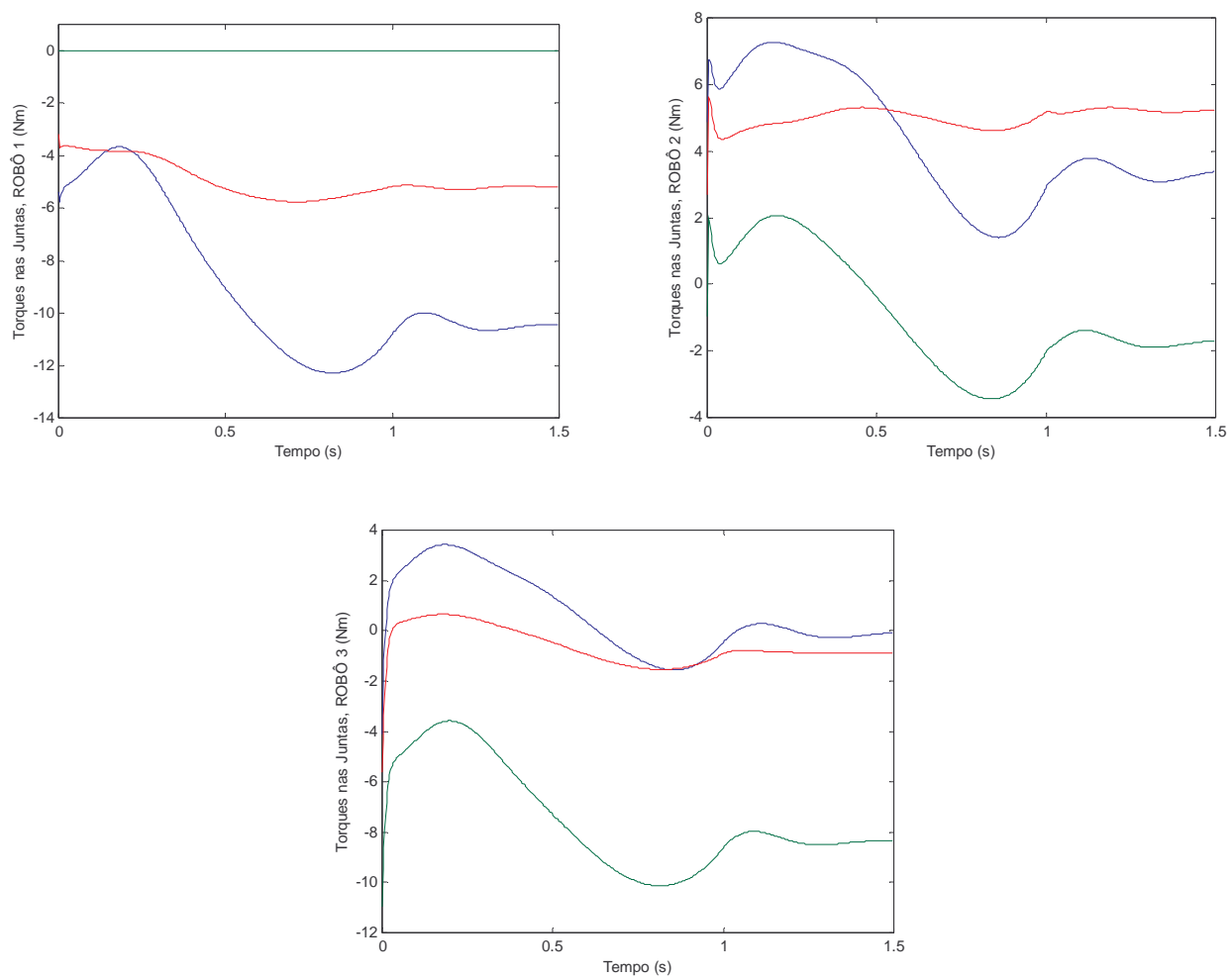

FIGURA 6.36. Torques nas juntas: junta $1 \mathrm{em}$ azul, junta $2 \mathrm{em}$ verde e junta $3 \mathrm{em}$ vermelho. Figura à esquerda (superior): Torques nas juntas do robô 1 ; Figura à direita (superior): Torques nas juntas do robô 2. Figura ao centro (inferior): Torques nas juntas do robô 3 .

\subsubsection{Sistema Real}

Os resultados desta seção foram obtidos com o sistema real formado por dois robôs UArmII (Seção 6.1.2) manipulando um objeto com $0,025 \mathrm{~kg}$ (objeto 1). Os controladores desenvolvidos para o sistema com falhas apresentados no Capítulo 5 foram utilizados no sistema cooperativo real com a substituição das leis de controle de movimento pelas eqs. (6.2) e (6.3). Os parâmetros dos controladores desenvolvidos para o controle do sistema com falhas podem ser vistos nas Tabelas E.9 e E.10 do Apêndice E.

As Figuras 6.37-41 mostram os resultados de uma trajetória do sistema cooperativo com a junta 2 do robô 1 passiva. Nesta trajetória, os robôs deviam mover o objeto para que o CM percorresse um círculo e a orientação ficasse constante. As Figuras 6.37-6.41 mostram, respectivamente, a trajetória espacial percorrida no plano $x y$ (mesa) pelo CM do objeto (Figura 6.37), as posições do CM e as orientações do objeto (Figura 6.38), as velocidades do objeto (Figura 6.39), as forças exercidas pelos efetuadores no objeto e a força de 
esmagamento (Figura 6.40) e os torques nas juntas dos robôs 1 e 2 (Figura 6.41). Observe que a trajetória foi percorrida por duas vezes com sucesso apesar dos ruídos introduzidos pelo cálculo de velocidade a partir das medidas dos encoders.

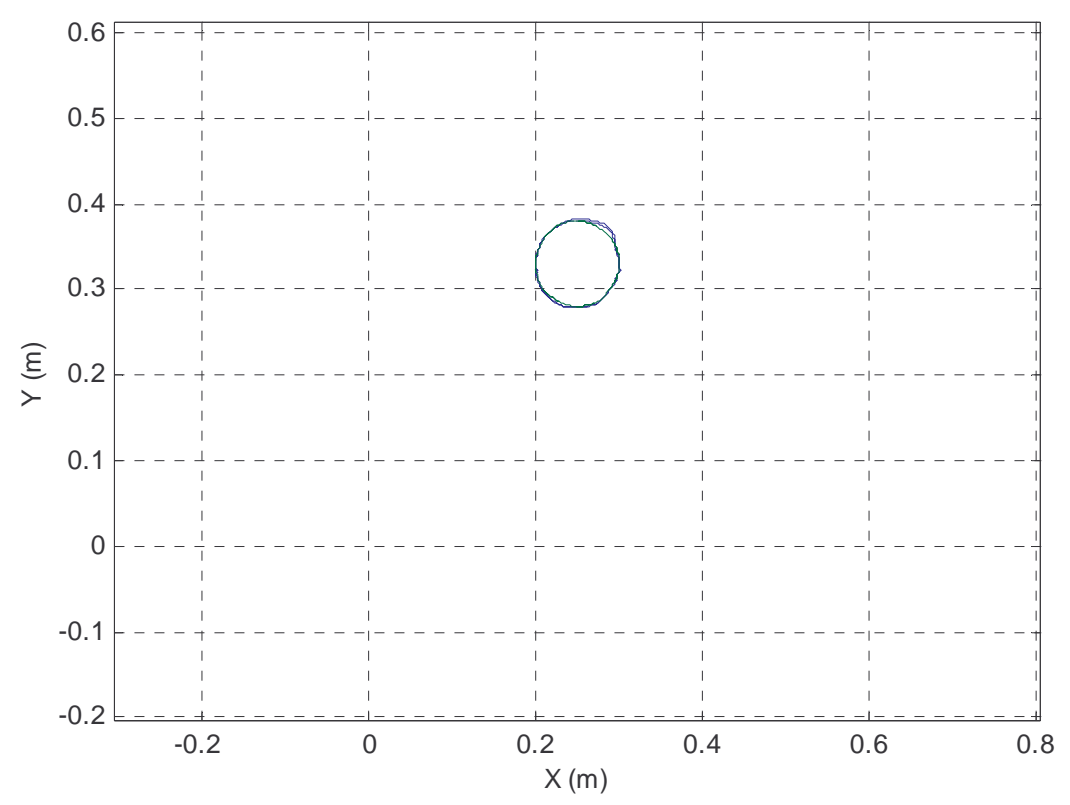

FIGURA 6.37. Trajetória espacial no plano $x y$ (mesa) do CM do objeto para o sistema com a junta 2 do manipulador 1 passiva. 0 traço azul representa a trajetória percorrida pelo $\mathrm{CM}$ do objeto e o verde indica a trajetória desejada.
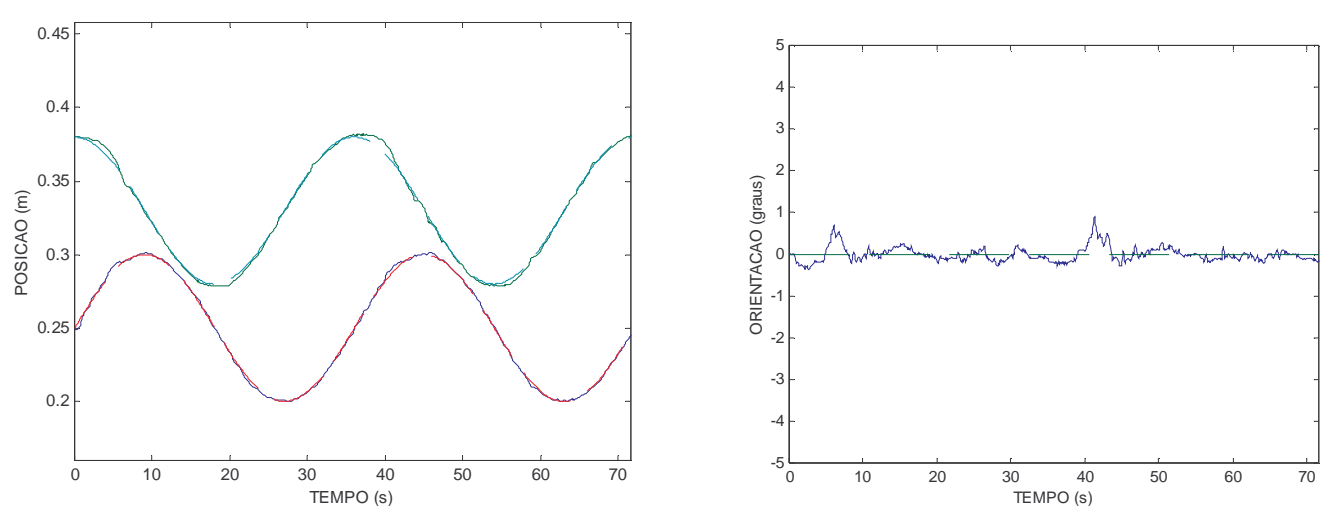

FIGURA 6.38. Trajetória com a junta 2 do manipulador 1 passiva. Figura à esquerda: linhas contínuas indicam a posição do CM do objeto (coordenada $x$ em azul e coordenada $y \mathrm{em}$ verde). Figura à direita: linhas contínuas indicam a orientação do objeto. As linhas tracejadas indicam os valores desejados. 

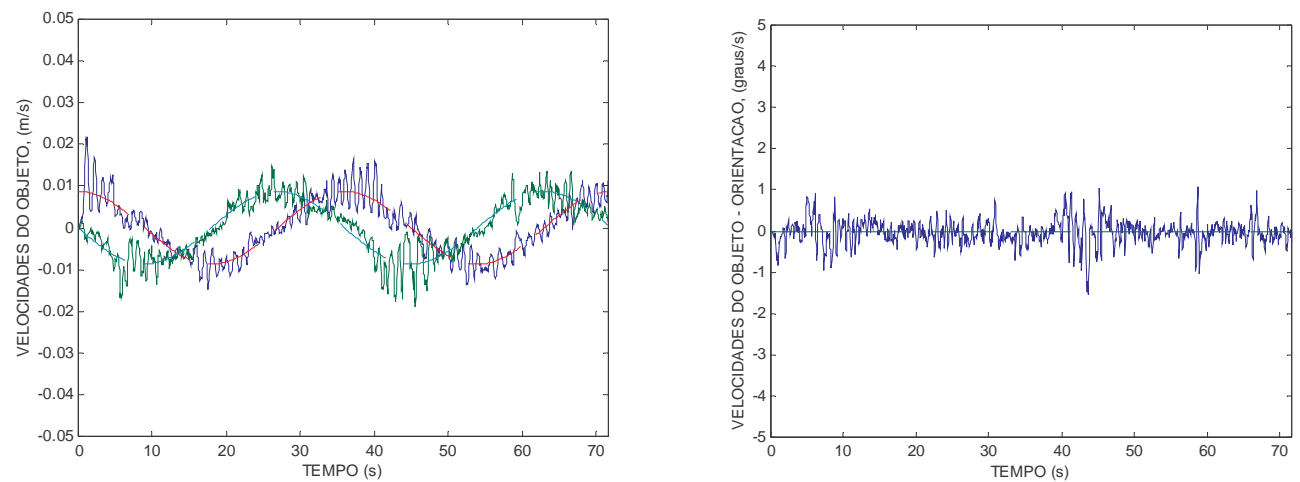

FIGURA 6.39. Trajetória com a junta 2 do manipulador 1 passiva. Figura à esquerda: linhas contínuas indicam a velocidade linear do objeto (coordenadas $x$ em azul e $y$ em verde). Figura à direita: linhas contínuas indicam a velocidade angular do objeto. As linhas tracejadas indicam os valores desejados.
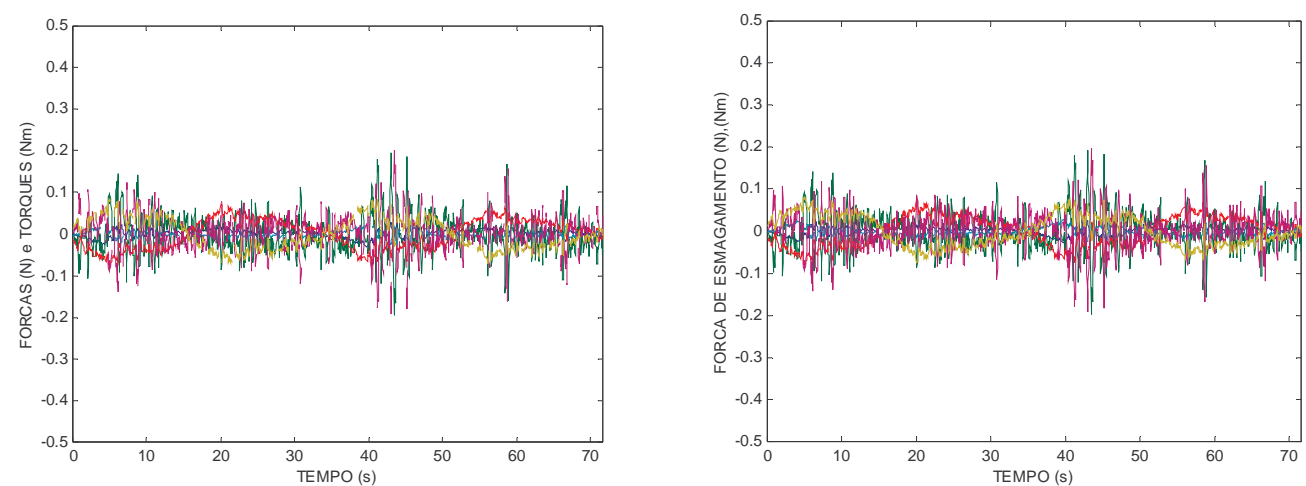

FIGURA 6.40. Trajetória com a junta 2 do manipulador 1 passiva. Figura à esquerda: forças aplicadas no objeto. Linhas contínuas: forças aplicadas pelo manipulador 1. Linhas tracejadas: forças aplicadas pelo manipulador 2. Figura à direita: força de esmagamento $\left(\mathrm{h}_{\mathrm{oe}}\right)$. As duas componentes que provocam torção (momentos) no objeto não são controladas.
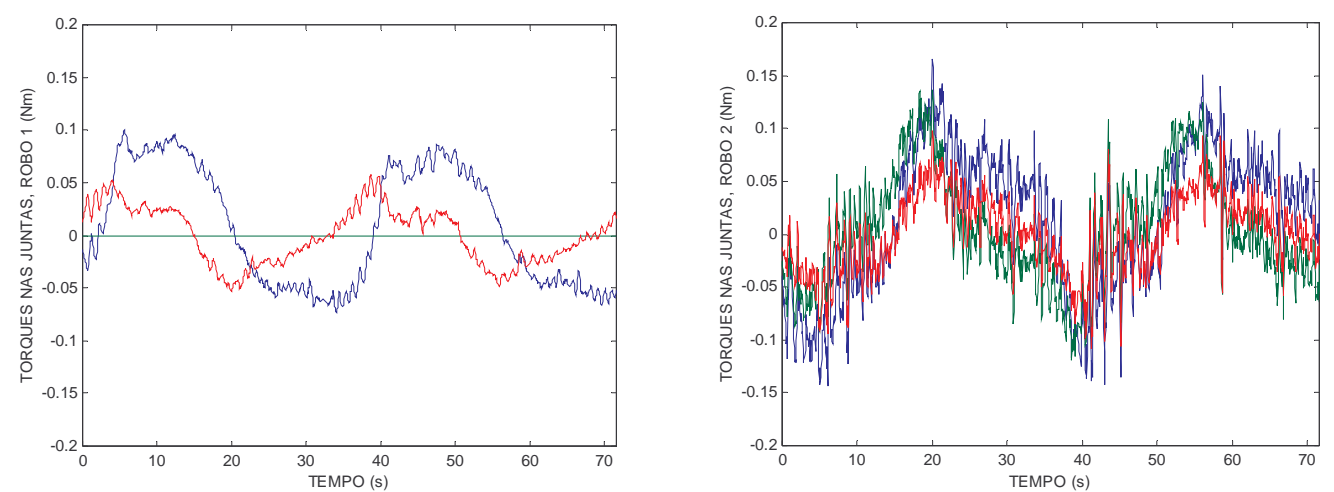

FIGURA 6.41. Trajetória com a junta 2 do manipulador 1 passiva. Figura à esquerda: Torques nas juntas do robô 1; Figura à direita: Torques nas juntas do robô 2. Torques nas juntas: junta $1 \mathrm{em}$ azul, junta $2 \mathrm{em}$ verde e junta $3 \mathrm{em}$ vermelho. 
As Figuras 6.42-45 mostram os resultados de uma trajetória do sistema cooperativo com a junta 3 do robô 1 bloqueada. As Figuras 6.42-6.45 mostram, respectivamente, as posições do $\mathrm{CM}$ e as orientações do objeto (Figura 6.42), as forças exercidas pelos efetuadores no objeto e a força de esmagamento (Figura 6.43), os ângulos e velocidades das juntas do robô 1 (Figura 6.44) e os torques nas juntas dos robôs 1 e 2 (Figura 6.45). Observe que a trajetória foi percorrida com sucesso até aproximadamente $8 \mathrm{~s}$. Até este instante, as posições da trajetória desejada pertenciam ao espaço de trabalhos dos dois manipuladores. Depois deste instante, as posições da trajetória desejada estavam fora do espaço de trabalho do manipulador com a junta bloqueada. Observe que, a partir deste instante, o objeto permanece em repouso (Figura 6.42) apesar do aumento dos torques nos manipuladores (Figura 6.45). Como resultado, a força de esmagamento aumenta, como pode ser visto na Figura 6.43.
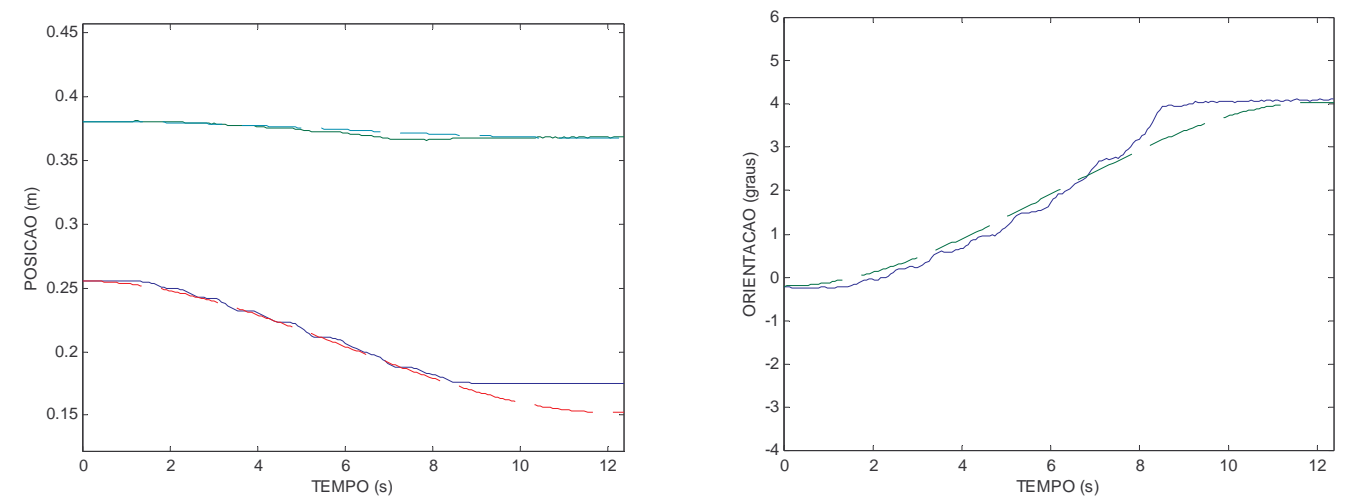

FIGURA 6.42. Trajetória com a junta 3 do robô 1 bloqueada. Linhas contínuas indicam a posição do $\mathrm{CM}$ (coordenadas $x$ em azul e $y$ em verde) e a orientação do objeto. As linhas tracejadas indicam os valores desejados.
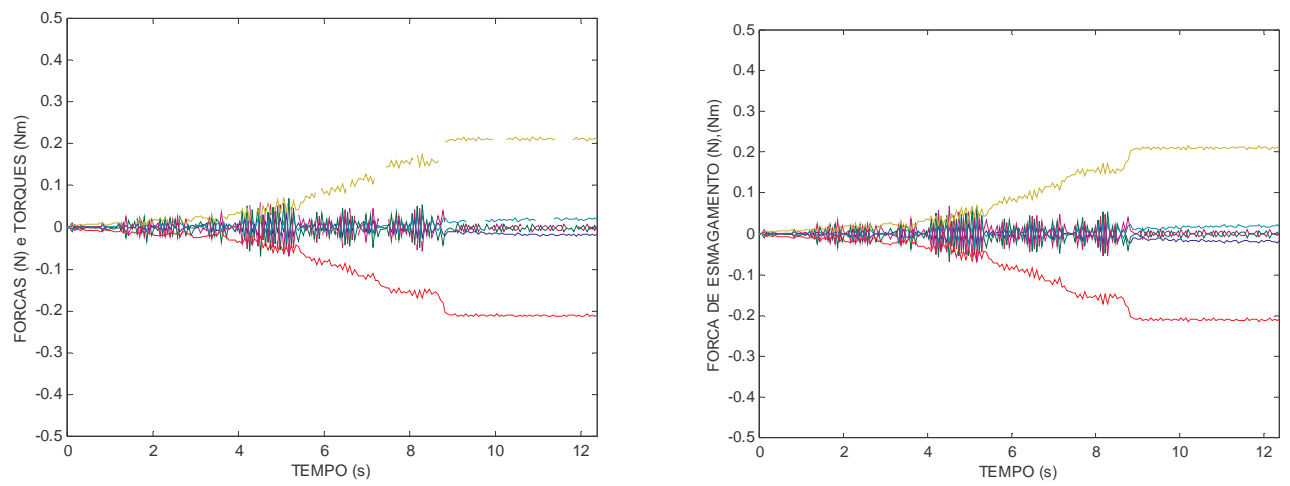

FIGURA 6.43. Trajetória com a junta 3 do robô 1 bloqueada. Figura à esquerda: forças aplicadas. Linhas contínuas: forças aplicadas pelo robô 1. Linhas tracejadas: forças aplicadas pelo robô 2 . Figura à direita: força de esmagamento $\left(h_{\circ e}\right)$. As duas componentes que provocam torção (momentos) no objeto não são controladas. 

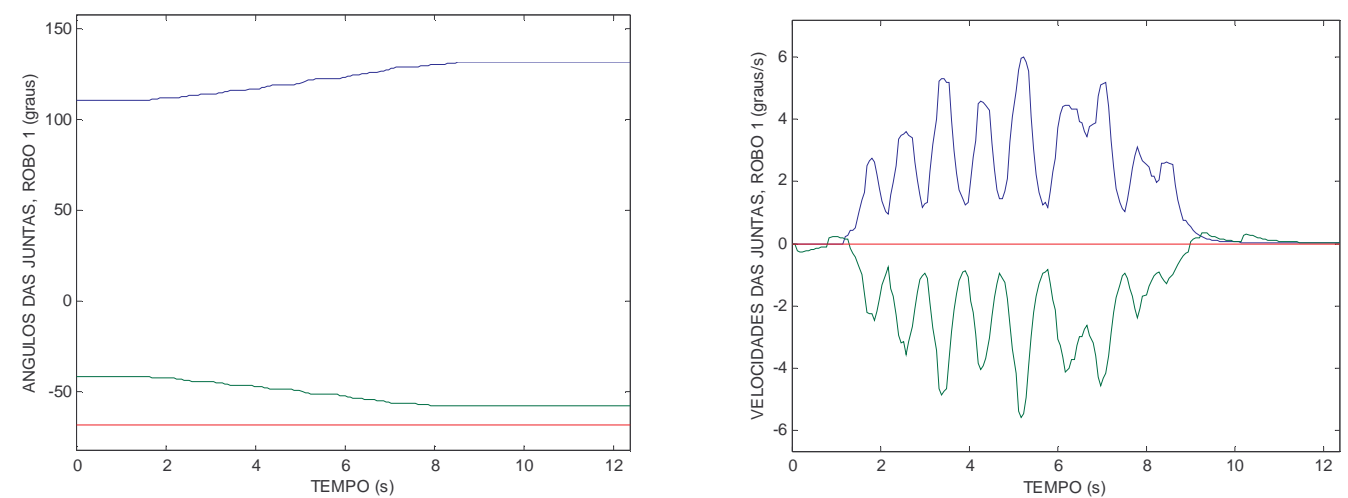

FIGURA 6.44. Trajetória com a junta 3 do manipulador 1 bloqueada. Figura à esquerda: Ângulos das juntas do robô 2; Figura à direita: Velocidades das juntas do robô 2 . Junta $1 \mathrm{em}$ azul; junta $2 \mathrm{em}$ verde e junta $3 \mathrm{em}$ vermelho.
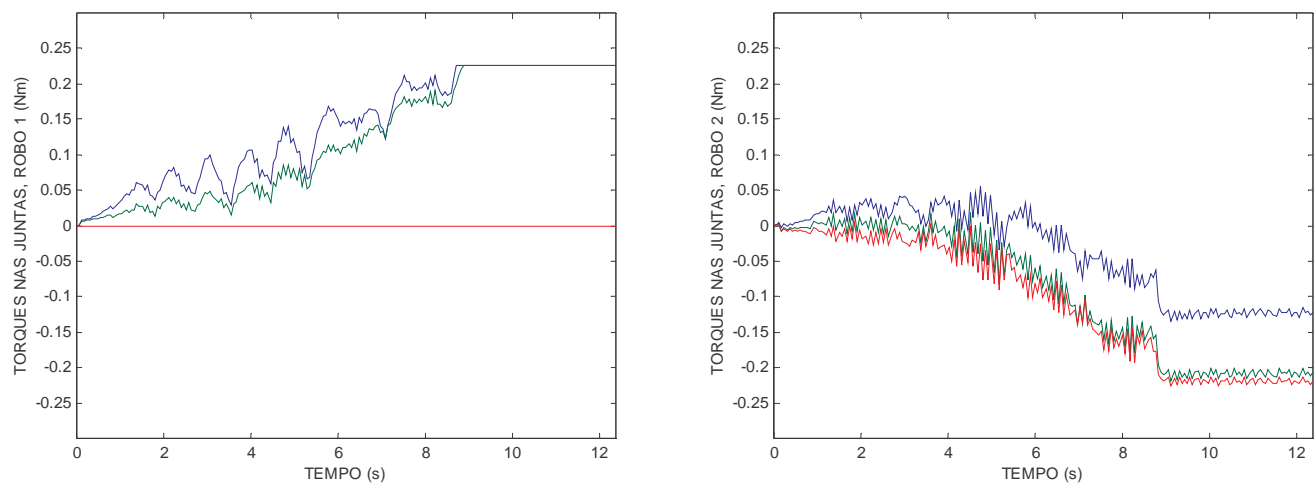

FIGURA 6.45. Trajetória com a junta 3 do manipulador 1 bloqueada. Figura à esquerda: Torques nas juntas do robô 1; Figura à direita: Torques nas juntas do robô 2. Junta 1 em azul, junta 2 em verde e junta 3 em vermelho.

\subsection{SISTEMA COMPLETO DE TOLERÂNCIA A FALHAS}

Esta seção traz os resultados do sistema completo de tolerância a falhas proposto neste trabalho. Nos resultados apresentados nesta seção, a trajetória não é reconfigurada para os casos de falhas do tipo informação incorreta de posição ou velocidade na junta. Isso ocorre porque, geralmente, tais falhas são isoladas muito rapidamente. Assim, quando uma falha do tipo informação incorreta de posição ou velocidade nas juntas é isolada, a reconfiguração proposta na Seção 5.4 é ativada sem que os freios dos robôs sejam aplicados e a trajetória desejada originalmente projetada não é alterada 
Quando uma falha do tipo junta com balanço livre ou bloqueada é isolada, os controladores apresentados nas Seções 5.2 e 5.3 são aplicados e uma nova trajetória é planejada a partir das posições e velocidades atuais do objeto. Assim, os freios das juntas não são aplicados quando o sistema muda a estratégia de controle de acordo com a falha isolada. Entretanto, tal esquema de reconfigução somente deve ser aplicado se, entre outros, as velocidades do sistema e a força de esmagamento não forem muito grandes, ou seja, se a falha for detectada rapidamente. Caso contrário, os freios devem ser aplicados e a trajetória reconfigurada a partir do repouso. Do mesmo modo que para o sistema em repouso, um polinômio de terceira ordem é utilizado para o planejamento da trajetória [KOIVO, 1989]. Esta nova trajetória desejada é inicializada com as posições e velocidades correntes e os mesmos valores finais do polinômio originalmente proposto são mantidos.

$\mathrm{O}$ esquema de tolerância a falhas completo foi aplicado nos mesmos sistemas em que projetou-se o Sistema DIF (Seção 6.3), ou seja, nos sistemas simulados 1 e 2, e no sistema real. A Seção 6.5.1 traz uma simulação de uma trajetória do Sistema 1 com falha do tipo informação incorreta de velocidade das juntas. A Seção 6.5.2 traz uma simulação de uma trajetória do Sistema Simulado 2 com falhas do tipo junta com balanço livre. Já a Seção 6.5.3 traz duas trajetórias do sistema real: uma com falha do tipo junta com balanço livre e outra com falha do tipo informação incorreta de posição das juntas.

\subsubsection{Sistema Simulado 1}

Os resultados desta seção foram obtidos com a simulação do sistema formado por dois robôs planares com 3 juntas rotacionais cada (Sistema Simulado 1). As Figuras 6.46-6.49 mostram os resultados da simulação de uma trajetória do sistema cooperativo com uma falha do tipo informação incorreta de velocidade da junta 2 do manipulador 1 ocorrendo em 0,2 s. As Figuras 6.46-49 mostram, respectivamente, as posições do CM e a orientação do objeto (Figura 6.46), as forças exercidas pelos efetuadores no objeto e a força de esmagamento (Figura 6.47), os ângulos e velocidades das juntas do robô 1 (Figura 6.48), e a detecção da falha do tipo informação incorreta de velocidade da junta 2 do manipulador 1 (Figura 6.49).

Após a DIF (Figura 6.49), as velocidades medidas na junta 2 do manipulador 1 são substituídas pelos valores estimados (Figura 6.48). Observe que o objeto continua percorrendo a trajetória desejada inicialmente projetada (Figura 6.46) e as forças de esmagamento ficam próximas dos valores desejados (Figura 6.47) após a isolação da falha (Figura 6.49). 

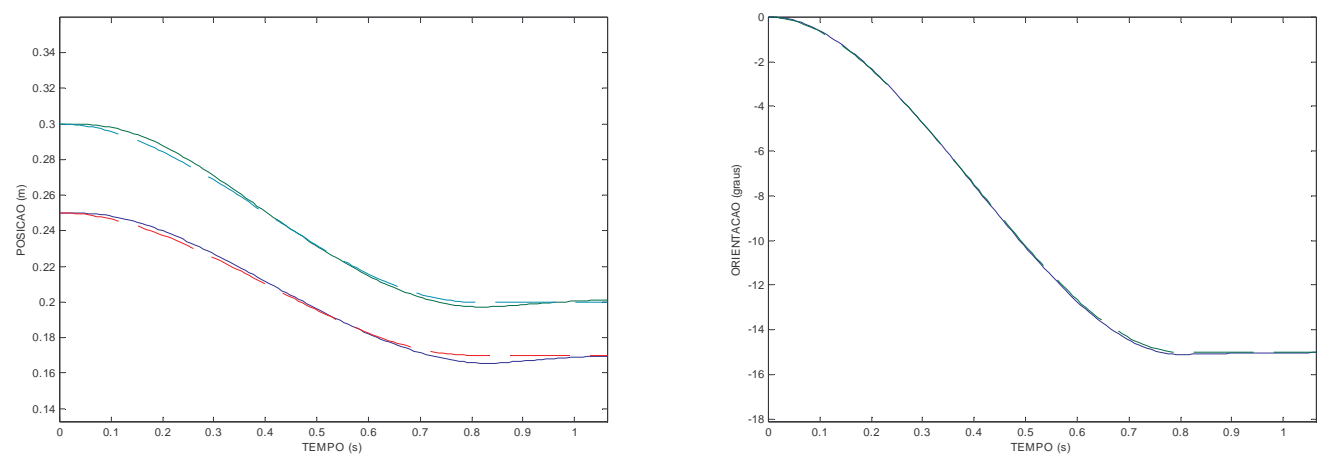

FIGURA 6.46. Simulação de uma trajetória com a falha do tipo informação incorreta de velocidade da junta 2 do manipulador 1 ocorrendo em $0,2 \mathrm{~s}$. Figura à esquerda: linhas contínuas indicam a posição do CM do objeto (coordenada $x$ em azul e coordenada $y$ em verde). Figura à direita: linhas contínuas indicam a orientação do objeto. As linhas tracejadas indicam os valores desejados.
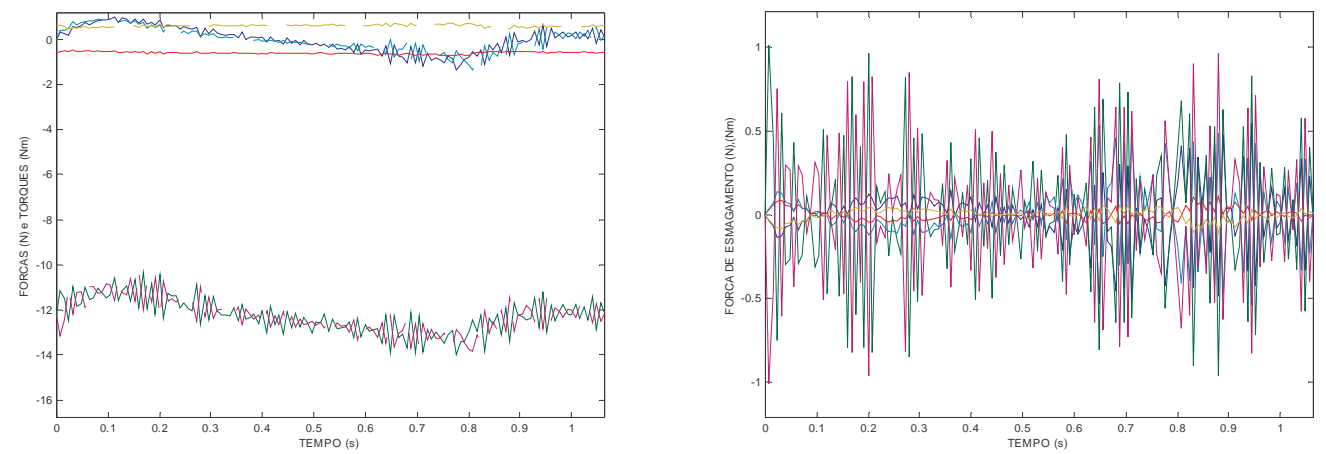

FIGURA 6.47. Figura à esquerda: forças aplicadas no objeto. Linhas contínuas: forças aplicadas pelo manipulador 1. Linhas tracejadas: forças aplicadas pelo manipulador

2. Figura à direita: força de esmagamento $\left(h_{o e}\right)$.
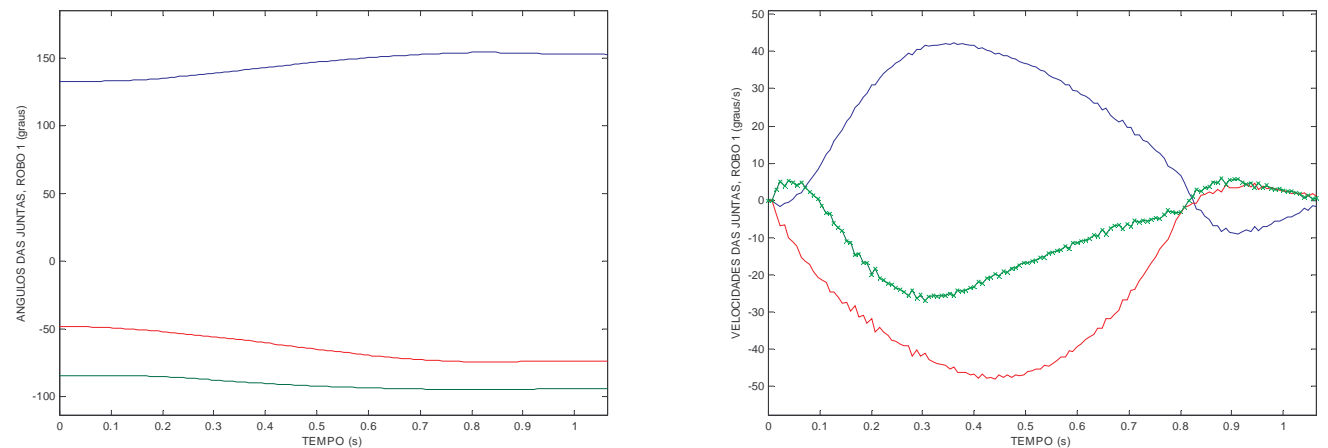

FIGURA 6.48. Figura à esquerda: Ângulos das juntas do robô 1; Figura à direita: Velocidades das juntas do robô 1. Linhas sólidas: ângulos/velocidades reais da junta 1 em azul, da junta 2 em verde e da junta 3 em vermelho; ' $x$ ': velocidades estimadas para a junta 2 do robô 1 . 


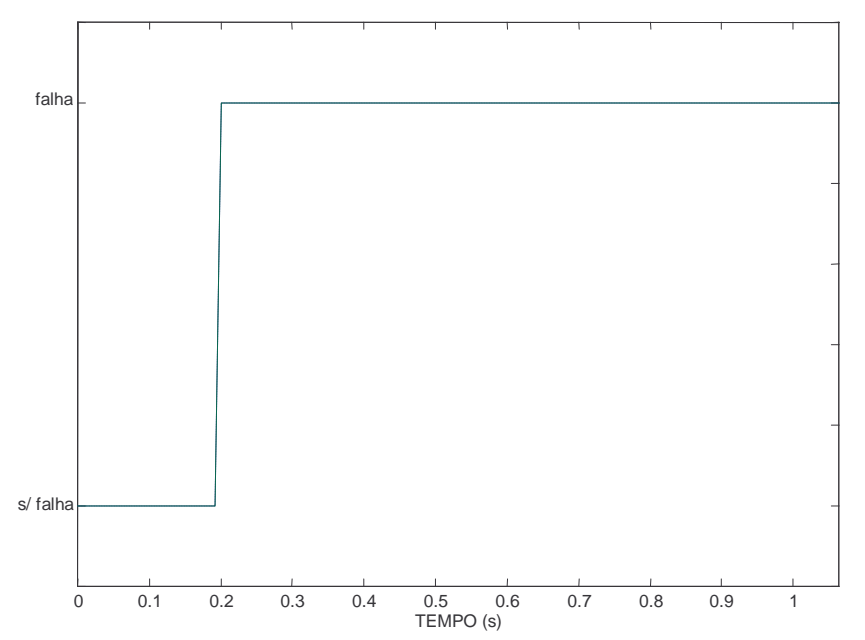

FIGURA 6.49. Detecção da falha do tipo junta 2 do manipulador 1 com informação incorreta de velocidade (linha contínua) e falha real (linha tracejada). Repare que os dois traços estão superpostos.

\subsubsection{Sistema Simulado 2}

Os resultados desta seção foram obtidos com a simulação do sistema formado por dois robôs Puma 560 (Sistema Simulado 2). As Figuras 6.50-54 mostram os resultados da execução de uma trajetória do sistema cooperativo formado pelos robôs Puma 560 com a falha do tipo junta 2 do manipulador 2 com balanço livre ocorrendo em $0,8 \mathrm{~s}$. Nesta simulação, a falha foi isolada e, então, a trajetória e o sistema de controle foram reconfigurados sem que os freios fossem aplicados. As figuras mostram, respectivamente, as posições do CM e as orientações do objeto (Figura 6.50), as velocidades do objeto (Figura 6.51), as forças exercidas pelos efetuadores no objeto e a força de esmagamento (Figura 6.52), os torques nas juntas dos robôs 1 e 2 (Figura 6.53), e os resíduos e as saídas da rede RBF (Figura 6.54).

Quando ocorre a falha em 0,8 s, o Sistema DIF a detecta em aproximadamente 0,1 s. e a trajetória desejada e o sistema de controle são reconfigurados. Observe que, quando ocorre a falha, não é mais possível controlar todos os componentes da força de esmagamento já que $n_{a}<k$ (Figura 6.52). 

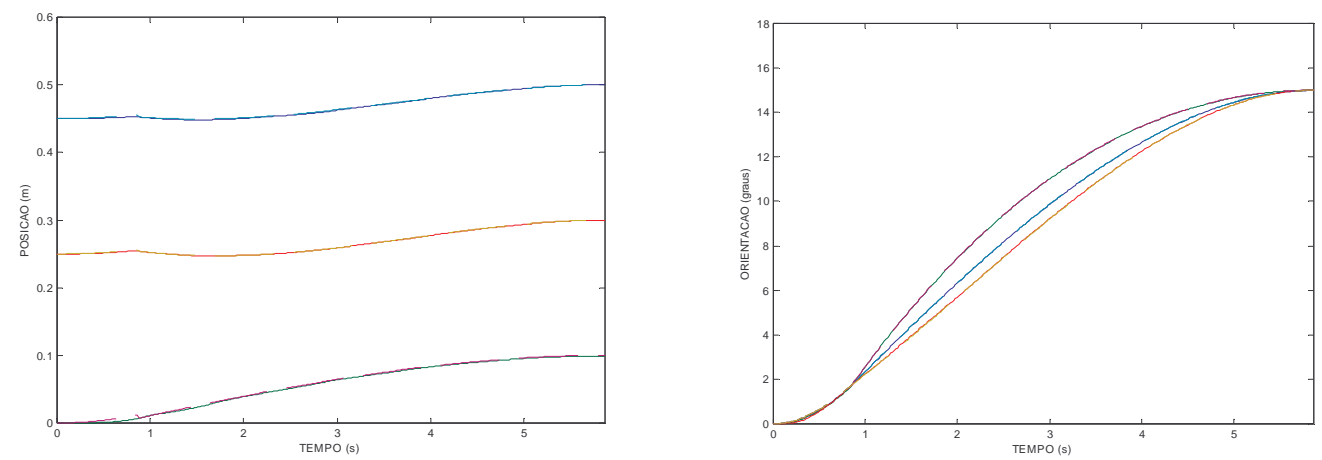

FIGURA 6.50. Trajetória do sistema com tolerância em uma simulação em que uma falha do tipo junta 2 do robô 2 com balanço livre ocorreu em $0,8 \mathrm{~s}$. Linhas contínuas: Figura à esquerda: posição do CM do objeto (coordenadas $x$ em azul, $y$ em verde e $z$ em vermelho); Figura à direita: orientação do objeto (roll em azul, pitch em verde $e$ yaw em vermelho). As linhas tracejadas indicam os valores desejados.
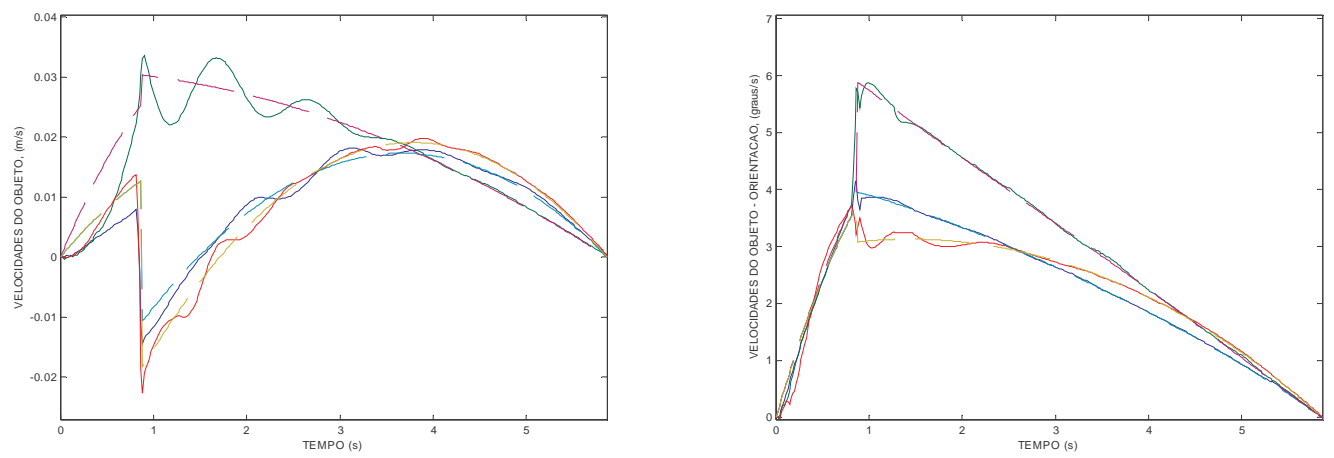

FIGURA 6.51. Figura à esquerda: linhas contínuas indicam as velocidades lineares do objeto (coordenadas $x$ em azul, $y$ em verde e $z$ em vermelho). Figura à direita: linhas contínuas indicam as velocidades angulares do objeto (coordenadas $x \mathrm{em}$ azul, $y \mathrm{em}$ verde e $z$ em vermelho). As linhas tracejadas indicam os valores desejados.
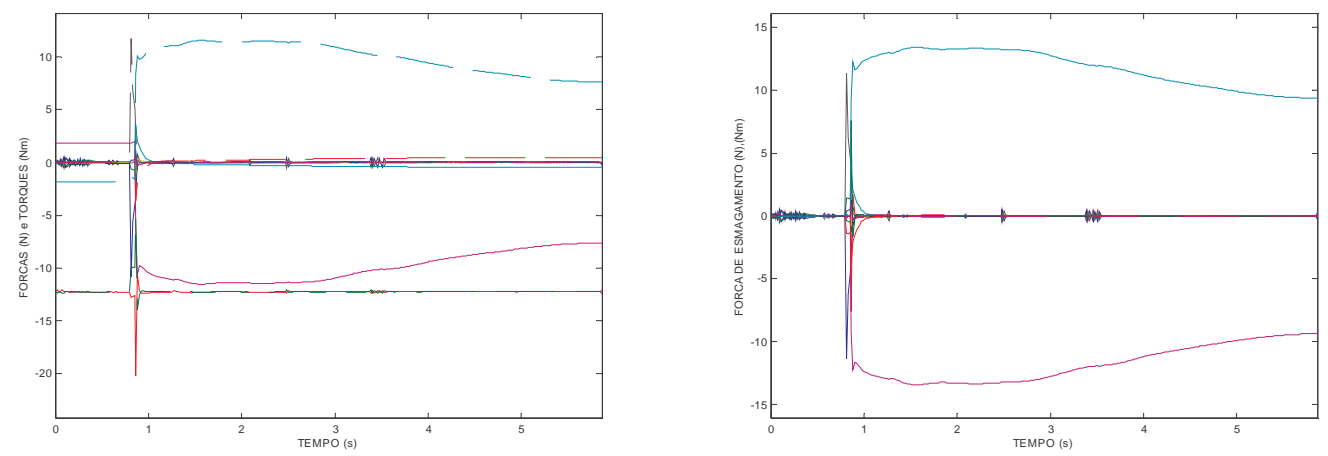

FIGURA 6.52. Figura à esquerda: forças aplicadas no objeto. Linhas contínuas: forças aplicadas pelo manipulador 1. Linhas tracejadas: forças aplicadas pelo manipulador

2. Figura à direita: força de esmagamento $\left(h_{o e}\right)$. As componentes que provocam torção no eixo $z$ não são controladas após a isolação da falha. 

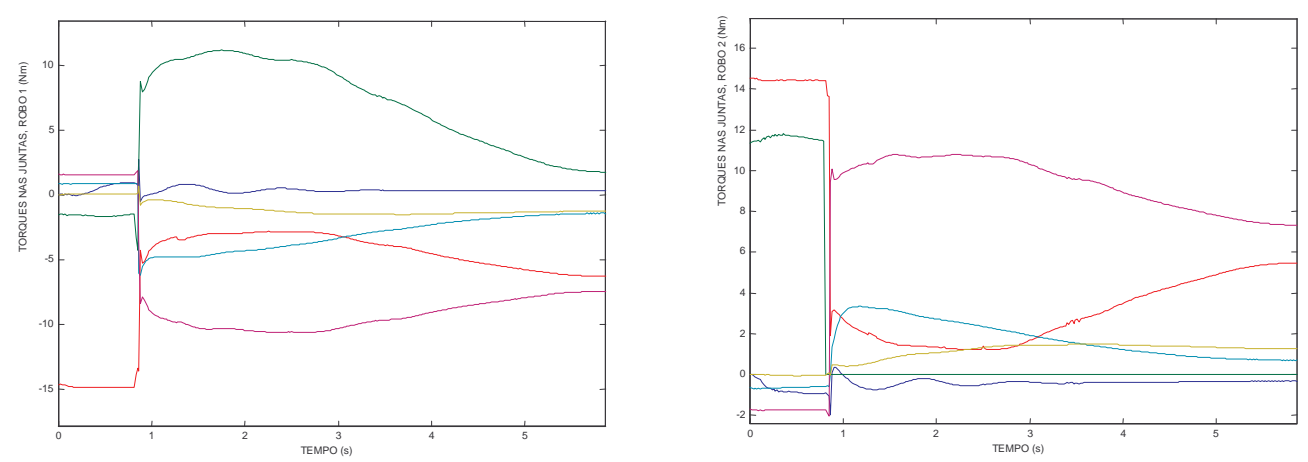

FIGURA 6.53. Figura à esquerda: Torques nas juntas do robô 1; Figura à direita: Torques nas juntas do robô 2 . Torque na junta $1 \mathrm{em}$ azul, na junta $2 \mathrm{em}$ verde escuro, na junta 3 e vermelho, na junta 4 em verde claro, na junta 5 em roxo e na junta 6 em amarelo.
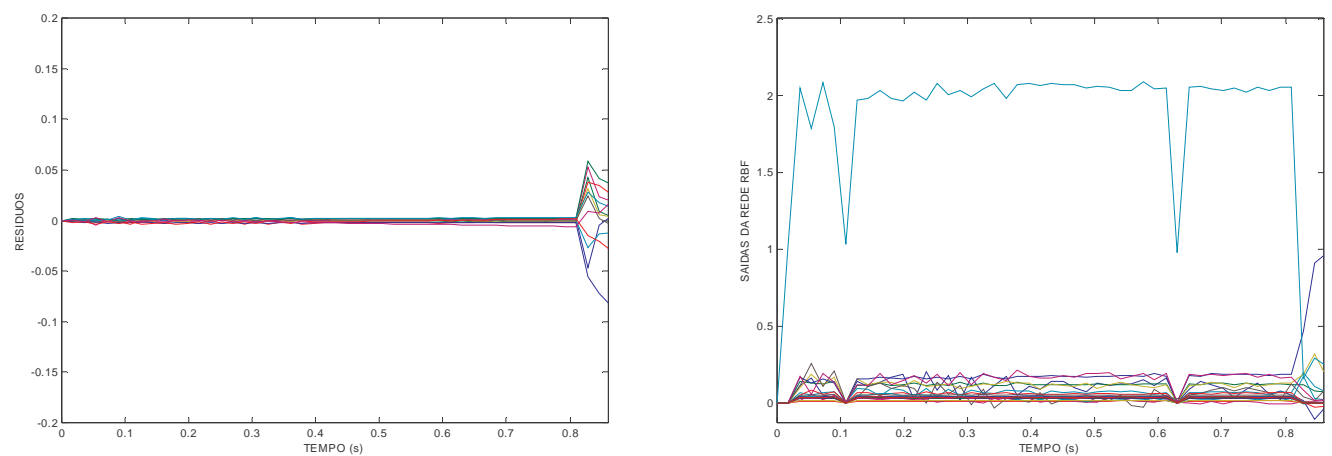

FIGURA 6.54. Resíduos e saídas da rede RBF (verde claro: saída responsável pela indicação da operação sem falhas; azul: saída responsável pela detecção da falha junta 2 do robô 2 com balanço livre).

\subsubsection{Sistema Real}

Os resultados desta seção foram obtidos com o sistema real formado por dois robôs UArmII (Seção 6.1.2) manipulando um objeto com 0,025 kg (objeto 1).

As Figuras 6.55-6.59 mostram os resultados da execução de uma trajetória do sistema cooperativo real com a falha do tipo junta 1 do manipulador 1 com balanço livre ocorrendo em $1 \mathrm{~s}$. As figuras mostram, respectivamente, as posições do $\mathrm{CM}$ e as orientações do objeto (Figura 6.55), as velocidades do objeto (Figura 6.56), as forças exercidas pelos efetuadores no objeto e a força de esmagamento (Figura 6.57), os torques nas juntas dos robôs 1 e 2 (Figura 6.58), e os resíduos e a detecção da falha do tipo junta 1 do manipulador 1 com balanço livre (Figura 6.59). 
Observe que, neste caso, a falha demorou a ser detectada (Figura 6.59). Isto ocorreu porque a velocidade da junta não aumentou abruptamente após a falha devido ao fato de o objeto ser leve e os termos gravitacionais terem pouca influencia na aceleração das juntas. Repare que, no intervalo de tempo entre a ocorrência da falha e a sua detecção, a força de esmagamento aumentou (Figura 6.57). Neste mesmo intervalo, os resíduos aumentaram suavemente até que a falha foi detectada no instante $3,8 \mathrm{~s}$ (Figura 6.59). Neste momento ocorreu a reconfiguração da trajetória (Figura 6.55) e do controlador, o que permitiu que o objeto seguisse a nova trajetória desejada e que a força de esmagamento diminuísse (Figuras $6.55-56)$
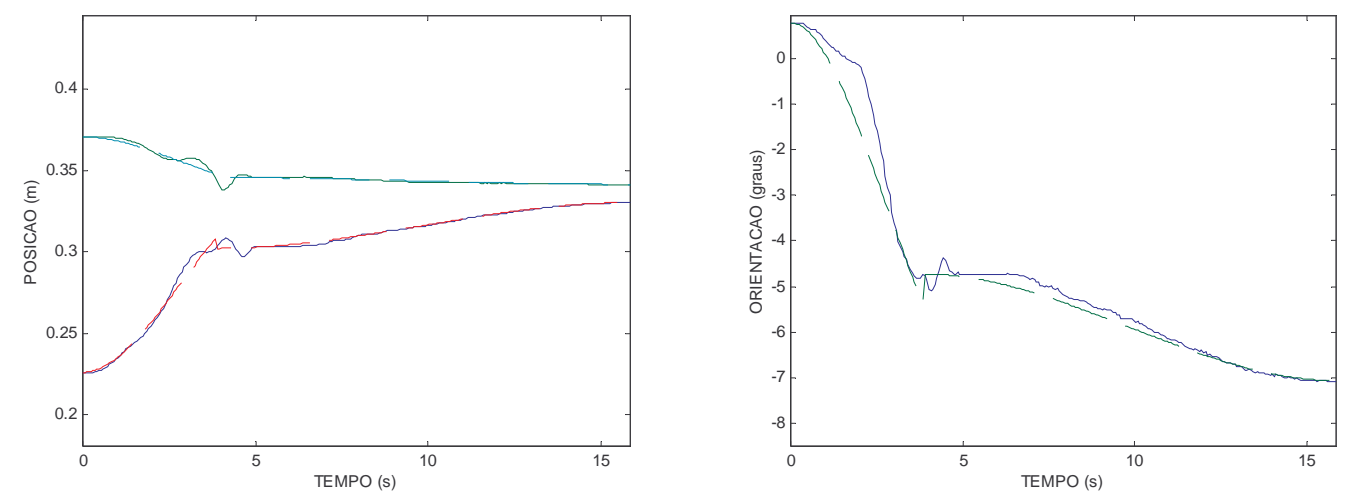

FIGURA 6.55. Trajetória em que uma falha do tipo junta 1 do robô 1 com balanço livre ocorreu em $1 \mathrm{~s}$. Figura à esquerda: linhas contínuas indicam a posição do $\mathrm{CM}$ do objeto (coordenadas $x$ em azul e $y$ em verde). Figura à direita: linhas contínuas indicam a orientação do objeto. As linhas tracejadas indicam os valores desejados.
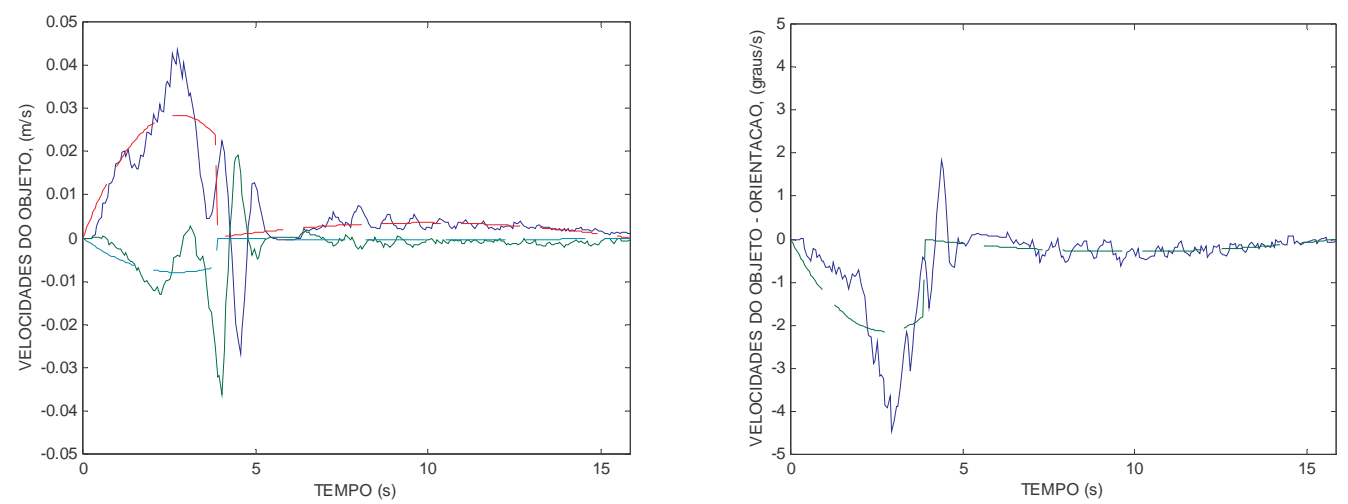

FIGURA 6.56. Trajetória em que uma falha do tipo junta 1 do robô 1 com balanço livre ocorreu em $1 \mathrm{~s}$. Figura à esquerda: linhas contínuas indicam a velocidade linear do objeto (coordenada $x$ em azul e $y$ em verde). Figura à direita: linhas contínuas indicam a velocidade angular do objeto. As linhas tracejadas indicam os valores desejados. 

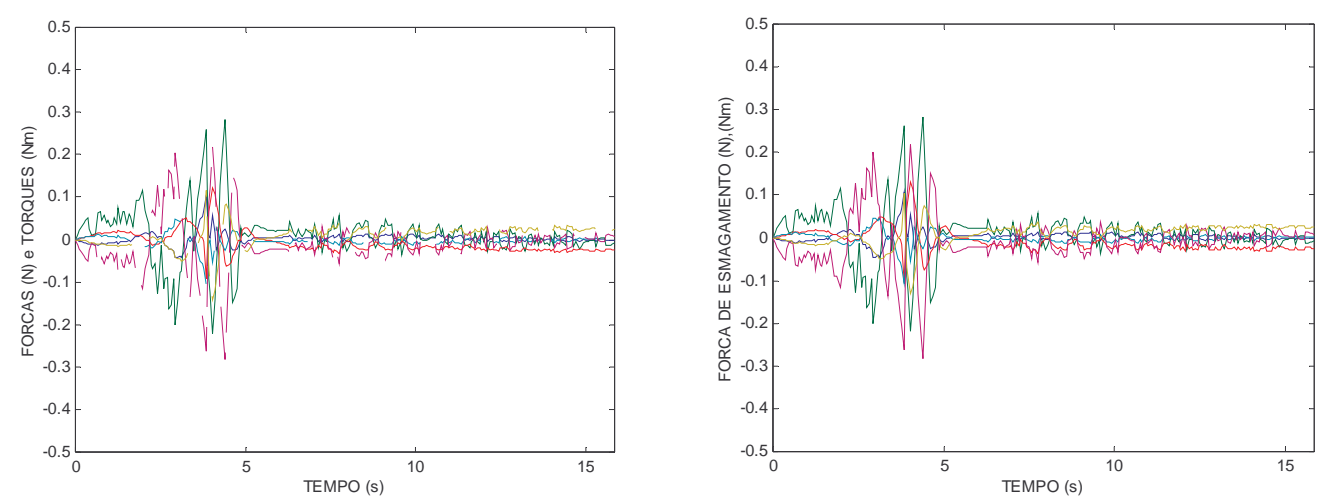

FIGURA 6.57. Trajetória em que uma falha do tipo junta 1 do robô 1 com balanço livre ocorreu em $1 \mathrm{~s}$. Figura à esquerda: forças aplicadas no objeto. Linhas contínuas:

forças aplicadas pelo manipulador 1. Linhas tracejadas: forças aplicadas pelo manipulador 2. Figura à direita: força de esmagamento $\left(h_{o e}\right)$. As duas componentes que provocam torção (momentos) no objeto não são controladas após a isolação da falha.
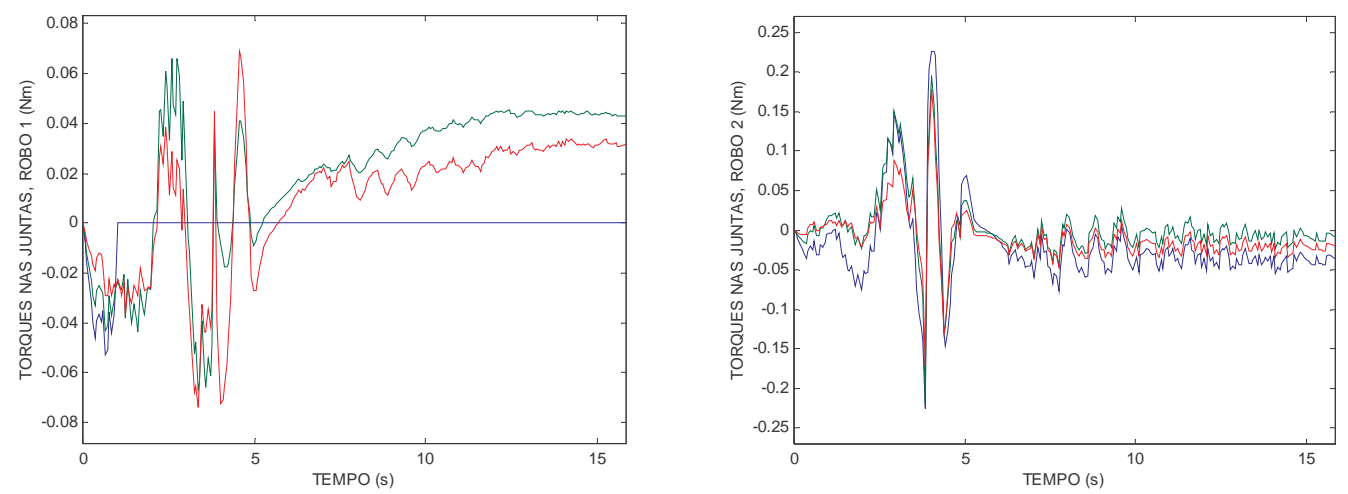

FIGURA 6.58. Trajetória em que uma falha do tipo junta 1 do robô 1 com balanço livre ocorreu em $1 \mathrm{~s}$. Figura à esquerda: Torques nas juntas do robô 1 ; Figura à direita:

Torques nas juntas do robô 2 . Torques nas juntas: junta $1 \mathrm{em}$ azul, junta $2 \mathrm{em}$ verde e junta 3 em vermelho. 

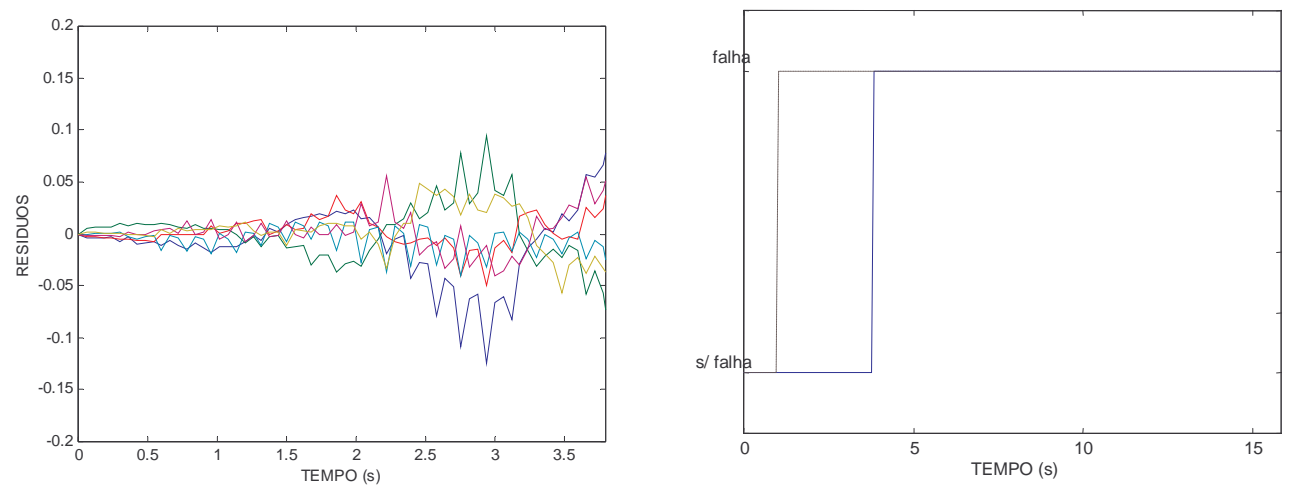

FIGURA 6.59. Trajetória em que uma falha do tipo junta 1 do robô 1 com balanço livre ocorreu em $1 \mathrm{~s}$. Figura à esquerda: Resíduos; Figura à direita: Detecção da falha do tipo junta 1 do robô 1 com balanço livre (linha contínua) e falha real (linha tracejada).

As Figuras 6.60-6.63 mostram os resultados da simulação de uma trajetória do sistema cooperativo real com uma falha do tipo informação incorreta de posição da junta 2 do manipulador 1 ocorrendo em 1 s. As Figuras 6.60-63 mostram, respectivamente, as posições do CM e a orientação do objeto (Figura 6.60), as velocidades do objeto (Figura 6.61), as forças exercidas pelos efetuadores no objeto e a força de esmagamento (Figura 6.62) e a detecção da falha do tipo informação incorreta de posição da junta 2 do manipulador 1 (Figura 6.63).

Após a DIF (Figura 6.63), as posições medidas na junta 2 do manipulador 1 são substituídas pelos valores estimados. Observe que o objeto continua percorrendo a trajetória desejada inicialmente projetada (Figura 6.60-61) e as forças de esmagamento ficam próximas dos valores desejados (Figura 6.62) após a isolação da falha (Figura 6.63).
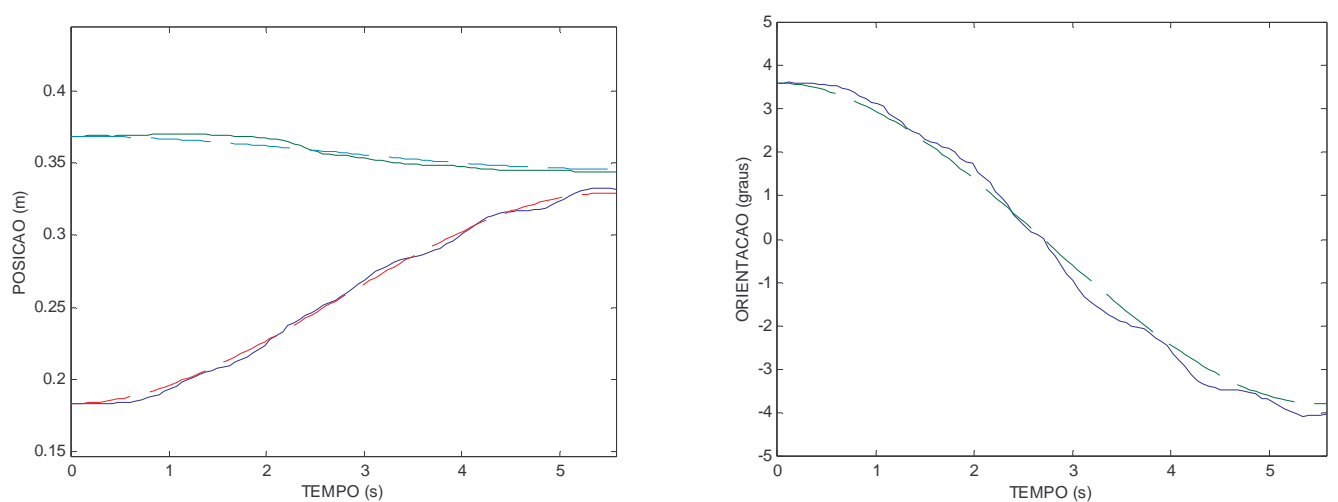

FIGURA 6.60. Trajetória em que uma falha do tipo junta 2 do robô 1 com informação incorreta de posição ocorreu em $1 \mathrm{~s}$. Linhas contínuas: Figura à esquerda: posição do CM do objeto (coordenadas $x$ em azul e $y$ em verde); Figura à direita: orientação do objeto. As linhas tracejadas indicam os valores desejados. 

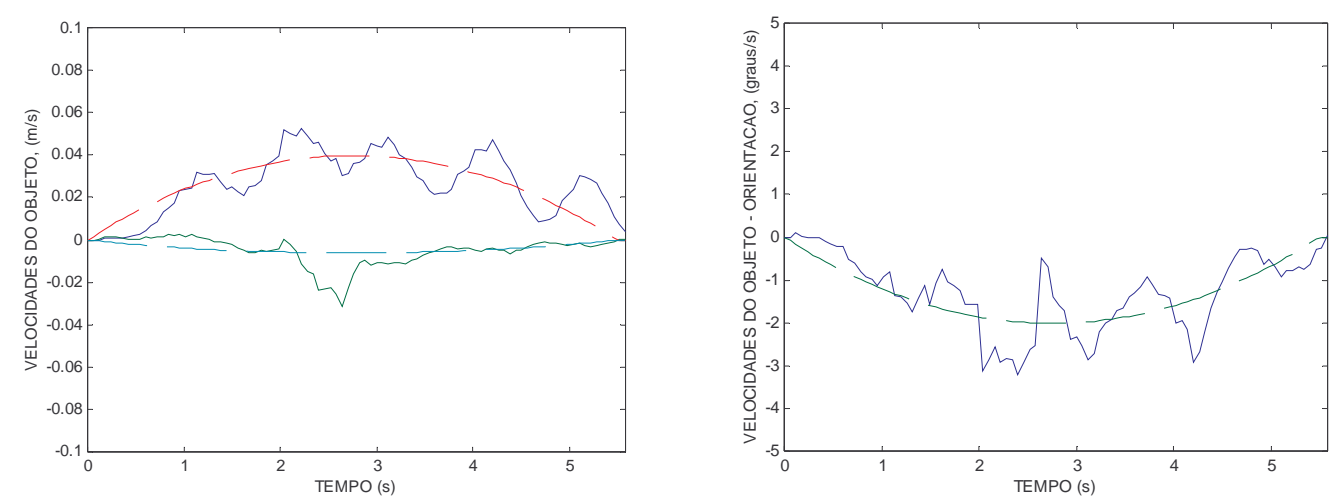

FIGURA 6.61. Trajetória em que uma falha do tipo junta 2 do robô 1 com informação incorreta de posição ocorreu em $1 \mathrm{~s}$. Linhas contínuas: Figura à esquerda: velocidade linear do objeto (coordenadas $x$ em azul e $y$ em verde); Figura à direita: velocidade angular do objeto. As linhas tracejadas indicam os valores desejados.
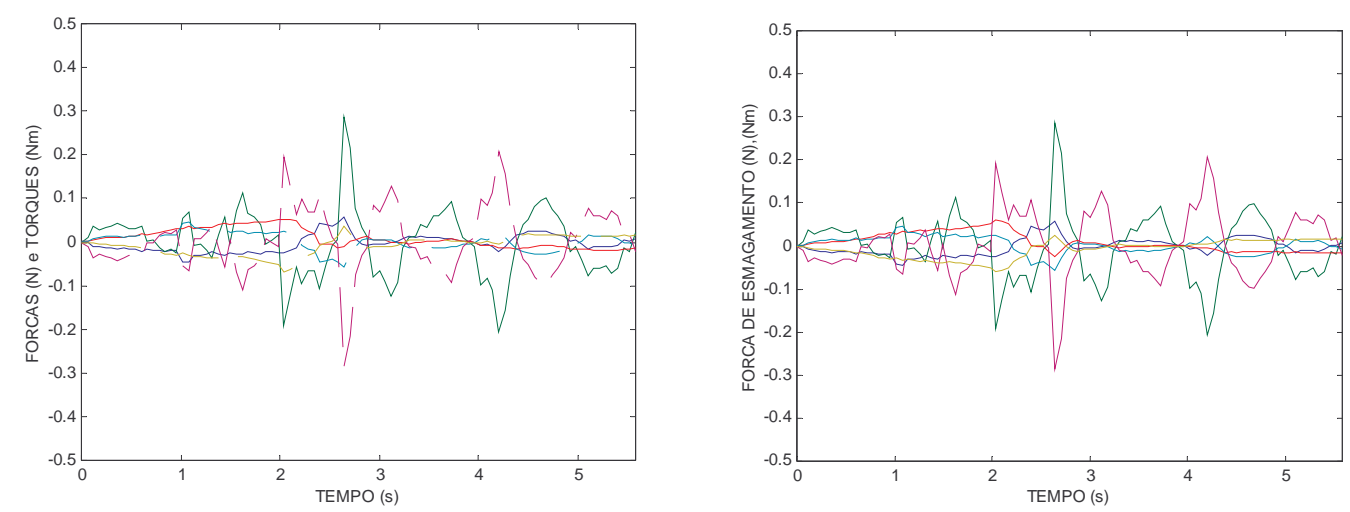

FIGURA 6.62. Trajetória em que uma falha do tipo junta 2 do robô 1 com informação incorreta de posição ocorreu em $1 \mathrm{~s}$. Figura à esquerda: forças aplicadas no objeto.

Linhas contínuas: forças aplicadas pelo manipulador 1. Linhas tracejadas: forças aplicadas pelo manipulador 2. Figura à direita: força de esmagamento $\left(\mathrm{h}_{\mathrm{oe}}\right)$.

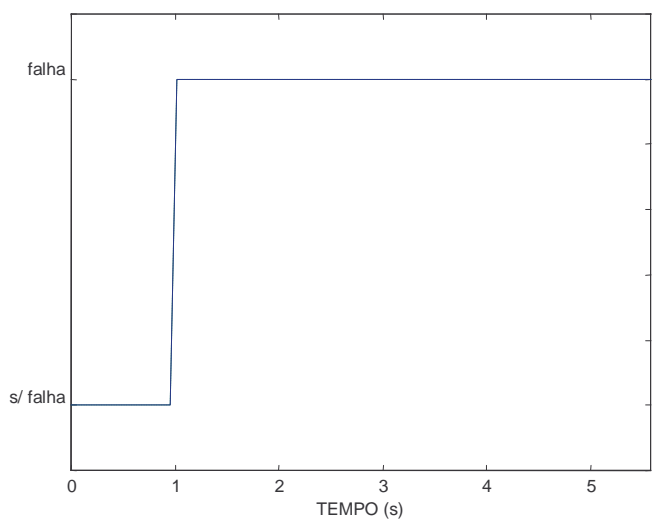

FIGURA 6.63. Detecção da falha do tipo junta 2 do robô 1 com informação incorreta de posição (linha contínua) e falha real (linha tracejada). Repare que os dois traços estão superpostos. 


\subsection{CAPACIDADE DINÂMICA DE CARGA}

O método apresentado na Seção 5.5.1 é usado aqui para analisar a CDC de um sistema cooperativo composto por dois robôs planares com três juntas cada manipulando um cilindro com raio 0,05 m e comprimento $0,092 \mathrm{~m}$. Os parâmetros dos robôs são os mesmos daqueles do Sistema Simulado 1 (Apêndice B.1). Os torques máximos permitidos em cada junta são de $25 \mathrm{Nm}$ (em módulo). A função "lp.m” do MATLAB foi utilizada para resolver o problema de programação linear descrito na Seção 5.5.1.

Primeiramente, a CDC do sistema cooperativo foi obtida para uma trajetória desejada (Figura 6.64) considerando-se três casos: com o sistema totalmente atuado, com apenas uma junta passiva e com duas juntas passivas (Figura 6.65). Como era de se esperar, a CDC do sistema cooperativo diminui para a mesma trajetória conforme aumentou o número de juntas passivas nos robôs.
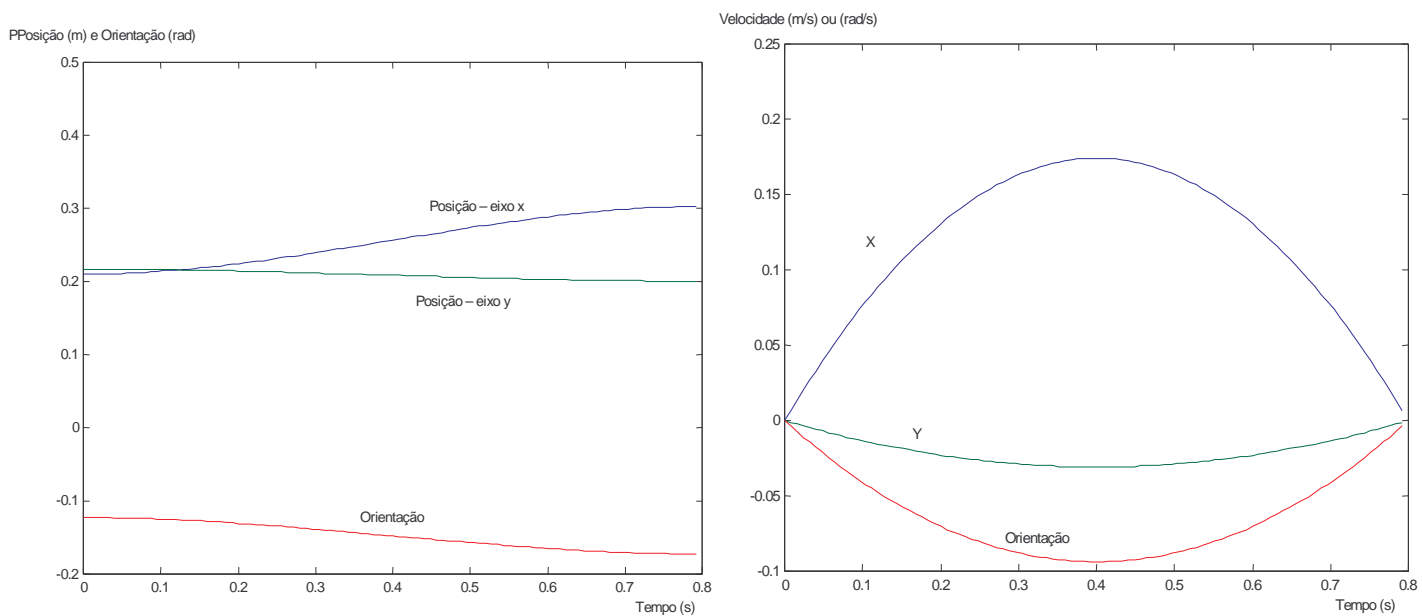

FIGURA 6.64. Trajetória desejada do objeto. Figura à esquerda: posições desejadas.

Figura à direita: velocidades desejadas. 


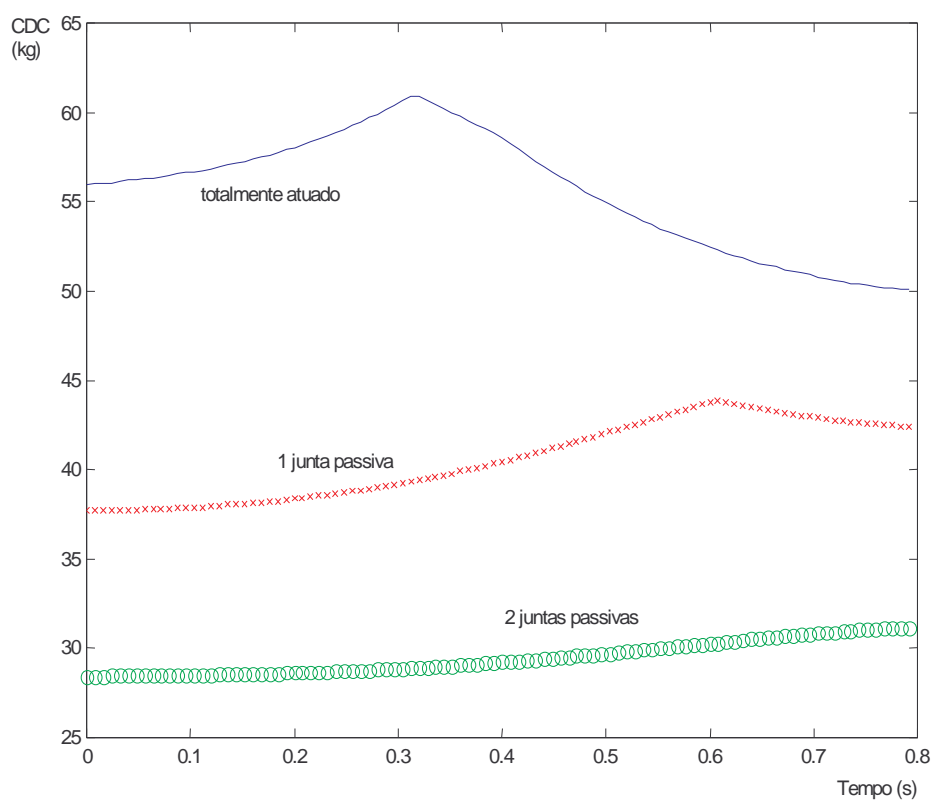

FIGURA 6.65. CDC durante a trajetória desejada. Linha contínua: CDC do sistema totalmente atuado (carga máxima = 50,05 kg); ' $x$ ': CDC do sistema com uma junta passiva (junta 2 do primeiro robô) (carga máxima = 37,68 kg);: 'o': CDC do sistema com uma junta passiva (juntas 2 e 3 do primeiro robô) (carga máxima $=28,44 \mathrm{~kg}$ ).

O passo seguinte foi a comparação, para a mesma trajetória, da CDC do sistema cooperativo com diferentes juntas sendo consideradas passivas. A Figura 6.66 mostra a CDC do sistema cooperativo para a trajetória desejada considerando-se sete configurações. $\mathrm{Na}$ primeira configuração, todas as juntas do sistema são atuadas. Nas 6 configurações restantes, diferentes juntas são consideradas passivas. Pode-se observar que a CDC é diferente para cada caso. Como os torques aplicados em cada junta variam durante a trajetória, a CDC é diferente quando diferentes juntas são consideradas passivas. Se os torques aplicados a uma junta $i$ em uma dada trajetória são menores que os torques aplicados em uma junta $j$, a carga máxima que pose ser manipulada pelo sistema com a junta passiva $i$ é maior que aquela do sistema com a junta passiva $j$ durante a trajetória desejada. 


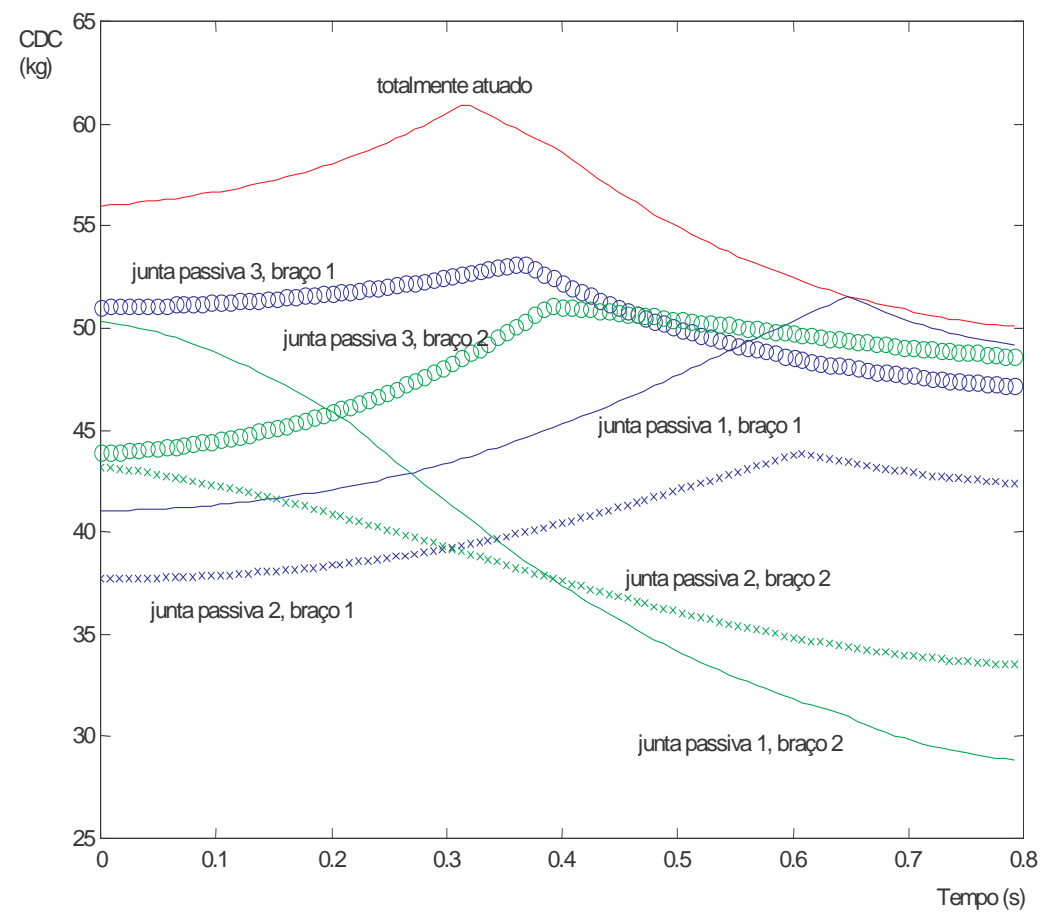

FIGURA 6.66. CDC durante a trajetória desejada para o sistema totalmente atuado e considerando-se diferentes juntas como passiva (em cada simulação, uma junta diferente foi considerada passiva).

A CDC pode ainda ser usada para planejar a trajetória do objeto manipulado para o sistema com juntas passivas. Trajetórias com os mesmos pontos iniciais e finais podem resultar em diferentes CDC já que os termos da equação dinâmica dos robôs variam com a posição, velocidade e aceleração das juntas. Assim, uma trajetória com acelerações e velocidades menores podem resultar em um CDC maior, como pode ser visto na Figura 6.67. Para a simulação apresentada no lado esquerdo na Figura 6.67, as acelerações e velocidades foram maiores do que aquelas da simulação apresentada no lado direito da mesma figura. Como resultado, a carga máxima que pode ser manipulada no segundo caso é quase $10 \mathrm{~kg}$ maior que aquela do primeiro caso. 

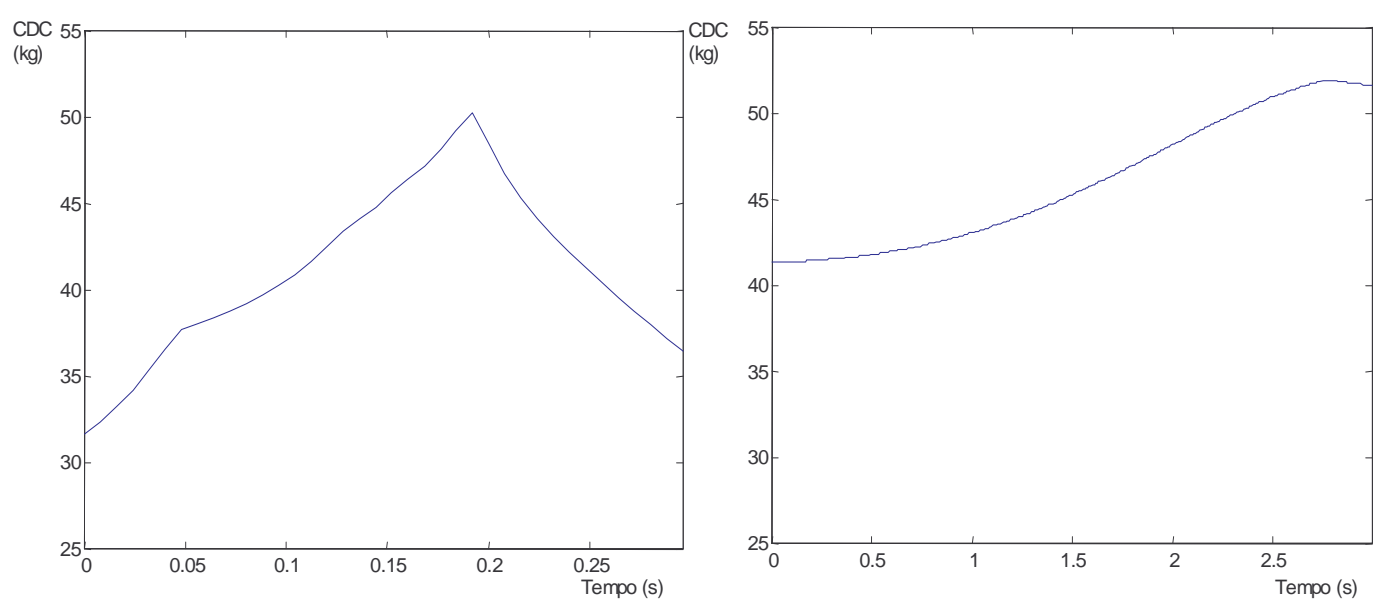

FIGURA 6.67. CDC para trajetórias com diferentes velocidades e acelerações. Figura à esquerda: CDC em uma trajetória em que a carga foi posicionada em 0,3 s. A carga máxima que pode ser manipulada neste caso é de $31,60 \mathrm{~kg}$. Figura à direita: CDC em uma trajetória em que a carga foi posicionada em 3,0 s. A carga máxima que pode ser manipulada neste caso é de $41,35 \mathrm{~kg}$. 


\section{Capítulo 7. CONCLUSÕES}




\subsection{CONTRIBUIÇÕES}

Nesta tese, o problema de tolerância a falhas em manipuladores cooperativos é pela primeira vez estudado. Quatro tipos de falhas que podem afetar gravemente a operação dos manipuladores cooperativos foram identificados através da Análise dos Modos e Efeitos das Falhas e da Análise por Árvore de Falhas (Capítulo 2). A tolerância a falhas no sistema cooperativo é alcançada pela reconfiguração após a DIF (Capítulo 4). Feita a isolação da falha, o controlador para o sistema com falhas é aplicado (Capítulo 5). A relação das publicações do autor relacionadas ao trabalho apresentado nesta tese é apresentada no Apêndice G.

As contribuições deste trabalho são sumarizadas a seguir.

\subsubsection{Análise de Falhas}

As falhas nos robôs do sistema cooperativo foram estudadas considerando-se o funcionamento básico do manipulador. Este estudo identificou as falhas que devem ser tratadas pelo sistema de tolerância, suas causas e seus efeitos. O estudo inclui:

- Análise das causas e efeitos das falhas nos robôs através da AMEF;

- Construção das árvores de falhas (AAF). As árvores de falhas permitem a rápida visualização das causas das falhas;

- Identificação das falhas que apresentam consequências mais graves para o sistema cooperativo. Estas foram quatro:

(i) Informação incorreta de posição da junta;

(ii) Informação incorreta de velocidade da junta;

(iii) Junta bloqueada e;

(iv) Junta com balanço livre.

- Estudo da dinâmica do sistema cooperativo para a falha do tipo junta com balanço livre;

- Estudo da dinâmica do sistema cooperativo para a falha do tipo junta bloqueada;

- Estudo da cinemática do sistema cooperativo para a falha do tipo informação incorreta de posição da junta e;

- Estudo da cinemática do sistema cooperativo para a falha do tipo informação incorreta de velocidade da junta. 


\subsubsection{Detecção e Isolação de Falhas}

Um Sistema DIF foi proposto para as quatro falhas que apresentam consequências mais graves para os robôs cooperativos. Este sistema inclui:

- Detecção e isolação para as falhas do tipo junta com balanço livre e junta bloqueada através de RNA's. Primeiro, MLP's são utilizados para mapear a dinâmica dos manipuladores. Então, uma rede RBF é empregada para classificar o vetor de resíduos produzido pelas diferenças entre as saídas dos MLP's e as medidas de velocidade, e;

- Detecção e isolação para as falhas do tipo informação incorreta de posição ou velocidade das juntas através da cinemática do sistema cooperativo. Isto só é possível porque existem cadeias cinemáticas fechadas no sistema cooperativo (redundância).

\subsubsection{Controle e Reconfiguração do Sistema com Falhas}

Um esquema de controle e reconfiguração para as quatro falhas que apresentam consequências mais graves para os robôs cooperativos foi desenvolvido. Este esquema inclui:

- Sistema de controle híbrido de movimento e esmagamento para os robôs cooperativos com juntas passivas;

- Sistema de controle híbrido de movimento e esmagamento para os robôs cooperativos com juntas bloqueadas, e;

- Estrutura da recuperação de dados em robôs cooperativos com informação incorreta de posições ou velocidades das juntas.

Relacionados ao controle e reconfiguração do sistema com falhas, foram estudados os seguintes problemas:

- Estudo da reconfiguração das trajetórias do sistema após as falhas, e;

- Proposição de um algoritmo para determinação da capacidade dinâmica de carga do sistema cooperativo com juntas passivas. 


\subsubsection{Experimentos}

Além das simulações, um sistema cooperativo real foi montado com o intuito de demonstrar a aplicabilidade do sistema de tolerância proposto. O sistema cooperativo real é composto por dois robôs UArmII adquiridos através dos processos 98/00649-5 e 99/10031-1 da Fundação de Amparo à Pesquisa do Estado de São Paulo (Fapesp). Para o controle e simulação do sistema real com tolerância a falhas, o ASCSR foi desenvolvido. As seguintes metodologias propostas neste trabalho foram aplicadas no sistema cooperativo real:

- Sistema DIF;

- Controle híbrido do sistema cooperativo com juntas passivas;

- Controle híbrido do sistema cooperativo com juntas bloqueadas;

- Recuperação de dados em robôs cooperativos com informação incorreta de posições ou velocidades das juntas;

- Reconfiguração de trajetórias após as falhas, e;

- Sistema de tolerância completo.

\subsection{O FUTURO...}

As principais extensões deste trabalho visualizadas pelo autor são:

(i) Estudo de outros tipos de falhas que afetem o sistema cooperativo. Algumas falhas, como informação incorreta de força nos efetuadores e rompimento da conexão entre objeto e robôs, não foram estudadas neste trabalho. Possivelmente a primeira, causada por falhas nos sensores de força acoplados aos efetuadores, pode ser detectada através do esquema de geração de resíduos, ou seja, através das RNA's. O mesmo Sistema DIF proposto aqui para as falhas do tipo junta com balanço livre e junta bloqueada pode ser redefinido para incluir a isolação de falhas do tipo informação incorreta de força nos efetuadores. Deve-se, no entanto, observar se os resíduos gerados por estas falhas ocupam a mesma região do espaço de entradas da rede RBF que aqueles gerados pelas outras falhas. Em caso afirmativo, adaptações devem ser feitas no Sistema DIF proposto no Capítulo 4. Já as falhas do tipo rompimento da conexão entre os robôs e o objeto podem ser isoladas através do uso da redundância presente na cinemática do sistema cooperativo, semelhantemente 
ao modo que as falhas do tipo informação incorreta de posição ou velocidade das juntas são detectadas.

(ii) Aplicação em outros sistemas robóticos. Não foge ao autor que o Sistema DIF, os controladores e o esquema de tolerância a falhas completo desenvolvidos aqui possam ser adaptados a outros sistemas robóticos que contenham cadeias cinemáticas fechadas. Entre estes sistemas, podem ser citados

- Garras. As garras utilizadas para a manipulação de objetos podem ser modeladas como manipuladores cooperativos. No entanto, a aplicação das metodologias apresentadas aqui não é direta já que as garras não são, geralmente, rigidamente conectadas ao objeto (ver tópico (iii) a seguir).

- Manipuladores paralelos. Robôs manipuladores paralelos, empregados em simuladores de vôo, são geralmente conectados a plataformas móveis através de juntas esféricas passivas. Em [NOTASH, 2000], as restrições cinemáticas são utilizadas para a detecção de falhas do tipo informação incorreta de posição das juntas e reconfiguração em robôs manipuladores paralelos. As metodologias apresentadas nesta tese podem ser adaptadas para os manipuladores paralelos com falhas, já que estes podem ser modelados como robôs cooperativos com juntas passivas esféricas.

- Robôs caminhantes. Cadeias cinemáticas fechadas aparecem quando duas ou mais pernas de um robô caminhante tocam o chão. Assim, se uma anormalidade é detectada no funcionamento de um robô caminhante, este pode ser comandado para que seus pés assumam uma configuração padrão que torne possível a aplicação da metodologia de tolerância a falhas descrita aqui.

(iii) Aplicação em manipuladores cooperativos que não estejam rigidamente conectados à carga. Dependendo do tipo e da geometria da conexão, o número de restrições cinemáticas do sistema cooperativo pode variar. Isto afeta diretamente o Sistema DIF. No caso de uma conexão que permita um movimento de rotação do objeto em relação ao efetuador, o sistema cooperativo pode ser modelado como contendo juntas passivas rotacionais. Neste caso, o controle descrito na Seção 5.2 pode ser aplicado.

(iv) Aplicação em robôs cooperativos manipulando cargas flexíveis. Este problema é semelhante ao anterior já que as restrições cinemáticas do sistema mudam. Neste caso, o Sistema DIF deve ser remodelado. 
(v) Estudo da minimização das forças de esmagamento em sistemas cooperativos com juntas passivas ou bloqueadas através da escolha da Matriz Jacobiana $\mathbf{Q}(\mathbf{q})$. Como visto na Seção 5.2, a matriz $\mathbf{Q}(\mathbf{q})$ não é única quando $n_{a}$ é maior que $k$. Neste trabalho, a matriz $\mathbf{Q}(\mathbf{q})$, utilizada no controle de movimento, gera indiretamente forças no subespaço de esmagamento. Assim, torna-se interessante achar uma matriz $\mathbf{Q}(\mathbf{q})$ que minimize a força de esmagamento gerada pelo controle de movimento. Entretanto, esta busca deve ser feita em todo o instante amostral, o que praticamente impossibilita sua aplicabilidade em um sistema real. Um método analítico de cálculo desta matriz $\mathbf{Q}(\mathbf{q})$ seria bastante útil.

(vi) Estudo de técnicas de controle robusto para o sistema cooperativo com falhas. Técnicas de controle robusto podem melhorar o desempenho dos controladores do sistema com falhas quando existem erros de modelagem.

(vii) Estudo dos problemas de reconfiguração das trajetórias após a isolação da falha. É interessante estudar quando é necessária a aplicação dos freios após a isolação da falha. Outro problema é a escolha da melhor trajetória após a isolação da falha, ou seja, aquela que minimize algum critério de desempenho, como por exemplo, as forças de esmagamento.

(viii) Aplicação em manipuladores cooperativos com elos flexíveis. Este é um problema complexo já que a cinemática se torna um problema difícil de ser tratado. A aplicação de RNA's para o mapeamento da dinâmica do sistema cooperativo parece ser interessante, tanto para o problema de DIF quanto para o de controle após a falha.

(ix) Estudo do problema de DIF em sistemas cooperativos com variações paramétricas. Se ocorrem variações paramétricas no sistema cooperativo, os MLP's devem ser treinados novamente para que possam mapear a nova dinâmica do sistema. $\mathrm{O}$ estudo de quando e como retreinar deve ser tratado.

(x) Estudo da confiabilidade na isolação das falhas. A confiabilidade da detecção é maior que aquela da isolação, como pode ser visto no Capítulo 6. Quanto uma falha é detectada, o sistema pode ser freado e novos testes podem ser realizados com o intuito de aumentar a confiabilidade da isolação.

(xi) Estudo de trajetórias, configurações e parâmetros dos robôs que minimizem os efeitos das falhas. Assim como nos robôs livres [ENGLISH \& MACIEJEWSKI, 1998], [PAREDIS \& KHOSLA, 1996b], existem trajetórias e configurações do sistema cooperativo em que as consequências das falhas são mais ou menos desastrosas. O mesmo ocorre para os parâmetros construtivos dos robôs ou de seu 
sistema de controle sem falhas. A busca dos parâmetros mais interessantes para uma determinada tarefa levará a uma maior confiabilidade e segurança do robôs que está sendo projetado. Esta busca pode ser feita, por exemplo, através dos algoritmos evolucionários. 


\section{REFERÊNCIAS BIBLIOGRÁFICAS.}

Aldridge, H. A. (1996). "Robot position sensor fault tolerance", PhD Thesis, Carnegie Mellon University, 168 p., Pittsburgh, USA.

American National Standards Institute (1993). "American national standard for industrial robots and robots systems: reliability acceptance testing - guidelines", ANSI/RIA R.15.053, New York.

Arai, H. (1997). "Feedback control of a 3-DOF planar underactuated manipulator". In the Proc. of the IEEE International Conference on Robotics and Automation (ICRA'1997), Albuquerque, USA, p. 703-709.

Arai, H. \& Tachi, S. (1991). "Position control of a manipulator with passive joints using dynamic coupling". IEEE Transactions on Robotics and Automation, v. 7, n. 4: p. 528-534.

Asimov, I. (1973). “Eu, Robồ", 10ª ed., Exped-Expansão Editorial, RJ, Brasil.

Bergerman, M. (1996). "Dynamics and control of underactuated manipulators", PhD Thesis, Carnegie Mellon University, 129 p., Pittsburgh, USA.

Bergerman, M.; Xu, Y. \& Liu, Y. H. (1997). "Nonlinear feedback control of cooperative underactuated manipulators". Nos Anais do Simpósio Brasileiro de Automação Inteligente, Vitória, ES, Brasil, p. 156-167.

Bergerman, M.; Terra, M. H.; Tinós, R.; Siqueira, A. A. G.; Xu, Y. \& Sun, L. -W. (2000). "Fault tolerant control of mechanical manipulators: a hybrid systems approach". In the Proc. of the $6^{\text {th }}$ International IFAC Symposium on Robot Control (SYROCO 2000), September 21-23, Vienna, Austria.

Bicchi, A. \& Prattichizzo, D. (2000). "Manipulability of cooperating robots with unactuated joints and closed-chain mechanisms". IEEE Transactions on Robotics and Automation, v. 16, n. 4: p. 336-345.

Bonitz, R. \& Hsia, T. (1996). "Internal force-based impedance control for cooperating manipulators" IEEE Transactions on Robotics and Automation, v. 12, p. 78-89. 
Brockett, R. W. (1983). "Asymptotic stability and feedback stabilization", In R. W., Milman, R. S., \& Sussmann, H. J.,(Eds.), Differential Geometric Control Theory, Brockett, Boston, USA: Birkhauser, p. 181-191.

Caccavale, F. (1997). "Task-space regulation of cooperative manipulators", PRISMA Lab. Technical Report 97-04, Univesità degli Studi di Napoli Federico II, Napoli, Italy.

Caminhas, W. M. (1997). "Estratégias de detecção e diagnóstico de falhas em sistemas dinâmicos", Tese de Doutorado, Universidade Estadual de Campinas, 161p., Campinas, Brasil.

Caminhas, W. M.; Tavares, H. M. F. \& Gomide, F. (1996). "Rede lógica neurofuzzy: aplicação em diagnóstico de falhas em sistemas dinâmicos", Nos Anais do XI Congresso Brasileiro de Automática (CBA’1996), São Paulo, Brasil, p.459-464.

Carignan, C. R. \& Akin, D. L. (1988). "Cooperative control of two arms in the transport of an inertial load in zero gravity", IEEE Journal of Robotics and Automation, v. 4, n.4, p. 414-419.

Carreras, C. \& Walker, I. D. (2000). "On interval methods applied to robot reliability quantification”, Reliability Engineering and System Safety, v. 70, p. 291-303.

Chen, J. \& Patton, R. J. (1999). "Robust model-based fault diagnosis for dynamic systems", Kluwer Academic Publishers.

Chow, E. Y. \& Willsky, A. S. (1984). “Analytical redundancy and design of robust failure detection systems", IEEE Transactions on Automatic Control, vol. 29, p.603-614.

Chung, W. J.; Nakamura, Y. \& Sørdalen, O. J. (1995). "Prototyping a nonholonomic manipulator". Proc. of the 1995 IEEE International Conference on Robotics and Automation (ICRA'1995), p. 2029-2036.

Corke, P. I. (1996). “A robotics toolbox for MATLAB”, IEEE Transactions on Robotics \& Automation Magazine, vol. 3, n. 1, p.24-32.

Corke, P. I. \& Armstrong-Hélouvry, B. S. (1994). "A search for consensus among model parameters reported for Puma 560 robot", In the Proceedings of the IEEE Conference on Robotics and Automation, San Diego, USA.

Cybenko, G. (1989). "Approximation by superpositions of a sigmoidal function", Mathematics of Control, Signals, and Systems, 2, p.303-314.

Dick, P. K. (1988). “The dark haired girl”, Mark V. Ziesing, USA. 
Dhillon, B. S. (1987). “On robot reliability and safety - Bibliography”, Microelectronics and Reliability, v. 27, p. 105-118.

Dhillon, B. S. (1991). "Robot reliability and safety”, Springer-Verlag, New York.

Dhillon, B. S. \& Yang, N. (1996). "Availability analysis of a robot with safety system", Microelectronics and Reliability, v. 36, n. 2, p. 169-177.

Dhillon, B. S. \& Fashandi, A. R. M. (1997). "Robotic systems probabilistic analysis", Microelectronics and Reliability, v. 37, n. 2, p. 211-224.

Dixon, W. E.; Walker, I. D.; Dawson, D. M. \& Hartranft, J. P. (2000). "Fault detection for robot manipulators with parametric uncertainty: a prediction-error-based approach", IEEE Transactions on Robotics and Automation, v. 16, n. 6, p. 689-699.

Flashner, H. \& Efrati, T. (1997). "Tracking of mechanical systems using artificial neural networks", Revista Brasileira de Ciências Mecânicas, v. 19, n. 2, p. 217-227.

English, J. D. \& Maciejewski, A. A. (1998). "Fault tolerance for kinematically redundant manipulators: anticipating free-swinging joint failures", IEEE Transactions on Robotics and Automation, v. 14, n. 4, p. 566-575.

Frank, P. M. (1987). "Fault diagnosis in dynamic systems via state estimation - A survey", In Tsafestas, S. M. Singh and G. Schmidt (Eds.), System Fault Diagnostics, Reliability and Related Knowledge-Based Approaches, vol. 1, p.35-98.

Frank, P. M. (1990). "Fault Diagnosis in Dynamic Systems Using Analytical and Knowledge-based Redundancy - A Survey and Some New Results". Automatica, vol. 26, n. 3, p.459-474.

Franklin, S. (1995). “Artificial minds”, MIT Press.

Gertler, J. (1988). "A survey of model-based failure detection and isolation in complex plants", IEEE Control Systems Magazine, vol. 8, n. 6, p.3-11.

Gertler, J. (1991). “Analytical redundancy methods in fault detection and isolation - Survey and synthesis", In the Proc. of the IFAC Symposium on Fault Detection, Supervision and Safety for Technical Processes (SAFEPROCESS'1991), Baden Baden, Germany, vol. 1, p.9-23.

Gertler, J. (1997). “A cautious look at robustness in residual generation”, In the Proc. of the IFAC Symposium on Fault Detection, Supervision and Safety for Technical Processes (SAFEPROCESS'1997),, Kingston Upon Hull, U. K., vol.1, p.133-139. 
Green, M. \& Limebeer, D. J. N. (1995). “Linear Robust Control”, New Jersey, Prentice Hall.

Haykin, S. S. (1994). "Neural networks: a comprehensive foundation", New York: Macmillan.

Hertz, J.; Krogh, A. \& Palmer, R. G. (1991). "Introduction to the theory of neural computation", Addison-Wesley Publishing Company.

Hibbeler, R. C. (1995). "Engineering mechanics - dynamics", $7^{\text {th }}$ ed., Prentice Hall, New Jersey, USA.

Hirano, G.; Yamamoto, M. \& Mohri, A. (2002). "Study on cooperative multiple manipulators with passive joints", In the Proc. of the 2002 IEEE/RSJ International Conference on Intelligent Robots and Systems, (IROS'2002), Lausanne, Switzerland, p. 2855-2860.

Horak, D. T. (1988). "Failure detection in dynamic systems with modeling errors", AIAA Journal of Guidance, Control and Dynamics, v. 11, n. 6, p. 508-516.

Isermann, R. (1993). "Fault diagnosis of machines via parameter estimation and knowledge processing - tutorial paper", Automatica, vol. 29, 4, p.815-835.

Isermann, R. (1997). "Supervision, fault-detection and fault-diagnosis methods - an introduction", Control Engineering Practice, v. 5, n. 5, p. 639-652.

Khodabandehloo, K. (1996). "Analyses of robot systems using fault and event trees: case studies”, Reliability Engineering and System Safety (special issue on Safety of Robotic Systems), v. 53, n. 3, p. 247-264.

Kohonen, T. (1995). “Self-organizing maps", Springer-Verlag, Berlin.

Koivo, A.J. (1989). "Fundamentals for control of robotic manipulators", John Wiley \& Sons Inc..

Koivo, A. J. \& Unseren, M. A. (1991). "Reduced order model and decoupled control architecture for two manipulators holding a rigid object", Journal of Dynamic Systems, Measurement, and Control (Transactions of the ASME), v. 113, p. 646-654.

Köppen-Seliger, B. \& Frank, P. M. (1996). "Neural Networks in Model-Based Fault Diagnosis", In the Proc. of the 13th IFAC World Congress, San Francisco, USA, p.6772.

Korbicz, J. (1997). "Neural networks and their application in fault detection and diagnosis", In the Proc. of the IFAC Symposium on Fault Detection, Supervision and Safety for 
Technical Processes (SAFEPROCESS'1997), Kingston Upon Hull, U. K., vol.1, p.377-382.

Laroussi, K.; Hemami, H. \& Goddard, R. E. (1988). "Coordination of two planar robots in lifting”. IEEE Journal of Robotics and Automation, v. 4, n. 1, p. 77-85.

LaSalle, J. P. (1960). "Some extensions of Lyapunov's second method". IRE Transactions on Circuit Theory, v. 7, n. 4, p. 520-527.

Leonard, J. A. \& Kramer, M. A. (1991). "Radial basis function networks for classifying process faults", IEEE Control Systems, v. 11, n. 3, p.31-38.

Leuschen, M. L. (2001). "Derivation and application of nonlinear analytical redundancy techniques with applications to robotics", PhD Thesis, Rice University, 184 p., Houston, USA.

Leuschen, M. L., Walker, I. D. \& Cavallaro, J. R. (2002). "Robotic fault detection using nonlinear analytical redundancy", In the Proc. of the IEEE International Conference on Robotics and Automation (ICRA'2002), Washington, USA.

Lewis, C. L. \& Maciejewski, A. A. (1997). "Fault tolerant operation of kinematically redundant manipulators for locked joint failures", IEEE Transactions on Robotics and Automation, vol. 13, n. 4, p. 622-629.

Li, Z. \& Canny, F.. (1992). “Nonholonomic Motion Planning”, Kluwer: Norwell, USA.

Liu, Y. H. \& Xu, Y. (1997). "Cooperation of multiple manipulators with passive joints". In the Proc. of the IEEE International Conference on Robotics and Automation (ICRA'1997), Albuquerque, USA.

Liu, Y. H.; Xu, Y. \& Bergerman, M. (1999). "Cooperation control of multiple manipulators with passive joints", IEEE Transactions on Robotics and Automation, v. 15, n. 2, pp. 258-267.

Looney, C. G. (1997). "Pattern recognition using neural networks", Oxford University Press.

Luh, J. Y. S. \& Zheng, Y. F. (1987). "Constrained relations between two coordinated industrial robots for motion control". International Journal of Robotics Research, v. 6, n. 3, p. 60-70. 
Lynch, M. K.; Shiroma, N.; Arai, H. \& Tanie, K. (1997). "Motion planning for 3-DOF robot with a passive joint". In the Proc. of the IEEE International Conference on Robotics and Automation (ICRA'1997), Albuquerque, USA, p. 359-366.

McClamroch, N. H. \& Wang, D. (1988). "Feedback stabilization and tracking of constrained robots". IEEE Transactions on Automatic Control, v. 33, n. 5: p. 419-426.

Mangoubi, R. S. (1998). “Robust estimation and failure detection”, Springer-Verlag.

Mangoubi, R.; Appleby, B. D. \& Farrell, J. (1992). "Robust estimation in fault detection", In the Proc. of the $31^{\text {st }}$ IEEE Conference on Decision and Control (CDC'1992), p.39433948.

Marcu, T. \& Mirea, L. (1997). "Robust detection and isolation of process fault using neural networks". IEEE Control Systems, v. 17, n. 5, p. 72-79.

Moody, J. \& Darken, C. (1989). "Fast learning in networks of locally-tuned processing units", Neural Computation, 1, p. 289-303.

Mukherjee, R. \& Chen, D. (1993). "Control of free-flying underactuated space manipulators to equilibrium manifolds". IEEE Transactions on Robotics and Automation, v. 9, n. 5, p. 561-570.

Murray, R. M.; Li, Z. \& Sastry, S. S. (1993). "A mathematical introduction to robotic manipulation", CRC Press Inc.

Nahon, M. \& Angeles, J. (1992). "Minimization of power losses in cooperating manipulators", Journal of Dynamic Systems, Measurement, and Control (Transactions of the ASME), v. 114, June, p. 213-219.

Nakamura, Y. (1991). “Advanced robotics: redundancy and optimization”, Addison-Wesley Publishing Company, Inc.

Nakano, E.; Ozaki, S.; Ishida, T. \& Kato, I. (1974). "Cooperational control of the anthropomorphous manipulator 'MELARM'". In the Proc. of $4^{\text {th }}$ International Symposium on Industrial Robots, Tokyo, Japan, p. 251-260.

Naughton, J. M.; Chen, Y. C. \& Jiang, J. (1996). "A neural network application to fault diagnosis for robotic manipulator", In the Proc. of IEEE International Conference on Control Applications (CCA'1996), v. 1, p. 988-1003.

Nelles, O. \& Isermann, R. (1995). “A comparison between RBF networks and classical methods for identification of nonlinear dynamic systems", In the Proc. of the IFAC 
Congress on Adaptive System in Control and Signal Processing, Budapest, Hungary, p. 233-238.

Nobel, B. \& Daniel, J. W. (1986). "Álgebra linear aplicada", Prentice/Hall do Brasil, 2ª ed.

Norton, R. L. (1999). "Design of machinery: an introduction to the synthesis and analysis of mechanisms and machines", McGraw-Hill, $2^{\mathrm{a}}$. ed..

Notash, L. (2000). "Joint sensor fault detection for fault tolerant parallel manipulators". Journal of Robotic Systems, vol. 17, Issue 3, p. 149-157.

Ojala, T. \& Vuorimaa, P. (1995). "Modified Kohonen's learning laws for RBF networks", In the Proc. of the International Conference on Artificial Neural Nets and Genetic Algorithms, Ales, France, p. 356-359.

Oriolo, G. \& Nakamura, Y. (1991). "Free-joint manipulators: motion control under secondorder nonholonomic constraints". In the Proc. of the IEEE International Workshop on Intelligent Robots and Systems, p. 1248-1253.

Orr, M. J. L. (1996). "Introduction to radial basis function networks", Technical Report, Center for Cognitive Science, Edinburgh University, Scotland, U. K.

Papadopoulos, E. \& Dubowsky, S. (1991). "Failure recovery control for space robotic systems". In the Proc. of the American Control Conference (ACC'91), vol. 2: p. 14851490.

Paredis, C. J. J.\& Khosla, P. K. (1996a). "Designing fault tolerant manipulators: how many degrees-of-freedom?" International Journal of Robotics Research, v. 15, n. 6, p. 611628.

Paredis, C. J. J. \& Khosla, P. K. (1996b). "Fault tolerant task execution through global trajectory planning," Reliability Engineering and System Safety (special issue on Safety of Robotic Systems), v. 53, n. 3, p. 225-235.

Perdereau, P. \& Drouin, M. (1996). "Hybrid external control for two robot coordinated motion". Robotica, 14, p. 141-153.

Patton, R. J.; Frank, P. M. \& Clark, R. N. (1989). "Fault diagnosis in dynamic systems theory and application", Prentice Hall International.

Sadrnia, M.A; Chen, J. \& Patton, R. J. (1997). "Robust $H_{\infty} / \mu$ observer-based residual generation for fault diagnosis", In the Proc. of the IFAC Symposium on Fault 
Detection, Supervision and Safety for Technical Processes (SAFEPROCESS'1997), Kingston Upon Hull, U. K., vol.1, p.147-153.

Sato, K. (1982). "Case study of maintenance of spot-welding robots", Plant Maintenance, v. 14, p. 28.

Scapin, C. A. (1999). "Análise sistêmica de falhas", Editora de Desenvolvimento Gerencial, Belo Horizonte, Brasil.

Schneider, H. \& Frank, P. M. (1996). "Observer-based supervision and fault-detection in robots using nonlinear and fuzzy logic residual evaluation", IEEE Transactions on Control Systems Technology, v. 4, n. 3, p. 274-282.

Sciavicoo, L. \& Siciliano, B. (1996). "Modeling and control of robot manipulators", McGraw-Hill International Editions.

Shima, S. (1982). "Safety control on the introduction of industrial robots to factories", Safety, 33, p. 18.

Sorsa, T. \& Koivo, H. N. (1993). "Application of artificial neural networks in process fault diagnosis". Automatica, v. 29, n. 4, p. 843-849.

Spong, M. W. \& Vidyasagar, M. (1989). "Robot dynamics and control”, John Wiley \& Sons.

Stamatis, D. H. (1995). "Failure mode and effect analysis: FMEA from theory to execution", Quality Press.

Stengel, R. F. (1991). "Intelligent failure-tolerant control”, IEEE Control Systems, v. 11, n. 4, p. 14-23.

Sugimoto, N. \& Kawaguchi, K. (1983). "Fault tree analysis of hazards created by robots", In the Proc. of the $13^{\text {th }}$ International Symposium on Industrial robots, p. 9.13-9.28.

Sun, D.; Mills, J. K. \& Liu, Y. (1998). "Position control of multiple robots manipulating a flexible payload". In the Proc. of the American Control Conference (ACC'98), p. 456460.

Takegaki, M. \& Arimoto, S. (1981). "A new feedback method for dynamic control of manipulators". ASME Journal of Dynamic. Systems, Measurement and Control, v. 102.

Terra, M. H. \& Tinós, R. (2001). "Fault detection and isolation in robotic manipulators via neural networks: a comparison among three architectures". Journal of Robotic Systems, vol. 18, Issue 7, p. 357-374. 
Terra, M. H.; Bergerman, M.; Tinós, R. \& Siqueira, A. A. G. (2001). "Controle tolerante a falhas de robôs manipuladores". Revista Controle \& Automação, vol. 12, n. 2, p. 7392.

Tinós, R. (1999). "Detecção e diagnóstico de falhas em robôs manipuladores via redes neurais artificiais", Dissertação de Mestrado, Escola de Engenharia de São Carlos, USP, $118 \mathrm{p}$.

Tinós, R.; Terra, M. H. \& Bergerman, M. (2000). "Detecção e isolação de falhas em manipuladores cooperativos via redes neurais artificiais". Nos Anais do XIII Congresso Brasileiro de Automática (CBA’2000), Florianópolis, Brasil.

Tinós, R. \& Terra, M. H. (2001). "Fault detection and isolation in robotic manipulators using a multilayer perceptron and an RBF network trained by the Kohonen's Self-organizing map". Revista Controle \& Automação, vol. 12, n. 1, p. 11-18.

Tinós, R.; Terra, M. H. \& Bergerman, M. (2001). "Fault detection and isolation in cooperative manipulators via artificial neural networks". In the Proc. of the 2001 IEEE Conference on Control Applications (CCA’2001), México City, México, p. 492-497.

Tinós, R. \& Terra, M. H. \& Bergerman, M. (2002). "Fault tolerance in cooperative manipulators". In the Proceedings of the 2002 IEEE International Conference on Robotics and Automation (ICRA'2002), Washington, USA, pp. 470-475.

Uchiyama, M. (1998). "Multirobots and cooperative systems". Control problems in robotics and automation / eds.: Siciliano, B. \& Valavanis, K. P., Springer-Verlag, London.

Uchiyama, M. \& Dauchez, P. (1993). "Symmetric kinematic formulation and nonmaster/slave coordinated control of two-arm robots". Advanced Robotics, 7, p. 361383.

Vemuri, A. T. \& Polycarpou, M. M. (1997). "Neural-network-based robust fault diagnosis in robotic systems", IEEE Transactions on Neural Networks, v. 8, n. 6, p. 1410-1420.

Visinsky, M. L.; Cavallaro, J. R. \& Walker, I. D. (1994). "Robotic fault detection and fault tolerance: A survey", Reliability Engineering and System Safety, 46, p. 139-158.

Visinsky, M. L.; Cavallaro, J. R. \& Walker, I. D. (1995). “A dynamic fault tolerance framework for remote robots". IEEE Transactions on Robotics and Automation, v. 11, n. 4 , p. 477-490. 
Vukobratovic, M. \& Tuneski, A. (1998). "Mathematical model of multiple manipulators: cooperative compliant manipulation on dynamical environments". Mechanism and Machine Theory, v. 33, p. 1211-1239.

Walker, I. D. \& Cavallaro, J. R. (1996). "Failure mode analysis for a hazardous waste cleanup manipulator”, Reliability Engineering and System Safety (special issue on Safety of Robotic Systems), v. 53, n. 3, p. 277-290.

Wang, L. T. \& Kuo, M. J. (1994). "Dynamic load-carrying capacity and inverse dynamics of multiple cooperating robotic manipulators", IEEE Transactions on Robotics and Automation, vol. 10, n. 1, p. 71-77.

Warwick, K. \& Craddock, R. (1996). “An introduction to radial basis function for system identification: A comparison with other neural networks", Conference on Decision and Control (CDC'1996), Kobe, Japan, p. 464-469.

Wen, T. \& Kreutz-Delgado, K. (1992). "Motion and force control for multiple robotics manipulators", Automatica, v. 28, n. 4, p. 729-743.

Wijngaard (1996). "An adaptive filter for low frequency encoder applications", Measurement, v. 18, n. 1, p. 1-7.

Yu, K.H.; Takahashi, T. \& Inooka, H. (1995). "Dynamics and motion control of a two-link robot manipulator with a passive joint", In the Proc. of the 1995 IEEE/RSJ International Conference on Intelligent Robots and Systems, (IROS'95), Pittsburgh, PA, USA, v. 2, p. 311-316.

Zhao, Y. S.; Lu, L.; Gao, F.; Huang, Z. \& Zhao, T. S. (1998). "The novel approaches for computing the dynamic load-carrying capacity of multiple cooperating robotic manipulators", Mechanism and Machine Theory, vol. 34, n. 4, p. 637-643.

Zefran, M.; Kumar, V.; Desai, J. \& Henis, E. (1995). "Two-arm manipulation: What can we learn by studying humans?", In the Proc. of the 1995 IEEE/RSJ International Conference on Intelligent Robots and Systems, (IROS'95), Pittsburgh, PA, USA. 


\section{APÊNDICE A. \\ Acompanhamento de Trajetórias de Dois Manipuladores Cooperativos com Juntas Passivas \\ [LIU et al., 1999]}

Utilizando o procedimento de redução descrito em [MCCLAMROCH \& WANG, 1988], as equações dinâmicas dos robôs cooperativos (eq. 3.5) com $n_{a}>k$ juntas ativas e do objeto (eq. 3.7) podem ser escritas como [LIU et al., 1999]

$\mathbf{M}_{\mathrm{r} 1}\left(\mathbf{q}_{\mathrm{ar} 1}\right) \ddot{\mathbf{q}}_{\mathrm{ar} 1}+\mathbf{S}_{\mathrm{r} 1}\left(\mathbf{q}_{\mathrm{ar} 1}, \dot{\mathbf{q}}_{\mathrm{ar} 1}\right)=\tau_{\mathrm{r} 1}$

$\mathbf{M}_{\mathrm{r} 2}\left(\mathbf{q}_{\mathrm{ar} 1}\right) \ddot{\mathbf{q}}_{\mathrm{ar} 1}+\mathbf{S}_{\mathrm{r} 2}\left(\mathbf{q}_{\mathrm{ar} 1}, \dot{\mathbf{q}}_{\mathrm{ar} 1}\right)=\tau_{\mathrm{r} 2}+\mathbf{J}_{\mathrm{ar} 2}(\mathbf{q})^{\mathrm{T}} \mathbf{h}_{\mathbf{e}}$

$\mathbf{M}_{\mathrm{r} 3}\left(\mathbf{q}_{\mathrm{ar} 1}\right) \ddot{\mathbf{q}}_{\mathrm{ar} 1}+\mathbf{S}_{\mathbf{r} 3}\left(\mathbf{q}_{\mathrm{ar} 1}, \dot{\mathbf{q}}_{\mathrm{ar} 1}\right)=\mathbf{J}_{\mathbf{p r}}(\mathbf{q})^{\mathrm{T}} \mathbf{h}_{\mathrm{e}}$

na qual $\mathbf{M}_{\mathbf{r} i}\left(\mathbf{q}_{\text {ari }}\right)$ e $\mathbf{S}_{\mathbf{r} i}\left(\mathbf{q}_{\text {ari }}, \dot{\mathbf{q}}_{\text {ari }}\right)$ denotam respectivamente a matriz de inércia e os termos não-lineares do sistema cooperativo na forma reduzida, $\mathbf{q}_{\text {ar1 }}$ é o vetor das posições das $k$ juntas ativas que formam o conjunto $1, \boldsymbol{\tau}_{\mathbf{r} 1}$ é o vetor das forças generalizadas nas juntas ativas do conjunto $1, \boldsymbol{\tau}_{\mathrm{r} 2}$ é o vetor das forças generalizadas nas juntas ativas restantes (conjunto 2), $\mathbf{J}_{\mathrm{ar} 2}(\mathbf{q})^{\mathrm{T}} \mathbf{h}_{\mathrm{e}}$ é a projeção das forças de esmagamento nas juntas ativas que formam o conjunto $2 \mathrm{e}, \mathbf{J}_{\mathbf{p r}}(\mathbf{q})^{\mathrm{T}} \mathbf{h}_{\mathbf{e}}$ é a projeção das forças de esmagamento nas juntas passivas (conjunto 3).

Em [LIU et al., 1999], as juntas ativas dos conjunto 1 e 2 são utilizadas, respectivamente, para o controle de movimento e para minimizar a diferença entres as forças de esmagamento e seus valores desejados. As leis de controle são dadas por

$\tau_{\mathrm{r} 1}=\mathbf{M}_{\mathrm{r} 1}\left(\mathbf{q}_{\mathrm{ar} 1}\right)\left(\ddot{\mathbf{q}}_{\mathrm{arl} \mathbf{d}}+\mathbf{K}_{\mathbf{v}} \Delta \dot{\mathbf{q}}_{\mathrm{ar} 1}+\mathbf{K}_{\mathrm{p}} \Delta \mathbf{q}_{\mathrm{ar} 1}\right)+\mathbf{S}_{\mathrm{r} 1}\left(\mathbf{q}_{\mathrm{ar} 1}, \dot{\mathbf{q}}_{\mathrm{ar} 1}\right)$

$\tau_{\mathbf{r} 2}=\mathbf{M}_{\mathbf{r} 2}\left(\mathbf{q}_{\text {arld }}\right) \ddot{\mathbf{q}}_{\text {arld }}+\mathbf{S}_{\mathbf{r} 2}\left(\mathbf{q}_{\text {arld }}, \dot{\mathbf{q}}_{\text {arld }}\right)-\mathbf{J}_{\mathrm{ar} 2}(\mathbf{q})^{\mathrm{T}} \mathbf{h}_{\text {sd }}$

na qual $\mathbf{K}_{\mathrm{v}}$ e $\mathbf{K}_{\mathbf{p}}$ são matrizes diagonais e positivas, $\Delta \mathbf{q}_{\operatorname{arl}}=\mathbf{q}_{\text {arld }}-\mathbf{q}_{\text {ar } 1}$ e o subscrito $d$ indica que os valores são desejados. Os vetores $\mathbf{q}_{\text {arld }}$ e $\dot{\mathbf{q}}_{\text {arld }}$ podem ser obtidos através das posições e velocidades desejadas do objeto. Neste caso, a matriz $\mathbf{Q}(\cdot)$ precisa ser calculada. 
Observe que a eq. (A.5) não projeta forças que estão inteiramente no subespaço de esmagamento.

Substituindo a lei de controle de movimento (eq. A.4) na eq. (A.1), então

$$
\ddot{\mathbf{q}}_{\mathrm{ar} 1}=\ddot{\mathbf{q}}_{\mathrm{ar} 1 \mathrm{~d}}+\mathbf{K}_{\mathrm{v}} \Delta \dot{\mathbf{q}}_{\mathrm{ar} 1}+\mathbf{K}_{\mathrm{p}} \Delta \mathbf{q}_{\mathrm{ar} 1} .
$$

Substituindo, agora, as eq. (A.5) e (A.6) na eq. (A.2), então

$$
\begin{aligned}
\mathbf{M}_{\mathrm{r} 2}\left(\mathbf{q}_{\mathrm{ar} 1 \mathrm{~d}}\right)\left[\ddot{\mathbf{q}}_{\mathrm{ar} 1 \mathrm{~d}}+\mathbf{K}_{\mathbf{v}} \Delta \dot{\mathbf{q}}_{\mathrm{ar} 1}+\mathbf{K}_{\mathrm{p}} \Delta \mathbf{q}_{\mathrm{ar} 1}\right]-\mathbf{M}_{\mathrm{r} 2}\left(\mathbf{q}_{\mathrm{arld}}\right) \ddot{\mathbf{q}}_{\mathrm{ar} 1 \mathrm{~d}}+ \\
+\mathbf{S}_{\mathrm{r} 2}\left(\mathbf{q}_{\mathrm{ar} 1}, \dot{\mathbf{q}}_{\mathrm{ar} 1}\right)-\mathbf{S}_{\mathrm{r} 2}\left(\mathbf{q}_{\mathrm{ar} 1 \mathrm{~d}}, \dot{\mathbf{q}}_{\mathrm{ar} 1 \mathrm{~d}}\right)=-\mathbf{J}_{\mathrm{ar} 2}(\mathbf{q})^{\mathrm{T}} \Delta \mathbf{h}_{\mathrm{sd}} .
\end{aligned}
$$

Analisando a eq. (A.7), observa-se que, se os erros de esmagamento são diferentes de zero, as eqs. (A.1) e (A.2) se tornam acopladas e, consequentemente, não é possível controlar independentemente o movimento e o esmagamento do objeto pelas leis de controle dadas pelas eqs. (A.4) e (A.5).

Como é possível controlar somente $n_{a}-k$ componetes da força de esmagamento através das $n_{a^{-}}-k$ juntas ativas do conjunto 2 , os erros de esmagamento geralmente são diferentes de zero se $n_{a}<m k$ (o que sempre é verdade se os robôs não são cinematimamente redundantes). Mesmo nos casos em que $n_{a} \geq m k$, não se garante que os erros de esmagamento serão sempre zero devido aos componentes da força de esmagamento induzidas pelo movimento. Portanto, não é possível controlar independentemente o movimento e o esmagamento do objeto através das leis de controle dadas pelas eqs. (A.4) e (A.5)

Liu, Y. H.; Xu, Y. \& Bergerman, M. (1999). "Cooperation control of multiple manipulators with passive joints", IEEE Transactions on Robotics and Automation, v. 15, n. 2, pp. 258-267.

McClamroch, N. H. \& Wang, D. (1988). "Feedback stabilization and tracking of constrained robots". IEEE Transactions on Automatic Control, v. 33, n. 5: p. 419-426. 


\section{APÊNDICE B.}

\section{Dados do Sistema Simulado 1}

TABELA B.1: Parâmetros dos robôs

\begin{tabular}{lc}
\hline parâmetros ${ }^{*}$ & valores \\
\hline gravidade & $\begin{array}{c}9,81 \mathrm{~m} / \mathrm{s}^{2} \text { no eixo } y \text { (ortogonal } \\
\text { ao eixo de movimento das } \\
\text { juntas) }\end{array}$ \\
\hline tamanho do elo $1\left(l_{1}\right)$ & $0,203 \mathrm{~m}$ \\
\hline tamanho do elo 2 $\left(l_{2}\right)$ & $0,203 \mathrm{~m}$ \\
\hline tamanho do elo $3\left(l_{3}\right)$ & $0,203 \mathrm{~m}$ \\
\hline massa no elo 1 $\left(m_{1}\right)$ & $0,85 \mathrm{~kg}$ \\
\hline massa no elo 2 $\left(m_{2}\right)$ & $0,85 \mathrm{~kg}$ \\
\hline massa no elo 3 $\left(m_{3}\right)$ & $0,625 \mathrm{~kg}$ \\
\hline distância da junta 1 ao CM do elo 1 & $0,096 \mathrm{~m}$ \\
\hline distância da junta 2 ao CM do elo 2 & $0,096 \mathrm{~m}$ \\
\hline distância da junta 3 ao CM do elo 3 & $0,077 \mathrm{~m}$ \\
\hline momento de inércia do elo 1 em relação ao CM & $0,0031 \mathrm{~kg} \mathrm{~m}{ }^{2}$ \\
\hline momento de inércia do elo 2 em relação ao CM & $0,0031 \mathrm{~kg} \mathrm{~m}{ }^{2}$ \\
\hline momento de inércia do elo 3 em relação ao CM & $0,0023 \mathrm{~kg} \mathrm{~m}^{2}$ \\
\hline posição da base do manipulador 1 & {$[x ; y ; z]=[0 ; 0 ; 0] \mathrm{m}$} \\
\hline posição da base do manipulador 2 & {$[x ; y ; z]=[0 ; 0,506 ; 0] \mathrm{m}$} \\
\hline
\end{tabular}

* os manipuladores 1 e 2 têm as mesmas características construtivas

TABELA B.2: Parâmetros do objeto

\begin{tabular}{lc}
\hline parâmetros & valores \\
\hline massa do objeto & $2,5 \mathrm{~kg}$ \\
\hline comprimento do objeto (distância entre os efetuadores dos robôs) & $0,1 \mathrm{~m}$ \\
\hline distância entre efetuadores e CM do objeto & $0,05 \mathrm{~m}$ \\
\hline momento de inércia do objeto em relação ao CM & $0,0022 \mathrm{~kg} \mathrm{~m}^{2}$ \\
\hline
\end{tabular}


TABELA B.3: Parâmetros do controlador (sem falhas)

\begin{tabular}{lc}
\hline parâmetros & valores \\
\hline torque máximo aplicado & $25 \mathrm{Nm}$ \\
\hline torque mínimo aplicado & $-25 \mathrm{Nm}$ \\
\hline $\mathbf{K}_{\mathbf{p}}$ & {$[50050050] \times \mathbf{I}_{3}{ }^{*}$} \\
\hline $\mathbf{K}_{\mathbf{v}}$ & $2 \sqrt{\mathbf{K}_{p}}$ \\
\hline $\mathbf{K}_{\mathbf{i}}$ & $0,45 \times \mathbf{I}_{6}{ }^{*}$ \\
\hline forças de esmagamento desejadas & $0 \mathrm{~N}$ \\
\hline momento de esmagamento desejado & $0 \mathrm{~N} \mathrm{~m}$ \\
\hline
\end{tabular}

* $\mathbf{I}_{n}$ : matriz identidade com posto $n$;

TABELA B.4: Espaço de trabalho do objeto (ver Figura B.1)

\begin{tabular}{lc}
\hline parâmetros & valores \\
\hline valor máximo da posição do CM nos eixos $x$ e $y$ & $0,32 \mathrm{~m} \mathrm{e} 0,32 \mathrm{~m}$ \\
\hline valor mínimo da posição do CM nos eixos $x$ e $y$ & $0,15 \mathrm{~m} \mathrm{e} 0,15 \mathrm{~m}$ \\
\hline valor máximo da orientação do objeto & $\pi / 12 \mathrm{rad}$ \\
\hline valor mínimo da orientação do objeto & $-\pi / 12 \mathrm{rad}$ \\
\hline
\end{tabular}

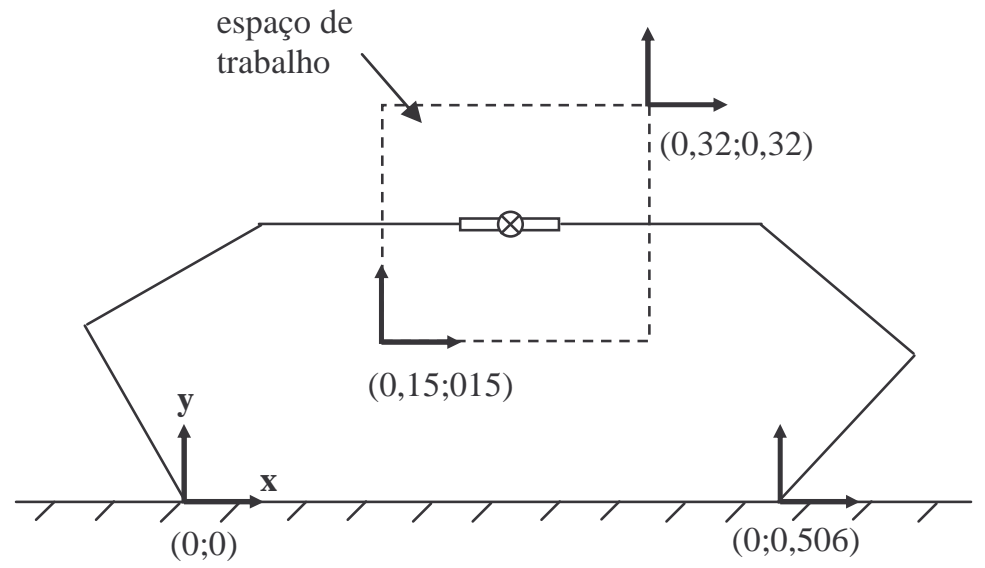

FIGURA B.1. Espaço de trabalho (posição) do CM do objeto (ver Tabela B.4). 
TABELA B.5: Parâmetros dos 2 MLP's treinados por retropropagação do erro.

\begin{tabular}{lc}
\hline número de neurônios de entrada & 12 \\
\hline número de neurônios na camada intermediária & 27 \\
\hline número de neurônios de saída & 3 \\
\hline taxa de aprendizagem & 0,05 \\
\hline termo de momentum & 0,7 \\
\hline número de padrões para treinamento & 7400 \\
\hline número de épocas de treinamento & 10000 \\
\hline tempo médio de treinamento ${ }^{*}$ & 8 h. e 56 min. \\
\hline
\end{tabular}

"para cada MLP, sendo o programa compilado pelo GCC e executado em uma estação SUN ULTRA.

TABELA B.6: Trajetórias utilizadas no treinamento da rede RBF.

\begin{tabular}{ll}
\hline trajetórias $^{*}$ & operação \\
\hline $1-20$ & falha na junta 1 (balanço livre), robô 1 (falha 1) \\
\hline $21-40$ & falha na junta 2 (balanço livre), robô 1 (falha 2) \\
\hline $41-60$ & falha na junta 3 (balanço livre), robô 1 (falha 3) \\
\hline $61-80$ & falha na junta 1 (balanço livre), robô 2 (falha 4) \\
\hline $81-100$ & falha na junta 2 (balanço livre), robô 2 (falha 5) \\
\hline $101-120$ & falha na junta 3 (balanço livre), robô 2 (falha 6) \\
\hline $121-140$ & falha na junta 1 (bloqueada), robô 1 (falha 7) \\
\hline $141-160$ & falha na junta 2 (bloqueada), robô 1 (falha 8) \\
\hline $181-180$ & falha na junta 3 (bloqueada), robô 1 (falha 9) \\
\hline $201-220$ & falha na junta 1 (bloqueada), robô 2 (falha 10) \\
\hline $241-240$ & falha na junta 2 (bloqueada), robô 2 (falha 11) \\
\hline $241-260$ & falha na junta 3 (bloqueada), robô 2 (falha 12)
\end{tabular}

* escolhe-se aleatoriamente 20 trajetórias que são apresentadas 13 vezes: uma vez em que não ocorrem falhas e uma vez para cada tipo de falha. 
TABELA B.7: Parâmetros da rede RBF treinada pelo MAOK.

\begin{tabular}{lc}
\hline número de neurônios de entrada & 12 \\
\hline número de neurônios de saída & 13 \\
\hline $\mathbf{R}$ (define o tamanho do campo receptivo das unidades radiais) & $\left.\begin{array}{rr}0,035 \mathbf{I}_{6} & \mathbf{0}_{6 x 6} \\
\mathbf{0}_{6 x 6} & 0,5 \mathbf{I}_{6}\end{array}\right]$ \\
\hline$\delta_{i}(t)$ (define entradas auxiliares) & 0,004 \\
\hline$\alpha(t)$ (taxa de aprendizagem - MAOK) & $t^{-1}{ }^{* *}$ \\
\hline$\sigma(t)$ (define o tamanho da vizinhança dos centros das unidades & $0,2 t^{-1}$ \\
radiais - MAOK) & 500 \\
\hline$t_{\text {max }}$ (total de épocas - MAOK) & 2691 \\
\hline número de padrões para treinamento & 5 h. e 9 min. \\
\hline tempo aproximado de treinamento ${ }^{* * *}$ & 898 \\
\hline número de unidades radiais (selecionadas pelo MAOK) & \\
\hline & $* \mathbf{I}_{n}:$ matriz identidade com posto $n ; \mathbf{0}_{\text {nxm }}:$ matriz de zeros $n \times m$ \\
\hline
\end{tabular}

TABELA B.8: Parâmetros do Sistema DIF (falhas de informação incorreta de posição ou velocidade das juntas).

\begin{tabular}{lc}
\hline$\gamma_{p 1}$ & 0,05 \\
\hline$\gamma_{p 2}$ & 0,05 \\
\hline$\gamma_{v 1}$ & 1,5 \\
\hline$\gamma_{v 2}$ & 1,5 \\
\hline
\end{tabular}

TABELA B.9: Parâmetros do controlador para o sistema com juntas passivas

\begin{tabular}{lc}
\hline parâmetros & valores \\
\hline torque máximo aplicado & $25 \mathrm{Nm}$ \\
\hline torque mínimo aplicado & $-25 \mathrm{Nm}$ \\
\hline $\mathbf{K}_{\mathbf{p}}$ & {$[15001500150] \times \mathbf{I}_{3}{ }^{*}$} \\
\hline $\mathbf{K}_{\mathbf{v}}$ & $2 \sqrt{\mathbf{K}_{\mathbf{p}}}$ \\
\hline $\mathbf{K}_{\mathbf{i}}$ & {$[0,40,40,3] \times \mathbf{I}_{3}{ }^{*}$} \\
\hline forças de esmagamento desejadas & $0 \mathrm{~N}$ \\
\hline momento de esmagamento desejado & $0 \mathrm{Nm}$ \\
\hline
\end{tabular}

* $\mathbf{I}_{n}$ : matriz identidade com posto $n$; 
TABELA B.10: Parâmetros do controlador para o sistema com juntas bloqueadas

\begin{tabular}{lc}
\hline parâmetros & valores \\
\hline torque máximo aplicado & $25 \mathrm{Nm}$ \\
\hline torque mínimo aplicado & $-25 \mathrm{Nm}$ \\
\hline $\mathbf{K}_{\mathbf{p}}$ & {$[6006000] \times \mathbf{I}_{3}{ }^{*}$} \\
\hline $\mathbf{K}_{\mathbf{v}}$ & $2 \sqrt{\mathbf{K}_{\mathbf{p}}}$ \\
\hline $\mathbf{K}_{\mathbf{i}}$ & {$[0,30,300,30,30] \times \mathbf{I}_{6}{ }^{*}$} \\
\hline forças de esmagamento desejadas & $0 \mathrm{~N}$ \\
\hline momento de esmagamento desejado & $0 \mathrm{Nm}$ \\
\hline
\end{tabular}

* $\mathbf{I}_{n}$ : matriz identidade com posto $n$; 


\section{APÊNDICE C.}

\section{Dados do Sistema Simulado 2}

TABELA C.1: Parâmetros do objeto manipulado

\begin{tabular}{lc}
\hline parâmetros & valores \\
\hline forma & cilíndrico \\
\hline massa & $2,5 \mathrm{~kg}$ \\
\hline $\begin{array}{l}\text { comprimento (distância entre os efetuadores dos } \\
\text { robôs) }\end{array}$ & $0,3 \mathrm{~m}$ \\
\hline raio & $0,1 \mathrm{~m}$ \\
\hline distância entre efetuadores e CM do objeto & $0,15 \mathrm{~m}$ \\
\hline tensor de inércia (em relação ao CM) & $\left.\begin{array}{ccc}0,0203 & 0 & 0 \\
0 & 0,0203 & 0 \\
0 & 0 & 0,0203\end{array}\right] \mathrm{kg} \mathrm{m}^{2}$ \\
\hline
\end{tabular}

TABELA C.2: Parâmetros do controlador (sem falhas)

\begin{tabular}{|c|c|}
\hline parâmetros & valores \\
\hline torque máximo aplicado (juntas de 1 a 6 ) & $\left.\begin{array}{llllll}56 & 97 & 52 & 10 & 10 & 10\end{array}\right] \mathrm{Nm}$ \\
\hline torque mínimo aplicado (juntas de 1 a 6 ) & {$\left[\begin{array}{llllll}-56 & -97 & -52 & -10 & -10 & -10\end{array}\right] \mathrm{Nm}$} \\
\hline $\mathbf{K}_{\mathbf{p}}$ & {$\left[\begin{array}{llllll}500 & 500 & 500 & 50 & 50 & 50\end{array}\right] \cdot \mathbf{I}_{6}{ }^{*}$} \\
\hline $\mathbf{K}_{\mathbf{v}}$ & $2 \sqrt{\mathbf{K}_{\mathbf{p}}}$ \\
\hline $\mathbf{K}_{\mathbf{i}}$ & {$\left[\begin{array}{llllll}0,75 & 0,75 & 0,75 & 0,25 & 0,25 & 0,25\end{array}\right] \cdot \mathbf{I}_{6}$} \\
\hline forças de esmagamento desejadas & $0 \mathrm{~N}$ \\
\hline momentos de esmagamento desejados & $0 \mathrm{~N} \mathrm{~m}$ \\
\hline
\end{tabular}

* $\mathbf{I}_{n}$ : matriz identidade com posto $n$; 
TABELA C.3: Espaço de trabalho do objeto (ver Figura C.1)

\begin{tabular}{lc}
\hline parâmetros & valores \\
\hline valores mínimos da posição do CM nos eixos $x, y$ e $z$ & $(0,3 ;-0,15 ; 0,2) \mathrm{m}$ \\
\hline valores máximos da posição do CM nos eixos $x, y$ e & $(0,6 ; 0,15 ; 0,6) \mathrm{m}$ \\
$z$ & \\
\hline valores mínimos da orientação do objeto $(r p y)$ & $(-\pi / 6 ;-\pi / 6 ;-\pi / 6) \mathrm{rad}$ \\
\hline valores máximos da orientação do objeto $(r p y)$ & $(\pi / 6 ; \pi / 6 ; \pi / 6) \mathrm{rad}$ \\
\hline
\end{tabular}

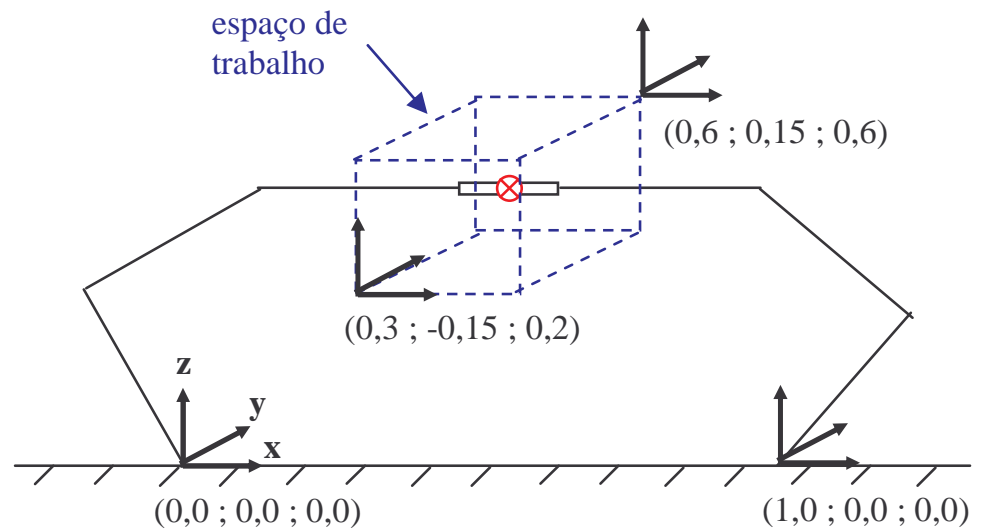

FIGURA C.1. Espaço de trabalho (posições) do CM do objeto (ver Tabela C.3).

TABELA C.4: Parâmetros dos 2 MLP's treinados por retropropagação do erro.

\begin{tabular}{lc}
\hline número de neurônios de entrada & 24 \\
\hline número de neurônios na camada intermediária & 49 \\
\hline número de neurônios de saída & 6 \\
\hline taxa de aprendizagem & 0,05 \\
\hline termo de momentum & 0,7 \\
\hline número de padrões para treinamento & 6804 \\
\hline número de épocas de treinamento & 10000 \\
\hline tempo médio de treinamento * & 19 h. e 29 min. \\
\hline "para cada MLP, sendo o programa compilado pelo GCC e executado em uma estação SUN ULTRA.
\end{tabular}


TABELA C.5: Trajetórias utilizadas no treinamento da rede RBF.

\begin{tabular}{|c|c|}
\hline trajetórias $^{*}$ & operação \\
\hline $1-10$ & falha na junta 1 (balanço livre), robô 1 (falha 1) \\
\hline $11-20$ & falha na junta 2 (balanço livre), robô 1 (falha 2) \\
\hline $21-30$ & falha na junta 3 (balanço livre), robô 1 (falha 3 ) \\
\hline $31-40$ & falha na junta 4 (balanço livre), robô 1 (falha 4) \\
\hline $41-50$ & falha na junta 5 (balanço livre), robô 1 (falha 5) \\
\hline $51-60$ & falha na junta 6 (balanço livre), robô 1 (falha 6) \\
\hline $61-70$ & falha na junta 1 (balanço livre), robô 2 (falha 7) \\
\hline $71-80$ & falha na junta 2 (balanço livre), robô 2 (falha 8) \\
\hline $81-90$ & falha na junta 3 (balanço livre), robô 2 (falha 9) \\
\hline $91-100$ & falha na junta 4 (balanço livre), robô 2 (falha 10) \\
\hline $101-110$ & falha na junta 5 (balanço livre), robô 2 (falha 11) \\
\hline $111-120$ & falha na junta 6 (balanço livre), robô 2 (falha 12) \\
\hline $121-130$ & falha na junta 1 (bloqueada), robô 1 (falha 13) \\
\hline $131-140$ & falha na junta 2 (bloqueada), robô 1 (falha 14) \\
\hline $141-150$ & falha na junta 3 (bloqueada), robô 1 (falha 15) \\
\hline $151-160$ & falha na junta 4 (bloqueada), robô 1 (falha 16) \\
\hline $161-170$ & falha na junta 5 (bloqueada), robô 1 (falha 17) \\
\hline $171-180$ & falha na junta 6 (bloqueada), robô 1 (falha 18) \\
\hline $181-190$ & falha na junta 1 (bloqueada), robô 2 (falha 19) \\
\hline $191-200$ & falha na junta 2 (bloqueada), robô 2 (falha 20) \\
\hline $201-210$ & falha na junta 3 (bloqueada), robô 2 (falha 21) \\
\hline $211-220$ & falha na junta 4 (bloqueada), robô 2 (falha 22) \\
\hline $221-230$ & falha na junta 5 (bloqueada), robô 2 (falha 23) \\
\hline $231-240$ & falha na junta 6 (bloqueada), robô 2 (falha 24) \\
\hline $241-250$ & sem falhas \\
\hline
\end{tabular}

* escolhe-se aleatoriamente 10 trajetórias que são apresentadas 25 vezes: uma vez em que não ocorrem falhas e uma vez para cada tipo de falha. 
TABELA C.6: Parâmetros da rede RBF treinada pelo MAOK.

\begin{tabular}{|c|c|}
\hline número de neurônios de entrada & 24 \\
\hline número de neurônios de saída & 25 \\
\hline $\mathbf{R}$ (define o tamanho do campo receptivo das unidades radiais) & {$\left[\begin{array}{cc}0,06 \mathbf{I}_{12} & \mathbf{0}_{12 x 12} \\
\mathbf{0}_{12 \times 12} & 0,1 \mathbf{I}_{12}\end{array}\right] *$} \\
\hline$\delta_{i}(t)$ (define entradas auxiliares) & $4 \times 10^{-5}$ \\
\hline$\alpha(t)$ (taxa de aprendizagem - MAOK) & $t^{-1 * *}$ \\
\hline $\begin{array}{l}\sigma(t) \text { (define o tamanho da vizinhança dos centros das unidades } \\
\text { radiais - MAOK) }\end{array}$ & $0,2 t^{-1}$ \\
\hline$t_{\max }($ total de épocas - MAOK) & 500 \\
\hline número de padrões para treinamento & 5291 \\
\hline tempo aproximado de treinamento ${ }^{* * *}$ & 12 h. e 48 min. \\
\hline número de unidades radiais (selecionadas pelo MAOK) & 2157 \\
\hline $\begin{array}{l}* \mathbf{I}_{n} \text { : matriz identidade com posto } n ; \mathbf{0}_{\mathrm{nxm}}: \text { matriz de zeros } n \\
* * t: \text { indíce da iteração; }{ }^{*} \\
* * * \text { programa compilado pelo GCC e executado em uma esta }\end{array}$ & ncorreta de posiçá \\
\hline$\gamma_{p l}$ & 0,01 \\
\hline$\gamma_{p 2}$ & 0,01 \\
\hline$\gamma_{v 1}$ & 0,8 \\
\hline$\gamma_{v 2}$ & 0,8 \\
\hline
\end{tabular}

TABELA C.8: Parâmetros do controlador para o sistema com juntas passivas

\begin{tabular}{|c|c|c|c|c|c|c|}
\hline \multirow{2}{*}{$\begin{array}{l}\text { parâmetros } \\
K_{p}\end{array}$} & \multicolumn{6}{|c|}{ valores } \\
\hline & {$[2000$} & 2000 & 2000 & 200 & 200 & $200] \cdot \mathbf{I}_{6}$ \\
\hline $\mathbf{K}_{\mathrm{v}}$ & \multicolumn{6}{|c|}{$2 \sqrt{\mathbf{K}_{\mathbf{p}}}$} \\
\hline $\mathbf{K}_{\mathbf{i}}$ & {$[0,75$} & 0,75 & 0,75 & 0,25 & 0,25 & $0,25] \cdot \mathbf{I}_{6}{ }^{*}$ \\
\hline forças de esmagamento desejadas & \multicolumn{6}{|c|}{$0 \mathrm{~N}$} \\
\hline momentos de esmagamento desejados & \multicolumn{6}{|c|}{$0 \mathrm{Nm}$} \\
\hline
\end{tabular}

* $\mathbf{I}_{n}$ : matriz identidade com posto $n$; 
TABELA C.9: Parâmetros do controlador para o sistema com juntas bloqueadas

\begin{tabular}{lcccccc}
\hline parâmetros & {$\left[\begin{array}{llllll}2000 & 2000 & 2000 & 200 & 200 & 200\end{array}\right] \cdot \mathbf{I}_{6}{ }^{*}$} \\
\hline $\mathbf{K}_{\mathbf{p}}$ & \multicolumn{5}{c}{$2 \sqrt{\mathbf{K}_{\mathbf{p}}}$} \\
\hline $\mathbf{K}_{\mathbf{v}}$ & {$\left[\begin{array}{llllll}0,75 & 0,75 & 0,75 & 0,25 & 0,25 & 0,25\end{array}\right] \cdot \mathbf{I}_{6}{ }^{*}$} \\
\hline $\mathbf{K}_{\mathbf{i}}$ & \multicolumn{5}{c}{$0 \mathrm{~N}$} \\
\hline forças de esmagamento desejadas & \multicolumn{7}{c}{$\mathbf{N m}$} \\
\hline momentos de esmagamento desejados
\end{tabular}

$* \mathbf{I}_{n}$ : matriz identidade com posto $n$; 


\section{APÊNDICE D.}

\section{Dados do Sistema Simulado 3}

TABELA D.1: Parâmetros dos robôs

\begin{tabular}{|c|c|}
\hline parâmetros * & valores \\
\hline gravidade & $\begin{array}{c}9,81 \mathrm{~m} / \mathrm{s}^{2} \text { no eixo } y \text { (ortogonal } \\
\text { ao eixo de movimento das } \\
\text { juntas) }\end{array}$ \\
\hline tamanho do elo $1\left(l_{l}\right)$ & $0,30 \mathrm{~m}$ \\
\hline tamanho do elo $2\left(l_{2}\right)$ & $0,30 \mathrm{~m}$ \\
\hline tamanho do elo $3\left(l_{3}\right)$ & $0,05 \mathrm{~m}$ \\
\hline massa no elo $1\left(m_{1}\right)$ & $1,00 \mathrm{~kg}$ \\
\hline massa no elo $2\left(m_{2}\right)$ & $1,00 \mathrm{~kg}$ \\
\hline massa no elo $3\left(m_{3}\right)$ & $0,40 \mathrm{~kg}$ \\
\hline distância da junta 1 ao CM do elo 1 & $0,15 \mathrm{~m}$ \\
\hline distância da junta 2 ao CM do elo 2 & $0,15 \mathrm{~m}$ \\
\hline distância da junta 3 ao CM do elo 3 & $0,025 \mathrm{~m}$ \\
\hline momento de inércia do elo 1 em relação ao CM & $0,03 \mathrm{~kg} \mathrm{~m}^{2}$ \\
\hline momento de inércia do elo 2 em relação ao $\mathrm{CM}$ & $0,03 \mathrm{~kg} \mathrm{~m}^{2}$ \\
\hline momento de inércia do elo 3 em relação ao CM & $3,3310^{-4} \mathrm{~kg} \mathrm{~m}^{2}$ \\
\hline posição da base do manipulador 1 & {$[x ; y ; z]=[0 ; 0 ; 0] \mathrm{m}$} \\
\hline posição da base do manipulador 2 & {$[x ; y ; z]=[0 ; 0,30 ; 0] \mathrm{m}$} \\
\hline posição da base do manipulador 3 & {$[x ; y ; z]=[0 ; 0,15 ; 0] \mathrm{m}$} \\
\hline
\end{tabular}

TABELA D.2: Parâmetros do objeto

\begin{tabular}{lc}
\hline parâmetros & valores \\
\hline massa do objeto & $5,0 \mathrm{~kg}$ \\
\hline comprimento do objeto (distância entre os efetuadores dos robôs) & $0,1 \mathrm{~m}$ \\
\hline distância entre efetuadores e CM do objeto & $0,05 \mathrm{~m}$ \\
\hline momento de inércia do objeto em relação ao CM & $0,50 \mathrm{~kg} \mathrm{~m}^{2}$ \\
\hline
\end{tabular}


TABELA D.3: Parâmetros do controlador para o sistema com juntas passivas

\begin{tabular}{lc}
\hline parâmetros & valores \\
\hline torque máximo aplicado & $25 \mathrm{Nm}$ \\
\hline torque mínimo aplicado & $-25 \mathrm{Nm}$ \\
\hline $\mathbf{K}_{\mathbf{p}}$ & {$[300030002000] \cdot \mathbf{I}_{3}{ }^{*}$} \\
\hline $\mathbf{K}_{\mathbf{v}}$ & $2 \sqrt{\mathbf{K}_{\mathbf{p}}}$ \\
\hline $\mathbf{K}_{\mathbf{i}}$ & {$[0,90,90,180,90,90,18] \cdot \mathbf{I}_{6}{ }^{*}$} \\
\hline forças de esmagamento desejadas & $0 \mathrm{~N}$ \\
\hline momentos de esmagamento desejados & $0 \mathrm{Nm}$ \\
\hline
\end{tabular}

* $\mathbf{I}_{n}$ : matriz identidade com posto $n$; 


\section{APÊNDICE E.}

\section{Dados do Sistema Cooperativo Real}

TABELA E.1: Parâmetros dos robôs

\begin{tabular}{lc}
\hline parâmetros $^{*}$ & valores \\
\hline tamanho do elo $1\left(l_{1}\right)$ & $0,203 \mathrm{~m}$ \\
\hline tamanho do elo 2 $\left(l_{2}\right)$ & $0,203 \mathrm{~m}$ \\
\hline tamanho do elo 3 $\left(l_{3}\right)$ & $0,203 \mathrm{~m}$ \\
\hline massa no elo $1\left(m_{1}\right)$ & $0,85 \mathrm{~kg}$ \\
\hline massa no elo 2 $\left(m_{2}\right)$ & $0,85 \mathrm{~kg}$ \\
\hline massa no elo 3 $\left(m_{3}\right)$ & $0,625 \mathrm{~kg}$ \\
\hline distância da junta 1 ao CM do elo 1 & $0,096 \mathrm{~m}$ \\
\hline distância da junta 2 ao CM do elo 2 & $0,096 \mathrm{~m}$ \\
\hline distância da junta 3 ao CM do elo 3 & $0,077 \mathrm{~m}$ \\
\hline momento de inércia do elo 1 em relação ao CM & $0,0031 \mathrm{~kg} \mathrm{~m}{ }^{2}$ \\
\hline momento de inércia do elo 2 em relação ao CM & $0,0031 \mathrm{~kg} \mathrm{~m}{ }^{2}$ \\
\hline momento de inércia do elo 3 em relação ao CM & $0,0023 \mathrm{~kg} \mathrm{~m}{ }^{2}$ \\
\hline posição da base do manipulador 1 & {$[x ; y ; z]=[0 ; 0 ; 0] \mathrm{m}$} \\
\hline posição da base do manipulador 2 & {$[x ; y ; z]=[0 ; 0,506 ; 0] \mathrm{m}$} \\
\hline
\end{tabular}

* os manipuladores 1 e 2 têm as mesmas características construtivas

TABELA E.2: Parâmetros dos objetos

\begin{tabular}{lcc}
\hline parâmetros & objeto 1 & objeto 2 \\
\hline massa do objeto & $0,025 \mathrm{~kg}$ & $0,45 \mathrm{~kg}$ \\
\hline $\begin{array}{l}\text { comprimento do objeto (distância entre os efetuadores } \\
\text { dos robôs) }\end{array}$ & $0,092 \mathrm{~m}$ & $0,092 \mathrm{~m}$ \\
\hline distância entre efetuadores e CM do objeto & $0,046 \mathrm{~m}$ & $0,046 \mathrm{~m}$ \\
\hline momento de inércia do objeto em relação ao CM & $2,2810^{-5} \mathrm{~kg} \mathrm{~m}^{2}$ & $6,0010^{-4} \mathrm{~kg} \mathrm{~m}^{2}$ \\
\hline
\end{tabular}


TABELA E.3: Parâmetros do controlador (sem falhas)

\begin{tabular}{lc}
\hline parâmetros & valores \\
\hline torque máximo aplicado & $0,2254 \mathrm{Nm}$ \\
\hline torque mínimo aplicado & $-0,2254 \mathrm{Nm}$ \\
\hline $\mathbf{K}_{\mathbf{p}}$ & {$[18180,8] \times \mathbf{I}_{3}{ }^{*}$} \\
\hline $\mathbf{K}_{\mathbf{v}}$ & $2 \sqrt{\mathbf{K}_{\mathbf{p}}}$ \\
\hline $\mathbf{K}_{\mathbf{i}}$ & {$[0,150,150,02] \times \mathbf{I}_{3}{ }^{*}$} \\
\hline $\mathbf{K}_{\mathbf{i m}}$ & {$[1,81,80,08] \times \mathbf{I}_{3 .}{ }^{*}$} \\
\hline forças de esmagamento desejadas & $0 ~ \mathrm{~N}$ \\
\hline momento de esmagamento desejado & $0 \mathrm{Nm}$ \\
\hline
\end{tabular}

$* \mathbf{I}_{n}$ : matriz identidade com posto $n$;

TABELA E.4: Espaço de trabalho do objeto (ver Figura E.1)

\begin{tabular}{lc}
\hline parâmetros & valores \\
\hline valor máximo da posição do CM nos eixos $x$ e $y$ & $0,34 \mathrm{~m} \mathrm{e} 0,38 \mathrm{~m}$ \\
\hline valor máximo da posição do CM nos eixos $x$ e $y$ & $0,12 \mathrm{~m} \mathrm{e} 0,285 \mathrm{~m}$ \\
\hline valor máximo da orientação do objeto & $\pi / 24 \mathrm{rad}$ \\
\hline valor mínimo da orientação do objeto & $-\pi / 24 \mathrm{rad}$ \\
\hline
\end{tabular}

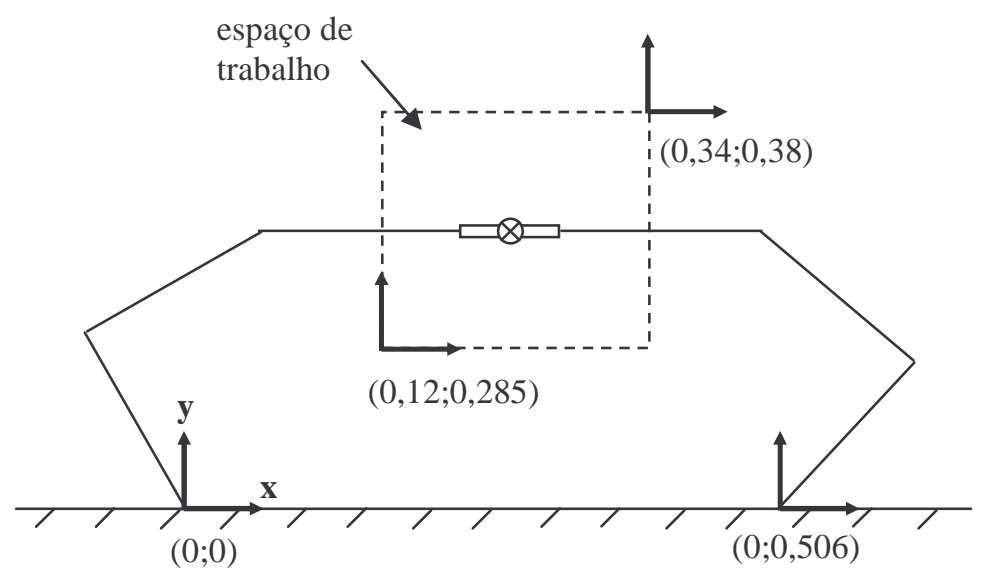

FIGURA E.1. Espaço de trabalho (posição) do CM do objeto (ver Tabela E.4). 
TABELA E.5: Parâmetros dos 2 MLP's treinados por retropropagação do erro.

\begin{tabular}{lc}
\hline número de neurônios de entrada & 12 \\
\hline número de neurônios na camada intermediária & 37 \\
\hline número de neurônios de saída & 3 \\
\hline taxa de aprendizagem & 0,05 \\
\hline termo de momentum & 0,7 \\
\hline número de padrões para treinamento & 3250 \\
\hline número de épocas de treinamento & 10000 \\
\hline tempo médio de treinamento ${ }^{*}$ & 9 h. e 02 min. \\
\hline
\end{tabular}

para cada MLP, sendo o programa compilado pelo GCC e executado em uma estação SUN ULTRA.

TABELA E.6: Trajetórias utilizadas no treinamento da rede RBF.

\begin{tabular}{ll}
\hline trajetórias $^{*}$ & operação \\
\hline $1-20$ & falha na junta 1 (balanço livre), robô 1 (falha 1) \\
\hline $21-40$ & falha na junta 2 (balanço livre), robô 1 (falha 2) \\
\hline $41-60$ & falha na junta 3 (balanço livre), robô 1 (falha 3) \\
\hline $61-80$ & falha na junta 1 (balanço livre), robô 2 (falha 4) \\
\hline $81-100$ & falha na junta 2 (balanço livre), robô 2 (falha 5) \\
\hline $101-120$ & falha na junta 3 (balanço livre), robô 2 (falha 6) \\
\hline $121-140$ & falha na junta 1 (bloqueada), robô 1 (falha 7) \\
\hline $141-160$ & falha na junta 2 (bloqueada), robô 1 (falha 8) \\
\hline $161-180$ & falha na junta 3 (bloqueada), robô 1 (falha 9) \\
\hline $201-220$ & falha na junta 1 (bloqueada), robô 2 (falha 10) \\
\hline $221-240$ & falha na junta 2 (bloqueada), robô 2 (falha 11) \\
$241-260$ & falha na junta 3 (bloqueada), robô 2 (falha 12) \\
\hline
\end{tabular}

* escolhe-se aleatoriamente 20 trajetórias que são apresentadas 13 vezes: uma vez em que não ocorrem falhas e uma vez para cada tipo de falha. 
TABELA E.7: Parâmetros da rede RBF treinada pelo MAOK.

\begin{tabular}{lc}
\hline número de neurônios de entrada & 12 \\
\hline número de neurônios de saída & 13 \\
\hline $\mathbf{R}$ (define o tamanho do campo receptivo das unidades radiais) & {$\left[\begin{array}{cc}0,03 \mathbf{I}_{6} & \mathbf{0}_{6 \times 6} \\
\mathbf{0}_{6 \times 6} & 0,1 \mathbf{I}_{6}\end{array}\right] *$} \\
\hline$\delta_{i}(t)$ (define entradas auxiliares) & $410^{-8}$ \\
\hline$\alpha(t)$ (taxa de aprendizagem - MAOK) & $t^{-1}$ \\
\hline$\sigma(t)$ (define o tamanho da vizinhança dos centros das unidades & $0,2 t^{-1}$ \\
radiais - MAOK) & 500 \\
\hline$t_{\text {max }}$ (total de épocas - MAOK) & 2506 \\
\hline número de padrões para treinamento & $6 \mathrm{~h}$. e 47 min. \\
\hline tempo aproximado de treinamento & 944 \\
\hline número de unidades radiais (selecionadas pelo MAOK) &
\end{tabular}

\footnotetext{
* $\mathbf{I}_{n}$ : matriz identidade com posto $n ; \mathbf{0}_{\mathrm{nxm}}$ : matriz de zeros $n \times m$

** $t$ : indíce da iteração; *

*** programa compilado pelo GCC e executado em uma estação SUN ULTRA.
}

TABELA E.8: Parâmetros do Sistema DIF (falhas de informação incorreta de posição ou velocidade das juntas).

\begin{tabular}{lc}
\hline$\gamma_{p 1}$ & 0,05 \\
\hline$\gamma_{p 2}$ & 0,05 \\
\hline$\gamma_{v 1}$ & 0,15 \\
\hline$\gamma_{v 2}$ & 0,15 \\
\hline
\end{tabular}


TABELA E.9: Parâmetros do controlador para o sistema com juntas passivas

\begin{tabular}{lc}
\hline parâmetros & valores \\
\hline torque máximo aplicado & $0,2254 \mathrm{Nm}$ \\
\hline torque mínimo aplicado & $-0,2254 \mathrm{Nm}$ \\
\hline $\mathbf{K}_{\mathbf{p}}$ & {$[35403,8] \times \mathbf{I}_{3}{ }^{*}$} \\
\hline $\mathbf{K}_{\mathbf{v}}$ & $2 \sqrt{\mathbf{K}_{p}}$ \\
\hline $\mathbf{K}_{\mathbf{i}}$ & {$[0,150,150,02] \cdot \mathbf{I}_{3}{ }^{*}$} \\
\hline $\mathbf{K}_{\mathbf{i m}}$ & {$[3,54,00,38] \cdot \mathbf{I}_{3}{ }^{*}$} \\
\hline forças de esmagamento desejadas & $0 \mathrm{~N}$ \\
\hline momento de esmagamento desejado & $0 \mathrm{Nm}$ \\
\hline
\end{tabular}

$* \mathbf{I}_{n}$ : matriz identidade com posto $n$;

TABELA E.10: Parâmetros do controlador para o sistema com juntas bloqueadas

\begin{tabular}{lc}
\hline parâmetros & valores \\
\hline torque máximo aplicado & $0,2254 \mathrm{Nm}$ \\
\hline torque mínimo aplicado & $-0,2254 \mathrm{Nm}$ \\
\hline $\mathbf{K}_{\mathbf{p}}$ & {$[30302] \cdot \mathbf{I}_{3}{ }^{*}$} \\
\hline $\mathbf{K}_{\mathbf{v}}$ & $2 \sqrt{\mathbf{K}_{p}}$ \\
\hline $\mathbf{K}_{\mathbf{i}}$ & {$[1,81,80,8] \cdot \mathbf{I}_{3}{ }^{*}$} \\
\hline $\mathbf{K}_{\mathbf{i m}}$ & {$[0,30,30,2] \cdot \mathbf{I}_{3}{ }^{*}$} \\
\hline forças de esmagamento desejadas & $0 \mathrm{~N}$ \\
\hline momento de esmagamento desejado & $0 \mathrm{Nm}$ \\
\hline
\end{tabular}

$* \mathbf{I}_{n}$ : matriz identidade com posto $n$; 


\section{APÊNDICE F.}

\section{Ambiente de Simulação e Controle do Sistema}

Real

O Ambiente de Simulação e Controle do Sistema Real (ASCSR) é carregado através da função util.m escrita em MATLAB. A seguir, os menus, comandos e janelas do ASCSR são descritas.

F.1) Janela Principal: Interface Gráfica com o Usuário (Graphical User Interface GUI):

A interface gráfica com o usuário (GUI) é composta por 7 partes principais: a janela que mostra os manipuladores, os menus "USER COMANDS", "SIMULATION PARAMETERS", “OBJECT PARAMETERS", "GRAPHICS”, a linha de texto "CHANGE PARAMETERS" e os campos de visualização dos tempos. A GUI é apresentada a seguir. 


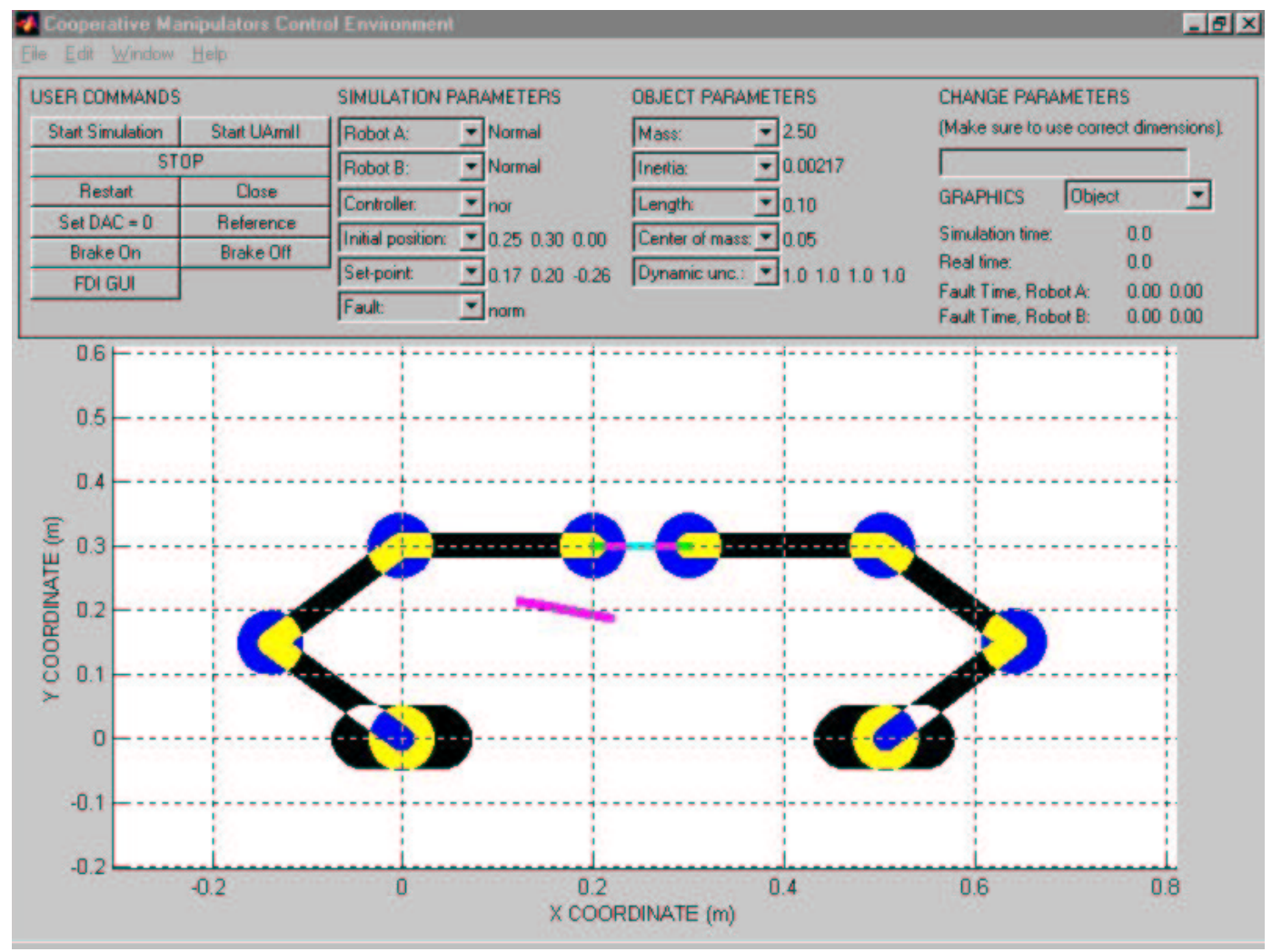

F.2) Menu “USER COMMANDS”:

USER COMMANDS
\begin{tabular}{|c|c|}
\hline Start Simulation & Start UA,rmll \\
\hline \multicolumn{2}{|c|}{ STOP } \\
\hline Restart & Close \\
\hline Set DAC $=0$ & Reference \\
\hline Brake On & Brake Off \\
\hline FDI GUI & \\
\hline
\end{tabular}

O Menu "USER COMANDS" é composto pelos seguintes botões:

"Start Simulation" - inicia a simulação;

"Start UarmII" - inicia a trajetória do sistema real;

"Stop" - finaliza simulação ou trajetória do sistema real;

"Restart" - reinicia a GUI ;

"Close" - fecha a GUI; 
"Set DAC = 0" - aplica tensão (torque) zero nos atuadores dos robôs reais;

"Reference" - inicializa as posições dadas pelos encoders dos robôs reais (antes, deve-se colocar os robôs na posição de referência);

"Brake On" - Aplica freio em todas as juntas do sistema real;

"Brake Off "- Libera todos os freios do sistema real;

“FDI GUI" - chama interface gráfica do Sistema DIF e de tolerância (ver Seção F.6).

\section{F.3) Menu “SIMULATION PARAMETERS":}

\begin{tabular}{ll}
\hline SIMULATION PARAMETERS \\
\hline Robot A: \\
\hline Robot B: \\
\hline Fantroller:
\end{tabular}

O Menu “SIMULATION PARAMETERS" é composto pelos seguintes botões:

F.3.1) "Robot A" - configuração do robô A (esquerda no vídeo).

\begin{tabular}{|c|c|c|}
\hline \multicolumn{3}{|c|}{ SIMULATION PARAMETERS } \\
\hline Robot A: & 7 & Normal \\
\hline $\begin{array}{l}\text { Robot A: } \\
\text { Normal } \\
\text { Fault at Joint } 1 \\
\text { Fault at Joint } 2 \\
\text { Fault at Joint 3 } \\
\text { Fault Time }\end{array}$ & & $\begin{array}{lll}\text { Normal } & & \\
\text { nor } & & \\
0.25 & 0.30 & 0.00\end{array}$ \\
\hline Set-point: & 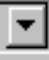 & $0.17 \quad 0.20-0.26$ \\
\hline Fault: & $\nabla$ & norm \\
\hline
\end{tabular}

Composto pelas seguintes configurações :

"Normal" - robô A sem falhas;

"Fault at Joint $i$ " - falha na junta $i$ do robô A durante os instantes de falhas definidos por "Fault Time" (vistos na tela principal a direita no campo de visualizações) ou para o caso do controle do sistema com falhas; 
"Fault Time" - configura os instantes de início e fim das falhas para o robô A.

F.3.2) “Robot B” - configuração do robô B (direita no vídeo).

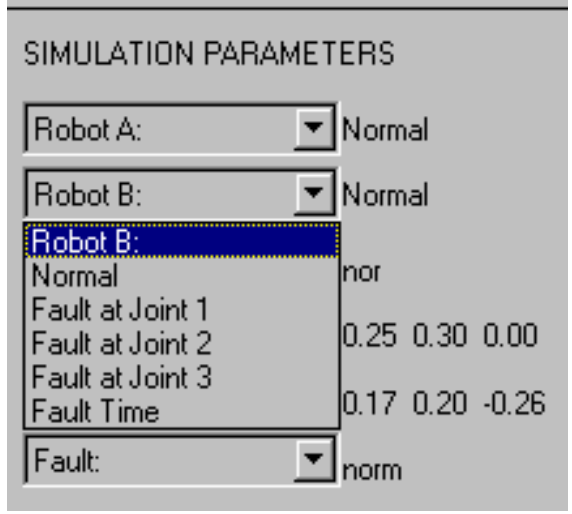

Composto pelas seguintes configurações :

"Normal" - robô B sem falhas;

"Fault at Joint $i$ " - falha na junta $i$ do robô B durante os instantes de falhas definidos por "Fault Time" (vistos na tela principal a direita no campo de visualizações) ou para o caso do controle do sistema com falhas;

"Fault Time" - configura os instantes de início e fim das falhas para o robô B.

F.3.3) “Controller" - configura o controlador (quando a função de tolerância está ativada, o controlador é configurado automaticamente de acordo com a falha detectada).

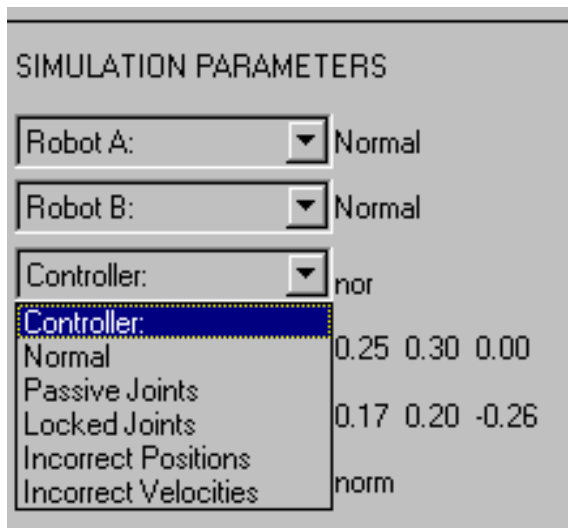

Composto pelas seguintes configurações :

"Normal" - controlador para o sistema sem falhas;

"Passive Joints" - controlador para o sistema com juntas passivas;

"Locked Joints" - controlador para o sistema com juntas bloqueadas;

"Incorrect Positions" - reconfiguração para o sistema com informação incorreta de posições nas juntas; 
"Incorrect Velocities" - reconfiguração para o sistema com informação incorreta de velocidades nas juntas.

F.3.4) "Initial Position" - configura as posições iniciais do sistema cooperativo (robôs e objeto). A posições podem ser configuradas diretamente através do cursor - deve-se mover o cursor no espaço de trabalho permitido ao objeto e clicar na posição desejada. O CM do objeto será posicionado neste local (a orientação do objeto será calculada aleatoriamente) e, através da cinemática inversa, os manipuladores serão posicionados.

\begin{tabular}{|c|c|}
\hline \multicolumn{2}{|c|}{ SIMULATION PARAMETERS } \\
\hline Robot A: & Tormal \\
\hline Robot B: & - Normal \\
\hline Controller: & $\nabla_{\text {nor }}$ \\
\hline Initial position: & $\nabla_{0.25} 0.300 .00$ \\
\hline $\begin{array}{l}\text { Initial position } \\
\text { Default } \\
\text { Random } \\
\text { User defined }\end{array}$ & $\begin{array}{lll}0.17 & 0.20 & -0.26 \\
\text { norm }\end{array}$ \\
\hline
\end{tabular}

Composto pelas seguintes opções :

"Default" - inicializa o sistema cooperativo nas posições e orientações armazenadas no programa;

"Random" - inicializa a posição e a orientação do objeto com valores aleatórios (dentro do espaço de trabalho). Os manipuladores serão posicionados através da cinemática inversa;

"User defined" - inicializa a posição e a orientação do objeto com os valores fornecidos pelo usuário no campo "CHANGE PARAMETERS" localizado a direita no video. Os manipuladores serão posicionados através da cinemática inversa.

F.3.5) "Set-point" - configura as posições e orientações finais desejadas da trajetória polinomial ou define trajetórias desejadas como sendo do tipo senoidal. 


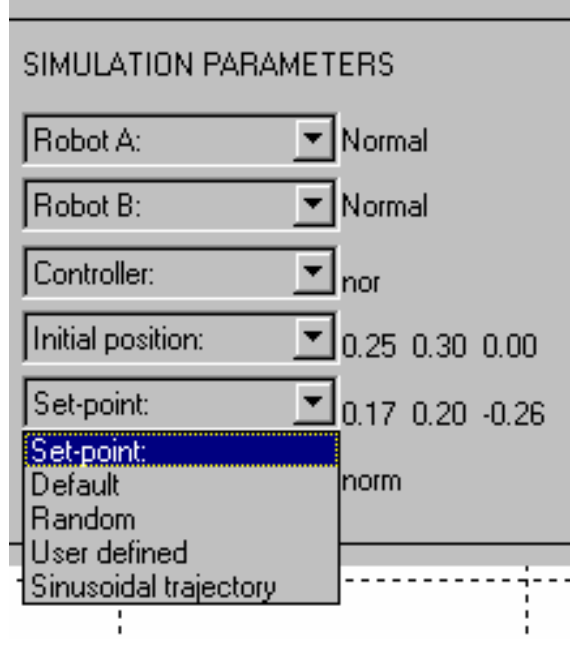

Composto pelas seguintes opções :

"Default" - configura as posições e orientações finais da trajetória polinomial de acordo com os valores armazenados no programa;

"Random" - configura a posição e a orientação final do objeto na trajetória polinomial com valores aleatórios (dentro do espaço de trabalho). Os manipuladores serão posicionados através da cinemática inversa;

"User defined" - configura a posição e a orientação final do objeto na trajetória polinomial com os valores fornecidos pelo usuário no campo "CHANGE PARAMETERS" localizado na direita do video. Os manipuladores serão posicionados através da cinemática inversa;

"Sinusoidal trajectory" - configura a trajetória desejada como senoidal no tempo (no espaço de trabalho, as posições do objeto deverão formam um círculo).

F.3.6) "Fault" - configura a falha a ser simulada no sistema cooperativo (real ou simulado). A falha ocorre nas juntas durante o tempo configurado através dos menus "Robot A" (F.3.1) e "Robot B" (F.3.2) 


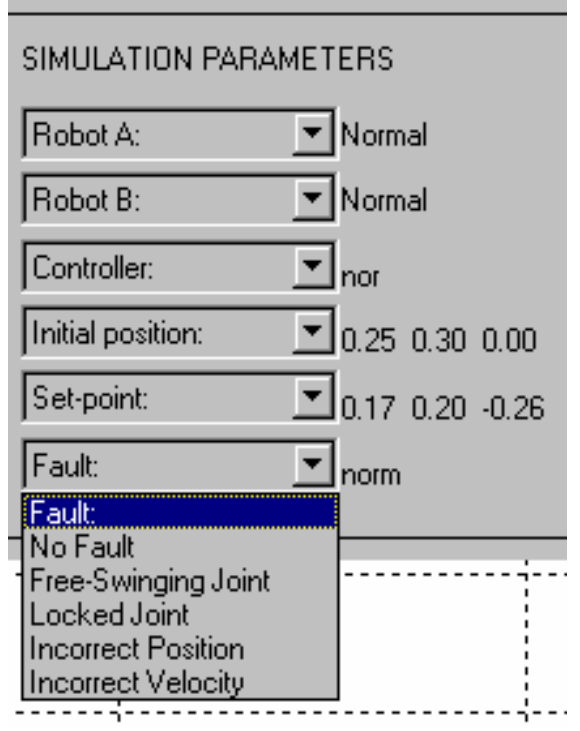

Composto pelas seguintes opções :

"No Fault" -sistema sem falhas

"Free-swinging Joints" - falha do tipo junta com balanço livre;

"Locked Joint" - falha do tipo junta bloqueada;

"Incorrect Position" - falha do tipo informação incorreta de posição da junta;

"Incorrect Velocities" - falha do tipo informação incorreta de velocidade da junta.

\section{F.4) Menu “OBJECT PARAMETERS”:}

OBJECT PARAMETERS
Lenter of mass:
Dynamic unc:
Lengt:

Este Menu define os parâmetros do objeto:

"Mass" - massa do objeto;

"Inertia" - inércia do objeto;

"Length" - tamanho do objeto;

"Center of mass" - distância do centro de massa do objeto o efetuador do manipulador A; 
"Dynamic unc." - fator de incerteza nos parâmetros de massa, inércia, tamanho e distância até o CM do objeto (fator igual a "1.0" representa que não há incerteza no parâmetro)

Os parâmetros são ajustados da mesma forma (figura a seguir):

\begin{tabular}{l}
\hline OBJECT PARAMETERS \\
\hline Mass: \\
Mefault \\
User defined \\
\hline Center of mass:
\end{tabular}

"Default" - configura parâmetro com o valor armazenado no programa;

"User defined" - configura parâmetro com os valores fornecidos pelo usuário no campo "CHANGE PARAMETERS" localizado na direita do vídeo.

F.5) Campos “CHANGE PARAMETERS", “GRAPHICS” e de visualização dos tempos:

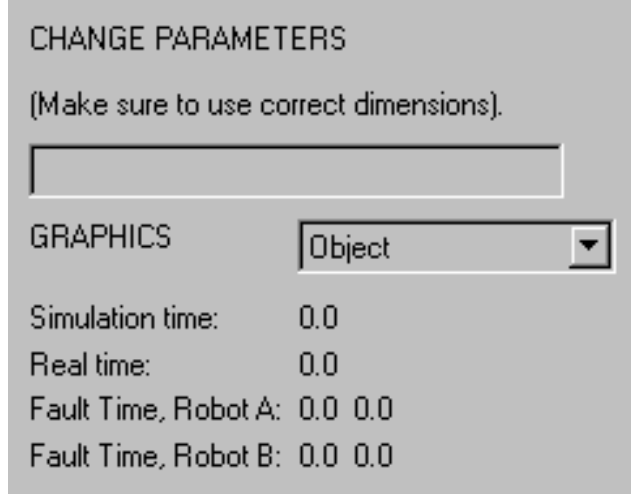

“CHANGE PARAMETERS" - campo para entrada de valores pelo usuário (ver funções anteriores);

"Simulation time" - tempo atual durante simulação;

"Real time" - tempo atual desde o inicio da trajetória do sistema real;

"Fault Time, Robot $i$ " - tempo de início e fim das falhas no robô $i$. 


\section{F.5.1) Menu “GRAPHICS"}

CHANGE PARAMETERS
[Make sure to use correct dimensions].
GRAPHICS
$\begin{array}{ll}\text { Simulation time: } & \text { Object } \\ \text { Real time: } & \begin{array}{l}\text { Robots } \\ \text { Fault Graphics }\end{array}\end{array}$

Fault Time, Robot A: 0.00 .0

Fault Time, Robot B: 0.00 .0

Este Menu chama as seguintes janelas de gráficos:

“Object”: janela de gráficos do objeto ;

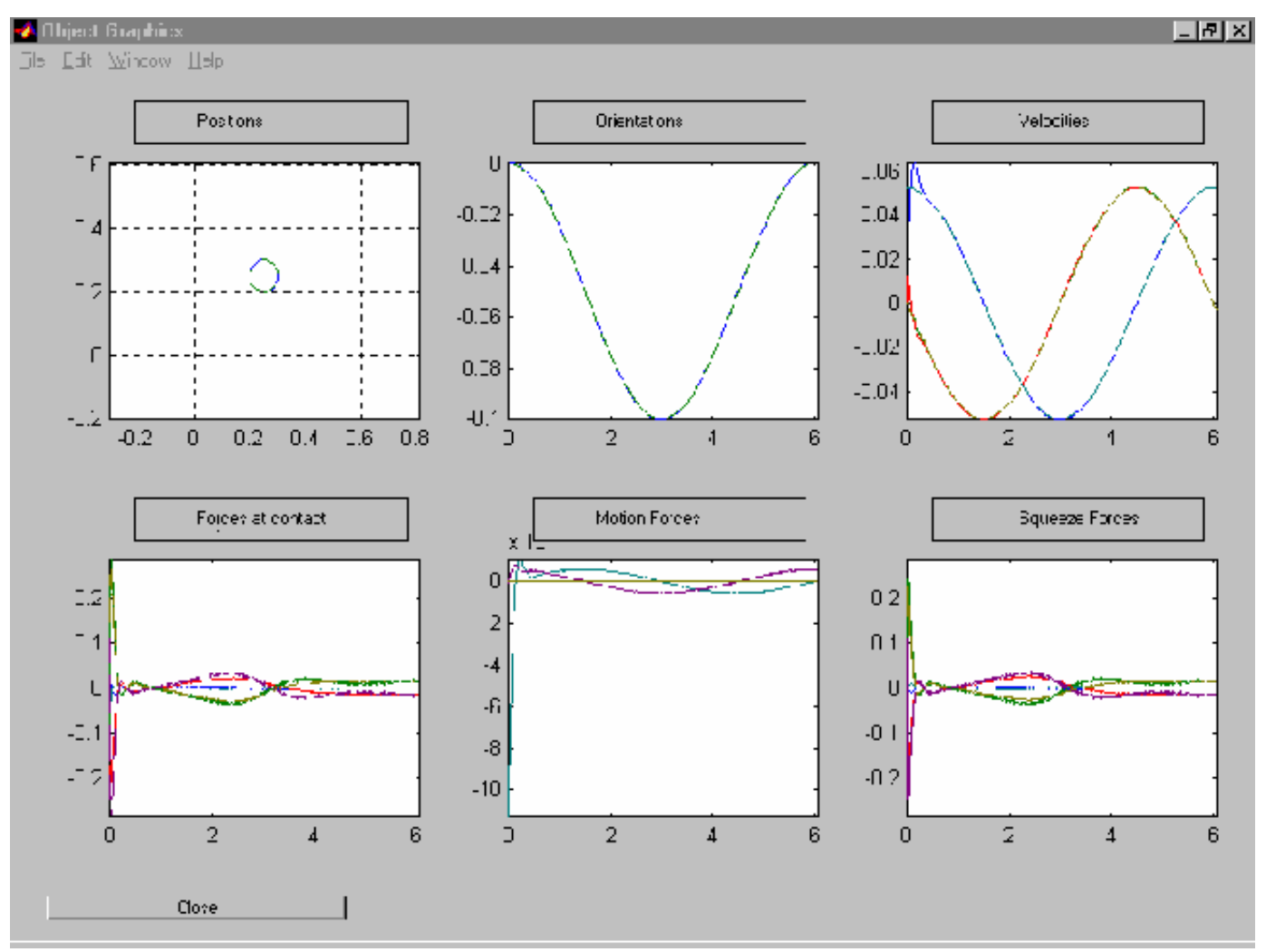

"Robots": janela de gráficos dos robôs nos quais aparecem os gráficos das posições, velocidade e torques nos dois robôs; 
Arulum A firenthiiz:

Jl) [ft linixow لlp
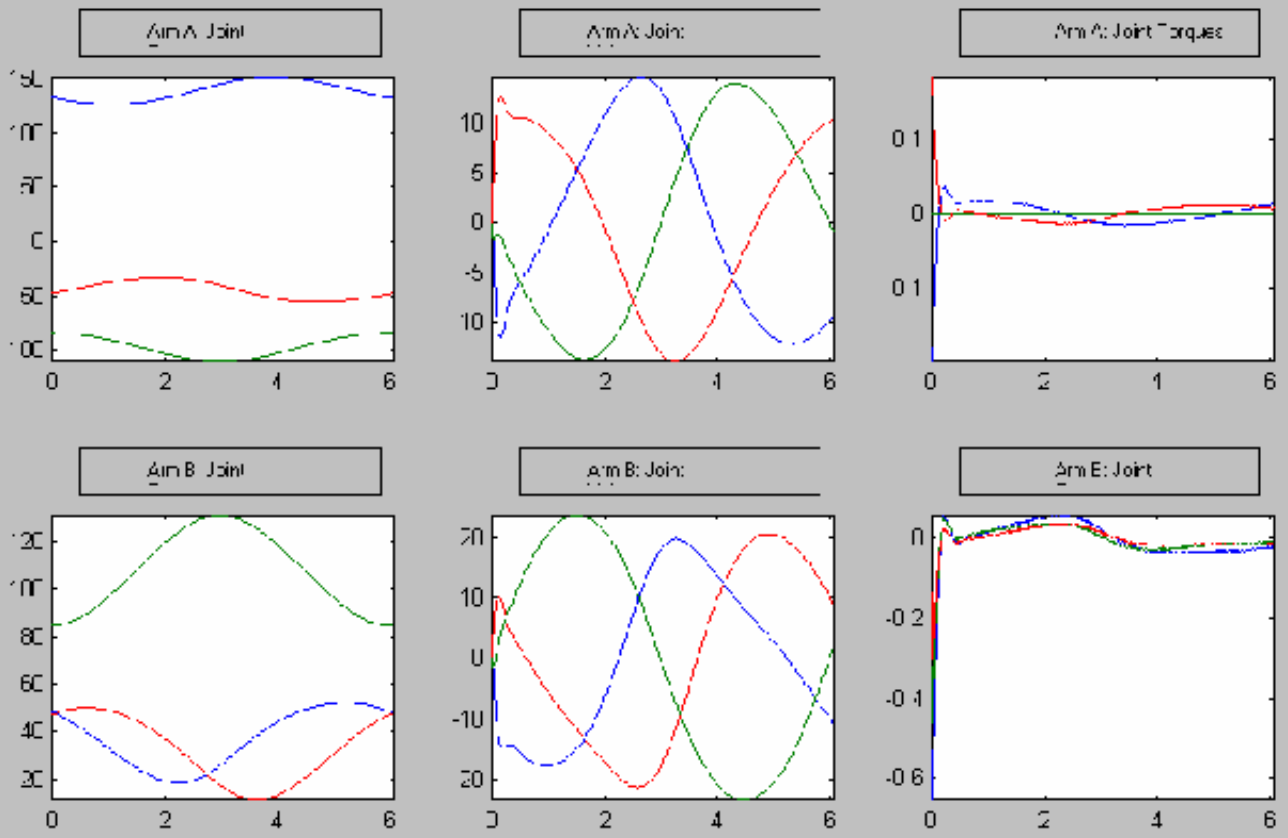

Clo:

1

"Fault": janela com gráficos dos resíduos, saídas da rede RBF e variáveis de DIF.

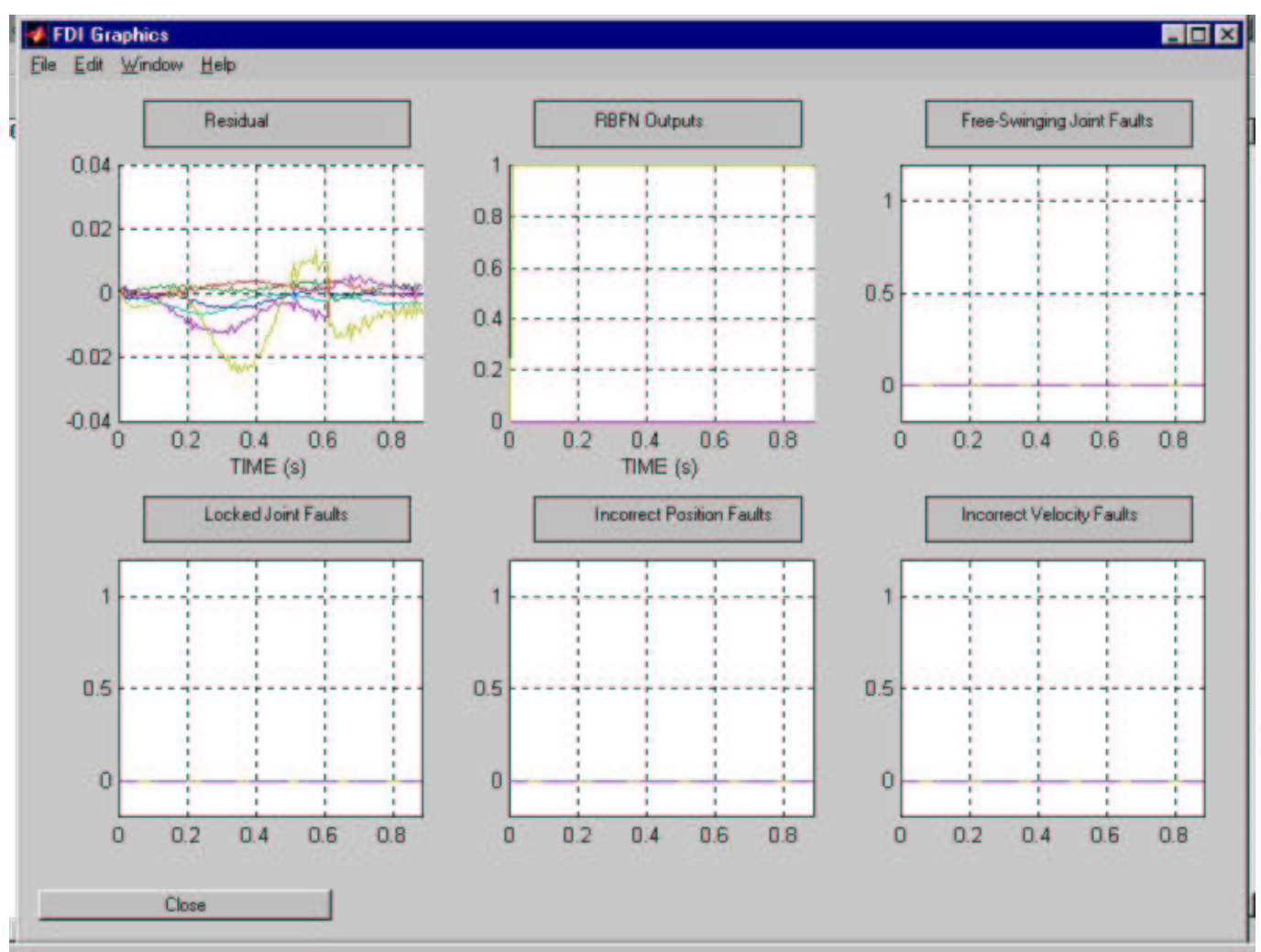


F.6) Interface gráfica com o usuário para verificação de dados e mudança de parâmetros dos sistema DIF e de tolerância a falhas:

Esta Interface é chamada através do botão "FDI GUI" localizado no Menu "USER COMANDS" da janela principal. Os menus, botões e campos desta Interface são apresentados a seguir.

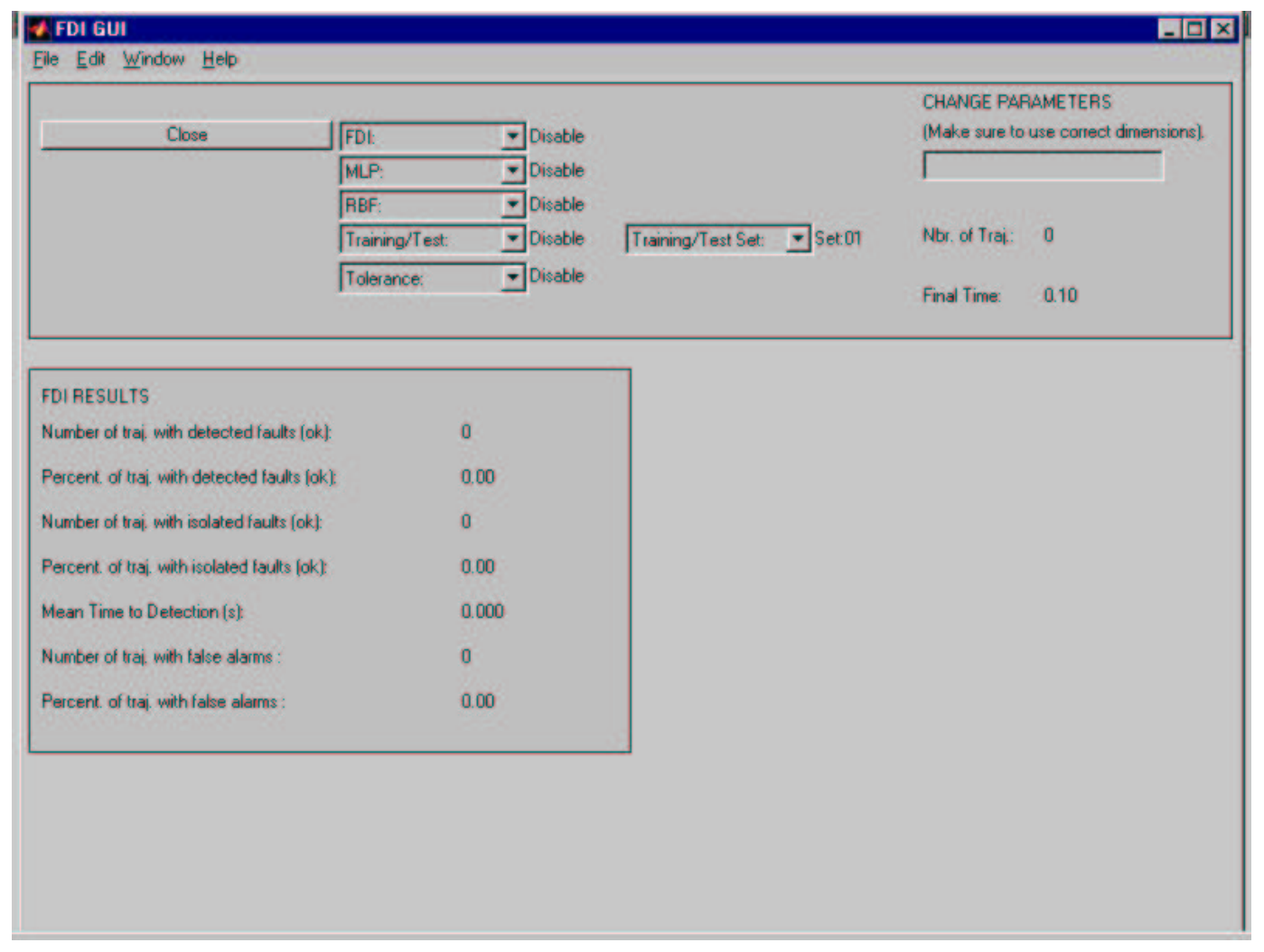

\section{F.6.1) Menu FDI (Fault Detection and Isolation).}

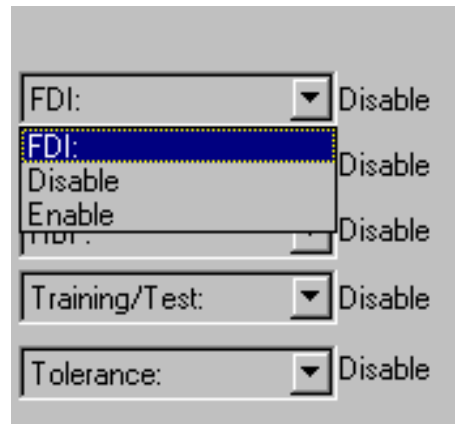

O Menu "FDI" é composto pelos seguintes botões:

"Disable" - desativa DIF;

"Enable" - ativa DIF. 


\section{F.6.2) Menu "MLP”' (Multilayer Perceptron).}

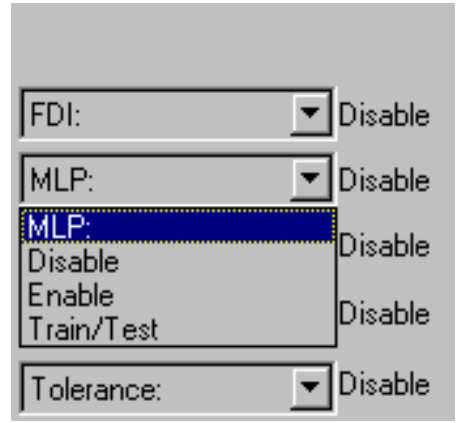

Composto pelos seguintes botões:

"Disable" - desativa MLP;

"Enable" - ativa MLP;

“Train/Test" - treina ou testa MLP (devem ser configurados antes o parâmetros do menu "Training/Test" (Seção F.6.4))

\section{F.6.3) Menu "RBF" (rede RBF)}

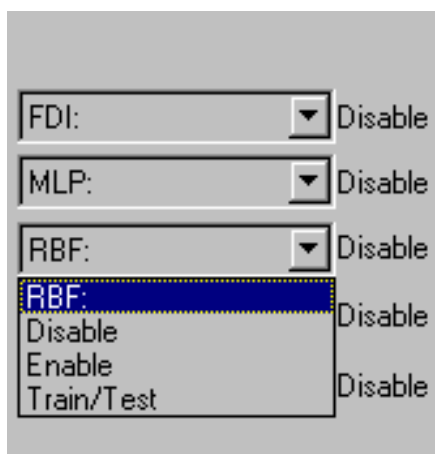

Composto pelos seguintes botões:

"Disable" - desativa rede RBF;

"Enable" - ativa rede RBF;

"Train/Test" - treina ou testa rede RBF (devem ser configurados antes o parâmetros do menu "Training/Test" (Seção F.6.4)) 


\section{F.6.4) Menu “Training/Test".}

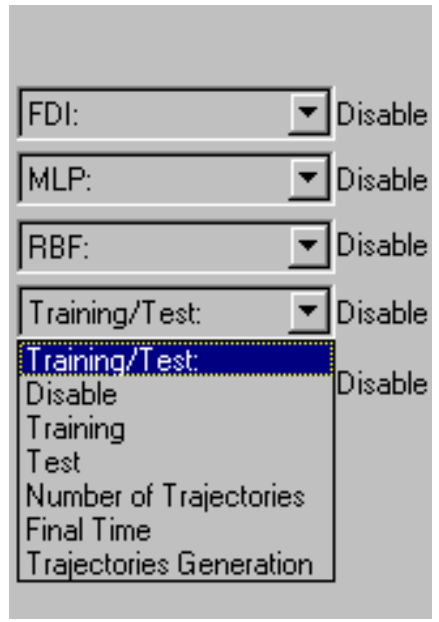

Composto pelos seguintes botões:

"Disable" - desativa treinamento ou teste do MLP e da rede RBF;

“Training" - ativa treinamento do MLP ou da rede RBF usando os parâmetros de número de trajetórias, tempo final e conjunto de treinamento;

"Test" - ativa teste do MLP, da rede RBF ou do Sistema DIF utilizando os parâmetros de número de trajetórias, tempo final e conjunto de treinamento;

"Number of Trajectories" - configura o número de trajetórias para treinamento ou teste com os valores fornecidos pelo usuário no campo "CHANGE PARAMETERS";

"Final Time" - configura a duração das trajetórias para treinamento ou teste com os valores fornecidos pelo usuário no campo "CHANGE PARAMETERS";

"Trajectories Generation" - gera conjunto de treinamento ou teste para pontos iniciais e finais do conjunto de trajetórias dado.

\section{F.6.5) Menu “Tolerance".}

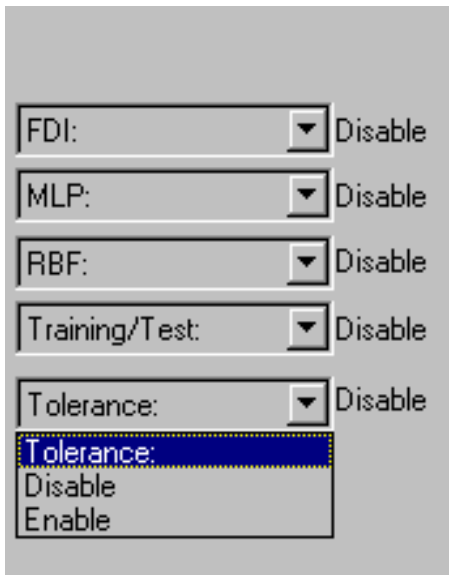

Composto pelos seguintes botões:

"Disable" - desativa reconfiguração automática do controlador após falhas; 
"Enable" - ativa reconfiguração automática do controlador após falhas.

F.6.6) Menu "Training-Test Set".

Carrega conjuntos de treinamento ou teste com pontos iniciais e finais das trajetórias.

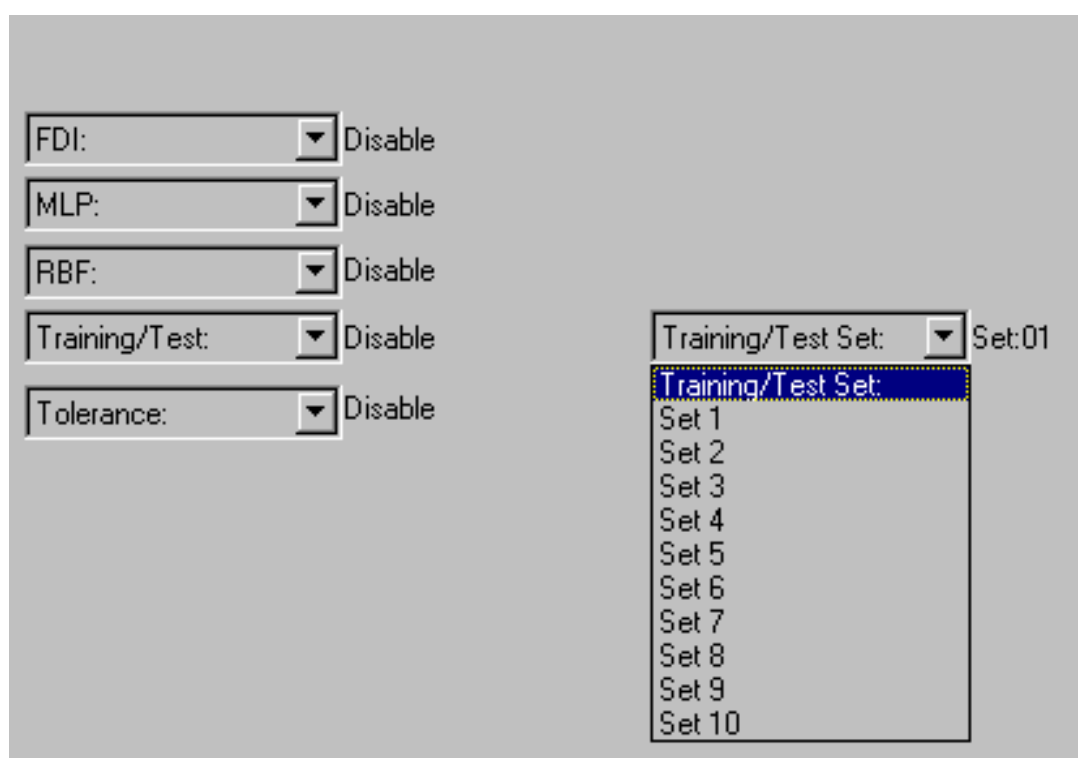

\section{F.6.7) Menu “FDI Results".}

Fornece as estatísticas do sistema DIF para o teste realizado. 


\section{APÊNDICE G. Publicações do Autor}

Segue abaixo a relação das publicações do autor relacionadas aos robôs cooperativos derivadas do trabalho descrito nesta tese.

Tinós, R.; Terra, M. H. \& Bergerman, M. (2000). "Detecção e isolação de falhas em manipuladores cooperativos via redes neurais artificiais". Nos Anais do XIII Congresso Brasileiro de Automática (CBA’2000), Florianópolis, Brasil.

Tinós, R.; Terra, M. H. \& Bergerman, M. (2001). "Fault detection and isolation in cooperative manipulators via artificial neural networks". In the Proceedings of the 2001 IEEE Conference on Control Applications (CCA’2001), México City, México, p. 492-497.

Tinós, R. \& Terra, M. H. \& Bergerman, M. (2002). "Fault tolerance in cooperative manipulators". In the Proceedings of the 2002 IEEE International Conference on Robotics and Automation (ICRA'2002), Washington, USA, pp. 470-475.

Tinós, R. \& Terra, M. H. (2002). "Control of cooperative manipulators with passive joints". In the Proceedings of the 2002 American Control Conference (ACC'2002), Anchorage, USA, pp. 1129-1134.

Tinós, R. \& Terra, M. H. (2002). "Free-swinging and locked joint fault detection and isolation in cooperative manipulators" Paper in the invited session "Neural Network Techiniques in Fault Detection and Isolation" organised by S. Simani (University of Ferrara - Italy) of the 10th European Symposium on Artificial Neural Networks (ESANN`2002), In the Proceedings of ESANN'2002, Bruges, Belgium.

Tinós, R. \& Terra, M. H. (2002). "Fault detection and isolation for multiple manipulators". In the Proceedings of the 2002 IFAC Work Congress (IFAC'2002), Barcelona, Spain.

Tinós, R.; Terra, M. H. \& Bergerman, M.. "A fault tolerance framework for cooperative robotic manipulators". Submitted to IEEE Transactions on Robotics and Automation (2002). 
Tinós, R. \& Terra, M. H.. "Fault detection and isolation system for cooperative manipulation". Submitted to IEEE Transactions on Reliability (2002).

Tinós, R.; Terra, M. H. \& Ishihara, J. Y.. "Motion and force control of cooperative robotic manipulators with passive joints". Submitted to IEEE Transactions on Robotics and Automation (2002). 